Universidade de São Paulo

Instituto de Física

\title{
Bremsstrahlung de elétrons no microtron do \\ IFUSP: medidas, simulação e proposta de aplicação ao estudo da ressonância fluorescente nuclear.
}

\section{Neivy López Pino}

Orientadora: Profa. Dra. Nora Lía Maidana

Tese de doutorado apresentada ao Instituto de Física para a obtenção do título de Doutor em Ciências

Comissão Examinadora:

Profa. Dra. Nora Lía Maidana, IFUSP

Prof. Dr. Nilberto Heder Medina, IFUSP

Profa. Dra. Márcia de Almeida Rizzutto, IFUSP

Profa. Dra.Carmen Cecilia Bueno Tobias, IPEN

Prof. Dr. Hélio Yoriyaz, IPEN

São Paulo 
FICHA CATALOGRÁFICA

Preparada pelo Serviço de Biblioteca e Informação do Instituto de Física da Universidade de São Paulo

Pino, Neivy López

Bremsstrahlung de elétrons no microtron do IFUSP: medidas, simulação e proposta de aplicação ao estudo da ressonância fluorescente nuclear. - São Paulo, 2011.

Tese (Doutorado) - Universidade de São Paulo. Instituto de Física - Depto. de Física Experimental

Orientador: Profa. Dra. Nora Lia Maidana

Área de Concentração: Laboratório do Acelerador Linear

Unitermos: 1. Física Nuclear; 2. Física Experimental;

3. Interações Eletromagnéticas;

USP/IF/SBI-040/2011 


\title{
Bremsstrahlung de elétrons no microtron do IFUSP: medidas, simulação e proposta de aplicação ao estudo da Ressonância Fluorescente Nuclear
}

\begin{abstract}
Resumo
Apresentam-se os resultados dos primeiros experimentos com o novo acelerador de elétrons do Laboratório do Acelerador Linear (LAL) do Instituto de Física da USP, cuja primeira fase de montagem encontra-se concluída. Adicionou-se uma linha de irradiação ao projeto original do Microtron, que permite usar o feixe de elétrons com 1,9 MeV de energia do injetor. Espectros de bremsstrahlung de elétrons em alvos finos de $\mathrm{Ag}$ e $\mathrm{Au}$, observados a $30^{\circ}$ e $60^{\circ}$ em relação ao feixe, foram medidos com um detector coaxial de HPGe, cujas dimensões, inclusive do orifício interno e da camada morta do cristal, foram determinadas por medidas experimentais e simulações de Monte Carlo com o código MCNPX, a fim de estimar a resposta do detector para a deconvolução dos espectros. As secções de choque de produção de bremsstrahlung foram medidas tanto para todo o espectro observado $(100-1910 \mathrm{keV})$ quanto para a região próxima ao tip $(1700-1910 \mathrm{keV})$. Os resultados na região do tip concordam com as previsões dos códigos MCNPX e PENELOPE. As causas das discrepâncias observadas para energias menores que $1800 \mathrm{keV}$ são discutidas. Apresenta-se também o projeto de um sistema de medidas de Ressonância Fluorescente Nuclear (NRF) para o estudo de excitações dipolares dos núcleos com fótons de bremsstrahlung, que se pretende usar assim que a energia dos elétrons do Microtron alcance $10 \mathrm{MeV}$. O projeto desse sistema leva em conta as particularidades da instalação do acelerador e da sala de irradiação e busca minimizar a radiação devida aos fótons espalhados nas paredes e aos nêutrons produzidos em reações fotonucleares. O comportamento dos elementos que conformam o sistema de NRF: radiador, colimador, blindagem dos detectores e coletor do feixe de fótons foram estudados por simulação em função das suas características dimensões, formas, materiais - com o código MCNPX. Com o projeto final do arranjo experimental, avaliaram-se as intensidades de NRF que serão observadas pelos detectores de fótons com um alvo de ${ }^{27} \mathrm{Al}$, típico nesse tipo de medições, que indica a viabilidade desse tipo de experimento com o Microtron.
\end{abstract}




\title{
Electron Bremsstrahlung in the IFUSP microtron: measurements, simulation and proposal for a
}

\section{Nuclear Resonance Fluorescence observation setup}

\begin{abstract}
The results of the first experiments carried out in the new electron accelerator of the Linear Accelerator Laboratory (LAL) of the Physics Institute of Universidade de São Paulo are reported here. A $1.9 \mathrm{MeV}$ beam line, which allows the use of the injector beam for experimental physics, was added to the original accelerator design. Electron bremsstrahlung spectra for $\mathrm{Ag}$ and $\mathrm{Au}$ thin targets observed at $30^{\circ}$ and $60^{\circ}$ with respect to the beam direction were collected in a HPGe coaxial detector, whose dimensions, including crystal inner hole dimensions and dead layer thickness, were estimated by means of combined experimental measurements and Monte Carlo simulations with the MCNP code, to evaluate the detector response function to perform the deconvolution of the spectrum. Cross sections for bremsstrahlung yield were determined for the entire measured energy range $(100-1910 \mathrm{keV})$ and for the tip region $(1700-1970 \mathrm{keV})$. The results in the tip region are in agreement with MCNPX and PENELOPE predictions. The possible causes for the disagreement at energies lower than $1800 \mathrm{keV}$ are discussed. The design of a Nuclear Resonance Fluorescence (NRF) setup, aiming the study of dipolar excitations in nuclei with bremsstrahlung photons when the Microtron electron energy reaches $10 \mathrm{MeV}$, is also shown. The setup was designed with the characteristics of the Microtron building and facilities in mind, and searches to minimize the radiation caused by scattered photons and neutrons from photonuclear reactions. The behavior of the NRF setup elements: converter, collimator, detector shielding and photon beam dump, were studied by simulation as functions of their characteristics - dimensions, shapes, materials - using the MCNPX code. The spectral intensity to be observed by the photon detector in the designed NRF setup with a ${ }^{27} \mathrm{Al}$ reference target, typical for NRF measurements, was assessed by simulation and shows the feasibility of this sort of experiment with the Microtron.
\end{abstract}




\section{Dedicatória}

A minha tia Haydee, a meus pais Lucy, Aldo e Rodolfo, a meu amor Fátima, e à maior alegria de minha vida, Marquitos...

A mi tía Haydee, a mis padres Lucy, Aldo y Rodolfo, a mi amor Fátima, y a la mayor alegría de mi vida, Marquitos... 


\section{Agradecimentos}

À Prof. Nora pelos prazos estendidos, pela ajuda insuperável em muitas coisas alem do doutorado, por fazer deste trabalho quase seu segundo Phd., sem ela simplesmente eu não estaria escrevendo estes agradecimentos,

Ao Prof. Vito pela linha de baixa energia, pelas correções e sugestões e pelo grande tempo dedicado,

A Vicky, sempre agradecido, sem ela para mi o Brasil, fora o carnaval de Rio, as brigas no vôlei das cubanas e as brasileiras..., mas só na TV,

Ao Prof. Marcos, meu primeiro orientador, sempre exigente, preciso e disposto a ajudar,

A Alexandre e Alfredo por fazerem o Microtron funcionar, por conseguirem superar as múltiplas inconveniências,

A Roberto e ao pessoal da oficina mecânica, sempre ágeis e atentos,

À Wanda Gabriel Pereira Engel do LAFN pelo preparo dos alvos,

À Prof. Márcia de Almeida Rizzutto e ao LAMFI pelas medições de espessura dos alvos,

Ao Kaka e Edu pela recuperação do detector e ao pessoal do LAL, Juliana, Eliana e Marcelo...

Aos estudantes do LAL por compensarem a saudade por Cuba e pelos bons momentos no bandejão... Felisberto sempre direito e amigo, Thiago pelas dicas e as medidas das espessuras dos alvos,

Aos estudantes cubanos no IFUSP, antes Felix e Cesar agora Israel e Yoelvis,

A meu amigo Mario, a Dona Cida e ao Sr. Orlando,

A meu amigo Tulio Rodrigues por seus conselhos e dicas, 
Ao pessoal em Cuba que cobre minhas costas... Katia, Juano, Amaya, Yasser, Oscar, Cesar, Alina, Doris, Alis, Maylin, Camilo...

E não menos significativo por vir depois, à minha família: Mayi pelo chat e ajudar a Fátima; Ana pelas dicas experientes; Andrea apoiando muito e sempre, por gerações; "El Chino" sempre atento e preocupado; meu pai sempre ajudando muito desde longe; minha mãe incansável e alegre, especial; Fátima que em todo momento acreditou que era possível, que compreendeu as múltiplas viagens ao Brasil, que ficou lá com Marquitos pequeno; e a Marquitos que nos momentos de solidão na sala de trabalho foi minha inspiração...

E finalmente:

À CPG do Instituto de Física da USP, em particular à Profa. Carmen Prado, por acreditar na viabilidade de concluir o trabalho alternando o país de residência a cada semestre e me apoiar em todas as solicitações.

Ao Centro Latino Americano de Física, CLAF, pela bolsa e passagens concedidas para que eu pudesse realizar este trabalho,

À FAPESP, CAPES e CNPq, pelo apoio financeiro no desenvolvimento do Microtron,

... a todos eles, e aos que não mencionei mas deveriam ser incluídos,

\section{Muchas Gracias}




\section{CONTEÚDO}

\section{CAPÍTULO 1}

$\begin{array}{ll}\text { INTRODUÇÃO } & 1\end{array}$

\section{CAPÍTULO 2}

FUNDAMENTOS TEÓRICOS

$\begin{array}{ll}2.1 \text { BREMSSTRAHLUNG } & 7\end{array}$

2.2 FORMALISMO TEÓRICO DA RESSONÂNCIA FLUORESCENTE NUCLEAR 11

2.2.1 Probabilidades de transição 11

2.2.2 Distribuições Angulares e Spins 14

2.2.3 Polarização e Paridade 15

2.2.4 Determinação do número K em núcleos deformados 19

CAPÍTULO 3

SimulaÇão POR MONTE CARLO: O CÓDIGO MCNPX 21

3.1 INTRODUÇÃO

3.2 O CÓDIGO MCNPX 22

3.2.1 Estrutura dos parâmetros de entrada 23

3.2.2 Peso estatístico e trajetória da partícula 24

$\begin{array}{ll}3.2 .3 \text { Transporte de fótons } & 27\end{array}$

3.2.3.1 Tratamento físico detalhado 28

3.2.4 Transporte de elétrons $\quad 34$

3.2.4.1 Passos e Subpassos de um elétron 35

3.2.4.2 Poder de freamento $\quad 37$

3.2.4.3 Flutuações da Energia $\quad 39$

3.2.4.4 Deflexões Angulares $\quad 41$

3.2.4.5 Bremsstrahlung $\quad 42$

3.3 CONFIABILIDADE DOS CÓDIGOS MCNP E MCNPX 44

3.3.1 Comparações com experimentos e com outros códigos 44

3.3.2 Bremsstrahlung, Fotonêutrons, e Função Resposta de um detector. 
MÉTODO EXPERIMENTAL

4.1. O MICROTRON DO LAL (IFUSP)

4.1.1 Descrição Geral 51

4.1.2 O Microtron do LAL e a técnica de NRF 54

4.2 DESCRIÇÃO DO ARRANJO EXPERIMENTAL DE MEDIDA DO BREMSSTRAHLUNG 55

4.2.1 Copo de Faraday 56

4.2.2 Colimador de Feixe de Bremsstrahlung $\quad 57$

4.3 CARACTERIZAÇÃO DO CRISTAL DE HPGE

4.3.1 Determinação da espessura da camada morta $\quad 60$

4.3.2 Varredura do cristal $\quad 61$

4.3.3 Calibração de eficiência $\quad 66$

4.3.4 Função Resposta

4.3.5 Deconvolução dos espectros

4.4 FONTES DE FÓTONS PARA MEDIDAS DE UM SISTEMA DE NRF 73

4.4.1 Reator Nuclear $\quad 74$

4.4.2 Aniquilação de Pósitrons em Vôo

4.4.3 Espalhamento de laser em elétrons de alta energia (LCP) 75

4.4.4 Radiação de freamento (Bremsstrahlung) 76

\begin{tabular}{lr} 
CAPÍTULO 5 & 81 \\
\hline
\end{tabular}

Medidas das SecÇões de CHOQue De PROduÇão de BREMSSTRAHLung 81

5.1 IRRADIAÇÕES DOS ALVOS E ESPECTROS

5.2 TESTE DO PROCEDIMENTO DE DECONVOLUÇÃO

5.3 SECÇÕES DE CHOQUE. ESTIMATIVA DO BACKGROUND 84

\begin{tabular}{lr} 
CAPÍTULO 6 & 93 \\
\hline
\end{tabular}

ARRANJO PARA EXPERIMENTOS DE NRF OPTIMIZADO POR SIMULAÇÃO 93

6.1 INTRODUÇÃO

6.2 FONTE DE FÓTONS $\quad 94$

6.2.1 Características das simulações realizadas. $\quad 94$

6.2.2 Intensidade e distribuição angular dos Fótons de Bremsstrahlung 96

6.2.3 Fotonêutrons produzidos no radiador 99 
$\begin{array}{ll}\text { 6.2.4 Potência dissipada no radiador } & 103\end{array}$

6.3 COLIMAdOR DO FEIXE DE FÓTONS 104

$\begin{array}{ll}\text { 6.3.1 Colimador junto ao radiador } & 104\end{array}$

6.3.1.1 Descrição do sistema e da simulação 104

6.3.1.2 Largura do feixe de Bremsstrahlung 106

6.3.1.3 Espalhamento dos fótons no colimador 107

6.3.2 Colimador depois do "Tagger". 109

6.3.2.1 Largura do feixe de Bremsstrahlung e comparação entre $\mathrm{Cu}$, Ni e Pb. 110

6.3.2 Produção de nêutrons no colimador. 112

6.3.3 Raio externo do colimador. 115

6.4 BLINDAGEM DOS DETECTORES DE HPGE 116

6.5 COLETOR DO FEIXE DE FÓTONS 118

$\begin{array}{ll}\text { 6.5.1 Variantes estudadas } & 119\end{array}$

6.5.2 Efeito do coletor em uma simulação completa do experimento 122

6.6 PROJETO FINAL DE ARRANJO PARA O SISTEMA DE NRF 124

\begin{tabular}{lr} 
CAPÍTULO 7 & 125 \\
\hline
\end{tabular}

$\begin{array}{ll}\text { DISCUSSÃO } & 125\end{array}$

7.1 BREMSSTRAHLUNG: DISTRIBUIÇÃO ANGULAR E INTENSIDADE NO TIP. 125

7.2 ARRANJO PARA MEDIDAS DE NRF 129

\begin{tabular}{lr} 
CAPÍTULO 8 & 133 \\
\hline
\end{tabular}

$\begin{array}{ll}\text { CONCLUSÕES } & 133\end{array}$

\begin{tabular}{lr} 
ANEXOS & 135 \\
\hline
\end{tabular}

ANEXO I SISTEMAS DE MEDIDAS DE NRF EM OUTROS LABORATÓRIOS 135

I.1 ARRANJO NO ACELERADOR DYNAMITRON 4,3 MV EM STUTTGART 135

I.1.1 Calibração do Sistema 137

$\begin{array}{ll}\text { I.2 ARRANJO NO ACELERADOR S-DALINAC EM DARMSTADT } & 138\end{array}$

I.3 ARRANJO NO ACELERADOR LINEAR DE 15 MEV EM GENT 142

I.4 ARRANJO NO ACELERADOR ELBE EM DRESDEN 145

$\begin{array}{ll}\text { I.4.1 Radiador } & 146\end{array}$

$\begin{array}{ll}\text { I.4.2 Colimador } & 147\end{array}$

$\begin{array}{ll}\text { I.4.3 Sistema de detectores e sua blindagem } & 147\end{array}$ 
ANEXO II CARACTERÍSTICAS GERAIS DOS PRINCIPAIS ELEMENTOS UTILIZADOS NAS SIMULAÇÕES.

ANEXO III. SEÇÕES DE CHOQUE $(\gamma, N)$ DOS ISÓTOPOS EMPREGADOS NA SIMULAÇÃO.

ANEXO IV PRODUÇÃO DE FÓTONS E NÊUTRONS PELOS RADIADORES PARA OUTRAS ENERGIAS DO FEIXE DE ELÉTRONS INCIDENTE.

ANEXo V MEdidas de OBSERVÁVEIS DE PolarizaÇão

V.1 FEIXES DE FótONS POLARIZADOS USANDO BREMSSTRAHLUNG

V.2 MEdidas da PolarizaÇÃo dos Fótons EsPalHados 


\section{Capítulo 1}

\section{Introdução}

O Laboratório do Acelerador Linear (LAL) do Instituto de Física da Universidade de São Paulo (IFUSP) está construindo um acelerador de elétrons tipo Microtron, com energia máxima de $38 \mathrm{MeV}$ em regime de onda contínua [Ma04]. O injetor de 1,9 MeV encontra-se operacional e o booster, com energia de saída de $5 \mathrm{MeV}$, está em fase final de montagem. Atualmente, adicionou-se uma linha de baixa energia ao projeto original do Microtron, de modo a permitir a realização de experimentos na área de física atômica simultaneamente com os trabalhos de teste do booster [Va11].

Os resultados que apresentamos nesta tese combinam simulações por Monte Carlo (MC) das primeiras experiências realizadas no acelerador, correspondentes a medidas de bremsstrahlung de elétrons, com o projeto de um arranjo experimental para medidas de Ressonância Fluorescente Nuclear (NRF) usando fótons de bremsstrahlung, que permite estudar as excitações dipolares dos núcleos, mas que requer energias maiores que 1,9 MeV para sua aplicação [Kn96].

Embora o bremsstrahlung seja um processo bastante estudado por seu caráter de interação fundamental, não existe uma teoria única capaz de explicar as distribuições energéticas e angulares das partículas emitidas, fótons de bremsstrahlung e elétrons residuais, para qualquer energia dos elétrons incidentes e número atômico $Z$ [Se86, Eb03]. A literatura acerca da comparação entre os resultados experimentais e os cálculos aceitos atualmente mostra concordância entre eles, mas usa modelos diferentes nas várias faixas de energia e os cálculos têm correções ad-hoc. Além disso, na região de maior energia do espectro de fótons, conhecida em inglês como tip region, encontram-se discordâncias pronunciadas. As principais medidas experimentais datam de mais de vinte anos e, em muitas delas, as incertezas são omitidas ou têm valores 
relativamente elevados. Por essa razão, o estudo das secções de choque, em particular na região do tip, ainda hoje constitui uma questão de interesse [Pr60, Pr75, St72, Da72, Ja64, O178, Fe83, Fa08].

A fronteira entre as diferentes teorias que se aplicam ao bremsstrahlung de baixa energia e alta energia encontra-se em $2 \mathrm{MeV}$ [Se86], o que é um incentivo adicional para realizar estudos de bremsstrahlung com os elétrons de $1,9 \mathrm{MeV}$ do injetor do microtron. Por outro lado, o regime de onda contínua e a possibilidade de trabalhar com correntes baixas no Microtron, da ordem de nano-ampéres, permitem fazer medidas diretas com detectores de germânio hiperpuro, o que evita os problemas de empilhamento característicos dos aceleradores pulsados. Adicionalmente, a literatura sobre medidas diretas do bremsstrahlung de elétrons com detectores de HPGe [Re72, St72, Ae75], que têm resolução em energia dos fótons uma ordem de grandeza melhor que a das medidas anteriores, é escassa. Dois trabalhos se restringem a energias menores que 0,25 MeV [Re72, Ae75] e um terceiro, com elétrons de 1,84 MeV [St72], encontrou resultados em grande desacordo com a teoria; em análise subsequente, Pratt e Tseng [Pr75] verificaram que o desacordo para elementos de alto $Z$ era devido a dificuldades com as aproximações efetuadas no cálculo, mas o mesmo não acontecia em relação aos elementos de baixo Z. Assim, as medidas apresentadas aqui, com resolução de poucos $\mathrm{keV}$, podem contribuir para esclarecer a situação ainda indefinida da forma do espectro de bremsstrahlung na região do tip.

A determinação do espectro de bremsstrahlung, tanto em intensidade quanto na forma, é um aspecto importante dos experimentos de NRF, porque ele constitui a fonte de partículas que excita os núcleos do alvo e é um dos fatores na determinação das seções de choque [Ga00, Wa05]. Assim, medidas de bremsstrahlung de elétrons com 1,9 MeV permitem compreender os detalhes da medição do espectro de fótons, que serão úteis nas experiências posteriores a maiores energias.

O estudo da NRF é uma das linhas de pesquisa abertas pelo segundo estágio do Microtron, com elétrons de $10 \mathrm{MeV}$ de energia, e que podem ser iniciadas já com a conclusão do primeiro estágio, quando os elétrons alcançarão $5 \mathrm{MeV}$ [Ma04]. Elas permitem obter muitas informações sobre características de importância fundamental na estrutura do núcleo. Assim, no espectro dos fótons detectados medem-se as energias de excitação dos níveis observados; a distribuição angular dos raios gamas define os spins 
dos estados excitados, no caso de núcleos par-par; as seções de choque fornecem as larguras radiativas das transições e, finalmente, da medida da polarização dos fótons emitidos extraem-se as paridades dos estados excitados, pela separação entre transições E1 e M1 [Kn96, Be87].

A NRF teve um auge na década de 1990 motivado pelo interesse nos modos dipolares elétricos e magnéticos em núcleos pesados com baixas energias de excitação [Be87], que passaram a ser acessíveis pelos avanços na área experimental. Os aceleradores de elétrons de baixas energias com feixe contínuo e o progresso na espectroscopia gama, com o emprego de complexos arranjos de detectores de germânio com alta eficiência e excelente resolução, garantiram experimentos de NRF de sensibilidade elevada [Wi96, Mi00, Dr06]. Também foram desenvolvidos polarímetros Compton de $\mathrm{Ge}$ eficientes [Sc94, Hu02] e feixes de fótons polarizados, que permitiram medidas da paridade de estados excitados [Kn92, Oh94, Go94]. Nos últimos anos, houve um aumento significativo no número de publicações nessa área, tanto relacionadas à estrutura nuclear [Er09, Ad11, He10, Ku10, Ru09, Ye10], quanto voltadas para aspectos mais direcionados a problemas de astrofísica nuclear [De10, Er10] e às ressonâncias de dipolo pigméias [Sa08, Sc08, Av09].

O objetivo central do desenho do arranjo de NRF foi minimizar a interferência da radiação proveniente do espalhamento de fótons nas paredes do edifício e da absorção dos nêutrons das reações fotonucleares. Por meio de simulações de MC de cada um dos componentes do sistema: radiador, colimador, blindagem dos detectores e coletor do feixe de fótons, elaborou-se um projeto de um arranjo para medidas de NRF no LAL, o que poupará gastos de materiais, economizará tempo e esforços experimentais. $\mathrm{O}$ arranjo foi concebido para usar o bremsstrahlung de elétrons de 10 $\mathrm{MeV}$, mas também foi preparado de modo a poder ser usado com outras energias de feixe.

As simulações, tanto as do arranjo de NRF quanto as dos experimentos de bremsstrahlung, foram realizadas com o código MCNPX, que usa o método de MC para avaliar o transporte de partículas e inclui geometria 3D, transporte contínuo desde energias da ordem dos $\mathrm{keV}$ até os $\mathrm{TeV}$, assim como uma variedade de opções para fontes de partículas e "tallies" (saídas do código) [Pe05]. 
Nosso trabalho focou-se então em dois objetivos principais e vários específicos, que contribuem a alcançar essas duas tarefas centrais:

\section{Medir o bremsstrahlung de elétrons de 1,9 MeV}

$\checkmark$ Caracterizar um detector de HPGe combinando procedimentos experimentais e de Monte Carlo, o qual implica a determinação da configuração geométrica do cristal de Ge,

$\checkmark$ Determinar a função resposta do detector de HPGe na geometria de medição do bremsstrahlung,

$\checkmark$ Medir as seções de choque de produção de bremsstrahlung para alguns ângulos de emissão dos fótons em relação ao feixe de elétrons incidentes.

\section{Desenhar um sistema de medidas de Ressonância Fluorescente Nuclear}

$\checkmark$ Recomendar um radiador para produzir o feixe de bremsstrahlung estudando a intensidade de fótons e a geração de nêutrons em radiadores com diferentes espessuras e números atômicos,

$\checkmark$ Determinar o material e as dimensões ótimas para o colimador do feixe de fótons, estudando a largura do feixe na posição do alvo de NRF e a produção de nêutrons no colimador,

$\checkmark$ Desenhar um coletor para o feixe de fótons, conjugando materiais de baixo e alto número atômico, que permita diminuir consideravelmente o background de fótons retroespalhados sem incrementar o fundo de nêutrons,

$\checkmark$ Avaliar o sistema desenhado, estimando as intensidades dos fotopicos para um isótopo padrão em medidas de NRF e os tempos de medição em experiências sem observais de polarização.

O texto está organizado em oito capítulos, incluindo a introdução (cap. 1), a discussão (cap. 7) e as conclusões (cap. 8). No capítulo 2 são descritos os aspectos teóricos de Ressonância Fluorescente Nuclear e do bremsstrahlung de elétrons de interesse para este trabalho. O terceiro capítulo centra-se na simulação de MC. O capítulo 4 é dedicado aos métodos experimentais, subdividido em quatro blocos: a descrição do Microtron do LAL, do arrango experimental de medida do bremsstrahlung, 
caracterização do cristal de HPGe, e as particularidades da técnica experimental de NRF. Finalmente, os resultados do trabalho são apresentados nos capítulos 5 e 6, correspondentes às medidas experimentais de bremsstrahlung e ao projeto do arranjo de NRF, respectivamente. O texto é complementado por seis anexos, que apresentam informações importantes no desenvolvimento do arranjo de NRF proposto: os sistemas de medida de NRF mais referenciados na literatura, as características dos materiais usados nas simulações, secções de choque $(n, \gamma)$, os resultados de simulações para energias de elétrons maiores que $10 \mathrm{MeV}$, uma descrição sobre as medidas de observáveis de polarização nos sistemas de NRF, e um breve glossário de alguns termos relativos ao uso do código MCNPX. 


\section{Capítulo 2}

\section{Fundamentos Teóricos}

\subsection{Bremsstrahlung}

Os elétrons, com energias entre as dezenas de $\mathrm{keV}$ até centenas de $\mathrm{MeV}$, perdem energia ao interagir com a matéria devido a dois processos fundamentais: perdas por colisões inelásticas, que resultam em excitação ou ionização eletrônica, e por radiação de freamento (bremsstrahlung). O primeiro destes fenômenos predomina a baixas energias, enquanto a maiores energias as perdas por radiação são mais importantes. A energia do elétron, na qual as perdas por excitação e ionização atômica e por bremsstrahlung se igualam, é conhecida como energia crítica (eq. 2.1) [Le94], e depende do numero atômico $Z$ do material:

$E_{c}=\frac{800 \mathrm{MeV}}{Z+1.2}$

Assim, por exemplo, para o $\mathrm{Au}(\mathrm{Z}=79)$ esse valor é aproximadamente $10 \mathrm{MeV}$ enquanto que, para a $\mathrm{Ag},(\mathrm{Z}=47)$ é $16 \mathrm{MeV}$.

Durante muitos anos, têm sido estudadas as secções de choque de produção de bremsstrahlung por elétrons que impactam alvos de materiais leves, intermediários e pesados. No entanto, não existe uma teoria única do bremsstrahlung que permita explicar os resultados experimentais tanto para baixas quanto para altas energias em toda a faixa de valores de Z. Igualmente, na região de maior transferência de momento linear do elétron ao fóton produzido, ou seja, na região de maiores energias do espectro de bremsstrahlung, conhecida em inglês como "tip region" [Fa58, Fa59a, Pr60, Pr75, Ja64, St72, Da72, Ja64, O178, Bo82, Fe83], várias correções devem ser introduzidas com o fim de explicar os dados experimentais [Am89]. Por outro lado, e apesar dos 
diversos estudos experimentais, existem lacunas em intervalos de energias e de valores de $\mathrm{Z}$, onde ou não se encontram resultados experimentais ou estes aparecem com incertezas elevadas.

A compilação de secções de choque de produção de bremsstrahlung mais completa e amplamente usada, estimada por modelos teóricos e corrigida pela dependência observada experimentalmente conforme a região, é devida a Stephen M. Seltzer e Martin J. Berger [Se86], que publicaram um extenso trabalho determinando a secção de choque diferencial $\frac{d \sigma}{d k}$ em energia do fóton emitido $(k)$, para elétrons com energia entre $1 \mathrm{keV}$ e $1 \mathrm{GeV}$, em átomos neutros com $1 \leq \mathrm{Z} \leq 100$. Esta secção de choque depende da energia $\mathrm{k}$ do fóton emitido, da energia cinética $T_{1}$ do elétron incidente, e do número atômico $\mathrm{Z}$ do átomo alvo. A energia do elétron emergente é, portanto, $T_{2}=T_{1}-k$. Para um átomo neutro esta seção de choque pode ser expressa como a soma de dois termos:

$\frac{d \sigma}{d k}=\frac{d \sigma_{n}}{d k}+Z \frac{d \sigma_{e}}{d k}$

onde o primeiro termo $\frac{d \sigma_{n}}{d k}$ representa o bremsstrahlung produzido no campo do núcleo atômico blindado, e o segundo $Z \frac{d \sigma_{e}}{d k}$ é a contribuição devida aos $Z$ elétrons atômicos. Geralmente a equação (2.2) é reescrita como:

$\frac{d \sigma}{d k}=\left(1+\frac{\eta}{Z}\right) \frac{d \sigma_{n}}{d k}$

sendo $\eta$ a divisão entre as duas secções de choque:

$$
\eta=\frac{d \sigma_{e}}{d k} /\left(\frac{1}{Z^{2}} \frac{d \sigma_{n}}{d k}\right)
$$

A teoria que explica as secções de choque de bremsstrahlung tem sido desenvolvida fazendo varias aproximações, e é sujeita a limitações e regiões de aplicabilidade. As primeiras teorias analíticas datam dos anos 50 do século XX e foram compiladas por Koch e Motz no ano 1959 [Ko59]. Para determinar $\frac{d \sigma_{n}}{d k}$ eles recomendam um conjunto de fórmulas, fatores de correção coulombianos e correções empíricas que devem ser usadas de acordo com as energias inicial e final do elétron. Em 
1977, Pratt et al. [Pr77, Pr81] publicaram um conjunto de dados correspondentes a $\frac{d \sigma_{n}}{d k}$ onde o processo de bremsstrahlung foi tratado como a transição simples de um elétron em um potencial central auto-consistente que representa o campo coulombiano do núcleo atômico blindado. Mais recentemente, em 1985, Pratt e Feng [Pr85] analisaram as diversas teorias usadas no limite das baixas energias $\left.\left(1 \mathrm{keV} \leq T_{1} \leq 2 \mathrm{MeV}\right)\right]$. No limite de altas energias $\left(T_{1} \geq 50 \mathrm{MeV}\right)$ freqüentemente se aplica a teoria analítica de Davie, Bethe, Maximon e Olsen (DBMO) [Da54], onde tanto $T_{1}$ quanto $T_{2}$ são consideradas grandes comparadas com a energia de repouso do elétron. Os resultados obtidos por DBMO são considerados precisos, exceto no limite de alta transferência de energia onde $k=T_{1}$. Nesta região, a teoria desenvolvida por Jabbur e Pratt constitui uma melhor alternativa [Pr75, Ja64]. Para baixas energias, Seltzer e Berger [Se86] obtiveram os valores de secções de choque no limite de alta freqüência conectando os dados tabelados por Jabbur e Pratt [Ja64] com os de Pratt et al. [Pr77, Pr81]. No intervalo de energias intermediárias ( $2 \mathrm{MeV} \leq T_{1} \leq 50 \mathrm{MeV}$ ), onde as aproximações realizadas pelas teorias mencionadas não tem validez, o tratamento teórico se complica substancialmente, e por exemplo, Seltzer e Berger optaram por realizar ajustes de mínimos quadrados, das secções de choques a baixas e altas energias.

A seção de choque de bremsstrahlung, resultado da interação elétron-elétron, $\frac{d \sigma_{e}}{d k}$ se diferencia da $\frac{d \sigma_{n}}{d k}$ em vários aspectos: a blindagem do campo dos elétrons atômicos é diferente da blindagem pelos elétrons do átomo ao núcleo; $\frac{d \sigma_{e}}{d k}$ cai à zero no limite de alta frequiência devido à repulsão coulombiana entre os elétrons; nas interações elétron-elétron aparece uma componente de bremsstrahlung de baixa energia produzida pelos elétrons retroespalhados; existe um limite superior cinemático na energia do fóton emitido, o qual varia desde $k_{\max }=T_{1}$ para $\beta_{1}=1$ à $k_{\max }=T_{1} / 2$ para $\beta_{1}=0$ sendo $\beta=\frac{v}{c}$ a relação entre a velocidade do elétron e da luz no vácuo; e $\frac{d \sigma_{e}}{d k}$ tende a desaparecer a baixas energias dos elétrons incidentes como conseqüência da ausência de momento dipolar para o sistema elétron - elétron. A aproximação de Born proposta por Haug, a correção colulombiana de Maxon e Corman, e a teoria para altas energias de Wheeler e Lamb, para determinar a correção por blindagem, foram usadas por Seltzer e Berger para compilar seus resultados [Se86, Ma67]. 
Na região de baixas energias, a maioria dos resultados experimentais disponíveis [Mo55, Mo58, Re67, Re72] concordam com as previsões de Seltzer e Berger, dentro dos limites das incertezas experimentais e teóricas, que no caso das experimentais muitas vezes são elevadas. A exceção são os resultados de Motz [Mo55] que se encontram por cima dos outros, e que de acordo com Rester et al. [Re67] é devido à subtração incorreta do fundo. Para energias superiores, existe boa concordância com os experimentos, por exemplo, os resultados experimentais reportados por M. N. Martins et al. em 1984 para radiadores de $\mathrm{Cu}, \mathrm{Mo}$, Ta, e Th, e elétrons de energias incidentes entre 20 e $60 \mathrm{MeV}$ [Ma84].

Praticamente todas as medidas experimentais de espectros de bremsstrahlung em alvos finos foram feitas há mais de vinte anos, usando detectores cintiladores para medir direitamente o espectro de bremsstrahlung, a baixas correntes do feixe incidente, ou usando laminas de ativação com diferentes limiares de energia de reações $(\gamma, n),(\gamma, p)$, $(\gamma, n+p)$, etc. $\mathrm{Na}$ atualidade a disponibilidade de detectores de $\mathrm{Ge}$ com elevada eficiência, de uma eletrônica mais rápida que permite maiores taxas de contagem, e de aceleradores que trabalham em regime de corrente continua (DC), e portanto não concentram toda a radiação em pulsos de pequena duração, permitem realizar medidas diretas dos espectros de bremsstrahlung a diferentes ângulos e com melhor resolução energética, o que é sumamente importante na região do tip [Fa58, Fa59a, Pr60, Pr75, Ja64, St72, Da72, O178, Bo82, Fe83]. Paralelamente, os avanços na área da computação têm permitido, com o emprego de programas de simulação por Monte Carlo como MCNPX, GEANT, EGS4, PENELOPE [Pe05, Al06, Sa03, Ne85] um melhor conhecimento da função resposta dos detectores, fazendo a análise e a deconvolução dos espectros mais confiável [Ro00, Ze01, Ka03, Sc06, Ro07, Ma10, Pa10].

As medidas de secções de choque de produção de bremsstrahlung não só são importantes para corroborar as diversas teorias e para contribuir a complementar com menores incertezas os dados experimentais disponíveis, senão também podem constituir um aporte em áreas aplicadas como a física médica, especificamente a radioterapia com aceleradores de elétrons, fazendo as estimações das doses mais confiáveis. Por outra parte, nas medidas de NRF um dos aspectos fundamentais é a estimativa da forma do espectro de bremsstrahlung que é a fonte de fótons usada. Mesmo que existam outros métodos on-line de estudar o espectro mediante fótons monoenergéticos de NRF 
produzidos em alvos conhecidos, a medida direta garante uma alternativa adicional a esses métodos, além do comportamento com a energia do espectro contínuo.

\subsection{Formalismo Teórico da Ressonância Fluorescente Nuclear}

\subsubsection{Probabilidades de transição}

A Ressonância Fluorescente Nuclear (NRF) está baseada na absorção ressonante de um fóton que excita um estado nuclear, o qual subseqüentemente se desexcita emitindo um fóton. Este estado nuclear de energia $E_{x}$ pode ser excitado, por exemplo, por meio de radiação multipolar de ordem $L_{1}$ ou $L_{1}^{\prime}$, e dependendo dos spins dos estados inicial $J_{i}^{\pi}$, intermediário $J^{\pi}$ e final $J_{f}^{\pi}$, a seção de choque de espalhamento do fóton correspondente terá um determinado valor. Em NRF o estado inicial corresponde ao estado fundamental do núcleo, então $J_{i}^{\pi}=J_{o}^{\pi}$ (Fig. 2.1).

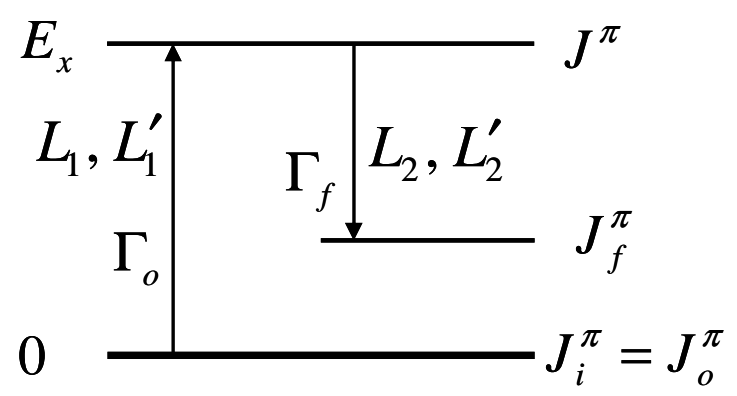

Fig. 2.1 Definição das ordens multipolares das transições $L_{1}, L_{2}, L_{1}^{\prime}$ e $L_{2}^{\prime}$, das larguras radiativas $\Gamma_{o}$ e $\Gamma_{f}$ e spins $J_{o}^{\pi}, J^{\pi}$ e $J_{f}^{\pi}$ do núcleo. Os índices (1) e (2) denotam os canais de entrada e de saída, respectivamente.

O coeficiente de mistura das transições $L_{n}$ e $L_{n}^{\prime}\left(\operatorname{com} L_{n}^{\prime}=L_{n}+1\right.$ e $n=1$, 2, no exemplo da Fig. 2.1 é definida como a relação entre os elementos de matriz [Kn96, Ma95]:

$\delta_{n}=\frac{\left\langle\psi_{f}\left|L_{n}+1\right| \psi_{i}\right\rangle}{\left\langle\psi_{f}\left|L_{n}\right| \psi_{i}\right\rangle}$.

A seção de choque $\sigma$ de absorção e reemissão subseqüente do fóton, partindo do estado fundamental com spin e paridade $J_{o}^{\pi}$ para o estado excitado $J^{\pi}$, que decai novamente ao estado fundamental ou a um estado excitado de menor energia $J_{f}^{\pi}$, tem 
forma de uma ressonância do tipo Breit-Wigner, mas com uma largura maior devido ao Efeito Doppler [Me59]. Na maioria dos experimentos de NRF recentes é usada uma fonte de fótons com espectro contínuo (bremsstrahlung), de modo que a seção de choque $I_{s}$ é integrada por todo o intervalo de energia e está determinada pela expressão:

$$
I_{s}=\frac{2 J+1}{2 J_{o}+1}\left(\pi \frac{\hbar c}{E_{\gamma}}\right)^{2} \frac{\Gamma_{o} \Gamma_{f}}{\Gamma} \frac{W(\Theta)}{4 \pi}
$$

onde $J$ e $J_{o}$ são os spins dos estados excitado e fundamental respectivamente; $W(\Theta)$ é a distribuição angular dos fótons; $\Gamma_{o}, \Gamma_{f}$ e $\Gamma$ são as larguras radiativas do estado fundamental, do estado final, e a largura total respectivamente. Deste modo, por exemplo, no caso do espalhamento elástico do fóton, $\Gamma_{o}=\Gamma_{f}$, a seção de choque será proporcional á $\Gamma^{2} / \Gamma_{o}[\mathrm{Ma} 95]$.

Com a técnica de NRF podem ser medidos valores de $\Gamma$ da ordem de $100 \mathrm{meV}$. Lembrando que $\Gamma$ está relacionado com o tempo de vida $\tau$ do nível excitado por meio do Princípio da Incerteza de Heisenberg:

$$
\Gamma=\frac{\hbar}{\tau}
$$

então, por meio de experimentos de NRF é possível medir estados com tempos de vida da ordem de $10^{-15}$ segundos. Desta maneira, as medidas com NRF são complementares às medições de tempo de vida que empregam, por exemplo, o Método DSA (Doppler Shift Attenuation) [No79, Be93].

A largura radioativa está ligada ao elemento de matriz da transição. Assim, $\Gamma_{o}$ é proporcional à probabilidade reduzida de transição $B\left(\Pi L, E_{\gamma}\right) \uparrow$ onde $\Pi$ denota o tipo de transição $\left(\Pi=E\right.$ - Elétrica, ou $\Pi=M$ - Magnética), e $E_{\gamma}$ a energia do fóton [Ma95, Vo06]:

$$
\Gamma_{o}=8 \pi \sum_{\Pi L=1}^{\infty} \frac{(L+1)\left(E_{\gamma} / \hbar c\right)^{2 L+1}}{L[(2 L+1) ! !]^{2}} \frac{2 J_{o}+1}{2 J+1} B\left(\Pi L, E_{\gamma}\right) \uparrow
$$


O Principio do Balanço Detalhado relaciona as probabilidades reduzidas de transição do estado fundamental ao excitado $B\left(\Pi L, E_{\gamma}\right) \uparrow$, e do estado excitado ao fundamental $B\left(\Pi L, E_{\gamma}\right) \downarrow$ :

$\left(2 J_{o}+1\right) B\left(\Pi L, E_{\gamma}\right) \uparrow=(2 J+1) B\left(\Pi L, E_{\gamma}\right) \downarrow$

e costuma-se definir o fator de spin como:

$$
g=\frac{\left(2 J_{o}+1\right)}{(2 J+1)}
$$

Para as transições dipolares em núcleos par-par, por exemplo, a expressão (2.8) se reduz às seguintes relações numéricas entre a probabilidade reduzida de transição e $\Gamma_{o}[\mathrm{Kn} 96, \mathrm{Be} 87]:$

$$
\begin{aligned}
& B(E 1) \uparrow=2.866 \times 10^{-3} \frac{\Gamma_{o}}{E_{\gamma}^{3}} \quad\left\lfloor e^{2} \mathrm{fm}^{2}\right\rfloor \quad \text { (Dipolar Elétrica) } \\
& B(M 1) \uparrow=0.2598 \frac{\Gamma_{o}}{E_{\gamma}^{3}} \quad\left\lfloor\mu_{N}^{2}\right\rfloor \quad \text { (Dipolar Magnética) }
\end{aligned}
$$

nas expressões (2.11) e (2.12) as energias $E_{\gamma}$ dos fótons se expressam em $\mathrm{MeV}$ e as larguras de transição $\Gamma_{o}$ em meV.

No caso de experimentos de espalhamento inelástico de fótons, isto é, transições do estado fundamental para um estado excitado e deste para outro com energia superior ao fundamental, as probabilidades reduzidas de transição podem ser medidas em função do momento transferido ao núcleo. Como o momento transferido depende diretamente dos fatores de forma (form factor), estas medidas fornecem informação sobre a estrutura nuclear dos níveis excitados que, complementada com dados de experimentos de espalhamento de elétrons, permitem fazer uma análise completa da estrutura nuclear em estudo [Ri90, Ri95, Bo86]. 


\subsubsection{Distribuições Angulares e Spins}

Os spins dos estados excitados podem ser determinados a partir de experimentos de NRF fazendo medidas das distribuições angulares dos fótons espalhados em relação ao feixe de fótons incidentes. O formalismo que descreve as distribuições angulares é equivalente ao formalismo que descreve as correlações angulares $\gamma-\gamma$. Assim, a função de correlação angular $W(\Theta)$ do fóton espalhado $\gamma_{2}$ em relação ao fóton incidente $\gamma_{1}$ para os casos onde $L_{n} \leq 2$, que são os de maior interesse em estudos de NRF, pode ser expandida em polinômios de Legendre como [Kn96, Ma95]:

$W(\Theta)=\sum_{v=0,2,4} A_{v}(1) A_{v}(2) P_{v}(\cos (\Theta))$

onde os coeficientes da expressão (2.13) são determinados pelas expressões:

$$
\begin{aligned}
& A_{v}(1)=\left(\frac{1}{1+\delta_{1}^{2}}\right)\left\{F_{v}\left(L_{1} L_{1} J_{o} J\right)+2 \delta_{1} F_{v}\left(L_{1} L_{1}^{\prime} J_{o} J\right)+\delta_{1}^{2} F_{v}\left(L_{1}^{\prime} L_{1}^{\prime} J_{o} J\right)\right\} \\
& A_{v}(2)=\left(\frac{1}{1+\delta_{2}^{2}}\right)\left\{F_{v}\left(L_{2} L_{2} J_{o} J\right)+2 \delta_{2} F_{v}\left(L_{2} L_{2}^{\prime} J_{o} J\right)+\delta_{2}{ }^{2} F_{v}\left(L_{2}^{\prime} L_{2}^{\prime} J_{o} J\right)\right\}
\end{aligned}
$$

Os coeficientes $F_{v}$ podem ser achados em várias compilações [Si65]. Deste modo, por exemplo, a distribuição angular dos fótons espalhados por um núcleo par-par com transições dipolares puras entre níveis de spin $0 \rightarrow 1 \rightarrow 0$, que representa o caso mais simples, se expressa como:

$W(\Theta)_{\text {Dipolar }}=\frac{3}{4}\left(1+\cos ^{2} \Theta\right)$

Da mesma maneira, para o caso de transições quadrupolares puras entre níveis de spin $0 \rightarrow 2 \rightarrow 0$ :

$$
W(\Theta)_{\text {Cuadrupolar }}=\frac{5}{4}\left(1-3 \cos ^{2} \Theta+4 \cos ^{4} \Theta\right)
$$


A Fig. 2.2 mostra a distribuição angular em um gráfico polar para as transições dipolar pura $(0 \rightarrow 1 \rightarrow 0)$, e quadrupolar pura $(0 \rightarrow 2 \rightarrow 0)$. Nos núcleos par-par é possível, por tanto, determinar diretamente os spins dos estados a partir de medidas em dois ângulos diferentes; o par de ângulos mais favorável e também mais usado é $\Theta=90^{\circ}$ e $\Theta=127^{\circ}$ em relação ao feixe incidente. No caso de núcleos par-par, a relação $W\left(90^{\circ}\right) / W\left(127^{\circ}\right)$ é 0,734 e 2,280 para transições dipolares e quadrupolares, respectivamente [Kn96].

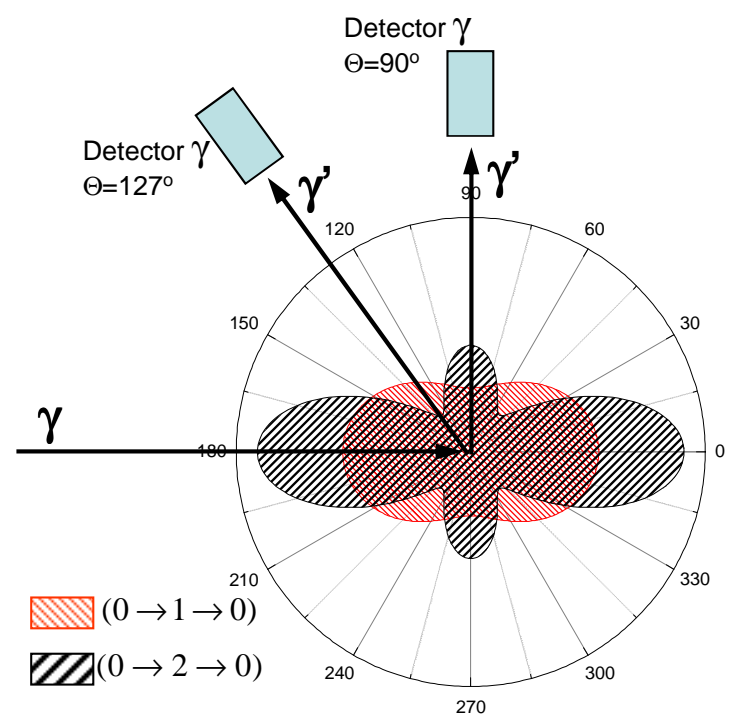

Fig. 2.2. Padrões das distribuições angulares para fótons espalhados em núcleos par-par (em cascata dipolar pura $(0 \rightarrow 1 \rightarrow 0)$, e quadrupolar pura $(0 \rightarrow 2 \rightarrow 0)$ ).

Infelizmente, no caso de núcleos com número de massa (A) ímpar, as distribuições angulares são praticamente isotrópicas, porque as cascatas gama envolvem estados com valor semi-inteiro de spin. Neste tipo de caso, fica difícil obter uma informação conclusiva sobre os spins dos níveis excitados. Usando uma instalação típica de NRF, só em poucos casos favoráveis de núcleos com A ímpar é possível determinar os spins [Ge94].

\subsubsection{Polarização e Paridade}

A determinação da paridade é de importância vital na interpretação das excitações dipolares em experimentos de NRF. Em princípio existem duas maneiras para medir observáveis da polarização: irradiar o alvo com fótons linearmente 
polarizados, o que é conhecido como experimentos $(\vec{\gamma}, \gamma)$ [Vo06, Oh94, Sa05, Go94, Go94a], ou medir a polarização dos fótons espalhados, experimentos $(\gamma, \vec{\gamma})$ [Go94a, Kn92, Kn95, Br00a, Ko05].

A distribuição angular dos fótons espalhados ressonantemente é determinada pela expressão [Kn96, Ma95]:

$$
\begin{aligned}
& W(\Theta, \Phi)=W(\Theta)+( \pm)_{L_{n}^{\prime}} \sum_{v=2,4} A_{v}^{\prime}(1) A_{v}(2) P_{v}^{(2)}(\cos \Theta) \cos (2 \Phi) \\
& A_{v}^{\prime}(1)=\left(\frac{1}{1+\delta_{n}^{2}}\right)\left\{\begin{array}{l}
-\kappa_{v}\left(L_{n} L_{n}\right) F_{v}\left(L_{n} L_{n} J_{i} J_{x}\right)+2 \delta_{n} \kappa_{v}\left(L_{n} L_{n}^{\prime}\right) F_{v}\left(L_{n} L_{n}^{\prime} J_{i} J_{x}\right)+ \\
+\delta_{n}^{2} \kappa_{v}\left(L_{n}^{\prime} L_{n}^{\prime}\right) F_{v}\left(L_{n}^{\prime} L_{x}^{\prime} J_{i} J_{x}\right)
\end{array}\right\}
\end{aligned}
$$

onde $W(\Theta)$ é a distribuição angular para fótons não polarizados, e tanto os polinômios associados não normalizados de Legendre $P_{v}^{(2)}$ quanto os coeficientes de polarização $\kappa_{v}\left(L_{n}^{\prime}, L_{n}\right)$ aparecem compilados no artigo de Fagg e Hanna [Fa59]. O fator $( \pm)_{L_{n}^{\prime}}$ é igual a +1 ou -1 para transições $L_{n}^{\prime}$ elétricas ou magnéticas, respectivamente.

Em experimentos $(\vec{\gamma}, \gamma)$ usando, por exemplo, bremsstrahlung linearmente polarizado [Vo06, Go94], $\Phi$ é o ângulo entre o vetor campo elétrico $\vec{E}$ do fóton do feixe incidente e o plano de espalhamento, o subscrito $n$ refere-se ao fóton incidente $\gamma_{1}$, o seja $n=1$, e os momentos angulares $J_{i}$ e $J_{x}$ correspondem aos estados básico e excitado $\left(J_{i}=J_{o}, J_{x}=J\right)$. Então, o ângulo azimutal $\Theta$ dos fótons espalhados ressonantemente serve como base para a determinação da paridade.

Em experimentos $(\gamma, \vec{\gamma})$ usando detectores sensíveis à polarização, como os polarímetros Compton que permitem medir a polarização dos fótons espalhados [Sc94], a distribuição angular dos fótons espalhados $\gamma_{2}$ depende do ângulo entre o vetor de campo elétrico $\vec{E}$ de $\gamma_{2}$ e o plano da reação $\gamma_{1}-\gamma_{2}$, pelo que $\Phi$ na equação (2.17) tem um significado diferente ao anteriormente descrito. O subscrito $n$ agora se refere ao fóton espalhado $(n=2)$, e os momentos angulares $J_{i}$ e $J_{x}$ aos estados excitado e final $\left(J_{i}=J, J_{x}=J_{f}\right)$. 
Definindo $N_{\perp}$ e $N_{\|}$respectivamente como o número de fótons espalhados perpendicular e paralelamente ao plano de polarização, que para $(\vec{\gamma}, \gamma)$ é definido pelo vetor campo elétrico $\vec{E}$ dos fótons incidentes e para $(\gamma, \vec{\gamma})$ corresponde ao plano da reação entre $\gamma_{1}$ e $\gamma_{2}$, podemos caracterizar a assimetria azimutal (para o ângulo $\Theta$ ) determinando experimentalmente a taxa de contagem da assimetria azimutal $\varepsilon\left(\Theta, E_{\gamma}\right)$ :

$$
\varepsilon\left(\Theta, E_{\gamma}\right)=\frac{N_{\perp}-N_{\|}}{N_{\perp}+N_{\|}}
$$

que nos experimentos $(\vec{\gamma}, \gamma)$ é igual ao produto dos graus de polarização dos fótons incidente $P_{\gamma}\left(E_{\gamma}\right)$ e espalhado ressonantemente $\Sigma(\Theta)$ :

$$
\varepsilon\left(\Theta, E_{\gamma}\right)=P_{\gamma}\left(E_{\gamma}\right) \Sigma(\Theta)
$$

e nos $(\gamma, \vec{\gamma})$ a grandeza $P_{\gamma}\left(E_{\gamma}\right)$ é substituída pela sensibilidade de polarização $Q\left(E_{\gamma}\right)$ do polarímetro Compton. A seção de choque de espalhamento de Compton, dada pela fórmula de Klein-Nishina, é maior para direções de espalhamento perpendiculares ao $\vec{E}$ do fóton incidente que para direções paralelas, o qual constitui o princípio de funcionamento desses polarímetros.

$\Sigma(\Theta)$ se define como a diferença relativa entre o número de $\gamma_{2}$ com vetor $\vec{E}$ paralelo ao plano da reação e o número de $\gamma_{2}$ com vetor perpendicular, então lembrando o significado de $\Phi$ para cada tipo de experimento:

$$
\begin{array}{ll}
\Sigma_{(\vec{\gamma}, \gamma)}(\Theta)=\frac{W\left(\Theta, \Phi=90^{\circ}\right)-W\left(\Theta, \Phi=0^{\circ}\right)}{W\left(\Theta, \Phi=90^{\circ}\right)+W\left(\Theta, \Phi=0^{\circ}\right)} & \text { Experimentos }(\vec{\gamma}, \gamma) \\
\Sigma_{(\gamma, \vec{\gamma})}(\Theta)=\frac{W\left(\Theta, \Phi=0^{\circ}\right)-W\left(\Theta, \Phi=90^{\circ}\right)}{W\left(\Theta, \Phi=90^{\circ}\right)+W\left(\Theta, \Phi=0^{\circ}\right)} & \text { Experimentos }(\gamma, \vec{\gamma})
\end{array}
$$

Assim nos $(\vec{\gamma}, \gamma)$, onde $P_{\gamma}\left(E_{\gamma}\right)$ é uma grandeza sempre positiva e conhecida previamente, a medida experimental de $\varepsilon\left(\Theta, E_{\gamma}\right)$ permite determinar $\Sigma_{(\vec{\gamma}, \gamma)}(\Theta)$, que depende da paridade do estado excitado e pode ser negativa ou positiva, com módulo 
menor que a unidade. Lembrando as equações (2.17) - (2.18) e utilizando os dados da Tabela 2.1, vemos que $\Sigma_{(\vec{\gamma}, \gamma)}(\Theta)$ apresenta um máximo no ângulo de espalhamento $\Theta=90^{\circ}$ para as cascatas $(0 \rightarrow 1 \rightarrow 0)$ e $(0 \rightarrow 2 \rightarrow 0)$, sendo +1 para transições elétricas dipolares (E1), e -1 para as dipolares magnéticas (M1) e as quadrupolares elétricas (E2) [Kn96]. Infelizmente estes experimentos estão restritos às excitações de mais alta energia, como as transições presentes em núcleos leves, devido ao baixo grau de polarização do feixe incidente $P_{\gamma}\left(E_{\gamma}\right) \approx 10-30 \%$ e à necessidade de usar bremsstrahlung de maior energia, o que pode causar problemas adicionais como o incremento do background produzidos pelas reações fotonucleares [Go94, Ju95].

Para experimentos $(\gamma, \vec{\gamma})$ conhecendo $Q\left(E_{\gamma}\right)$, que pode ser determinada por meio de cascatas $\gamma-\gamma$ de parâmetros conhecidos [We67], se calcula o grau de polarização $\Sigma_{(\gamma, \vec{\gamma})}(\Theta)$ e com isto a paridade do estado. Nos casos de transições dipolares e quadrupolares puras, núcleos par-par com seqüência de spin $(0 \rightarrow 1 \rightarrow 0)$ e $(0 \rightarrow 2 \rightarrow 0)$, é observada a máxima polarização $\left|\Sigma_{(\gamma, \vec{\gamma})}\right|=1$ para $\Theta=90^{\circ}$. Como é apresentado na Tabela 2.1, as transições E1 e M1 possuem a mesma distribuição angular, só que a polarização muda de sinal, o que permite determinar a paridade do estado. Outrossim, no caso de misturas de transições, combinando dados de correlação angular direcional com medidas de polarização, é possível determinar a razão de mistura, bem como seu sinal [Da68, We67, Mo72]. O Anexo V apresenta uma descrição sobre as medidas de observáveis de polarização nos sistemas de NRF.

Tabela 2.1 Coeficientes de correlação angular e observáveis da polarização em espalhamento de fótons, para o caso de transições dipolares e quadrupolares puras que alimentam o estado fundamental de núcleos par - par [Kn96].

\begin{tabular}{|c|c|c|c|c|c|}
\hline Multipolaridade & Seqüência de spin & $A_{22} *$ & $A_{44} * *$ & $\Sigma_{(\vec{\gamma}, \gamma)}\left(\Theta=90^{\circ}\right)$ & $\Sigma_{(\gamma, \vec{\gamma})}\left(\Theta=90^{\circ}\right)$ \\
\hline E1 & $0^{+} \rightarrow 1^{-} \rightarrow 0^{+}$ & $1 / 2$ & - & +1 & -1 \\
\hline M1 & $0^{+} \rightarrow 1^{+} \rightarrow 0^{+}$ & $1 / 2$ & - & -1 & +1 \\
\hline E2 & $0^{+} \rightarrow 2^{+} \rightarrow 0^{+}$ & $5 / 14$ & $8 / 7$ & -1 & +1 \\
\hline
\end{tabular}

$* A_{22}=A_{2}(1) A_{2}(2) ; * * A_{44}=A_{4}(1) A_{4}(2)$ 


\subsubsection{Determinação do número $\mathrm{K}$ em núcleos deformados}

Os estados excitados por meio do espalhamento de fótons podem decair ao estado fundamental do núcleo com spin $J_{o}$, ou a estados excitados de spin $J_{f}$ (lowlying states). A relação entre as probabilidades reduzidas de transição, conhecida como razão de ramificação $R_{\text {exp }}$, para o caso de cascata dipolar pura, pode ser expressa como [Sa05]:

$R_{\exp }=\frac{\Gamma_{f}}{\Gamma_{o}} \frac{E_{\gamma_{J_{o}}}^{3}}{E_{\gamma_{J_{f}}}^{3}}=\frac{B\left(J \rightarrow J_{f}\right)}{B\left(J \rightarrow J_{o}\right)}$

Para um núcleo deformado no caso do limite rotacional, a razão de ramificação teórica $R_{\text {teo }}$ é determinada pela expressão [Ma95]:

$R_{\text {teo }}=\left|\frac{\sqrt{2 J_{f}+1}\left\langle J_{f}, K_{f}, L, K-K_{f} \mid J, K\right\rangle}{\sqrt{2 J_{o}+1}\left\langle J_{o}, K_{o}, L, K-K_{o} \mid J, K\right\rangle}\right|^{2}$

Supondo válidas as regras de intensidade de Alaga [A155], então é possível determinar o número quântico $K$ do nível excitado.

No caso de núcleos par-par os estados excitados têm spin 1 e eles podem decair para o estado $0^{+}$ou para o primeiro estado excitado $2^{+}$. Deste modo dentro da validade das regras de Alaga $B(1 \rightarrow 2) / B(1 \rightarrow 0)$ deve ser igual a 2 ou 0,5 para $K=0$ ou $K=1$, respectivamente.

Para os núcleos de A ímpar com spin semi-inteiro no estado fundamental o valor da razão de ramificação pode conter informação valiosa sobre os spins dos estados fotoexcitados [Ba93, Ma95, Re97, No03]. 


\section{Capítulo 3}

\section{Simulação por Monte Carlo: O código MCNPX}

\subsection{Introdução}

O método de Monte Carlo, chamado assim pela capital do principado de Mônaco em alusão “à capital dos jogos de azar”, tem seus inícios em meados do século XX com o desenvolvimento do primeiro computador eletrônico, e é atribuído a Stanislaw Ulam, um matemático polonês que trabalhava para John von Neumann no projeto Manhatan durante a Segunda Guerra. Ulam é conhecido principalmente pelo desenvolvimento da bomba de hidrogênio conjuntamente com Edward Teller em 1951. Ulam criou o método nos anos 40 enquanto estimava as probabilidades de ganhar no jogo de cartas "solitário" [Me53, Me49, Me87].

O Método de Monte Carlo foi usado pela primeira vez como ferramenta de pesquisa, durante o desenvolvimento da bomba atômica. O trabalho envolvia a simulação de problemas probabilísticos de hidrodinâmica concernentes à difusão de nêutrons num material físsil. Embora na primeira etapa de pesquisas John von Neumann e Stanislaw Ulam tenham refinado esta curiosa "Roleta Russa" e os Métodos de "Splitting", o desenvolvimento sistemático destas idéias teve de esperar o trabalho de Harris e Herman Kahn em 1948 [Ka50]. Aproximadamente no mesmo ano, Fermi, Metropolis e Ulam obtiveram estimadores para os valores característicos da equação de Schrödinger para a captura de nêutrons no núcleo.

Hoje, entendemos como Método de Monte Carlo qualquer técnica de amostragem estatística (sampling technique) empregada para encontrar soluções de problemas quantitativos de diversos tipos. As aplicações deste método têm se incrementado grandemente não só pelo desenvolvimento tecnológico nas áreas da computação e a informática, que permitem o trabalho com enormes volumes de dados e 
a implementação de complexos algoritmos de cálculo, mas também pela economia de tempo e recursos que representa.

Na física nuclear experimental, assim como em suas aplicações, cada dia é mais comum o uso de simulações por Monte Carlo para otimizar experimentos, desenhar detectores, estimar fluxos e doses, calcular blindagens, fazer planejamentos de radioterapia, etc. Para isto, normalmente são usados códigos de Monte Carlo de confiabilidade reconhecida, desenvolvidos por coletivos de autores de prestigiosos laboratórios. Entre os mais renomados códigos estão: o MCNP e o MCNPX em suas diferentes versões desenvolvidas pelo Laboratório Nacional de Los Alamos [He00, Fo04, So04, Pe05, Gi05, Vi07], o GEANT do Centro Europeu de Pesquisas Nucleares (CERN) [Ag03, Vi07, Al06,] o FLUKA uma colaboração do CERN e o Instituto Nacional de Física Nuclear (INFN) [Ra97], o EGS4 do Laboratório Nacional de Standford (SLAC) [Ne85, Ya04, Vi07], e o PENELOPE [Sa03] desenvolvido na Universitat de Barcelona e a Politécnica de Cataluña. Cada um destes códigos tem suas vantagens e suas desvantagens, acertos e desacertos. A escolha do código é regida por vários critérios, desde a disponibilidade do código e versatilidade da interface com o usuário, até as particularidades específicas do problema que se deseja estudar: tipos de partículas que serão transportadas, faixas energéticas e variáveis que serão monitoradas. Selecionamos o MCNPX para este problema por causa de um conjunto de funcionalidades apresentadas no final da próxima seção.

\subsection{0 código MCNPX}

O MCNPX [Gi05] é um código de transporte de partículas de propósito geral que inclui geometria 3D, transporte contínuo em energias até alguns $\mathrm{TeV}$, uma variedade de fontes e "tallies" (saídas do código), gráficos interativos, assim como a possibilidade de ser executados em diferentes sistemas operacionais, incluindo também processamento paralelo. O MCNPX é uma versão estendida do MCNP4C (Monte Carlo $N$-Particle, Versão 4C) [Br00], que, adicionalmente a todas as capacidades deste último, pode transportar 34 tipos de partículas. Seu desenvolvimento começou em 1994 como um projeto de união dos códigos MCNP4B [Br97] e o LAHET 2.8 [Pr95]. O MCNP4B transportava nêutrons, fótons e elétrons, realizava estimativas de fluxos, energia 
depositada e doses, cálculos de criticalidade de sistemas multiplicativos, etc. Por outra parte, o LAHET era usado tipicamente para transporte de nêutrons e pions de energias intermediarias dentro de uma geometria, estimava o fluxo de partículas, deposição de energia, e dano em materiais. O LAHET também podia fazer cálculo de seções de choque diferenciais de produção de partículas a partir dos modelos incluídos no código [Mc05].

A primeira versão pública do MCNPX foi a 2.1.5 [Wa99]. No ano 2002, o MCNPX foi atualizado com o MCNP4C [Br00], convertido a Fortran 90, e melhorado com 12 novas opções, versão conhecida como a 2.4.0 [Wa02]. Em 2002 começou o trabalho numa nova versão (2.5.0) [De05], que incorporou dúzias de novas opções, as quais foram testadas por 1400 usuários em 300 instituições ao redor do mundo. Hoje em dia, o MCNPX é dos códigos de transporte de partículas mais usados no mundo. As aplicações são amplas e constantemente em desenvolvimento e incluem desenho e cálculo de blindagem para aceleradores e reatores [Ca04, Ra05], terapia médica (com nêutrons, fótons, prótons, etc.) [Be02, $\mathrm{Ak03}, \mathrm{Za04}, \mathrm{Ti05}]$, radiação do espaço, transporte de plasma, física nuclear, desenho de detectores [Pe05] e efeitos da radiação em componentes eletrônicos [Mc05].

Em nosso trabalho, usamos a versão 2.5.0, que tem a possibilidade de definir fontes de pósitrons, de fissão espontânea, de várias partículas ao mesmo tempo e em superfícies cilíndricas empregando a opção SDEF. Igualmente é implementada uma nova opção (FT PHL) para o tally de altura de pulso que permite simular esquemas anticoincidência ou coincidência, e também fazer gráficos de Mesh superpostos à geometria do problema [Mc05]. As principais limitações do código podem ser consultadas no segundo capítulo do Manual do Usuário do MCNPX V 2.5.0 [Pe05].

\subsubsection{Estrutura dos parâmetros de entrada}

A entrada de dados no MCNPX consiste em vários arquivos, alguns dos quais são configurados com a instalação do código, outros são gerados durante o processo de simulação e outros elaborados pelos usuários. 
Os arquivos montados pelos usuários contêm informação acerca da forma e tamanho dos componentes do arranjo experimental, a descrição dos materiais e a escolha das seções de choques, a localização e características das fontes de partículas, os tipos de respostas ou saídas (tallies) desejadas, e qualquer técnica de redução de variância usada para aumentar a eficiência da simulação. As instruções para cada uma das especificações anteriores se realizam por meio das opções (cartões). O MCNPX aceita todos os cartões padrões do MCNP4C com parâmetros adicionais para incorporar o transporte e geração de outras partículas [Pe05].

$\mathrm{O}$ arquivo de entrada, para iniciar a simulação de um problema, tem uma estrutura geral dividida em três blocos essenciais. Nos dois primeiros é especificada a geometria 3D do problema partindo da definição de células (cells) definidas pela intersecção e união de superfícies. No terceiro bloco são especificadas as partículas que se desejam transportar (cartão Mode); é definida a fonte de partículas (tipo de partícula, espectro energético, distribuição espacial e angular); se detalham os materiais especificando composição elementar e as seções de choque ou modelos teóricos, de acordo com a faixa de energia; se especificam os tallies, que não são mais que as respostas ou saídas que queremos obter (fluxos de partículas, energia ou carga depositada, etc.). Neste terceiro bloco podem ser incluídas, ainda, cartões para variar o tratamento físico de algumas partículas, ou aplicar técnicas de redução de variância que podem reduzir consideravelmente o processamento e melhorar a estatística do problema.

\subsubsection{Peso estatístico e trajetória da partícula}

A informação para todos os tallies do código, excetuando o de altura de pulso F8, é compilada a partir do aporte individual de cada partícula com seu peso estatístico. Assim, por exemplo, cada partícula do MCNPX pode representar um número $w$ de partículas emitidas pela fonte. Este número $w$ seria o peso inicial da partícula MCNPX. Todas as $w$ partículas físicas poderiam ter caminhos aleatórios diferentes, mas uma partícula MCNPX, que representa essas $w$ partículas, faria só um caminho aleatório. Isto claramente não é uma simulação estritamente exata, contudo o número real de partículas físicas é preservado no sentido da média estatística. Cada partícula MCNPX resultante é 
multiplicada por seu peso estatístico de maneira que os resultados das $w$ partículas físicas representadas por cada partícula MCNPX sejam refletidos no resultado final (tallies).

Deste jeito, o MCNPX permite usar muitas técnicas que não simulam exatamente o transporte das partículas, mas que contribuem sobremaneira para aumentar a eficiência computacional. Trabalhando com o peso estatístico da partícula MCNPX é possível incrementar o número de partículas que são amostradas em alguma parte de interesse especial do problema, evitando incrementar a amostragem em partes de menor interesse, e sem afetar o resultado do valor físico esperado (tally). Isto é conhecido como Técnica de Redução de Variância. No caso do tally de altura de pulsos (F8), que é usado, por exemplo, para reproduzir a função resposta de um detector, como seu resultado depende da coleção de um grupo de partículas em lugar do aporte das partículas individualmente, as técnicas de redução de variância trabalham com um "peso coletivo".

No MCNPX, quando uma partícula emerge da fonte é criada a "trajetória da partícula" (particle track). Por trajetória da partícula nos referimos a cada componente da partícula fonte durante sua história MCNPX. Assim, por exemplo, quando a partícula inicial é um nêutron e acontece uma reação $(n, 2 n)$, então é gerada uma trajetória adicional para seguir o outro nêutron. Igualmente são geradas trajetórias adicionais quando empregamos técnicas de redução de variância. Por exemplo, ao passar de regiões do problema de menor importância, definida no comando IMP, a outras de maior importância, o número de trajetórias é incrementado de acordo como o peso estatístico da partícula. As trajetórias são usadas para determinar os resultados dos tallies. Os tallies de comprimento de trajetórias (Tally F4) determinam magnitudes de interesse como fluxo, fluência, ou energia depositada, partindo do comprimento da trajetória numa célula dada. As trajetórias que atravessam uma superfície são empregadas igualmente para calcular a fluência, o fluxo (Tally F2) ou o espectro de alturas de pulso (Tally F8). As trajetórias que sofrem colisão permitem calcular fatores de multiplicação ou criticalidade. 
Dentro de uma célula de composição fixa, a amostragem da colisão da partícula ao longo de sua trajetória depende da probabilidade $p$ de ocorrência da primeira colisão entre o comprimento $l$ e $l+d l$ :

$$
p(l) d l=e^{-\Sigma_{t} l} \Sigma_{t} d l
$$

onde $\Sigma_{t}$ é a seção de choque macroscópica total do meio. Definindo o número aleatório $\xi$ entre zero e um como:

$$
\xi=\int_{0}^{l} e^{-\Sigma_{t} s} \Sigma_{t} d s=1-e^{-\Sigma_{t} l}
$$

então podemos amostrar a distância de colisão como:

$$
l=-\frac{1}{\sum_{t} l} \ln (1-\xi)
$$

e como $1-\xi$ tem a mesma distribuição que $\xi$, a distância de colisão pode ser escrita como:

$$
l=-\frac{1}{\sum_{t} l} \ln (\xi)
$$

Desta maneira, depois da cada processo de interação da partícula MCNPX com determinado peso estatístico, é escolhido o comprimento da trajetória da partícula até a próxima colisão mediante a geração do número aleatório $\xi$. Imediatamente depois é amostrado o tipo de interação de acordo com os valores respectivos das seções de choque, os ângulos e as energias de emissão das partículas criando novas trajetórias nos casos necessários. E assim sucessivamente até que as partículas alcançam uma região de importância zero, ou seus pesos estatísticos sejam muito pequenos, ou suas energias fiquem por baixo do limiar prefixado pelo usuário.

Os tipos de interação dominantes podem mudar em função do tipo de partículas e da energia, pelo que a simulação do transporte difere em dependência destas variáveis. Em seguida descreveremos alguns detalhes do transporte de elétrons e de fótons que são de interesse para nosso trabalho. 


\subsubsection{Transporte de fótons}

O MCNPX trabalha com dois modelos de interação de fótons: simples e detalhado. O modelo simples ignora os espalhamentos coerentes (Thomson) e os fótons fluorescentes devido à absorção fotoelétrica. Este modelo se aplica em problemas de fótons de altas energias ou onde os elétrons sejam livres. O modelo detalhado inclui os processos ignorados anteriormente e é usado para todos os fótons com energia menor que o parâmetro EMCPF do cartão PHYS:P. Então, EMCPF representa o limite máximo de energia para o tratamento detalhado dos fótons, e tem como valor predefinido $100 \mathrm{MeV}$. Este tratamento é o mais adequado para a maioria das aplicações, principalmente no transporte em materiais de número atômico elevado, ou problemas onde os fótons penetrem os materiais em profundidade.

Nos dois modelos, a geração de elétrons por fótons é similar, e pode ser tratada de três formas diferentes:

(1) No caso que seja ativado o transporte de elétrons (Mode E P), então todas as colisões dos fótons, exceto os espalhamentos coerentes, podem criar elétrons que são armazenados na memória para seu transporte posterior.

(2) No caso que não seja ativado o transporte de elétrons (Mode $P$ ) então é empregado um modelo de bremsstrahlung de alvo grosso (TTB - Thick Target Bremsstrahlung model). Este modelo gera elétrons, mas assume que eles são freados localmente.

(3) No caso em que o parâmetro IDES do cartão PHYS:P seja igual à unidade, então a produção de todos os elétrons é "desligada", não são criados elétrons induzidos por fótons, sendo suposto que a deposição de energia dos elétrons é local.

Em nossa simulação é usado o modelo de descrição física detalhada para o tratamento das interações dos fótons em Mode E P (transporte de elétrons e fótons). Não só estamos interessados nos fótons de maior energia gerados no espectro de bremsstrahlung, mas também nos de menor energia, que podem ser essenciais para determinar a blindagem dos detectores de HPGe que fazem as medidas dos fótons ressonantes emitidos pelo alvo de NRF. 


\subsubsection{Tratamento físico detalhado}

O tratamento detalhado dos fótons inclui os seguintes processos:

(a) Espalhamento Incoerente (Compton): Para simular o espalhamento Compton é necessário determinar o ângulo de espalhamento $\theta$ em relação à direção do fóton incidente, a nova energia $E^{\prime}$ do fóton espalhado, e a energia cinética residual do elétron $E-E^{\prime}$. A seção de choque é dada pela conhecida fórmula de Klein-Nishina (equação 3.6) modificada por um fator $I(Z, v)$ :

$$
\begin{aligned}
& \sigma_{I}(Z, \alpha, \mu) d \mu=I(Z, v) K(\alpha, \mu) d \mu \\
& K(\alpha, \mu)=\pi r_{o}{ }^{2}\left(\frac{\alpha^{\prime}}{\alpha}\right)^{2}\left[\frac{\alpha^{\prime}}{\alpha}+\frac{\alpha}{\alpha^{\prime}}+\mu^{2}-1\right] d \mu
\end{aligned}
$$

Nas equações anteriores $r_{o}=2,817938 \times 10^{-13} \mathrm{~cm}$ é o raio clássico do elétron, $\alpha \mathrm{e}$ $\alpha^{\prime}=\alpha /[1+\alpha(1-\mu)]$ são as energias do fóton incidente e do fóton espalhado em unidades de $m_{0} c^{2}=0,511 \mathrm{MeV}$, e $\mu=\cos \theta$. A fórmula de Klein-Nishina é amostrada exatamente mediante o método de Kahn para energias menores que 1,5 MeV, e pelo método Koblinger para energias maiores [Pe05].

O fator $I(Z, v)$ diminui a seção de choque de Klein-Nishina (por elétron) na direção frontal. Para qualquer valor de $Z, I(Z, v)$ aumenta de $I(Z, v)=0$ á $I(Z, \infty)=Z$ (Fig. 3.1), onde o parâmetro $v$ é expresso como:

$$
\begin{aligned}
& v=\operatorname{sen}(\theta / 2) / \lambda=\kappa \alpha \sqrt{1-\mu} \\
& \kappa=10^{-8} m_{o} c^{2} /(h \sqrt{2})=29,1445 \mathrm{~cm}^{-1}
\end{aligned}
$$




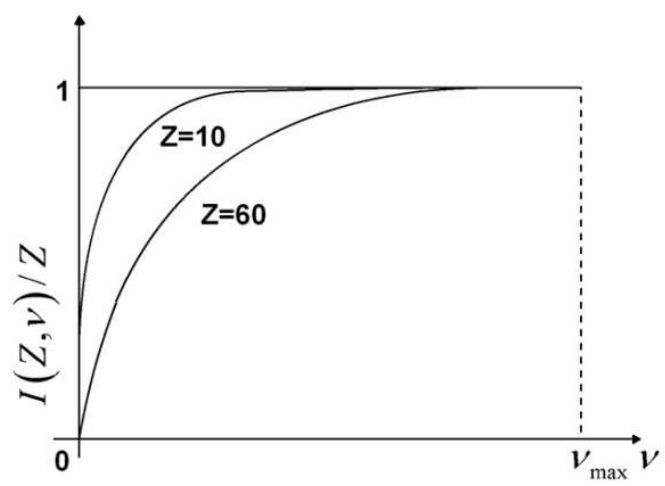

Fig. 3.1 Comportamento do fator $I(Z, v)$ com $v$ para valores de $\mathrm{Z}=10$ e $\mathrm{Z}=60$ [Gi05].

(b) Espalhamento Coerente (Thomson): Este tipo de espalhamento não envolve perdas de energia e por isto é o único processo de interação de fótons que não produz elétrons. Aqui só é computado o ângulo de espalhamento $\theta$, e depois o transporte do fóton continua.

A seção de choque diferencial $\sigma_{c}(Z, \alpha, \mu)$ é dada pela multiplicação da seção de Thomson $T(\mu)$ por um fator $C(Z, v)$, que modifica $T(\mu)$ independentemente do valor da energia do fóton incidente:

$\sigma_{c}(Z, \alpha, \mu) d \mu=C^{2}(Z, v) / Z^{2} T(\mu) d \mu$

$T(\mu)=\pi r_{o}^{2}\left(1+\mu^{2}\right) d \mu$

onde o termo $C^{2}(Z, v) / Z^{2}$ provoca uma redução na seção de choque de Thomson para as direções contrárias à de incidência (Fig. 3.2). Este efeito é oposto ao logrado com o termo $I(Z, v)$ no espalhamento incoerente. Para um determinado valor de $\mathrm{Z}, C(Z, v)$ decresce desde $C(Z, 0)=Z$ até $C(Z, \infty)=0$, função rapidamente decrescente de $\mu$; como $\mu$ vária de +1 a -1 , então a seção de choque coerente será máxima na direção frontal. Para altas energias do fóton incidente, o espalhamento coerente acontece freqüentemente na direção de vôo deste fóton, e por isto o espalhamento pode ser ignorado nessas energias. 


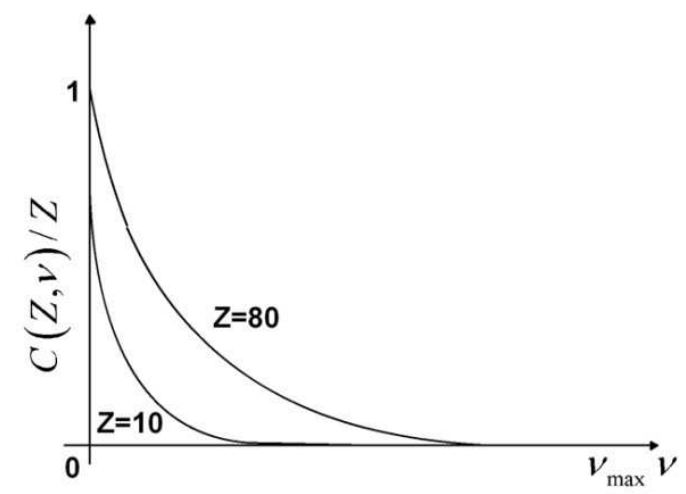

Fig. 3.2 Comportamento do fator $C(Z, v) / Z$ com $v$ para valores de $\mathrm{Z}=10$ e $\mathrm{Z}=80$ [Pe05].

(c) Efeito Fotoelétrico: Este efeito consiste na absorção do fóton incidente de energia $E$ e a expulsão (ou excitação) de um elétron orbital com energia de ligação $e<E$ e energia cinética $E-e$ com a subseqüente emissão de vários fótons fluorescentes. O programa trata os fótons fluorescentes com energia menor que $1 \mathrm{keV}$ como se depositassem sua energia no ponto de criação. Assim, na descrição a seguir, o termo "fótons fluorescentes" se aplica a fótons com mais de $1 \mathrm{keV}$. No processo podem ser emitidos zero, um ou dois fótons fluorescentes com energias maiores que $1 \mathrm{keV}$ :

(1) Nos eventos nos quais não são emitidos fótons fluorescentes, a cascata de elétrons que completa a vacância causada pela saída do fotoelétron produz elétrons e fótons de baixas energias (Efeito Auger). Os elétrons podem ser transportados em problemas com o Modo P E, ou podem ser tratados usando a aproximação TTB, ou sua energia ser depositada localmente. Como não são emitidos fótons fluorescentes então a trajetória do fóton termina com este evento.

(2) Nos eventos nos quais é emitido um fóton fluorescente, a energia $E^{\prime}$ deste fóton é a diferença entre a energia $E$ do fóton incidente e a energia $E-e$ do fotoelétron, menos a energia $e^{\prime}$ de excitação residual que é dissipada finalmente por processos Auger adicionais.

$$
E^{\prime}=E-(E-e)-e^{\prime}=e-e^{\prime}
$$

Estas transições primárias correspondem então aos rendimentos fluorescentes de todos os possíveis níveis superiores a $e^{\prime}$. O fóton emitido corresponderá às 
linhas de raios-x $\quad K \alpha_{1}\left(L_{3} \rightarrow K\right), \quad K \alpha_{2}\left(L_{2} \rightarrow K\right), \quad K \beta_{1}^{\prime}(M \rightarrow K) \quad$ e $K \beta_{2}^{\prime}(N \rightarrow K)$

(3) Os eventos nos quais são emitidos dois fótons fluorescentes podem acontecer quando a energia residual de excitação $e^{\prime}$ do caso (2) é maior que $1 \mathrm{keV}$. Um elétron de energia de ligação $e^{\prime \prime}$ pode ocupar a órbita de energia de ligação $e^{\prime}$, emitindo um fóton fluorescente secundário de energia $E^{\prime \prime}=e^{\prime}-e^{\prime \prime}$. A energia residual $e^{\prime \prime}$ é dissipada por processos Auger adicionais e a produção de elétrons. Estes podem ser transportados no Modo E P, ou aproximados com o modelo TTB, ou sua energia ser depositada localmente. Estas transições secundárias acontecem nas camadas superiores à camada L, de modo que as transições primárias devem ser $K \alpha_{1}$ ou $K \alpha_{2}$ para causar uma vacância na camada L.

$\mathrm{Na}$ simulação, é suposto que os fótons fluorescentes sejam emitidos isotropicamente. Um evento fotoelétrico termina a "história MCNPX" do fóton original para elementos com $\mathrm{Z}<12$ porque a energia fluorescente é menor que $1 \mathrm{keV}$. Para elementos com $12<Z \leq 31$ só acontece fluorescência simples (emissão de um fóton). Para $Z \geq 31$, é possível fluorescência dupla com linhas primárias $K \alpha_{1}, K \alpha_{2}$ e $K \beta_{1}^{\prime}$, e adicionalmente para $Z \geq 37$ também é possível a emissão da linha $K \beta_{2}^{\prime}$.

(d) Formação de pares (elétron-pósitron): O único mecanismo considerado ocorre no campo elétrico do núcleo. A energia limiar é de $2 m_{o} c^{2}[1+(m / M)] \cong 1.022 \mathrm{MeV}$ onde $M$ é a massa do núcleo e $m_{o}$ a massa de repouso do elétron. No MCNPX a simulação deste processo pode ser tratada por três vias:

(1) No caso de transporte de elétrons (Modo P E), o elétron e o pósitron são criados e posteriormente transportados, e a trajetória do fóton incidente termina;

(2) Em problemas com Modo P (só transporte de fótons) e com aproximação TTB, o elétron e o pósitron podem ser produzidos, mas não são transportados. $\mathrm{O}$ pósitron é aniquilado localmente criando um par de fótons como no caso (3);

(3) Nos problemas com o Modo $\mathrm{P}$, quando não são criados pósitrons pela aproximação TTB, o fóton incidente de energia $E$ desaparece. A energia cinética do par elétron-pósitron criado, suposta como $E-m c^{2}$, é depositada 
localmente no ponto onde acontece a colisão; é considerado que os pósitrons são aniquilados com um elétron no ponto da colisão, emitindo se um par de fótons com uma energia de $0,511 \mathrm{MeV}$. O primeiro fóton é emitido isotropicamente e o segundo em direção contraria à do primeiro.

(e) Reações Fotonucleares: Quando a energia dos fótons é relativamente elevada $\left(\mathrm{E}_{\gamma} \geq 5 \mathrm{MeV}\right)$ então são abertos os canais das reações fotonucleares. A interação fotonuclear começa com a absorção do fóton pelo núcleo, que pode acontecer por vários mecanismos. As bibliotecas de dados fotonucleares que existem atualmente contém informação até energias de $150 \mathrm{MeV}$. Este valor limite foi escolhido porque corresponde à energia limiar para a produção de píons. Abaixo de $150 \mathrm{MeV}$ os principais mecanismos primários para a fotoabsorção são a excitação da Ressonância Dipolar Gigante ou do par quasi-dêuteron [Ro05].

O mecanismo de absorção por Ressonância Dipolar Gigante (GDR) pode ser explicado como a interação de uma onda eletromagnética (o fóton incidente) com o momento dipolar do núcleo como um todo, cujo resultado é uma excitação coletiva do núcleo. Este é o processo mais importante com seções de choque da ordem de 6 - 10 mbarn para núcleos leves, e de 600 - 800 mbarn para pesados (Anexo III). As GDR ocorrem em energias entre $5-20 \mathrm{MeV}$ (Fig. 3.3), com largura de poucos $\mathrm{MeV}$. Para os núcleos deformados aparece um pico duplo (Fig. 3.4). Fora desta região de ressonância a seção de choque para as reações GDR é praticamente nula.

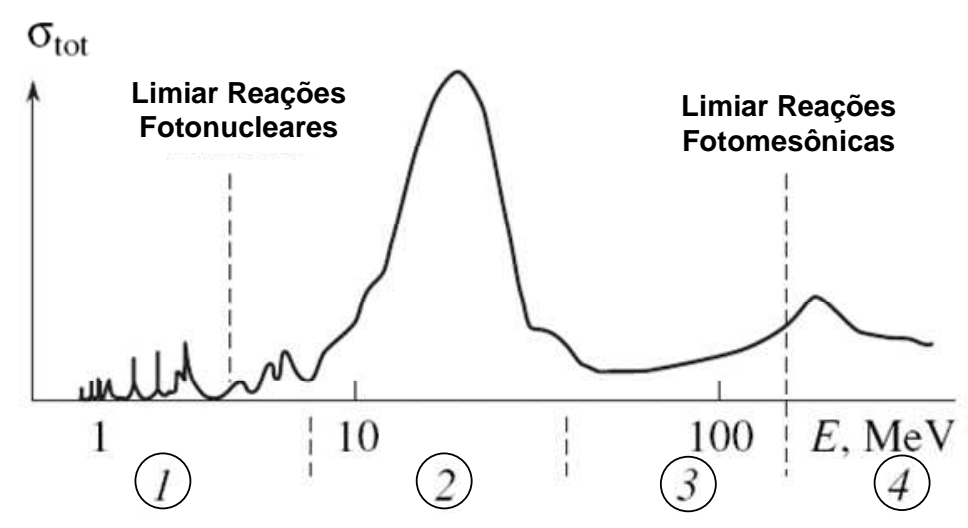

Fig. 3.3 Seção de choque total de absorção de fótons pelo núcleo em função da energia. (1) fotoexcitação dos estados ligados, (2) região da GRD, (3) região de efeitos do quasi-dêuteron, (4) região de fotomesons. 


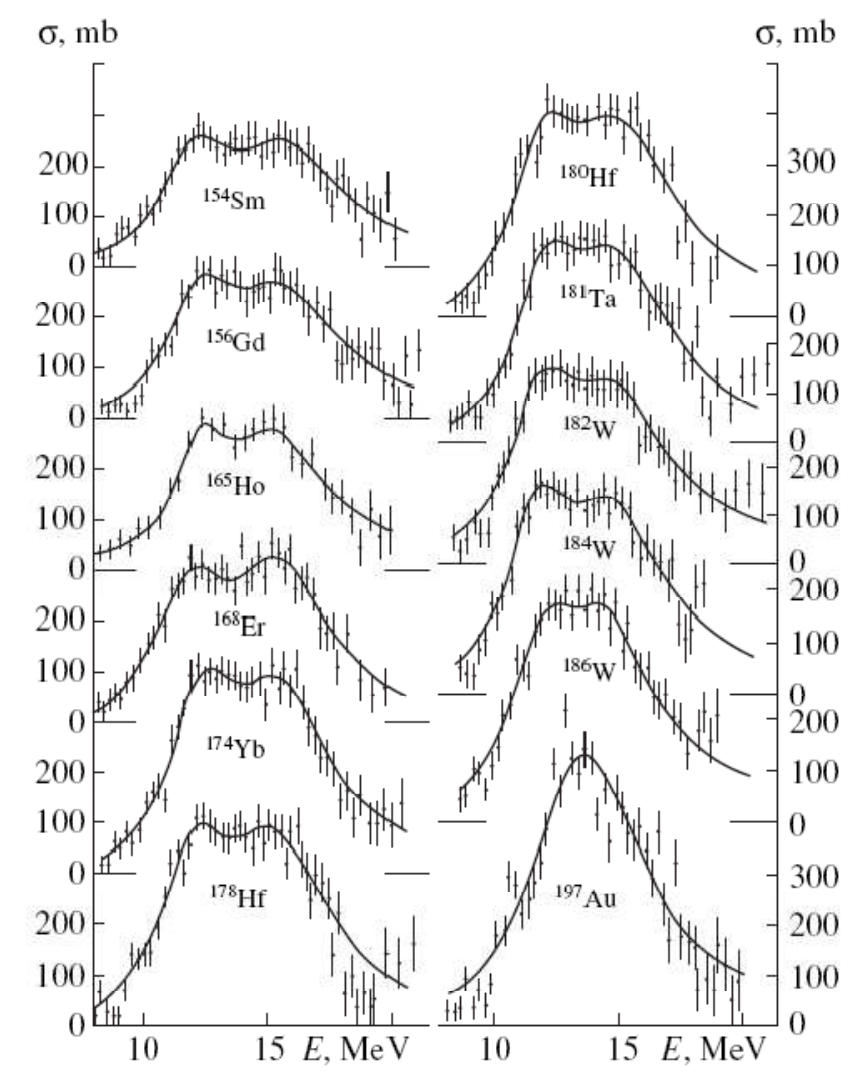

Fig. 3.4 Seção de choque total de absorção de fótons na faixa da GDR para núcleos com $154<$ A $<197$ [Ma06]

O mecanismo de absorção quasi-dêuteron (QD) é explicado como a interação da onda eletromagnética com o momento dipolar de um par nêutron - próton correlacionado. Neste caso o par é descrito como um QD com momento dipolar que interage com o fóton. Este mecanismo é menos intenso que a GDR, mas influi significativamente na forma da seção de choque para fótons com energias superiores ao limiar da produção de partículas.

Quando o fóton é absorvido pelo núcleo, uma ou mais partículas secundárias podem ser emitidas. Para energias menores que $150 \mathrm{MeV}$, estas reações produzem uma combinação de raios gamas, nêutrons, núcleos de ${ }^{1} \mathrm{H},{ }^{2} \mathrm{H},{ }^{3} \mathrm{H},{ }^{3} \mathrm{He},{ }^{4} \mathrm{He}$ e fragmentos de fissão. Estas partículas são emitidas, principalmente, mediante mecanismos de pre-equilíbrio e equilíbrio, e raramente por meio de um mecanismo de reação nuclear direta. 
Na emissão de pre-equilíbrio, a partícula no interior do núcleo recebe uma quantidade considerável da energia cedida ao núcleo pela absorção do fóton, e emerge deste depois de uma ou muito poucas interações com outros nucleons. Tipicamente isto acontece na absorção QD, onde a energia incidente é inicialmente dividida pelo quasedêuteron. As partículas emitidas por este mecanismo têm uma energia maior e a distribuição angular concentrada na direção de incidência do fóton [Ro05].

No mecanismo de equilíbrio, a energia cedida ao núcleo pelo fóton incidente é distribuída entre todos os núcleons. As partículas então emergem do núcleo atravessando a barreira de potencial nuclear, mediante um processo conhecido como “evaporação". Para as partículas carregadas e/ou com momento angular diferente de zero, aparecem contribuições adicionais devido ao potencial coulombiano e aos efeitos de conservação do momento angular. Então, para núcleos pesados, a evaporação de nêutrons é preferencial com relação à emissão de outras partículas. Mediante este mecanismo as partículas são emitidas isotropicamente e com um espectro de energia Maxwelliano.

O código MCNPX permite ativar ou desativar, mediante o cartão PHYS:P, especificamente com o parâmetro ISPN, a simulação de reações fotonucleares. Isto implica que, durante o cálculo da seção de choque macroscópica de um material, seja ou não incluída a absorção fotonuclear. No cartão $M$, que define o material, a opção PNLIB determina a biblioteca que será usada para as reações fotonucleares de cada isótopo presente no material. Algumas vezes não existem tabelas de seções de choque para um isótopo específico, então se usam os dados de outro isótopo de características similares recorrendo ao cartão $\mathrm{MX}[\mathrm{Pe} 05]$.

\subsubsection{Transporte de elétrons}

O transporte dos elétrons, como de qualquer partícula carregada, é bem diferente do transporte de fótons e nêutrons. O transporte de partículas com carga nula é caracterizado por colisões relativamente pouco freqüentes e isoladas, com um caminho entre colisões relativamente simples. No transporte de elétrons, as forças coulombianas de longo alcance são predominantes, causando um grande número de colisões. Por exemplo, uma partícula em alumínio, para diminuir sua energia de 0,5 MeV a $0,0065 \mathrm{MeV}$ precisa em média se for um nêutron de 30 colisões, um fóton poucas 
dezenas, mas um elétron precisa $\sim 10^{5}$ colisões. Para efeito da simulação por Monte Carlo, este grande número de interações implica numa maior complexidade computacional e um maior tempo de cálculo.

Durante anos, foram desenvolvidas e aperfeiçoadas diversas teorias de espalhamento múltiplo para explicar analítica e semi-analiticamente o transporte de partículas carregadas. Ainda hoje em dia se continua refinando e estudando estas teorias, que usam as seções de choque primárias, assim como a natureza estatística dos processos de espalhamentos múltiplos, para descrever as perdas de energia e as deflexões angulares dos elétrons. As mais importantes teorias para os algoritmos do MCNPX são: a teoria de Goudsmit-Saunderson [Go40] para as deflexões angulares, a teoria de Landau [La44] para as flutuações estatísticas nas perdas de energia, e as ampliações realizadas por Blunck-Leisengang à teoria de Landau [Fi80]. Estas teorias fazem várias aproximações que restringem sua aplicabilidade, pelo que não resolvem totalmente o problema do transporte de elétrons. Em particular, é suposto que as perdas de energia por passo de interação são bem menores que a energia do elétron [Pe05].

Para realizar o transporte de elétrons o caminho é dividido em muitos "passos". O comprimento dos passos é escolhido de maneira que sejam suficientemente longos para que aconteçam muitas colisões, sendo válidas as teorias de espalhamento múltiplo; e, ao mesmo tempo, suficientemente curtos para que as perdas de energia sejam pequenas, e as aproximações destas teorias mantenham sua validade. As perdas de energia e a deflexão angular do elétron, em cada um dos passos, são amostradas partindo de distribuições de probabilidade construídas por meio destas teorias. A acumulação dos efeitos nestes passos individuais, que são amostrados probabilisticamente, constitue a "história condensada" do Método de Monte Carlo durante o transporte do elétron.

\subsubsection{Passos e Subpassos de um elétron}

O caminho aleatório dos elétrons pode ser considerado em termos dos seguintes parâmetros $s_{n}, E_{n}, t_{n}, \vec{u}_{n}, \vec{r}_{n}$ que representam respectivamente o comprimento total do 
caminho, a energia, o tempo, a direção, e a posição do elétron ao término do passo $n$ de modo que formam uma seqüência:

$$
\left(0, E_{o}, t_{o}, \vec{u}_{o}, \vec{r}_{o}\right),\left(s_{1}, E_{1}, t_{1}, \vec{u}_{1}, \vec{r}_{1}\right),\left(s_{2}, E_{2}, t_{2}, \vec{u}_{2}, \vec{r}_{2}\right), \cdots
$$

Em média, a energia e o comprimento do caminho estão relacionados por:

$$
E_{n-1}-E_{n}=-\int_{S_{n-1}}^{S_{n}} \frac{d E}{d s} d s
$$

onde $-d E / d s$ representa o poder de freamento por unidade de energia por unidade de comprimento, e depende da energia do elétron e do material onde acontece a interação. No MCNPX é escolhida a seqüência de comprimento dos passos $\left\{s_{n}\right\}$ de maneira que:

$$
\frac{E_{n}}{E_{n-1}}=k
$$

com $k$ um valor constante. $\mathrm{O}$ valor de $k$ usado mais comumente é $k=2^{-1 / 8}$, que equivale à perda de energia por passo de 8,3\%. Estes passos são chamados passos maiores (major steps) ou passos de energia (energy steps). O MCNPX divide adicionalmente estes passos em subpassos, porque a representação das trajetórias dos elétrons é mais exata supondo deflexões angulares pequenas. Assim, um passo é dividido em $m$ subpassos, e as deflexões angulares e a emissão de partículas secundárias são amostradas nesses subpassos. O valor de $m$, que é um número inteiro, é escolhido em função do número atômico médio do material e foram determinados empiricamente, e vão desde $m=2$ para $Z \leq 6$ até $m=15$ para $Z>91$.

Em alguns casos, é necessário aumentar o valor de $m$, em particular para volumes pequenos. Para isto é usada a opção ESTEP do cartão M que define os materiais. Uma regra razoável para escolher o comprimento do subpasso é que o elétron deve ter como mínimo dez subpassos em qualquer material de importância do problema em estudo.

É importante dizer que, como o MCNPX emprega a teoria de GoudsmitSaunderson para amostrar as deflexões angulares, a direção de vôo do elétron só muda 
ao final de cada um dos subpassos. Assim, partindo da taxa de perdas de energia nesse momento e do comprimento do passo, é calculada a energia do elétron ao final do subpasso. Então, usando as distribuições de probabilidade, é amostrada a produção de partículas secundárias (raios-x fluorescentes, elétrons secundários devido a choques durante a ionização, e fótons de bremsstrahlung). Desse jeito, o comprimento do subpasso é calculado partindo do poder de freamento total (ionização e perdas por radiação), mas a perda de energia para esse subpasso é calculada empregando só o poder de freamento sem incluir as perdas por radiação. Por exemplo, quando um fóton de bremsstrahlung é emitido durante um subpasso, a energia do fóton só é subtraída da energia do elétron ao final desse subpasso. Assim, as perdas de energia por radiação são levadas em conta explicitamente, em contraste com as perdas por colisão, as quais são tratadas probabilisticamente e não estão correlacionadas com a energética do subpasso.

\subsubsection{Poder de freamento}

(a) Poder de Freamento por Colisão:

A perda de energia por unidade de comprimento devida a colisões implica a transferência de uma fração $\varepsilon$ da energia, menos um valor máximo $\varepsilon_{m}$, de acordo com Berger [Fi80]:

$$
\begin{aligned}
& -\left(\frac{d E}{d s}\right)_{\varepsilon_{m}}=N Z C\left\{\ln \frac{E^{2}(\tau+2)}{2 I^{2}}+f^{-}\left(\tau, \varepsilon_{m}\right)-\delta\right\} \\
& f^{-}\left(\tau, \varepsilon_{m}\right)=-1-\beta^{2}+\left(\frac{\tau}{\tau+1}\right)^{2} \frac{\varepsilon_{m}^{2}}{2}+\frac{2 \tau+1}{(\tau+1)^{2}} \ln \left(1-\varepsilon_{m}\right)+\ln \left[4 \varepsilon_{m}\left(1-\varepsilon_{m}\right)\right]+\frac{1}{1-\varepsilon_{m}}
\end{aligned}
$$

$\varepsilon$ e $\varepsilon_{m}$ representam a transferência de energia como fração da energia cinética $E$ do elétron, $I$ é o potencial médio de ionização, $\tau$ é a energia cinética do elétron em unidades de sua massa, $\delta$ é a correção por efeito densidade (relacionado com a polarização do material), $Z$ é o número atômico efetivo, $N$ é a densidade atômica em $\mathrm{cm}^{-3}$ e $c$ é uma constante, dada por:

$C=2 \pi e^{4} / m_{o} v^{2}$ 
onde $m_{o}, e$, e $v$ são a massa, a carga e a velocidade do elétron, respectivamente. A correção por efeito densidade $\delta$ é calculada empregando os procedimentos de Sternheimer, Berger e Seltzer [St82] para a biblioteca de dados e103, e usando o método de Sternheimer e Peierls [St71] no caso da biblioteca $e 1$.

Reescrevendo as equações (3.14) e (3.15) para o caso especial de $\varepsilon_{m}=2$, devido à indistinguibilidade entre o elétron incidente e o emergente, e considerando, por definição, que o elétron de maior energia seja o primário, então só a faixa de $\varepsilon<1 / 2$ é de interesse:

$$
\begin{aligned}
& f^{-}\left(\tau, \varepsilon_{m}\right)=-\beta^{2}+(1-\ln 2)+\left(\frac{1}{8}+\ln 2\right)\left(\frac{\tau}{\tau+1}\right)^{2} \\
& -\left(\frac{d E}{d s}\right)=N Z \frac{2 \pi e^{4}}{m_{o} v^{2}}\left\{\ln \left[\tau^{2}(\tau+2)\right]-C 2+C 3-\beta^{2}+C 4\left(\frac{\tau}{\tau+1}\right)^{2}-\delta\right\} \\
& C 2=\ln \left(2 I^{2}\right), C 3=1-\ln 2, C 4=\frac{1}{8}+\ln 2
\end{aligned}
$$

A expressão (3.18) é a taxa de perdas de energia em unidades de $\mathrm{MeV} / \mathrm{cm}$ num material determinado. No MCNPX trabalha-se em unidades de MeV/barn, assim que, dividindo esta expressão por $N$, multiplicando por $10^{24}$ barns $/ \mathrm{cm}^{2}$ e introduzindo a constante de estrutura fina $\alpha=\frac{2 \pi e^{2}}{h c}$, obteremos a expressão para $-d E / d s$ usada no MCNPX [Pe05]:

$$
-\left(\frac{d E}{d s}\right)=\frac{10^{24} \alpha^{2} h^{2} c^{2}}{2 \pi m_{o} c^{2}} Z\left\{\ln \left[\tau^{2}(\tau+2)\right]-C 2+C 3-\beta^{2}+C 4\left(\frac{\tau}{\tau+1}\right)^{2}-\delta\right\} \frac{1}{\beta^{2}}
$$

(b) $\quad$ Poder de Freamento por Radiação

O poder de freamento por radiação é determinado por:

$$
-\left.\frac{d E}{d s}\right|_{r a d}=10^{24} Z(Z+\bar{\eta})\left(\alpha r_{e}^{2}\right)\left(T+m_{o} c^{2}\right) \Phi_{r a d}^{(n)}
$$


onde $\Phi_{r a d}^{(n)}$ é a seção de choque de perdas de energia devido à interação elétron-núcleo, baseadas nas avaliações de Berger e Seltzer [Se85, Se86]. O parâmetro $\bar{\eta}$ está relacionado com a radiação de bremsstrahlung devido à interação elétron-elétron, $\alpha$ é a constante de estrutura fina, $m_{o} c^{2}$ a energia de repouso do elétron, e $r_{e}$ o raio clássico do elétron. As unidades do poder de freamento por radiação conforme a equação (3.21) são as mesmas que as do poder de freamento por colisão.

\subsubsection{Flutuações da Energia}

Como no transporte de elétrons um "passo" representa o efeito cumulativo de várias colisões aleatórias individuais, então acontecerão flutuações nas perdas de energia. Assim, as perdas de energia não serão só uma simples média $\Delta$, existindo uma função de probabilidade $f(s, \Delta) d \Delta$ a partir da qual serão amostradas estas perdas $\Delta$, para o passo de comprimento $s$. Landau estudou esta situação considerando as seguintes aproximações: a perda média de energia por passo é pequena comparada com a energia dos elétrons; o parâmetro $\xi$ definido mais adiante é grande comparado com a energia de excitação do meio; as perdas de energia podem ser obtidas corretamente partindo das seções de choque de Rutherford; e o limite superior de perda de energia pode ser tomado como infinito. Landau encontrou que a distribuição para as perdas de energia pode ser expressa como [Pe05]:

$f(s, \Delta) d \Delta=\phi(\lambda) d \lambda$

onde $\phi(\lambda)$ é uma função universal que depende da variável $\lambda$ :

$\lambda=\frac{\Delta}{\xi}-\ln \left[\frac{2 \xi m_{o} v^{2}}{\left(1-\beta^{2}\right) I^{2}}\right]+\delta+\beta^{2}-1+\gamma$

aqui $\gamma=0.5772157 \ldots$ é a constante de Euler e o parâmetro $\xi$ é definido por:

$\xi=\frac{2 \pi e^{4} N Z}{m_{o} v^{2}} s$ 
Esta função universal $\phi(\lambda)$ é expressa mediante a integral (3.25), onde $x$ é um número real positivo que especifica o caminho de integração:

$$
\phi(\lambda)=\frac{1}{2 \pi i} \int_{x-i \infty}^{x+i \infty} e^{\mu \ln \mu+\lambda \mu} d \mu
$$

Os valores de $\phi(\lambda) \phi(\lambda)$ para $-4 \leq \lambda \leq 100$ foram calculados numericamente nos trabalhos de Börsch-Supan, e o tratamento estatístico dado pelo MCNPX é baseado nestas tabulações. Para $\lambda<-4$ a função $\phi(\lambda)$ é desprezível, e para $\lambda>100$ é empregada a função assintótica:

$\phi(\lambda) \approx \frac{1}{w^{2}+\pi^{2}}$

onde $w$ é definido pela expressão:

$\lambda=w+\ln w+\gamma-\frac{3}{2}$

Blunck e Leisegang ampliaram os resultados de Landau incluindo o segundo momento da expansão da seção de choque. Este resultado pode ser expresso como [Pe05]:

$f^{*}(s, \Delta)=\frac{1}{\sqrt{2 \pi} \sigma} \int_{-\infty}^{+\infty} f(s, \Delta) \exp \left[\frac{\left(\Delta-\Delta^{\prime}\right)^{2}}{2 \sigma^{2}}\right] d \Delta^{\prime}$

Blunck e Westphal determinaram uma forma simples para a variância da Gaussiana [Pe05]:

$$
\sigma_{B W}^{2}=10 \mathrm{eV} \cdot \mathrm{Z}^{4 / 3} \bar{\Delta}
$$

Posteriormente Chechin e Ermilova [Ch76] encontraram uma estimativa para o erro relativo: 
$\varepsilon_{C E} \approx\left[\frac{10 \xi}{I}\left(1+\frac{\xi}{10 I}\right)^{3}\right]^{-\frac{1}{2}}$

Partindo deste último trabalho, Seltzer [Se91] descreve e recomenda uma correção para a variância proposta por Blunck e Westphal:

$$
\sigma=\frac{\sigma_{B W}}{1+3 \varepsilon_{C E}}
$$

Esta é a variância empregada no MCNPX para a Gaussiana.

\subsubsection{Deflexões Angulares}

Para amostrar a probabilidade das deflexões angulares dos elétrons o MCNPX emprega a teoria de Goudsmit-Saunderson. A deflexão angular de um elétron é amostrada uma vez em cada subpasso, partindo da distribuição [Pe05]:

$$
F(s, \mu)=\sum_{l=0}^{\infty}\left(l+\frac{1}{2}\right) \exp \left(-s G_{l}\right) P_{l}(\mu)
$$

onde $s$ é o comprimento do subpaso, $\mu=\cos \theta$ é a deflexão angular em relação à direção do vôo do elétron no início do subpaso, $P_{l}(\mu)$ é o polinômio de Legendre de ordem $l$, e $G_{l}$ é expressa em termos da seção microscópica $d \sigma / d \Omega$ e a densidade $N$ de átomos do meio pela expressão:

$$
G_{l}=2 \pi N \int_{-1}^{+1} \frac{d \sigma}{d \Omega}\left[1-P_{l}(\mu)\right] d \mu
$$

Para elétrons com energia abaixo de $0,256 \mathrm{MeV}$, as seções de choque $d \sigma / d \Omega$ são escolhidas das tabulações desenvolvidas por Riley [Ri75]. Para elétrons de maior energia, a seção de choque diferencial é aproximada por uma combinação das seções de choque de Mott e Rutherford, incluindo uma correção pela blindagem (screening correction). O MCNPX emprega as "seções de choque fatorizadas", dadas por Seltzer na forma [Gi05]: 
$\frac{d \sigma}{d \Omega}=\frac{Z^{2} e^{2}}{p^{2} v^{2}(1-\mu+2 \eta)^{2}}\left[\frac{(d \sigma / d \Omega)_{\text {Mott }}}{(d \sigma / d \Omega)_{\text {Rutherford }}}\right]$

onde $e, p$ e $v$ são a carga, o momento linear e a velocidade do elétron. A correção por blindagem é expressa como:

$\eta=\frac{1}{4}\left(\frac{\alpha m c}{0,885 p}\right)^{2} Z^{2 / 3}\left[1,13+3,76(\alpha Z / \beta)^{2}\right] \sqrt{\frac{\tau}{\tau+1}}$

onde $\tau$ é a energia do elétron expressa em unidades da massa de repouso do elétron.

\subsubsection{Bremsstrahlung}

O MCNPX estima a probabilidade de emissão dos fótons de bremsstrahlung em cada subpasso. Para isto, existem tabelas em bibliotecas predefinidas, que podem ser escolhidas pelo usuário no arquivo de entrada de dados. Na parte do transporte de elétrons, o código está baseado no ETRAN [Se91]. Os dados das bibliotecas predefinidas para amostrar os fótons de bremsstrahlung partem da aproximação de Born, expressão de Bethe-Heither [Ko59], com procedimentos específicos para a simulação por Monte Carlo desenvolvidos por Berger e Seltzer [Se85, Se86]. O conjunto de dados obtidos usando estas aproximações e procedimentos foram convertidos em tabelas, que incluem probabilidades de produção de bremsstrahlung, e distribuições energética e angular dos fótons.

Nas tabelas da biblioteca el03 a seção de choque para a produção de bremsstrahlung e seu espectro foram avaliados de acordo com Berger e Seltzer. Nesta avaliação é empregada uma descrição detalhada das seções de choque de interação elétron-núcleo para elétrons de energias entre 2 e $50 \mathrm{MeV}$. Para energias menores que $2 \mathrm{MeV}$ as tabelas estão baseadas nos resultados de Pratt, Tseng, e seus colaboradores [Ts71, Ts74, Pr81]. Para energias maiores que $50 \mathrm{MeV}$ são empregadas as teorias analíticas de Davies, Bethe, Maximon e Olsen [Da54, O155]. Também é incluído o bremsstrahlung devido às interações elétron-elétron utilizando a teoria de Haug, e 
incluindo fatores de correção por blindagem, obtidos a partir dos fatores de espalhamento incoerente de Hartree-Fock [Pe05].

Para os dados da biblioteca el03 a produção de bremsstrahlung é amostrada partindo da distribuição de Poisson ao longo de cada subpasso, de maneira que podem ser criados um ou mais fótons. Por outro lado, na biblioteca el1 só é possível criar zero ou um fóton em cada subpasso. Uma vez produzido o fóton, a energia e a direção de vôo é amostrada usando as tabelas previamente mencionadas. A direção de movimento do elétron não é alterada pela emissão do fóton, uma vez que a deflexão angular do elétron é estimada pela teoria dos espalhamentos múltiplos. Porém, ao final de cada subpasso é subtraída a energia do fóton emitido, à energia do elétron. Isto ocorre devido ao tratamento das perdas de energia realizado, com ou sem "straggling", ser baseado em processos não radiativos.

Existe um tratamento alternativo para o emprego de dados tabelados da distribuição angular do bremsstrahlung. Definindo o quarto parâmetro ibad $=1$ do cartão PHYS:e é escolhida uma distribuição de probabilidade simples, independente do material onde acontece a geração do bremsstrahlung [Pe05]:

$$
p(\mu) d \mu=\frac{1-\beta^{2}}{2(1-\beta \mu)^{2}} d \mu
$$

A equação (3.36), onde $\mu=\cos \theta$ e $\beta=v / c$, é utilizada para amostrar o ângulo de emissão do fóton relativo à direção de movimento do elétron de acordo com:

$\mu=\frac{2 \xi-1-\beta}{2 \xi \beta-1-\beta} \quad(\xi-$ Número Aleatório)

O processo de bremsstrahlung gera muitos fótons de baixas energias, mas os fótons de energias mais altas comumente são os de maior interesse. Com o objetivo de gerar uma maior quantidade de trajetórias destes últimos fótons, o MCNPX sugere a utilização do cartão BBREM. Esta é uma técnica de redução de variância que gera mais fótons de altas energias, mantendo o peso estatístico, e permitindo aumentar o número de eventos correspondentes aos fótons mais energéticos. 
A descrição do tratamento pelo código MCNPX de outros processos de interação dos elétrons (Ionização da camada eletrônica K, transições Auger, espalhamento elétron-elétron), assim como o tratamento do transporte de nêutrons, pode ser consultado na referência "MCNP - A General Monte Carlo N-Particle Transport Code, Version 5. Volume I: Overview and Theory" [Pe05].

\subsection{Confiabilidade dos códigos MCNP e MCNPX}

\subsubsection{Comparações com experimentos e com outros códigos}

Atualmente os códigos MCNP e MCNPX são utilizados freqüentemente para simular, desenhar, e otimizar experimentos usando nêutrons [Na03, Ja04], elétrons e fótons [Fl04, Au05, Sc06]. Durante anos a confiabilidade e precisão destes códigos têm sido estudada pela comparação com simulações realizadas por outros códigos e com experimentos. Mencionaremos alguns exemplos.

Em 1999 Jeraj et al. [Je99] realizaram uma comparação entre os códigos MCNP e EGS4, e experimentos em aceleradores de elétrons de uso médico. Nestes códigos, o modo de transportar os elétrons é diferente. As simulações com o MCNP foram realizadas empregando o MCNP4A e o MCNP4B, neste último caso com duas aproximações diferentes $\left(\mathrm{MCNP}_{\mathrm{def}}\right.$ - "bin-centred-treatment" e $\mathrm{MCNP}_{\mathrm{ITS}}$ - "ITS style"). Eles estudaram as doses depositadas em "água sólida" por elétrons de 6 e $20 \mathrm{MeV}$ espalhados em chumbo. Eles encontraram que os resultados do perfil de doses

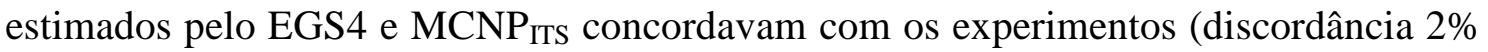
do valor máximo das doses), e os obtidos com o MCNP4A e MCNP def $_{\text {discordaram }}$ significativamente (discordância $15 \%$ do valor máximo da doses). Igualmente houve concordância entre os fatores de elétrons espalhados [EBF] determinados

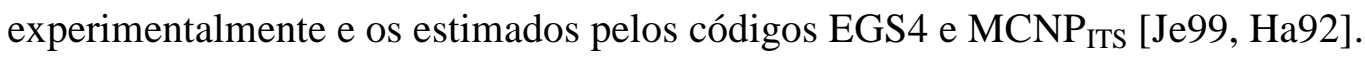

Schaart et al. [Sc02] reportaram em 2002 uma comparação entre o MCNP4C, o ITS 3.0 [Ha92] e resultados experimentais para o transporte de elétrons de energias entre $100 \mathrm{keV}$ e $20 \mathrm{MeV}$, estudando a distribuição de doses em água, e avaliando o efeito do tamanho do subpasso e do "voxel" na simulação. Eles mostraram que os

cálculos de distribuição podem ser alterados significativamente no caso em que o 
tamanho dos voxels é menor ou da ordem de $10 \%$ do alcance dos elétrons no meio, e que isto pode ser melhorado incrementando o número de subpassos. Igualmente eles concluíram que, em principio, é possível empregar o MCNP4C para o cálculo da distribuição de doses, concordando com resultados reportados pelo ITS 3.0. Porém, quando é necessário um alto grau de precisão alguns detalhes adicionais devem ser levados em conta.

Flaska et al. [Fl04] reportaram em 2004 a simulação do alvo de nêutrons GELINA com o código MCNP4C. Aqui os nêutrons são produzidos por um feixe primário de elétrons de energia entre 14 e $70 \mathrm{MeV}$, que incide sobre um alvo de U-Mo, e os nêutrons rápidos produzidos são moderados em Be. Para os cálculos empregaram a biblioteca de reações fotonucleares LA150u. Os resultados mostram concordância entre os experimentos e as simulações.

Lemrani et al. [Le06] em 2006 realizaram uma comparação da propagação de nêutrons de baixas energias (menores de $10 \mathrm{MeV}$ ) em rochas, $\mathrm{Pb}, \mathrm{e} \mathrm{CH}_{2}$, usando o MCNPX, o GEANT3 e o GEANT4. Eles compararam os espetros de energia obtidos pelos três códigos mostrando boa concordância entre todos os resultados.

Vilches et al. [Vi07] publicaram em 2007 uma comparação na simulação por Monte Carlo do transporte de elétrons em lâminas finas, utilizando os códigos PENELOPE, GEANT3, GEANT4, EGSnrc, MCNPX. Eles estudaram a distribuição angular dos elétrons que emergem das lâminas, cujas energias incidentes foram de 2,25 e 15,7 MeV, e compararam com experimentos antigos reportados previamente, encontrando algumas diferenças não rejeitáveis. Eles propõem a realização de novos experimentos com objetivo de fazer um teste completo das teorias de espalhamento múltiplo empregadas nos códigos.

\subsubsection{Bremsstrahlung, Fotonêutrons, e Função Resposta de um detector.}

Entre os principais aspectos que temos que considerar na simulação por Monte Carlo de nosso sistema de NRF estão a geração do bremsstrahlung, a produção de fotonêutrons, e a função resposta dos detectores de HPGe. 
Vários trabalhos aparecem na literatura mostrando comparações entre 0 bremsstrahlung simulado pelo MCNP e medidas experimentais. Por exemplo, em 1994 DeMarco et al. [De95] estudaram com o MCNP4A as intensidades e energias médias dos espectros de bremsstrahlung gerados por elétrons de $15 \mathrm{MeV}$ que incidem em alvos grossos de $\mathrm{Be}, \mathrm{Al}$, e $\mathrm{Pb}$. Eles mostraram que o MCNP4A era capaz de prever o rendimento integral de bremsstrahlung com uma discordância, em relação aos valores experimentais, menor que $6 \%$ para ângulos menores que $60^{\circ}$, e no caso da energia média, menor que $7 \%$ para todos os ângulos. Igualmente concluíram que quase todos os resultados obtidos estavam dentro da faixa de $95 \%$ do intervalo de confiança dos resultados experimentais.

Erhard et al. [Er06] quando estudaram a fotoativação induzida por bremsstrahlung no acelerador ELBE fizeram uma comparação dos espectros de bremsstrahlung simulados por diferentes códigos (GEANT 3, GEANT 4, MCNP4C2) para elétrons de $10 \mathrm{MeV}$ que incidem em um alvo de $\mathrm{Nb}(\mathrm{Z}=41)$ com $4 \mu \mathrm{m}$ de espessura, e comparam com os dados de Seltzer e Berger [Se85] representados por pontos vermelhos na Fig. 3.5. O gráfico mostra diferenças significativas entre os resultados das duas versões do GEANT e os dados de Seltzer e Berger. Os espectros obtidos pelo GEANT4 e o MCNP4C2 só concordam para energias maiores que $7 \mathrm{MeV}$. Estas divergências são devidas, fundamentalmente, ao emprego de bibliotecas de dados diferentes. Erhard et al. sugerem enfaticamente o emprego do código Roche [Ro72] e as tabelas de Seltzer e Berger, ou seja, o MCNP, para estimar o espectro do bremsstrahlung nessas energias.

Igualmente existem vários trabalhos que reportam comparações entre o MCNPX e valores experimentais dos fluxos de nêutrons gerados em reações fotonucleares. A produção de nêutrons é importante nos experimentos de NRF devido ao elevado background gama que criam as interações destes nêutrons com os materiais circundantes, afetando a relação pico-fundo nos espectros dos detectores de HPGe.

Akkurt et al. [Ak03] mostraram dados experimentais de rendimento de nêutrons produzidos em alvos de $\mathrm{W}$ natural (4, 6 e $8 \mathrm{~mm}$ de espessura) obtidos para energias dos fótons entre 13 e $33 \mathrm{MeV}$, consistentes com as estimativas realizadas empregando o código MCNP-GN [On00]. 


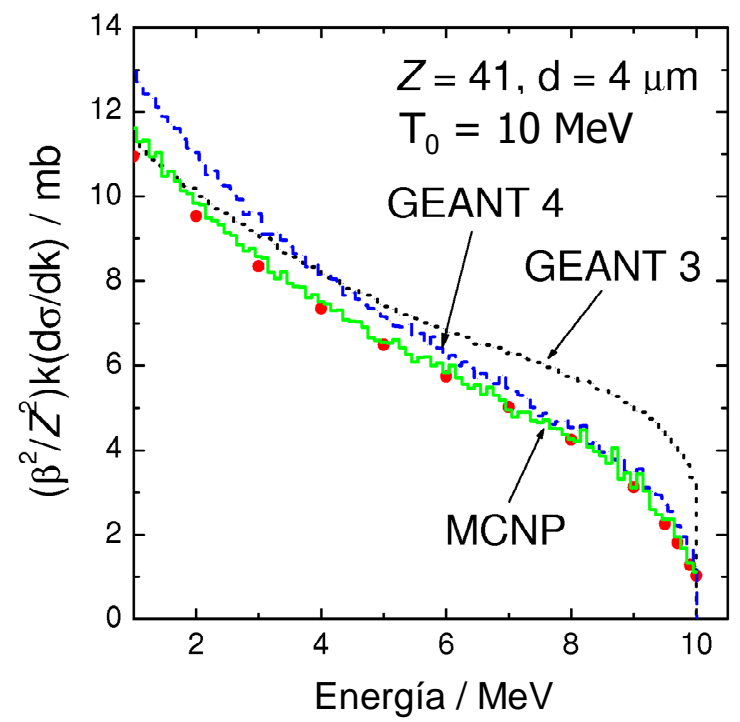

Fig. 3.5 Espectros de bremsstrahlung (GEANT3, GEANT4, MCNP4C2) comparados com os dados tabelados por Seltzer e Berger. Energia dos elétrons de $10 \mathrm{MeV}$, alvo de $\mathrm{Nb}(\mathrm{Z}=41)$, espessura $4 \mu \mathrm{m}$ [Er06].

Eshwarappa et al. [Es05] realizaram um estudo do rendimento de nêutrons produzidos em Be empregando um Microtron como fonte primária. Eles mostraram que os rendimentos de nêutrons, para uma energia de 8,7 MeV e várias espessuras de $\mathrm{Be}$, estimados com o MCNP4A concordavam com os resultados experimentais.

Huang et al. [Hu06] compararam os fotonêutrons produzidos em um linac de $15 \mathrm{MeV}$ utilizado em aplicações radiográficas. Eles fizeram medidas das doses de nêutrons em diferentes ângulos com relação à direção do feixe incidente, que incidia sobre um alvo de $\mathrm{Cu}$. Os valores obtidos experimentalmente coincidiram com os estimados por meio do código MCNP5.

Outro aspecto importante em nossa simulação é a função resposta dos detectores de HPGe, que farão as medidas dos raios gamas espalhados ressonantemente no alvo de NRF. Os códigos de Monte Carlo são amplamente empregados na simulação da função resposta ou para determinar a curva de eficiência de detecção.

Karamanis [Ka03] estudou a eficiência de detectores de HPGe e Si(Li) com os códigos MCNP4B e GEANT 3.21, fazendo também medidas experimentais. Os resultados das simulações concordaram com os experimentais quando foram ajustados os parâmetros dos detectores. O MCNP mostrou discordâncias elevadas para energias abaixo de $10 \mathrm{keV}$. 
Ródenas et al. [Ro00] determinaram as curvas de eficiência de um detector de Ge para diversas geometrias, mediante simulações com as versões 4A e 4B do MCNP. Compararam com resultados experimentais para energias dos fótons entre 661 - $1332 \mathrm{keV}$. Eles obtiveram concordância entre as curvas simuladas e as experimentais, mostrando que o MCNP constitui uma poderosa ferramenta na determinação das curvas de eficiências em caso de geometrias complexas. Em outro trabalho similar no ano 2007, Ródenas et al. [Ro07] estimaram essas curvas para geometria Marinelli e Petri com diferentes materiais, e fótons com energias entre 59,54 - 1835,48 keV. Observaram que em geral as diferenças com os valores experimentais são menores que $10 \%$.

Em 2007 Maidana et al. [Ma07] reportaram o pico do terceiro escape em espectros gama mediante o uso do MCNP e o MCNPX, para fótons incidentes com energias de 6 e $14 \mathrm{MeV}$, assim como a comparação com resultados experimentais onde se destaca a diferença entre os resultados abaixo de $10 \mathrm{MeV}$.

Em geral os códigos MCNP e MCNPX são empregados com sucesso em inumeráveis aplicações. Porém, o usuário nunca deve perder de vista os fenômenos físicos que acontecem no sistema em estudo e como estes fenômenos são tratados pelos códigos. Qualquer simulação implica no emprego de tabelas de dados e seções de choque, nem sempre tão precisas quanto necessitamos, assim como de modelos físicos para descrever o transporte das partículas no meio. A validade ou não das aproximações que realiza o código dependerá do tipo de partículas, faixa energética, geometria do problema e informação que desejamos obter. Em nosso trabalho foi escolhido o código MCNPX por várias razões:

(1) Disponibilidade do código no Laboratório do Acelerador Linear (LAL), evitando com isto, gastos adicionais, apesar de alguns códigos serem disponíveis livremente na internet, como o GEANT.

(2) Facilidade e versatilidade na elaboração dos arquivos de entrada do código, que permitem variar os parâmetros da geometria, e desenhar geometrias complexas com uma seqüência de comandos relativamente simples. Ao contrário, por exemplo, do GEANT e do EGS4, onde as mudanças de geometria podem implicar um trabalho árduo. 
(3) Possibilidade de simular os diferentes componentes do sistema de NRF e de obter toda a informação necessária empregando só o MCNPX. O GEANT permite obter maior e mais variada informação porque trabalha a simulação mais perto do nível de programação, porém para nosso estudo eram suficientes as saídas de dados do MCNPX.

(4) As tabelas de dados e de seções de choque, e os modelos para o transporte de elétrons, fótons e nêutrons na faixa de energia de nosso interesse (centenas de $\mathrm{keV}$ até dezenas de $\mathrm{MeV}$ ) estão disponíveis no MCNPX, e têm mostrado consistência e precisão. 


\section{Capítulo 4}

\section{Método Experimental}

\subsection{O Microtron do LAL (IFUSP)}

\subsubsection{Descrição Geral}

O Laboratório do Acelerador Linear (LAL) do Instituto de Física da Universidade de São Paulo (IFUSP) está finalizando a construção de um acelerador de elétrons. O novo acelerador tipo Microtron operará em regime de onda continua e as partículas alcançarão uma energia de $38 \mathrm{MeV}$. Algumas das principais características do mesmo aparecem na Tabela 4.1. O acelerador está composto por um injetor linac de onde os elétrons emergem com 1,9 MeV de energia. Posteriormente entram num Microtron "booster" de cinco voltas, que deve acelerar os elétrons até 4,9 MeV. Finalmente no Microtron principal as partículas serão aceleradas até $38 \mathrm{MeV}$ de energia, com uma corrente máxima de 50 ㅅ [Ta92, Ka98, Ta99, Ma00, Ma00a].

A Fig. 4.1 mostra, em vista isométrica, um desenho da montagem do novo acelerador no prédio do antigo acelerador linear. Na mesma figura pode-se ver o posicionamento do monocromador de fótons (tagger) e da linha que será utilizada para experiências com bremsstrahlung de alta intensidade, ou para produção de raios-X de radiação paramétrica (bremsstrahlung coerente). Esses equipamentos ficam no salão experimental, enterrado e 2,7 $\mathrm{m}$ abaixo do recinto onde se localizam as estruturas aceleradoras, de forma a minimizar a radiação na vizinhança da máquina. 
Tabela 4.1 Principais características do Acelerador Microtron do LAL (IFUSP)

\begin{tabular}{|l|l|}
\hline \multicolumn{2}{|l|}{ Canhão de Elétrons } \\
\hline Energia & $100 \mathrm{keV}( \pm 0,1 \%)$ \\
\hline Corrente & $2,0 \mathrm{~mA}$ \\
\hline Diâmetro do Feixe & $<2 \mathrm{~mm}$ \\
\hline Injetor \\
\hline Energia de entrada & $0,9 \mathrm{MeV}$ \\
\hline Energia de saída & $1,9 \mathrm{MeV}$ \\
\hline Booster & $1,9 \mathrm{MeV}$ \\
\hline Energia de entrada & $5 \mathrm{MeV}$ \\
\hline Energia de saída & $50 \mu \mathrm{A}$ \\
\hline Corrente Máxima & 5 \\
\hline Número de voltas & \\
\hline Microtron Principal & $5 \mathrm{MeV}$ \\
\hline Energia de entrada & $38 \mathrm{MeV}$ \\
\hline Energia de saída & $50 \mu \mathrm{A}$ \\
\hline Corrente máxima & 28 \\
\hline Número de voltas &
\end{tabular}

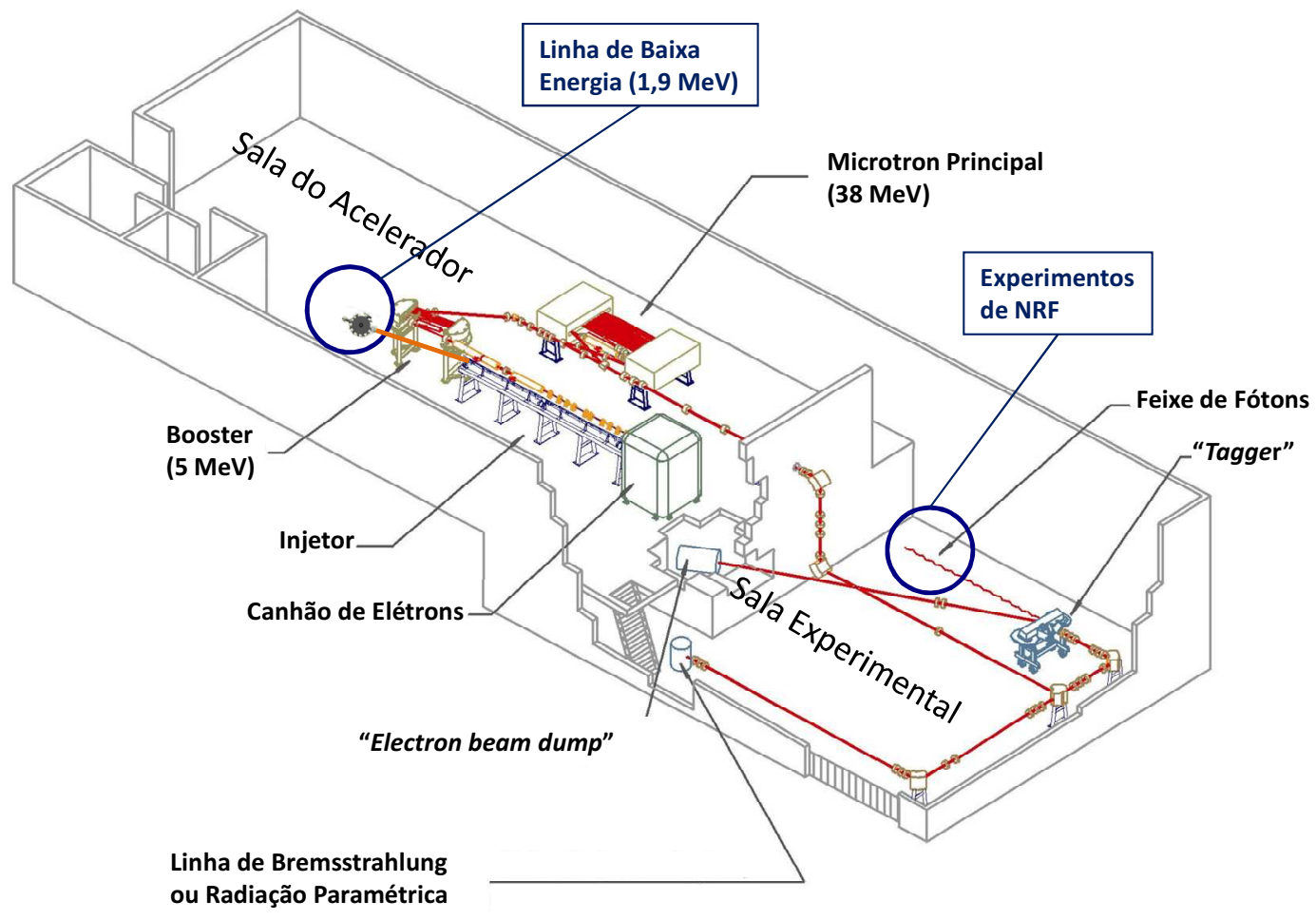

Fig. 4.1. Vista isométrica do acelerador Microtron no prédio do LAL.

$\mathrm{Na}$ atualidade só o injetor de 1,9 MeV encontra-se operacional e o booster está em fase final de montagem. O regime de onda contínua permite fazer estudos de física atômica na faixa de energia do injetor, e esse foi o motivo pelo qual se decidiu a construção de uma linha de baixa energia, que pode ser utilizada simultaneamente com os testes do booster. A figura 4.2 apresenta um esquema da linha, para o que foi inserido 
um analisador magnético (D) justamente antes do primeiro dipolo do booster (DB1), portanto, os três quadrupolos $(\mathrm{Q} 1, \mathrm{Q} 2$, e Q3) que conformam o feixe para o booster são usados nas duas linhas. Foram situados dois quadrupolos adicionais (Q4 e Q5) para focar o feixe no alvo localizado no centro da câmara de irradiação.

Como complemento experimental ao trabalho de simulação, se realizaram medidas do espectro de bremsstrahlung a $1,9 \mathrm{MeV}$ com alvos situados no interior da câmara de irradiação, figura 4.3. A simulação por Monte Carlo foi amplamente utilizada no processamento e análise dos dados e resultados experimentais, como é apresentado no Capítulo 5.

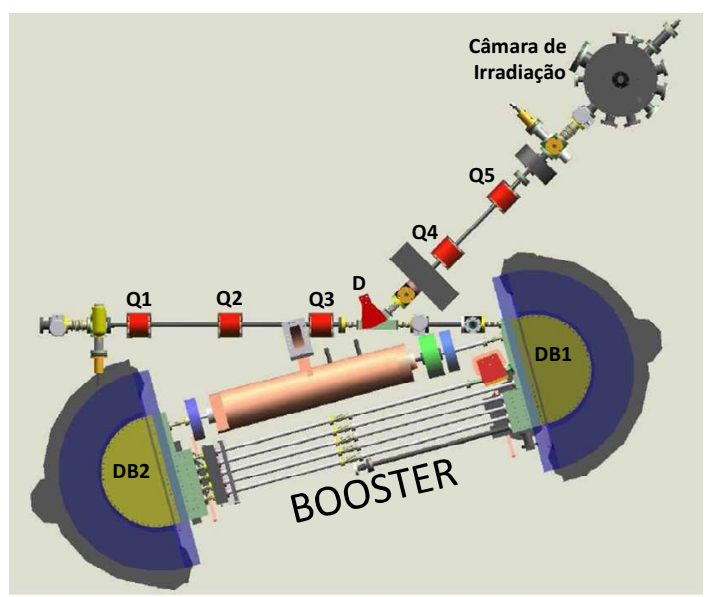

Fig. 4.2 Esquema da linha de baixa energia $(1,9 \mathrm{MeV})$ e do booster.

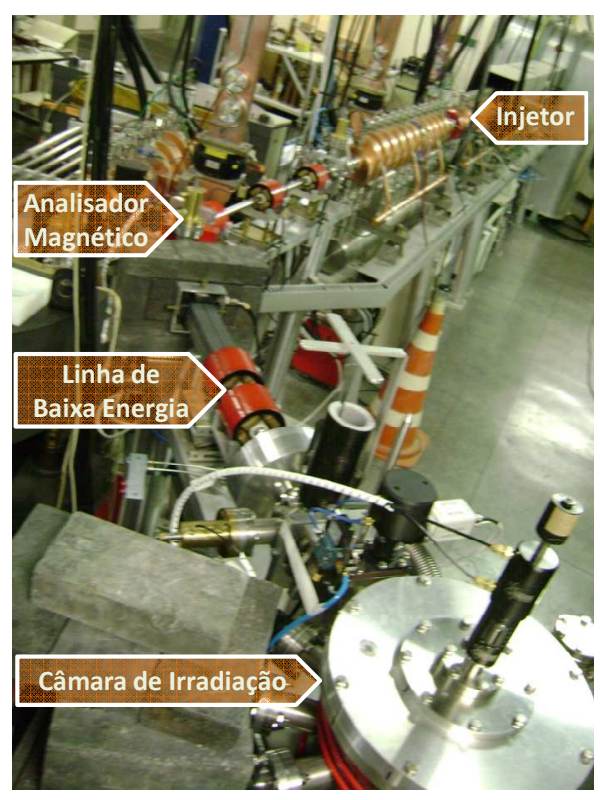

Fig. 4.3 Fotografia mostrando as estruturas aceleradoras do injetor e a linha de baixa energia. 


\subsubsection{O Microtron do LAL e a técnica de NRF}

No desenho deste acelerador, destacam-se duas características importantes que permitem seu emprego em experimentos de NRF. Em primeiro lugar, o Microtron do LAL opera em modo de onda contínua permitindo fazer medidas de NRF com o valor máximo de corrente $(50 \mu \mathrm{A})$, sem provocar problemas de empilhamento de pulsos. Por outra parte, dispõe-se de um monocromador de fótons, equipamento amplamente usado em experimentos de NRF e que permite reduzir o background. Desta maneira, a técnica de NRF encontra-se entre as principais perspectivas de aplicação do Microtron.

Como foi mencionado previamente ao descrever alguns dos mais renomados arranjos de NRF, no desenho dos sistemas de NRF devem se levar em conta uma série de detalhes para minimizar o background nos espectros gama medidos nos detectores HPGe, e assim obter a maior relação pico-fundo possível. O espalhamento dos fótons nos elementos circundantes e a produção de nêutrons constituem as principais causas deste background. Por esta razão devem se estudar as variantes de radiador (material, espessura), de colimador (material, espessura, ângulo de abertura), de blindagem (material e dimensões), e de posicionamento dos diversos componentes do sistema na sala de experimentos.

No caso da sala de experimentos do LAL, onde ficará o arranjo de NRF (Fig. 4.1), o desenho do sistema deve ser cuidadoso e detalhado devido às dimensões limitadas da sala $\left(10 \times 10 \times 5 \mathrm{~m}^{3}\right)$. Por exemplo, a falta de espaço dificulta a separação da área onde é produzido o bremsstrahlung da área dos detectores, ou do lugar onde os "beam dumps" fiquem. Neste espaço deverão ficar primeiro o radiador com seu sistema de resfriamento, em seguida o "tagger", que desviará os elétrons para o "electron beam dump", posteriormente o colimador e ao redor deste uma parede de concreto para separar a região de produção do bremsstrahlung da área de medidas. Entre 80 e $100 \mathrm{~cm}$ depois do colimador ficaria o alvo de NRF rodeado dos detectores blindados, localizados a $20 \mathrm{~cm}$ de distância do alvo aproximadamente, e, finalmente o "photon beam dump".

Neste trabalho é estudado cada um dos componentes principais de um arranjo de NRF: radiador, colimador, detectores, blindagem, etc. A procura das dimensões e materiais ótimos, partindo das experiências descritas na literatura especializada assim 
como das particularidades de nosso laboratório, constituem o objetivo central deste trabalho.

Por meio da simulação por Monte Carlo de cada um dos componentes previamente mencionados, e posteriormente de todos em seu conjunto, é possível propor um desenho para o arranjo de NRF, sem incorrer em gastos desnecessários de materiais, economizando tempo e esforços experimentais.

\subsection{Descrição do Arranjo Experimental de medida do bremsstrahlung}

A Fig. 4.4 mostra uma imagem superior do arranjo experimental especificando a direção do feixe de elétrons de 1,9 MeV, a câmara de irradiação, a blindagem do Copo de Faraday, que faz o monitoramento da corrente do feixe, o colimador de $\mathrm{Pb}$ do detector de HPGe usado para medir os espectros de bremsstrahlung, e a blindagem de um detector de HPGe para baixas energias utilizado em outras experiências. A câmara de irradiação, com dimensões de 26,0 cm de diâmetro e 20,7 cm de altura, tem oito canais de saída permitindo fazer medidas cada $30^{\circ}$, e outros três ângulos adicionais $\left(195^{\circ}, 225^{\circ}, 315^{\circ}\right)$ em relação ao feixe de elétrons. O alvo é colocado no centro da câmara por meio de um suporte conectado a um sistema pneumático que permite retirar o alvo do feixe.

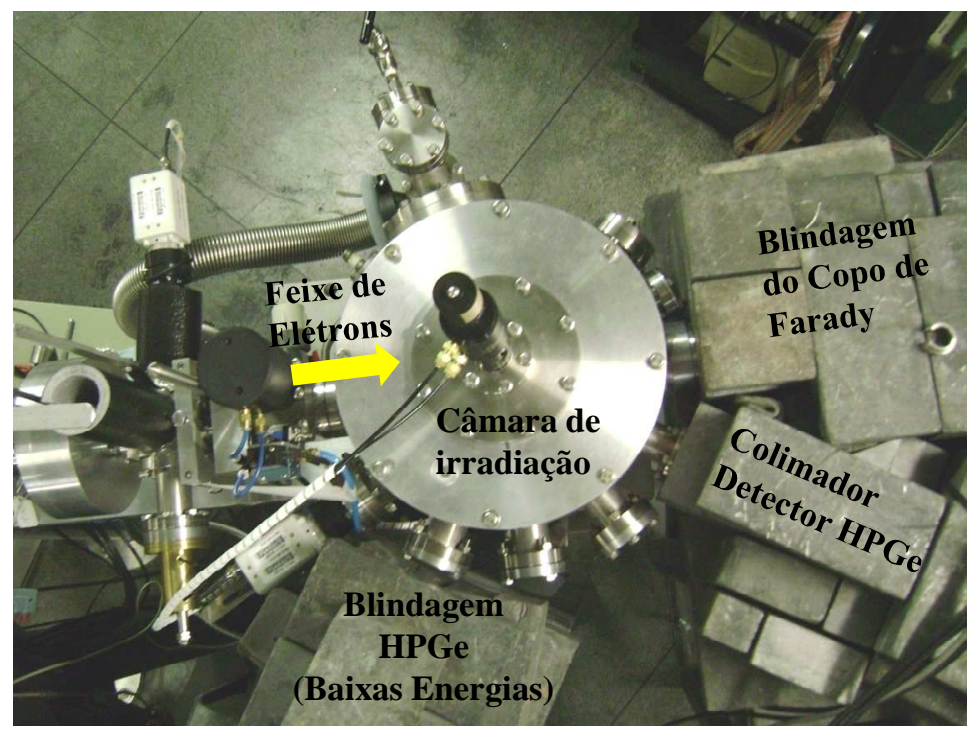

Fig. 4.4 Imagem superior da câmara de irradiação e outros elementos do sistema de medidas. 


\subsubsection{Copo de Faraday}

O Copo de Faraday foi construído na oficina mecânica do LAL e para seu desenho diversas variantes de materiais e geometria foram estudadas mediante simulação por Monte Carlo. Para testar os procedimentos de simulação, foi reproduzida a geometria descrita por Wright e Trump [ Wr62] e calculado o numero de elétrons retroespalhados para dois materiais $(\mathrm{Al}$ e $\mathrm{Cu})$ e três energias $(1,2,3 \mathrm{MeV})$. A tabela 4.2 mostra esta comparação, destacando que as diferenças relativas (ultima coluna) entre os resultados do MCNPX e os reportados são menores que $10 \%$.

Tabela 4.2 Comparação entre MCNPX e a referência [Wr62] para testar os procedimentos de simulação. $\mathrm{A} 3^{\circ}$ e $5^{\circ}$ colunas apresentam a fração de elétrons retroespalhados calculado pelo MCNPX e experimental, respectivamente. Na ultima coluna todos os dígitos são significativos.

\begin{tabular}{cccccc}
\hline Material & $\begin{array}{c}\text { Energia } \\
(\mathbf{M e V})\end{array}$ & MCNPX & $\begin{array}{c}\text { Incerteza } \\
\text { \% }\end{array}$ & $\begin{array}{c}\text { Ref } \\
\text { [Wr62] }\end{array}$ & $\begin{array}{c}(\text { MCNPX - Ref }) / \text { Ref } \\
(\%)\end{array}$ \\
\hline $\mathrm{Cu}$ & 1,0 & 0,213 & 1,76 & 0,21 & 1,64 \\
$\mathrm{Cu}$ & 2,0 & 0,167 & 2,71 & 0,16 & 4,34 \\
$\mathrm{Cu}$ & 3,0 & 0,135 & 3,64 & 0,13 & 3,50 \\
\hline $\mathrm{Al}$ & 1,0 & 0,086 & 2,43 & 0,08 & 7,98 \\
$\mathrm{Al}$ & 2,0 & 0,061 & 4,07 & 0,06 & 1,88 \\
$\mathrm{Al}$ & 3,0 & 0,040 & 5,29 & 0,04 & 0,82 \\
\hline
\end{tabular}

Foram estudadas três geometrias de Copo de Faraday, variando o ângulo de abertura (Fig. 4.5), e avaliando o comportamento da fração de elétrons que escapam de copo em três materiais: grafite, alumínio, e cobre [Tu75, Vo01, An07]. Estes materiais, além de condutores elétricos, são de baixo Z, o que reduz a produção de bremsstrahlung e a fração de retro-espalhamento. O copo foi especificado na geometria do MCNPX como um cilindro de comprimento muito maior que o alcance dos elétrons no material e um diâmetro de 2,0 cm. Na parte frontal, por onde os elétrons incidem, a simulação considerou ângulos de abertura de $30^{\circ}, 45^{\circ}$ ou $60^{\circ}$. A figura 4.5 mostra as trajetórias de elétrons e fótons para os três materiais estudados, um ângulo de abertura de $45^{\circ}$ e um feixe de $\phi=0,4 \mathrm{~cm}$, com $10^{5}$ eventos computados. Observa-se se que o aumento do $\mathrm{Z}$ do material incrementa o numero de elétrons retro-espalhados e de fótons produzidos devido à radiação de freamento. A tabela 4.3 resume os resultados obtidos, onde o grafite representa a melhor opção, garantindo para os três ângulos estudados que menos de $1 \%$ dos elétrons que incidem no copo escapem. As dimensões finais do copo 
construído foram um ângulo de abertura de $30^{\circ}$, um diâmetro de $2,0 \mathrm{~cm}$, e um comprimento de $6,5 \mathrm{~cm}$.
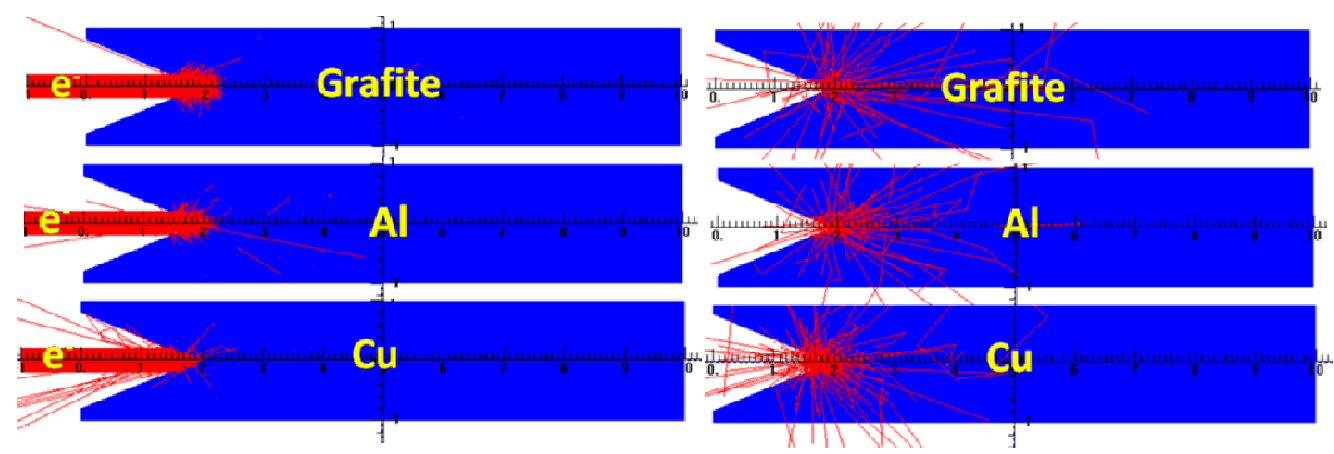

Fig. 4.5 Trajetórias dos elétrons (esquerda) e dos fótons (direita) para um feixe de elétrons de $2 \mathrm{MeV}$, $\phi=0,4 \mathrm{~cm}$, e um ângulo de abertura no Copo de Faraday de $45^{\circ}$.

Tabela 4.3 Fração de elétrons retro-espalhados para as variantes de Copos de Faraday simuladas (em \%).

\begin{tabular}{|c|c|c|c|c|}
\hline \multirow{2}{*}{$\begin{array}{l}\text { Energia } \\
(\mathrm{MeV})\end{array}$} & \multirow{2}{*}{ Material } & \multicolumn{3}{|c|}{ Elétrons retroespalhados em \% (Incerteza) } \\
\hline & & $30^{\mathbf{0}}$ & $45^{\circ}$ & $60^{\circ}$ \\
\hline 2 & Grafite & $0,22(7)$ & $0,38(1)$ & $0,52(1)$ \\
\hline 2 & Alumínio & $0,62(2)$ & $1,31(3)$ & $1,99(3)$ \\
\hline 2 & Cobre & $2,45(4)$ & $5,67(8)$ & $9,2(7)$ \\
\hline
\end{tabular}

\subsubsection{Colimador de Feixe de Bremsstrahlung}

Para definir as dimensões do colimador do feixe de bremsstrahlung, localizado entre a câmara de irradiação e o detector de HPGe (Seção 4.3), foram realizadas simulações com um feixe paralelo de fótons de $2 \mathrm{MeV}$ (Fig. 4.6), exigência mais rigorosa que o real comportamento do espectro decrescente em energia de bremsstrahlung. As simulações incluíram colimadores de $\mathrm{Pb}$ de 5, 10, 15 e $20 \mathrm{~cm}$ de comprimento, e quatro diâmetros do orifício desde 0,8 ate $2,0 \mathrm{~cm}$. A figura 4.6 apresenta trajetórias dos fótons nos colimadores com 15 e $20 \mathrm{~cm}$ de comprimento, e $\phi=1,6 \mathrm{~cm}$ de diâmetro; observa-se que praticamente nenhum fóton atravessa os $15-20 \mathrm{~cm}$ de $\mathrm{Pb}$. Tendo em conta que o espectro que se deseja medir é contínuo, então deve ser garantido que a probabilidade que um fóton espalhado no $\mathrm{Pb}$ atinja o detector seja pequena, compensando também o efeito do incremento na eficiência de detecção a menores energias dos fótons. As figuras 4.7 e 4.8 mostram os espectros de fótons à 
saída dos colimadores de 15 e $20 \mathrm{~cm}$. Os gráficos foram normalizados ao máximo valor, correspondente a numero de fótons a $2 \mathrm{MeV}$ de energia. Com $20 \mathrm{~cm}$ de comprimento o comportamento para os quatro diâmetros $(0,8,1,0,1,6$ e 2,0 cm) é praticamente idêntico e a probabilidade de que um fóton com energia menor que $2 \mathrm{MeV}$ atravesse o colimador, devido a espalhamentos no $\mathrm{Pb}$, é da ordem de $10^{-4}$, à exceção da região de mais baixas energias onde tem lugar processos de retroespalhamento e produção de raios- $\mathrm{X}$, onde essa fração cresce ate $10^{-3}$. O colimador de $\mathrm{Pb}$ efetivamente construído com $\phi=1,2 \mathrm{~cm}$ e $20 \mathrm{~cm}$ de comprimento.
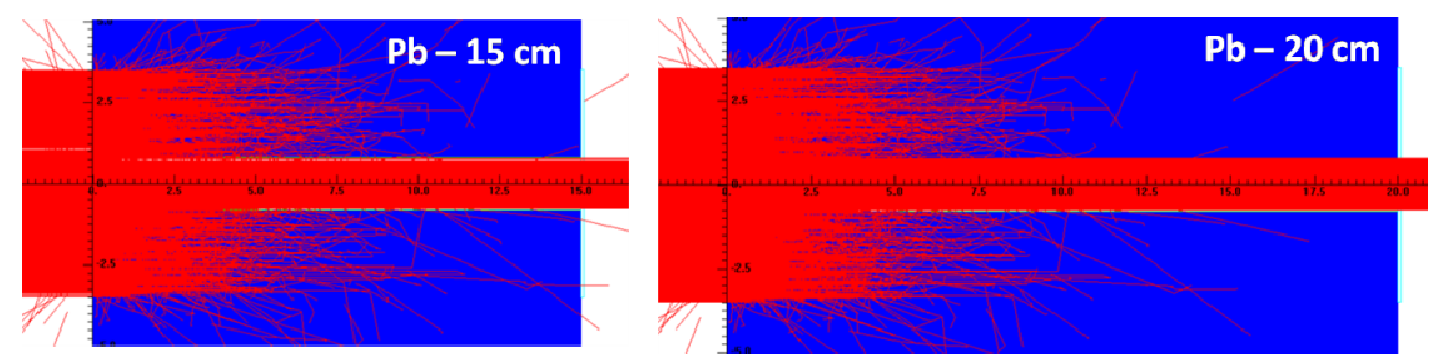

Fig. 4.6 Trajetórias de fótons nos colimadores de 15 e $20 \mathrm{~cm}$ para $5 \times 10^{4}$ eventos computados nas simulações.

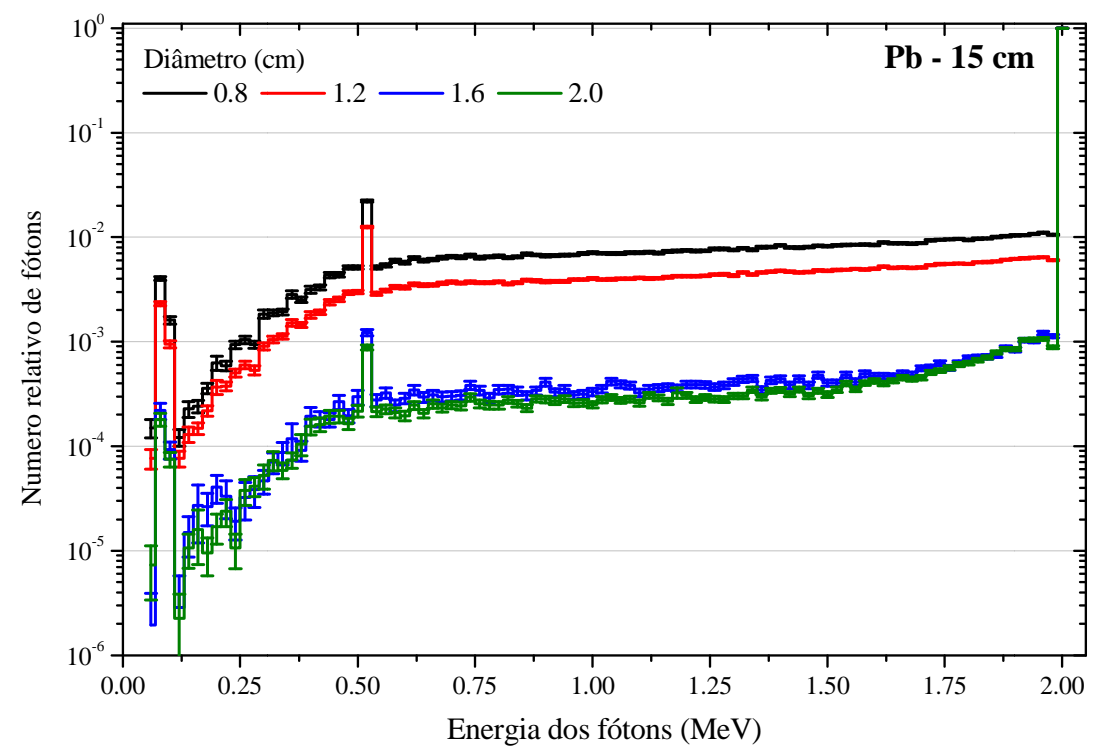

Fig. 4.7 Espectro simulado dos fótons na saída dos colimadores com $15 \mathrm{~cm}$ de comprimento. 


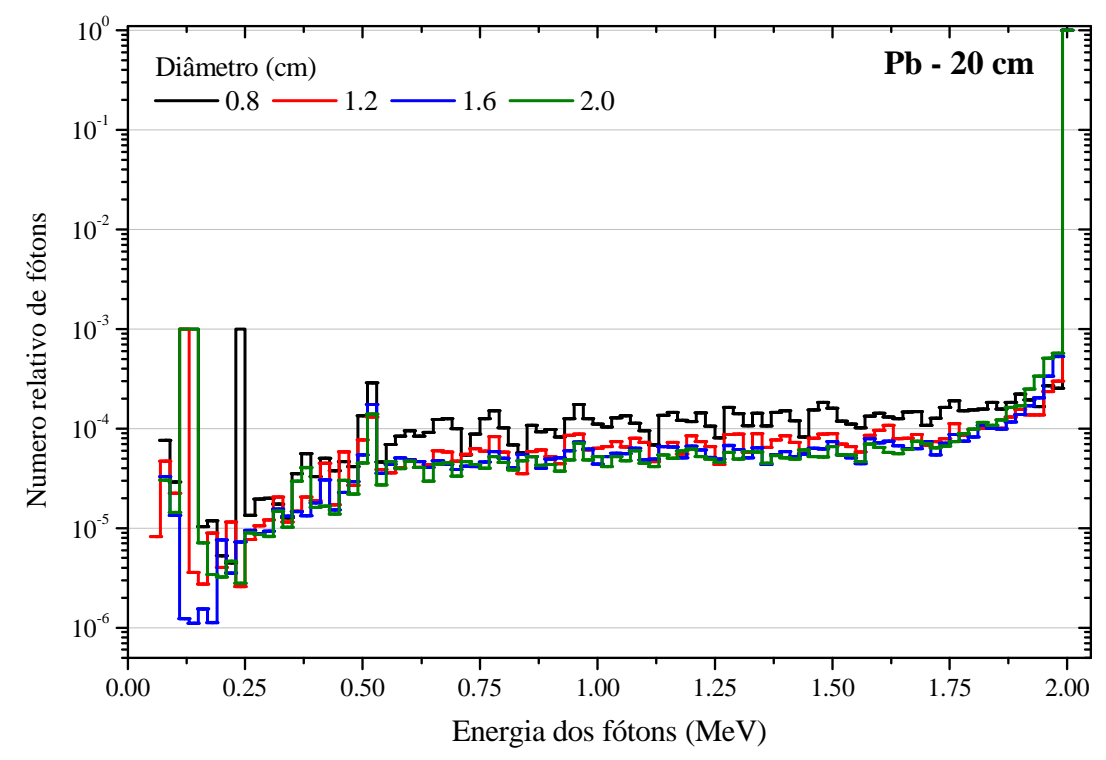

Fig. 4.8 Espectro simulado dos fótons na saída dos colimadores com $20 \mathrm{~cm}$ de comprimento.

\subsection{Caracterização do cristal de HPGe}

A medida do espectro de bremsstrahlung precisa de um conhecimento o mais detalhado possível da função resposta do detector de fótons, uma vez que o espectro é contínuo e requer um processo de deconvolução. A obtenção da função resposta e das curvas de eficiência de detecção para geometrias complexas mediante simulações por Monte Carlo é uma alternativa cada vez mais usada, no entanto é necessário conhecer as dimensões do cristal de Ge, incluindo não só as dimensões externas, mas também a espessura da camada morta, as dimensões do furo interno no caso dos detectores coaxiais, e o posicionamento relativo do cristal em relação à cápsula de alumínio. Nem sempre as informações fornecidas pelo fabricante do detector contêm todos estes detalhes, e mesmo assim, durante o processo de montagem do cristal, esses parâmetros podem mudar. Além disso, a camada morta aumenta com o tempo de vida do detector, e se o mesmo passou por processos de reparo por perdas de vácuo ou outros motivos, então, as características do cristal podem ser bem diferentes das explicitadas pelo fabricante [Bo08].

Abundante bibliografia pode ser encontrada sob os procedimentos para caracterizar o cristal de Ge, ou seja, determinar completamente a geometria real ou equivalente do detector, uma vez que só uma medida direta, mas impossível de fazer 
sem abrir o detector, garante o conhecimento das dimensionas verdadeiras. Radiografias tradicionais do detector conjuntamente com varreduras empregando, por exemplo, fontes radioativas, permitem determinar o tamanho do cristal, com o auxílio de processos de simulação, como no trabalho de F. Padilla Cabal et al. [Pa10].

Usamos um detector coaxial, tipo p, fabricado em 1989 e submetido a vários processos de reparo, o que fez mais necessária ainda sua caracterização experimental. A Tabela 4.4 apresenta os dados originais fornecidos pelo fabricante Ortec, que não informa as dimensões do orifício e contato internos. A eletrônica tradicional foi substituída por um espectrômetro digital da Ortec (DSPEC-Plus) conectado a um computador.

Tabela 4.4 Dados do detector GEM-33190-P da Ortec, que foi empregado nas medidas experimentais deste trabalho.

\begin{tabular}{|l|l|}
\hline Configuração & Pop Top \\
\hline Diâmetro do cristal & $56,2 \mathrm{~mm}$ \\
\hline Comprimento do cristal & $63,9 \mathrm{~mm}$ \\
\hline Distancia do cristal ao Al & $3 \mathrm{~mm}$ \\
\hline Espessura da cápsula de Al & $1,27 \mathrm{~mm}$ \\
\hline Camada morta do cristal & $0,7 \mathrm{~mm}$ \\
\hline
\end{tabular}

\subsubsection{Determinação da espessura da camada morta}

Para determinar a espessura da camada morta foram usadas as energias de $59 \mathrm{keV}$ do ${ }^{241} \mathrm{Am}$ e $81 \mathrm{keV}$ do ${ }^{133} \mathrm{Ba}$. Um colimador de $\mathrm{Pb}(\phi=0,2 \mathrm{~mm}$ e $\mathrm{L}=5,0 \mathrm{~cm})$ foi utilizado para fazer incidir o feixe de fótons a dois ângulos $\left(45^{\circ}\right.$ e $\left.90^{\circ}\right)$ sobre a parte frontal do detector. A camada morta foi medida em vários pontos, garantindo em cada medida que, quando o ângulo mudava de $90^{\circ}$ para $45^{\circ}$, o ponto de incidência do feixe se manteve fixo. Então, a diferença de intensidades entre as medidas feitas para os dois ângulos $\left(I_{90}, I_{45}\right)$ é devida a espessura $X_{G e}$ de camada morta, que pode ser determinada como segue [Bo08]:

$$
\begin{aligned}
& I_{90}=I_{o} e^{-\left(\mu_{A l} X_{A l}+\mu_{G e} X_{G e}\right)} \\
& I_{45}=I_{o} e^{-\left(\mu_{A l} X_{A l}+\mu_{G e} X_{G e}\right) / \operatorname{sen} 45^{\circ}}
\end{aligned}
$$


$X_{G e}=\frac{1}{\mu_{G e}}\left[\frac{\operatorname{sen} 45^{\circ}}{1-\operatorname{sen} 45^{\circ}} \ln \left(\frac{I_{90}}{I_{45}}\right)-\mu_{A l} X_{A l}\right]$

onde $\mu_{A l}$ e $\mu_{G e}$ são os coeficientes lineares de atenuação da radiação gama em $\mathrm{Al}$ e Ge respectivamente, $X_{A l}$ é a espessura da cápsula de alumínio. As médias das espessuras foram $2,1 \pm 0,4 \mathrm{~mm}$ e 2,2 $\pm 0,2 \mathrm{~mm}$ para 59 e $81 \mathrm{keV}$ respectivamente. Estes valores sao superiores ao valor nominal de $0,7 \mathrm{~mm}$, o que confirma o considerável incremento da camada morta observado em situações semelhantes [Hu07]. Foi suposta para a camada morta da superficie lateral do detector a mesma espessura que às obtidas pelas medidas frontais. Dita metodologia não pode ser aplicada nos detectores de HPGe tipo $n$ porque a camada morta é muito mais fina, da ordem de centenas de micrometros.

\subsubsection{Varredura do cristal}

Para determinar as dimensões do cristal, foram realizadas varreduras frontais e laterais do detector com fontes pontuais de ${ }^{137} \mathrm{Cs}$ e ${ }^{207} \mathrm{Bi}$, com um colimador de $\mathrm{Pb}$ de $10 \mathrm{~cm}$ de comprimento e $\phi=0,4 \mathrm{~cm}$ de diâmetro, como é apresentado na figura 4.9, onde são mostradas as trajetórias dos fótons para uma energia na fonte pontual de $1063 \mathrm{keV}$. As dimensões do cristal podem ser determinadas combinando os resultados das varreduras com simulações dessas geometrias, onde diversos parâmetros como o comprimento do cristal e do furo interno foram variados.

Primeiro, procurou-se avaliar a profundidade do furo interno do cristal $(\mathrm{H})$ mediante a comparação da relação de contagem com o feixe de fótons incidindo na direção do centro do orifício, portanto onde a varredura radial tivera um mínimo (Fig. 4.10-4.12), e fora do orifício (máximo na varredura radial). Variando H foram, então, obtidas curvas mediante simulações por MC para as três energias (tally F8), como é apresentado na figura 4.13. As interseções entre as curvas de MCNPX e os valores experimentais, representados pelas linhas horizontais, fornecem informação da profundidade do orifício [Pa10]. Os resultados para 569 e $661 \mathrm{keV}$ coincidem, mostrando um valor de $\mathrm{H}=51,0 \pm 0,1 \mathrm{~mm}$, mas para $1063 \mathrm{keV}$ o valor é ligeiramente superior $\mathrm{H}=53,2 \pm 0,2 \mathrm{~mm}$. Esta diferença pode ser explicada pelo o fato que, para $1063 \mathrm{keV}$, o caminho livre médio dos fótons é maior, e portanto existe uma influência do diâmetro do cristal na determinação de H. Uma vez que o valor de H é conhecido, 
então comparando o comportamento da varredura frontal experimental com simulações onde o diâmetro do orifício é variado, se determina essa outra dimensão do cristal. As figuras $4.10-4.12$ mostram que os resultados se ajustam para um diâmetro $\phi=9 \mathrm{~mm}$, incluindo a energia de $1063 \mathrm{keV}$, o que confirma a seleção correta de H =51,0 mm. A varredura radial também permite ajustar o valor do diâmetro externo do cristal, que coincidiu com o nominal fornecido pelo fabricante.
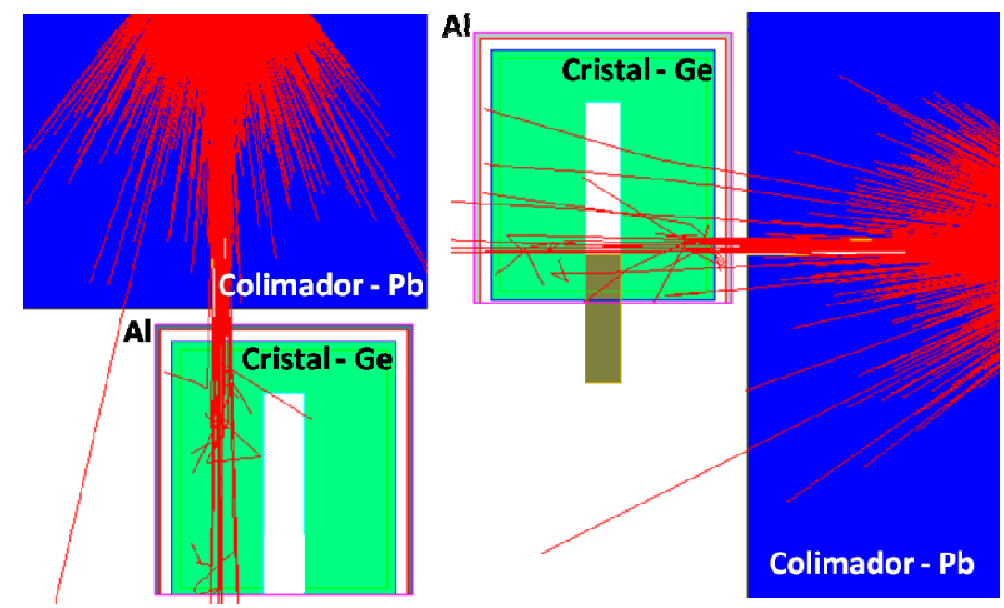

Fig. 4.9 Trajetórias dos fótons para uma energia da fonte pontual de $1063 \mathrm{keV}$, para os dois tipos de varreduras realizadas, frontal (esquerda) e lateral (direita); $10^{4}$ eventos computados.

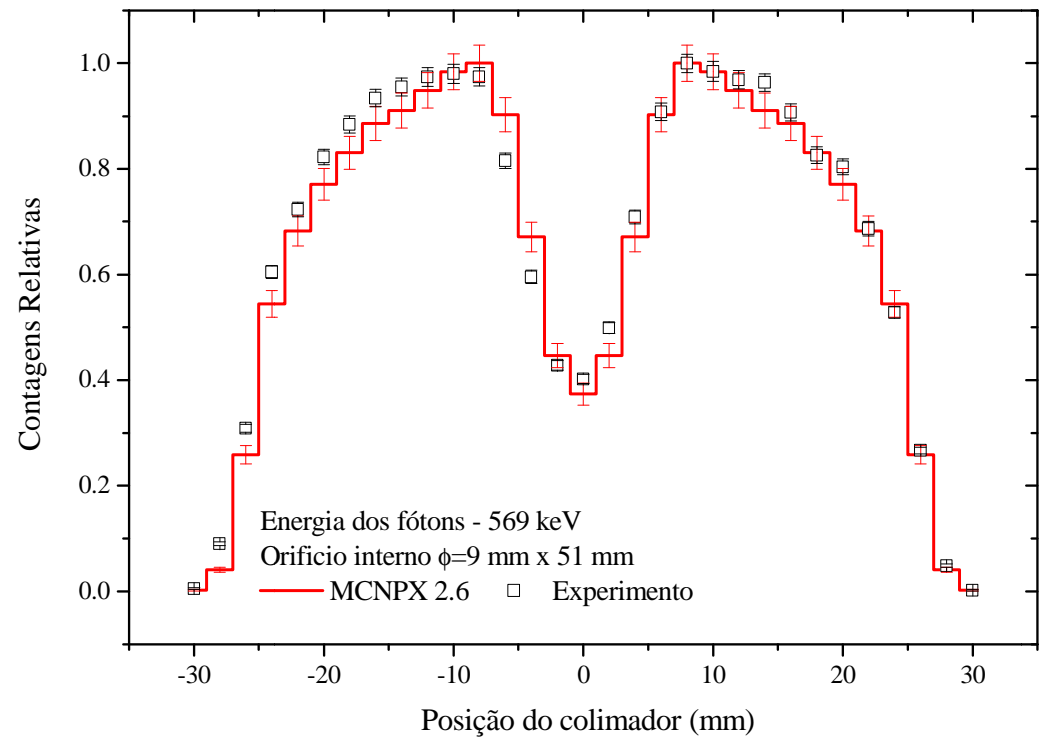

Fig. 4.10 Comparação das áreas do pico de $569 \mathrm{keV}$ da fonte de ${ }^{207} \mathrm{Bi}$ experimentais e simuladas em função da posição frontal de incidência do feixe de fótons. 


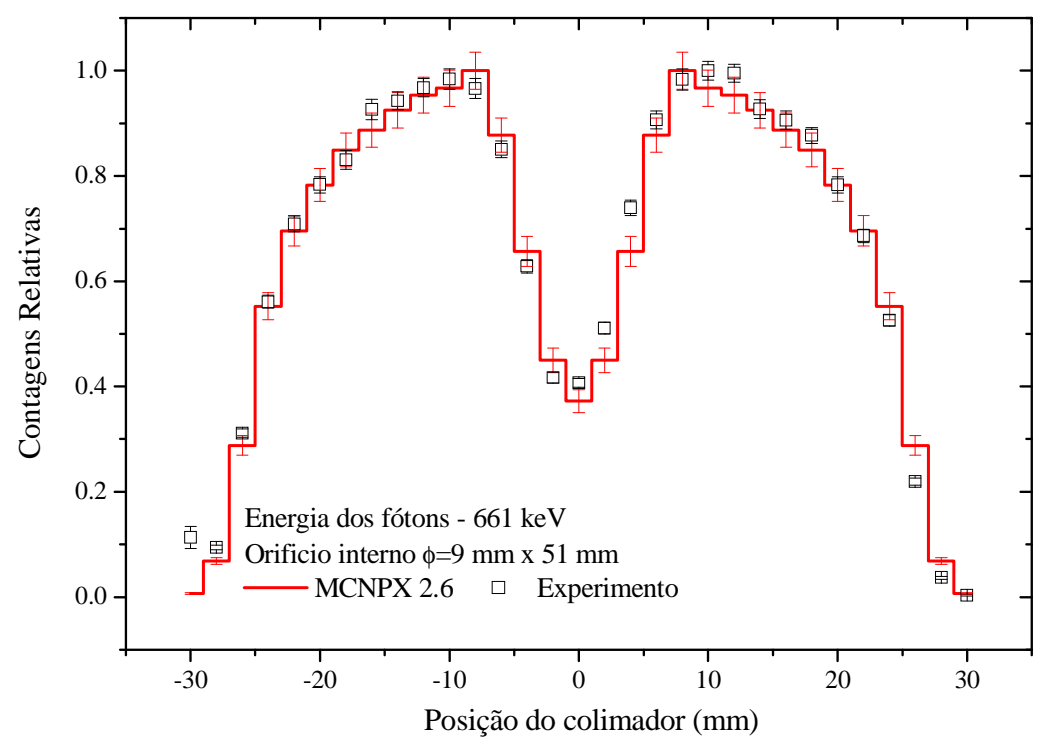

Fig. 4.11 Comparação das áreas do pico de $661 \mathrm{keV}$ da fonte de ${ }^{137} \mathrm{Cs}$ experimentais e simuladas em função da posição frontal de incidência do feixe de fótons.

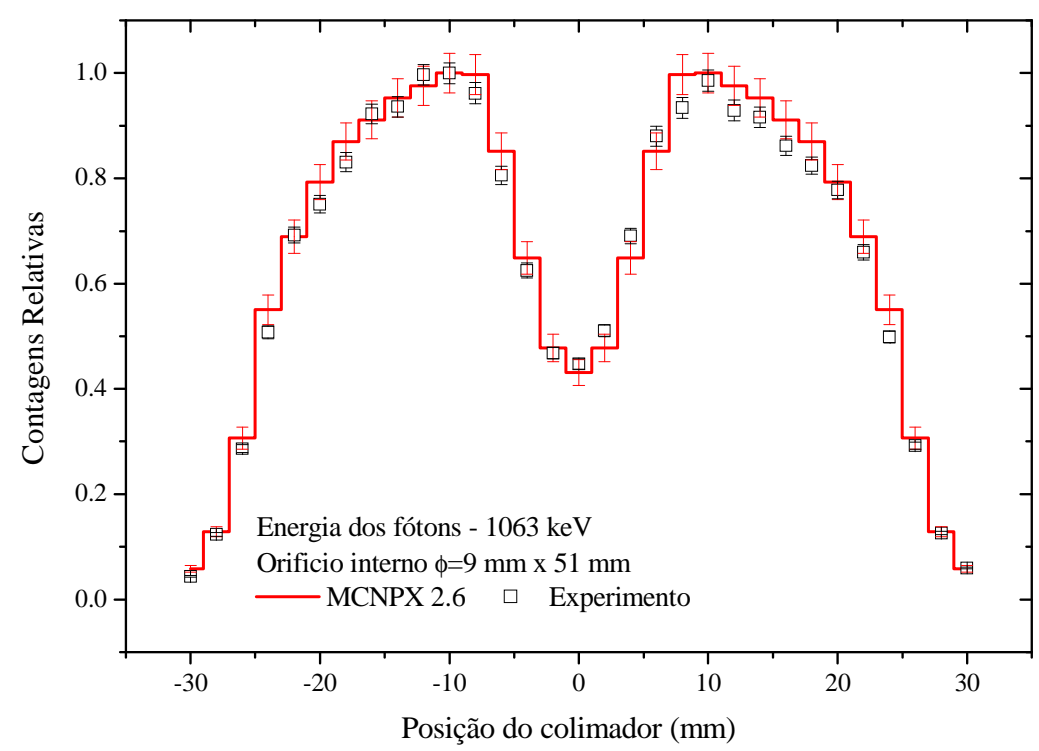

Fig. 4.12 Comparação das áreas do pico de $1063 \mathrm{keV}$ da fonte de ${ }^{207} \mathrm{Bi}$ experimentais e simuladas em função da posição frontal de incidência do feixe de fótons. 


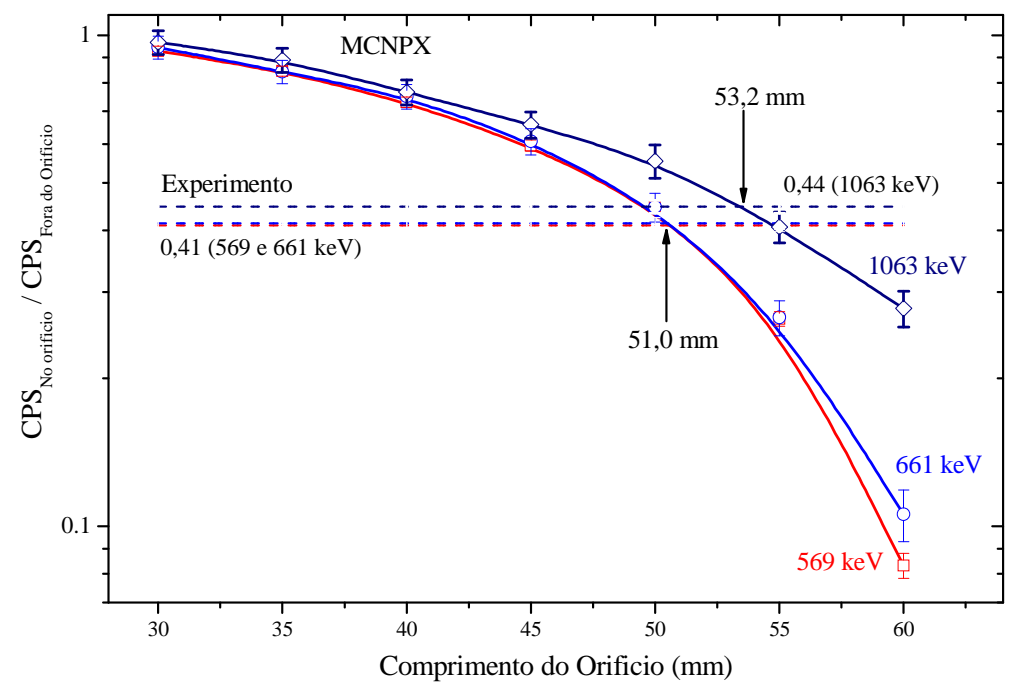

Fig. 4.13 Gráficos destinados à determinação da profundidade do orifício interno $(\mathrm{H})$; valores experimentais e simulados da razão das taxas de contagem no pico de absorção total de 569, 661 e $1063 \mathrm{keV}$, para incidência em direção ao orifício e fora do orifício, em função do comprimento do orifício central do detector de HPGe.

Por outro lado, a varredura lateral permitiu determinar o comprimento externo (L) do cristal. A figura 4.14 apresenta a comparação entre o resultado experimental e curvas obtidas para vários valores desse comprimento e introduzindo o "dedo frio" nas geometrias de MCNPX como um cilindro de cobre. O melhor ajuste foi alcançado para $\mathrm{L}=61,9 \mathrm{~mm}$ de comprimento, ou seja, dois milímetros menos que o comprimento nominal. Esta dimensão foi confirmada com as energias de 661 e $1064 \mathrm{keV}$, como mostram as figuras 4.15 e 4.16. Este estudo também permitiu comprovar que a distância entre a cápsula de alumínio e o cristal tem o valor nominal, pois o zero da escala horizontal nesses gráficos coincide com a posição da cápsula. 


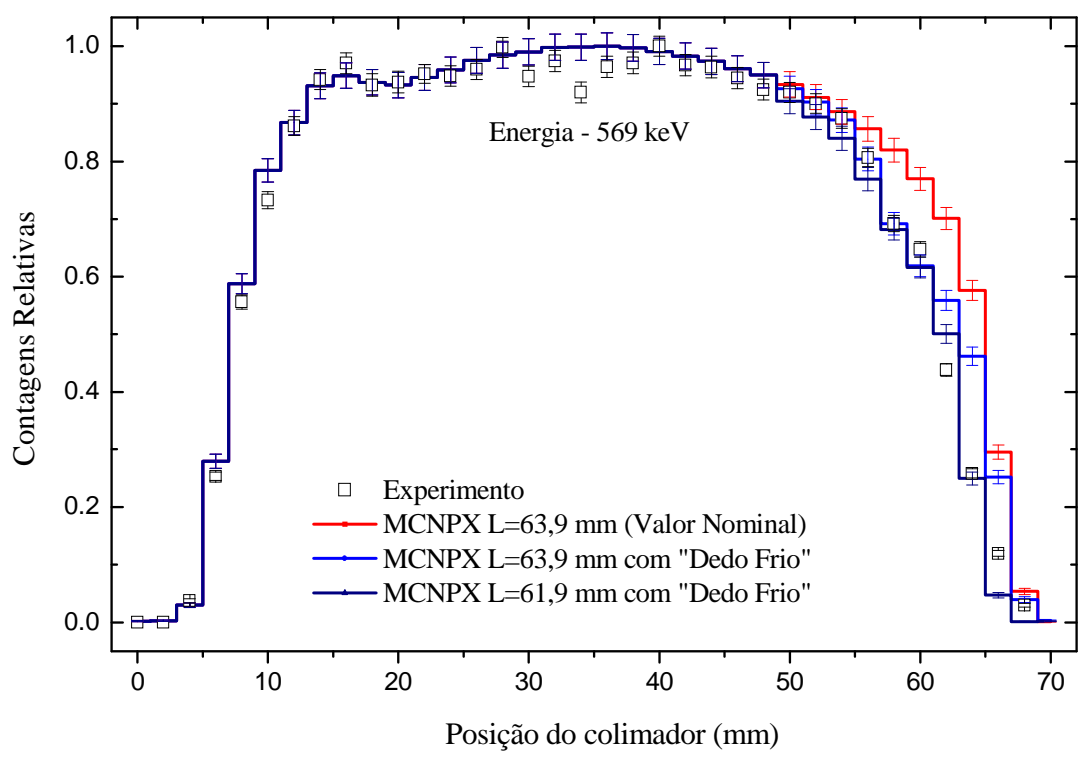

Fig. 4.14 Comparação das áreas do pico de $569 \mathrm{keV} \mathrm{do}{ }^{207} \mathrm{Bi}$ experimentais e simuladas para a varredura lateral. Observa-se a concordância dos valores experimentais para um comprimento do cristal $\mathrm{L}=61,9 \mathrm{~cm}$.

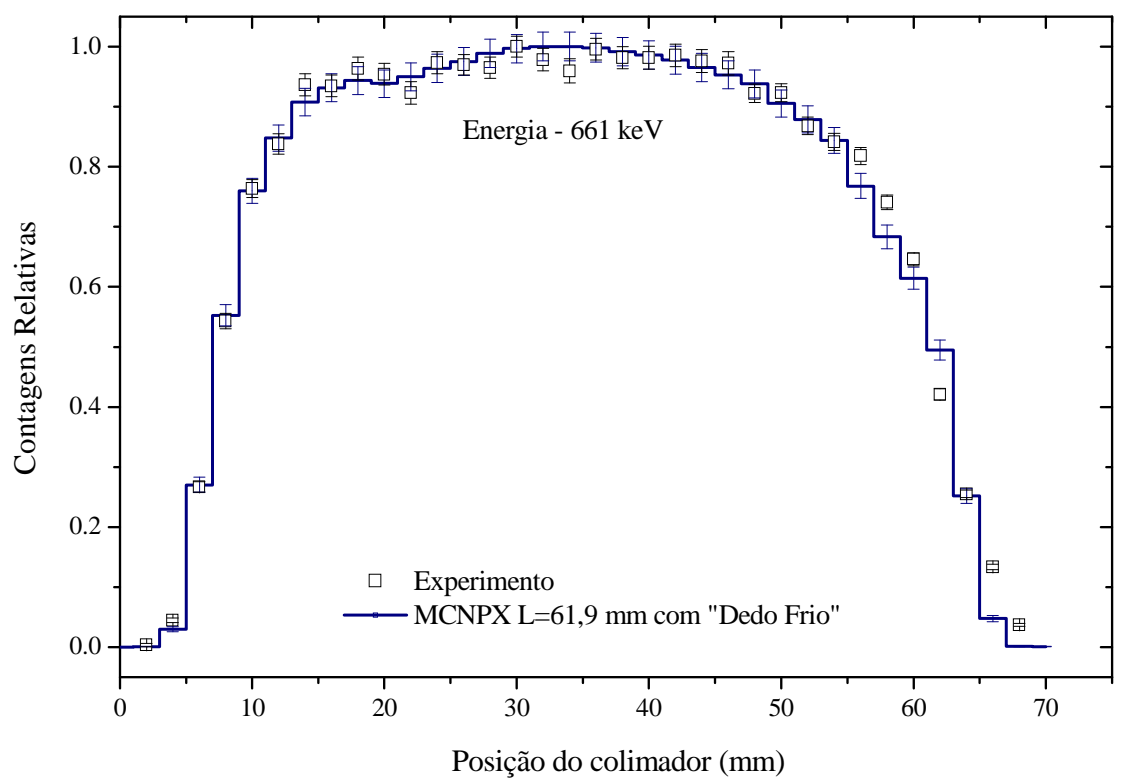

Fig. 4.15 Comparação das áreas do pico de $661 \mathrm{keV}$ do ${ }^{137} \mathrm{Cs}$ experimentais e simuladas para a varredura lateral. 


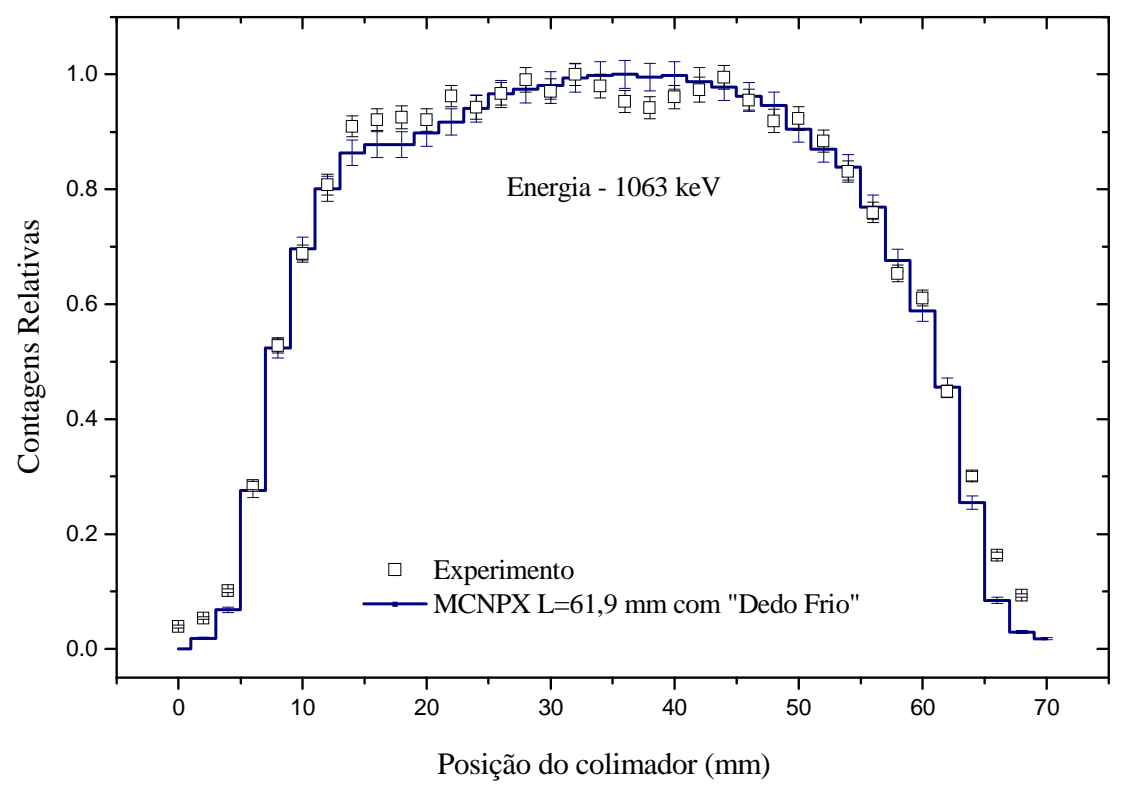

Fig. 4.16 Comparação das áreas do pico de $1063 \mathrm{keV} \mathrm{do}{ }^{207} \mathrm{Bi}$ experimentais e simuladas para a varredura lateral.

\subsubsection{Calibração de eficiência}

Para validar os procedimentos anteriores, o primeiro passo a seguir foi o de comparar as curvas de eficiência de pico de absorção total, para fontes pontuais a três distâncias $(7,11$ e $17 \mathrm{~cm})$ situadas no eixo do cristal de Ge, com curvas simuladas especificando os novos parâmetros (Tabela 4.5). Diversos autores [Vo01, Hu07] consideram que o processo de otimização é correto quando o Desvio Relativo $\Delta$ (eq. 4.4) entre o valor experimental $\left(\varepsilon_{\text {exp }}\right)$ e o valor estimado com MCNPX $\left(\varepsilon_{m c n p x}\right)$ fica menor que $10 \%$.

$\Delta=\frac{\varepsilon_{m c n p x}-\varepsilon_{\text {exp }}}{\varepsilon_{\exp }}$

As figuras 4.17 e 4.18 apresentam esta comparação, onde para 90\% dos resultados os desvios relativos são menores que 5\%, e em todos os casos são menores que $10 \%$, evidenciando que a geometria efetiva do cristal consegue reproduzir a situação experimental. 
Tabela 4.5 Parâmetros efetivos do detector de HPGe

\begin{tabular}{|l|l|}
\hline Diâmetro do cristal & $56,2 \mathrm{~mm}$ \\
\hline Comprimento do cristal & $61,9 \mathrm{~mm}$ \\
\hline Distancia do cristal ao Al & $3 \mathrm{~mm}$ \\
\hline Espessura da cápsula de Al & $1,27 \mathrm{~mm}$ \\
\hline Camada morta do cristal & $2,1 \mathrm{~mm}$ \\
\hline Diâmetro do orifício interno & $9 \mathrm{~mm}$ \\
\hline Profundidade do orifício interno & $51 \mathrm{~mm}$ \\
\hline
\end{tabular}

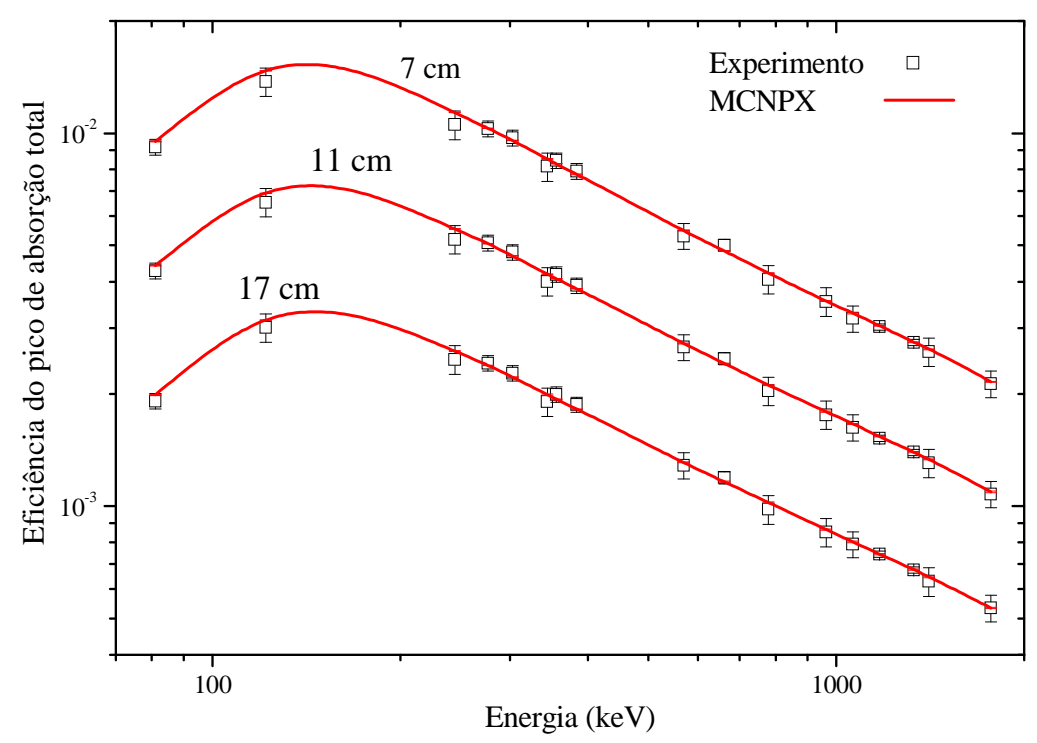

Fig. 4.17 Comparação entre as curvas de eficiências de pico experimentais e as obtidas com MCNPX usando as dimensões experimentais efetivas do detector.

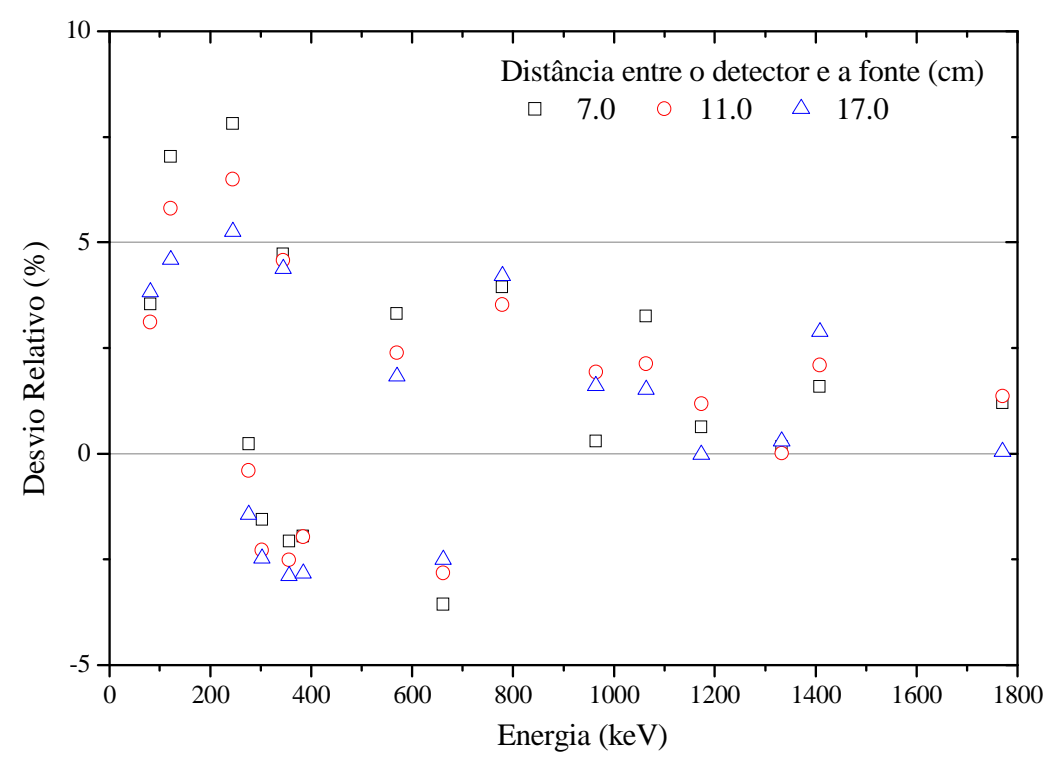

Fig. 4.18 Desvio relativo entre os resultados experimentais e as simulações por MC para as curvas de eficiências às três distâncias estudadas. 
Um estudo similar foi realizado colocando as fontes pontuais no interior da câmara de irradiação, exatamente no lugar onde ficariam os alvos a estudar. O detector de HPGe foi posicionado depois do colimador desenhado, como mostra a Fig. 4.19 correspondente a geometria especificada no MCNPX. As curvas de eficiência foram medidas e simuladas para três ângulos, e a principal diferença entre eles reside na espessura dos flanges de $\mathrm{Al}$, que no caso de $30^{\circ}$ foi de $9 \mathrm{~mm}$, e para $60^{\circ}$ e $90^{\circ}$ de $1 \mathrm{~mm}$. O eixo do cristal foi deslocado $12 \mathrm{~mm}$ em relação ao furo do colimador, para incrementar a eficiência e tirar fora do feixe de bremsstrahlung o orifício do cristal. A comparação das curvas de eficiência mostrou desvios relativos menores que $10 \%$ para as 17 energias estudadas. Os desvios relativos médios foram 3,$6 ; 5,9$ e 5,4 \% para $30^{\circ}$, $60^{\circ}$ e $90^{\circ}$ respectivamente. As curvas de eficiência para estes três ângulos são apresentadas na figura 4.20 .

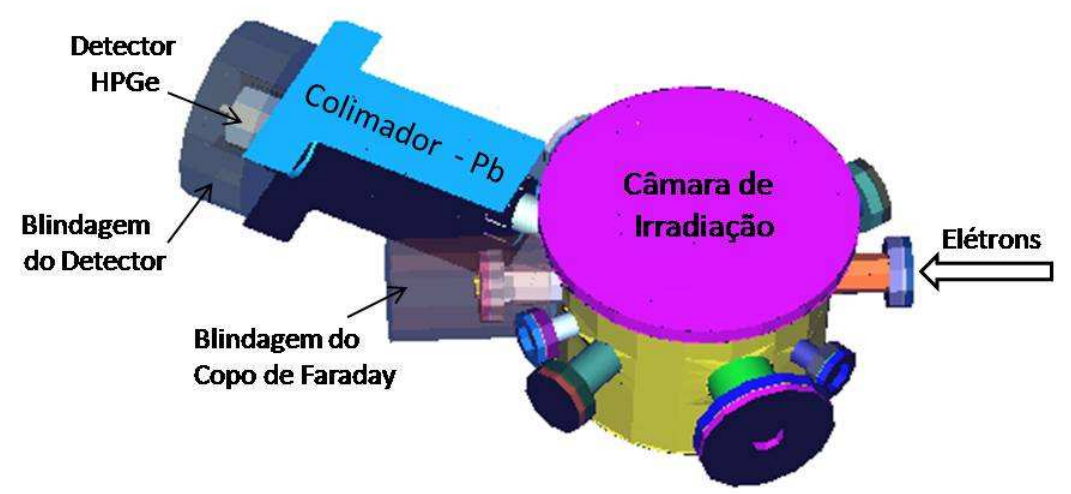

Fig. 4.19 Geometria 3D reproduzida no MCNPX da câmara de irradiação, colimador, e as blindagens do detector e o copo de Faraday.

Para determinar a probabilidade de que um fóton emitido pela a fonte na direção do detector seja absorvido totalmente no detector $\left(\varepsilon_{\Omega}\right)$ basta multiplicar a eficiência para uma emissão em $4 \pi\left(\varepsilon_{4 \pi}\right)$ pela relação entre $4 \pi$ e o ângulo sólido $\Omega$ que subtende o furo do colimador (eq. 4.5). A figura 4.21 ilustra a relação entre o $\Omega$ geométrico calculado partindo das dimensões do colimador, $\Omega_{\text {Geométrico }}=(6,93 \pm 0,10) \times 10^{-4} \mathrm{sr}$, e o determinado mediante MCNPX. Esta relação é praticamente independente da energia, mas na determinação de $\varepsilon_{\Omega}$ em cálculos posteriores foi levada em conta.

$\varepsilon_{\Omega}=\varepsilon_{4 \pi} \frac{4 \pi}{\Omega}$ 


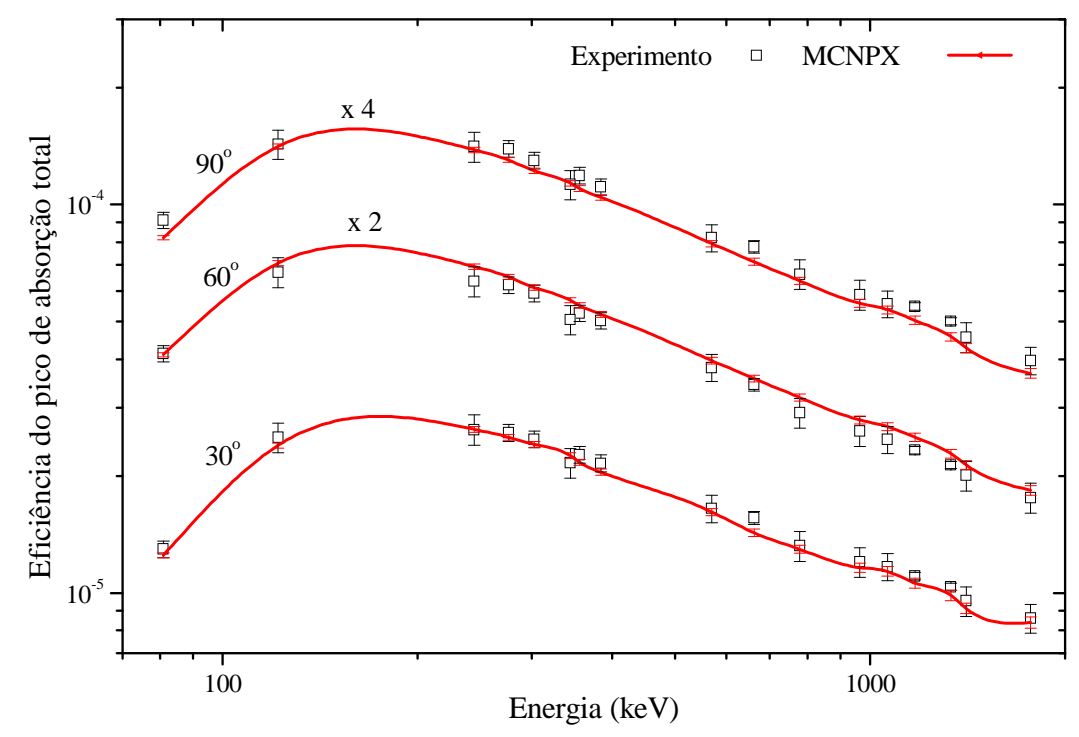

Fig. 4.20 Comparação entre eficiência experimental (pontos) e as curvas obtidas com MCNPX para calibração com fonte pontual na geometria da câmara de irradiação. A incerteza da simulação é da ordem de $2 \%$.

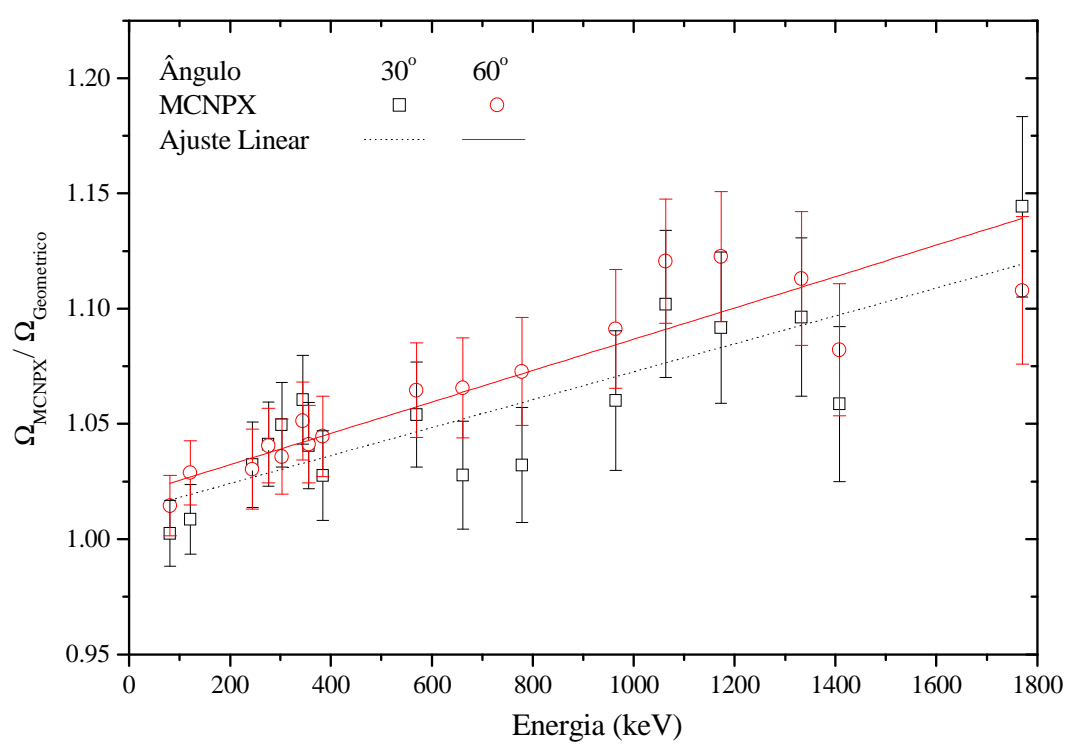

Fig. 4.21 Comportamento da relação entre o ângulo sólido determinado por MCNPX e o geométrico em função da energia dos fótons.

\subsubsection{Função Resposta}

Partindo dos parâmetros otimizados foram então simuladas as funções resposta para ${ }^{60} \mathrm{Co},{ }^{137} \mathrm{Cs}$ e o ${ }^{207} \mathrm{Bi}$ na geometria da câmara de irradiação. A comparação com os dados experimentais é apresentada nas figuras 4.22 - 4.24, onde os resultados estão normalizados à área do pico. A resolução em energia do espectrômetro $(2,9 \mathrm{keV}$ para a 
linha de $1332 \mathrm{keV}$ do ${ }^{60} \mathrm{Co}$ ) foi incluída na simulação mediante o emprego da função FT (tratamento especial dos "tallies") e a opção GEB que faz uma amostragem gaussiana da energia depositada no material e estimada pelo tally F8 [Pe05].

Em geral, a simulação consegue reproduzir o comportamento e intensidade do pico de absorção total nos espectros medidos, mas sistematicamente existe uma pequena tendência a subestimar a componente contínua do espectro. As relações Pico/Total determinadas para cada caso mostram este fato, os resultados das simulações com MCNPX são aproximadamente 9\% superiores. Fenômenos como a coleção incompleta de carga ou heterogeneidades no campo elétrico do semicondutor, que não são levados em conta nas simulações, modificam a função reposta com a inclusão de uma cauda na região do espectro de energias menores que o pico de absorção total [Ji86, Le87, Ut05]. Esta diferença foi levada em conta nos cálculos posteriores, fazendo uma correção na função resposta, ou seja, adicionando aos resultados do MCNPX a mencionada cauda.

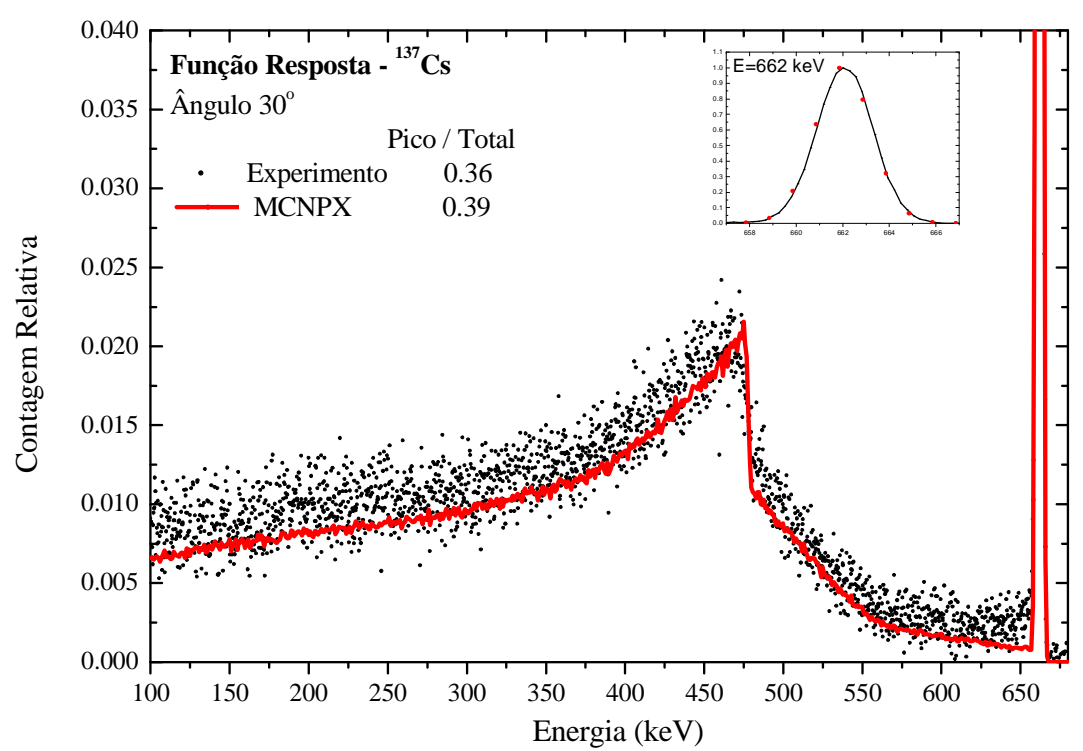

Fig. 4.22 Comparação entre a função resposta experimental e a simulada para o ${ }^{137} \mathrm{Cs}$. 


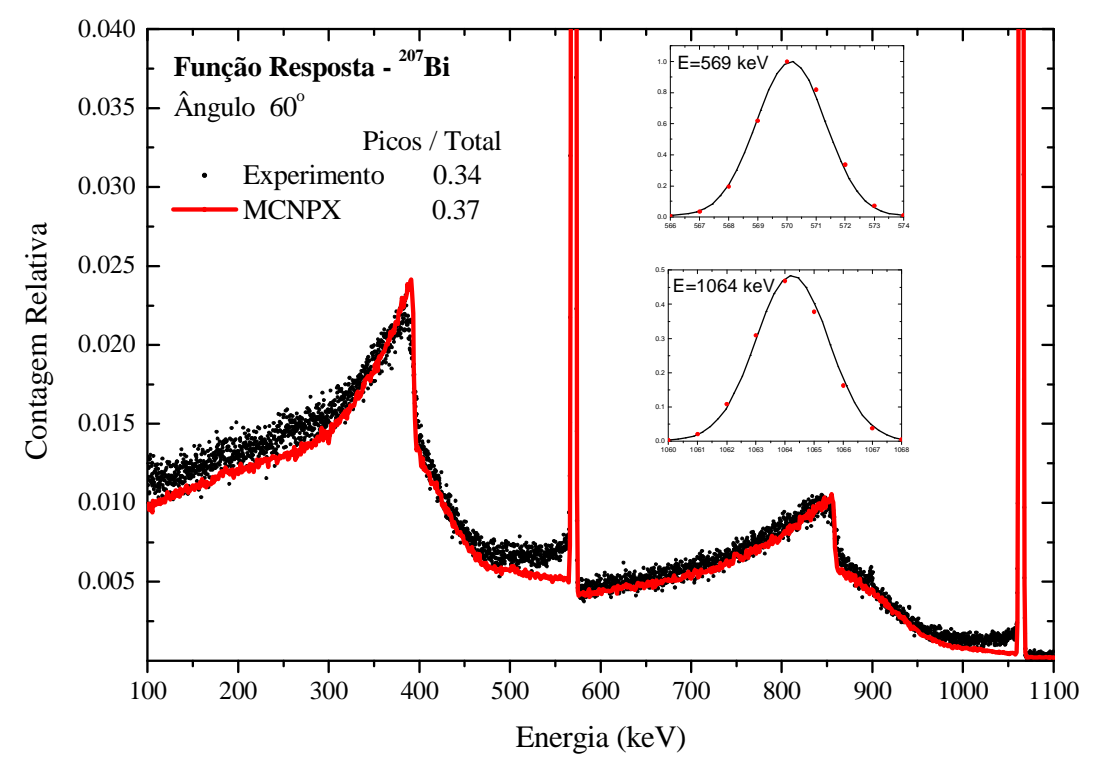

Fig. 4.23 Comparação entre a função resposta experimental e a simulada para o ${ }^{207} \mathrm{Bi}$.

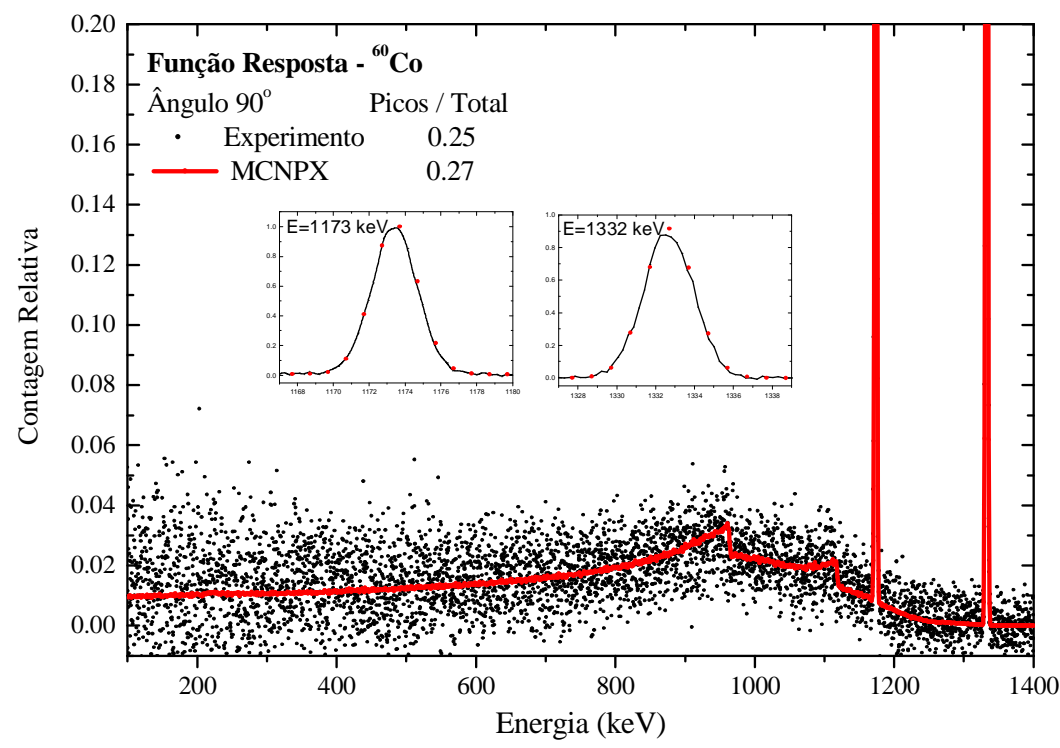

Fig. 4.24 Comparação entre a função resposta experimental e a simulada para o ${ }^{60} \mathrm{Co}$.

\subsubsection{Deconvolução dos espectros}

Com a caracterização do detector, uma das principais problemáticas fica resolvida, então o processo da deconvolução se reduz a determinar o vetor coluna $\mathbb{B}$, que na equação 4.6 representa o espectro de bremsstrahlung incidente, partindo do vetor espectro medido $\mathbb{E}$ e da matriz função resposta do detector $\mathbb{R}$. 
$\mathbb{E}=\mathbb{R} \mathbb{B} \quad \mathbb{B}=\mathbb{R}^{-1} \mathbb{E}$

Dependendo da precisão, ou seja, da resolução energética desejada para $\mathbb{B}$, o processo de construção de $\mathbb{R}$ e a determinação de sua inversa $\mathbb{R}^{-1}$ pode ser bem complicado.

Em nosso estudo, a determinação das seções de choque de produção de bremsstrahlung foi realizada para dois intervalos de energia: $100-2000 \mathrm{keV}$ e 1700 $1910 \mathrm{keV}$. O primeiro intervalo corresponde praticamente ao espectro completo medido no detector, levando em conta que a camada morta do cristal incrementa a absorção dos raios gamas de menor energia. Para simplificar o processo de deconvolução do espectro, então foram somadas as contagens em passos de $50 \mathrm{keV}$ de energia; desta forma, o espectro de bremsstrahlung $\mathbb{B}$ constitui um vetor coluna de 38 linhas, e calcula-se multiplicando a inversa da matriz função resposta do detector $\mathbb{R}^{-1}$ pelo o vetor espectro $\mathbb{E}$ formado pela contagem de cada passo de $50 \mathrm{keV}$.

A matriz $\mathbb{R}$, formada por vetores coluna que constituem a função resposta do detector no arranjo experimental para energias espaçadas cada $50 \mathrm{keV}$, foi determinada mediante simulações por Monte Carlo tanto para a geometria do detector de HPGe a $30^{\circ}$ quanto a $60^{\circ}$ em relação ao feixe de elétrons. A figura 4.25 apresenta as funções resposta para 10 dos 38 intervalos energéticos, da geometria de $30^{\circ}$.

No segundo intervalo estudado, 1700 - $1910 \mathrm{keV}$, foram agrupadas as contagens em passos de $5 \mathrm{keV}$ para $30^{\circ}$ e $10 \mathrm{keV}$ para $60^{\circ}$. A diferença é devida à menor quantidade de fótons coletados nesse ângulo. O espectro de bremsstrahlung foi igualmente calculado pela equação (4.6), só que nestes casos as dimensões de $\mathbb{R}, \mathbb{B}$ e $\mathbb{E}$ são diferentes. A resolução energética do detector foi também incluída na função resposta. O limite inferior de energia (1700 keV) foi escolhido atendendo a que nessa região a função resposta do detector não inclui a borda Compton, que, para $1910 \mathrm{keV}$, é $1685 \mathrm{keV}$, portanto a função resposta é muito mais simples. 

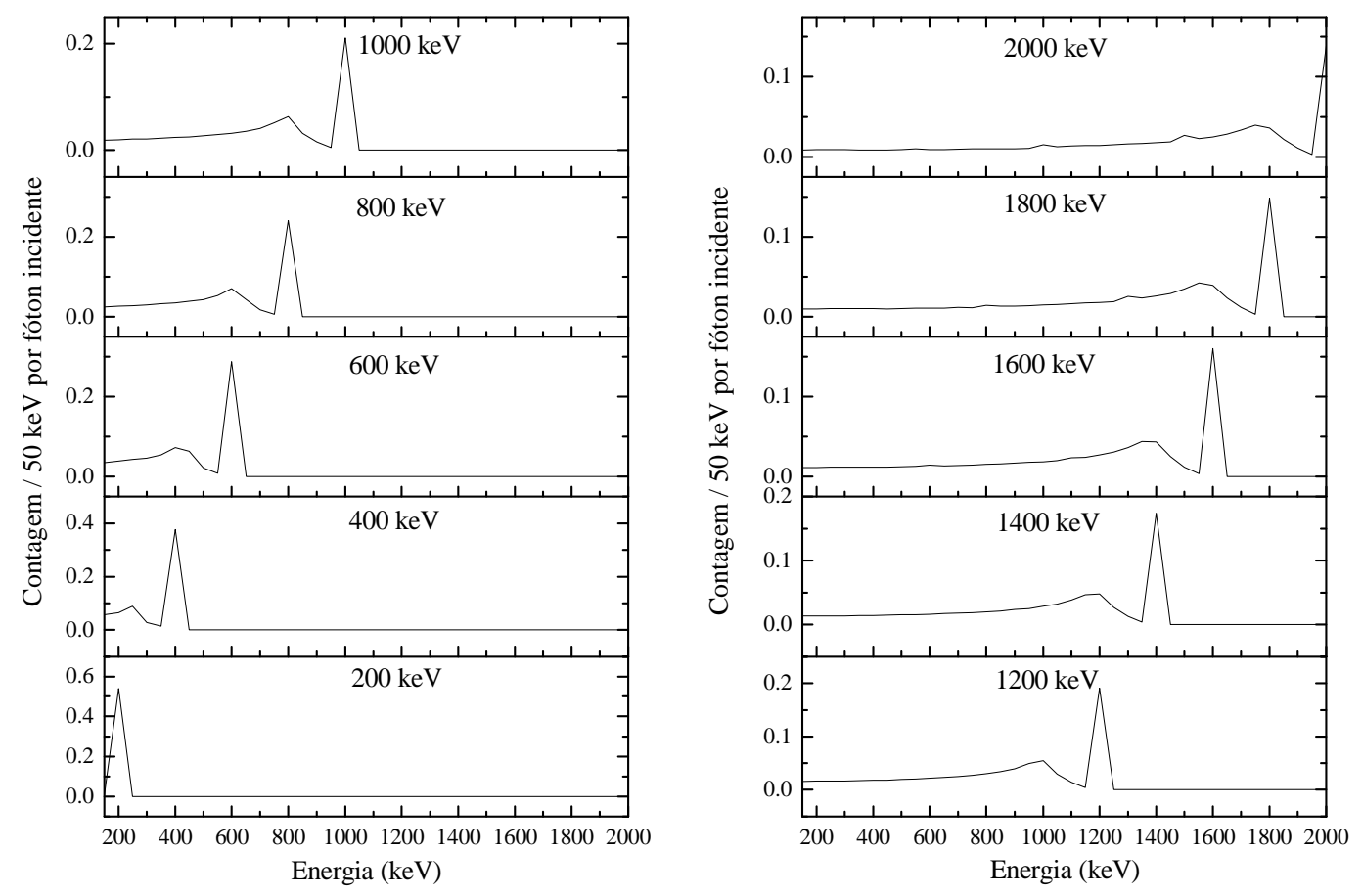

Fig. 4.25 Funções resposta para 10 dos 38 vetores colunas, cada $200 \mathrm{keV}$, da geometria de $30^{\circ}$.

\subsection{Fontes de Fótons para medidas de um sistema de NRF}

A Fig. 4.26 mostra um esquema geral de um sistema de medidas de NRF. Na figura está representada a fonte de fótons como radiação de bremsstrahlung gerada em um radiador por um feixe de elétrons, mas os fótons podem ser produzidos de várias maneiras como é descrito mais adiante. O colimador garante que o feixe de bremsstrahlung incidente sobre o alvo, interaja o menos possível com os elementos do sistema, em particular nos detectores que medem os fótons provenientes do alvo. Os detectores são blindados com o objetivo de reduzir o background. Adicionalmente podem ser colocados polarímetros, um "tagger" para monocromatizar o bremsstrahlung [Kn82, Ad90, Ow90, Va92], um monitor do fluxo do feixe de fótons; um coletor do feixe de elétrons (electron beam dump) e outro coletor para o feixe de fótons (photon beam dump), a fim de diminuir o background devido ao espalhamento do feixe nas paredes e outros elementos da sala de irradiação [Ga00, Wa05]. 

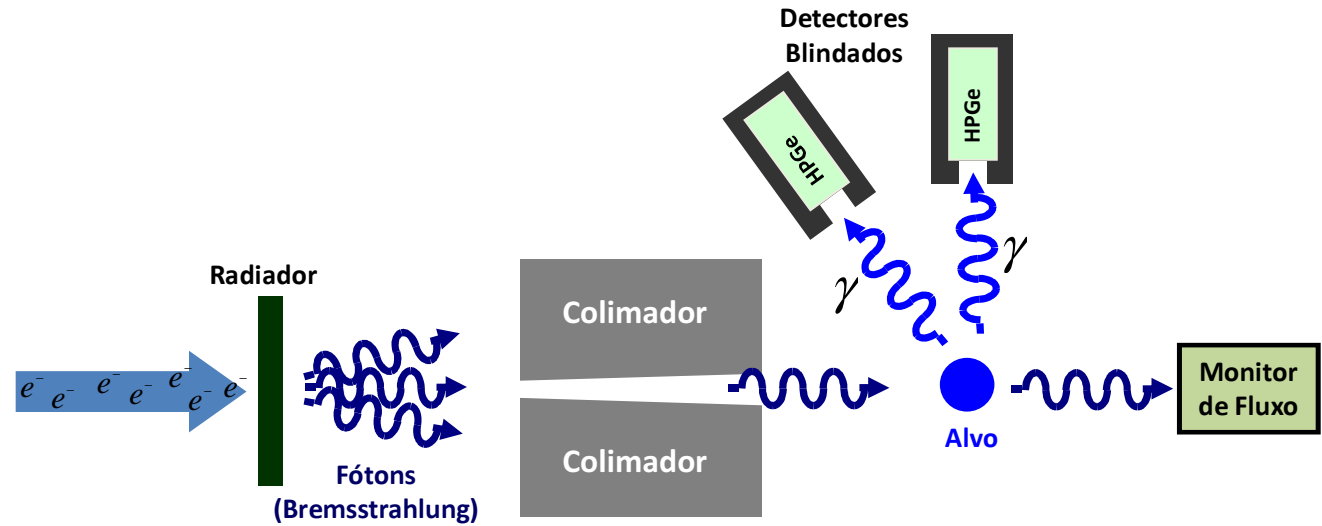

Fig. 4.26 Esquema geral para um sistema de medidas de NRF

Uma fonte ideal de fótons para experimentos de NRF deveria possuir as duas características seguintes:

1. Uma intensidade espectral elevada, $I=N_{\gamma} / \mathrm{eV} \cdot \mathrm{seg}$, quer dizer, um número alto de fótons por intervalo de energia do espectro por unidade de tempo, para poder excitar um maior número de núcleos no alvo,

2. Um elevado grau de polarização $\left(P_{\gamma} \approx 100 \%\right)$, o que permitiria realizar estudos das paridades dos estados excitados.

A seleção da fonte de fótons, entre os métodos que descreveremos a seguir, depende dos requerimentos específicos de cada experimento de NRF [Kn96, Wa05, Me59].

\subsubsection{Reator Nuclear}

Por meio da captura de nêutrons térmicos emergentes de um reator é possível obter um fluxo alto de fótons, ao redor de $10^{6}$ fótons $/ \mathrm{eV} \cdot \mathrm{seg} \cdot \mathrm{cm}^{2}$, com energias entre 0,3 e $12 \mathrm{MeV}$. A largura da distribuição em energia desses fótons é só da ordem de $5 \mathrm{eV}$, devido ao alargamento Doppler na região de nêutrons térmicos, de modo que os fótons têm uma energia praticamente bem definida. Nos experimentos de NRF, para garantir a condição de ressonância, é necessário que o espectro de emissão, que seriam 
esses fótons da captura neutrônica, superponha-se ao espectro de absorção (espectro de transições do núcleo). Com energias bem definidas esta condição de ressonância é difícil de lograr, de maneira que o uso de reatores como fonte de fótons é muito limitado, impedindo a realização sistemática de experiências de NRF [Mo79].

Outro método para obter fótons a partir de um reator nuclear é o uso da radiação gama emitida em reações diretas $(n, \gamma)$ com nêutrons rápidos e espalhada por Efeito Compton em um determinado material em ângulos de espalhamento diferentes, de modo que são obtidos fótons de várias energias. Este método na prática só é aplicável em reatores com um fluxo alto de nêutrons como o ILL de Grenoble [Jo95, St96].

\subsubsection{Aniquilação de Pósitrons em Vôo}

Um método para produzir fótons quasimonocromáticos é a aniquilação de pósitrons em vôo (Flight Positron Annihilation) usado com sucesso no estudo de reações fotonucleares [Be75, Di88]. Porém, a intensidade espectral deste método é muito baixa para experiências de NRF, onde são estudados níveis com largura radiativa $\Gamma \approx 1 \mathrm{eV}-1 \mathrm{meV}$. Os aceleradores mais modernos e de alto fator de utilização, como o MAINZ $\operatorname{com} E_{\gamma}<800 \mathrm{MeV}$ e uma intensidade espectral de $10^{6}$ fótons por segundo por canal energético à saída do tagger, não estão disponíveis para experimentos de NRF. Nesses aceleradores, a largura dos canais energéticos do tagger é da ordem de $50 \mathrm{keV}-1 \mathrm{MeV}$, pelo que a intensidade espectral não é suficiente para estudos de NRF $\left(10^{6} \frac{\gamma}{\mathrm{seg}} / 50 \mathrm{keV}=2 \times 10^{4} \frac{\gamma}{\mathrm{seg}} / \mathrm{keV}\right)[\mathrm{Ri} 84$, An91].

\subsubsection{Espalhamento de laser em elétrons de alta energia (LCP)}

Partindo da idéia original proposta por Milburn e Arutyunian et al. em 1963 [Mi63, Ar63] para a produção de fótons monocromáticos e altamente polarizados, a partir do espalhamento de luz laser em elétrons de alta energia (LCP - Laser Compton Photons), em 1994 Ohgaki et al. [Oh94] descreveram o primeiro experimento bem sucedido de NRF na instalação experimental de Tsukuba produzindo $4 \times 10^{4}$ fótons por segundo, com uma energia variável entre $1-10 \mathrm{MeV}$, uma resolução energética de ao 
redor de $3 \%$, e um grau de polarização perto de $100 \%$. Neste experimento, onde foi estudada a conhecida excitação dipolar do ${ }^{208} \mathrm{~Pb}$, a massa do alvo foi de $70 \mathrm{~g}$, com o objetivo de compensar a baixa intensidade espectral do sistema. Só foi possível obter fótons por esta via quando foram construídos anéis de armazenamento de alta intensidade de elétrons e poderosas fontes de laser. A energia dos fótons espalhados nos elétrons é mudada variando a energia dos elétrons [Fe80] ou aplicando técnicas de "tagging" [Th89].

\subsubsection{Radiação de freamento (Bremsstrahlung)}

A fonte de fótons mais intensa e mais usada é a radiação de freamento, conhecida como "bremsstrahlung", que é produzida ao bombardear um alvo, chamado comumente como radiador, com um feixe de elétrons. As partículas incidentes são elétrons porque a intensidade da radiação de freamento é inversamente proporcional ao quadrado da massa da partícula [Ha03].

O bremsstrahlung se caracteriza por um espectro de energias contínuo que se estende até a energia cinética das partículas incidentes, com uma distribuição angular cujo máximo aproxima-se à direção do feixe incidente à medida que a velocidade do elétron aproxima-se à velocidade da luz. Os fótons de energias mais elevadas estão concentrados no centro do feixe de bremsstrahlung. A Fig. 4.27 mostra a forma do espectro de bremsstrahlung representada no eixo vertical pela seção de choque, calculada a partir de vários modelos para um radiador fino com número atômico $Z=41$ (Nióbio) e uma energia dos elétrons incidentes de $T_{o}=10 \mathrm{MeV}$ [Er06]. Os espectros de bremsstrahlung determinados por estes modelos diferem entre si em aproximadamente $5 \%$, porém para as energias mais altas, perto do "end point", a diferença pode ser de até 20\%. A determinação teórica e experimental do espectro de bremsstrahlung na posição do alvo de NRF é uma tarefa complicada. Atualmente se usam simulações por Monte Carlo conjuntamente com medidas do fluxo de fótons para certas energias, para descrever a forma e a intensidade do espectro de bremsstrahlung [Be01].

Nos experimentos de NRF esta distribuição contínua de energia não representa desvantagem como acontece, por exemplo, nos estudos de reações fotonucleares acima 
do limiar de produção de partículas. Pelo contrário, o espectro contínuo do bremsstrahlung permite excitar vários níveis simultaneamente, e os fótons que emergem da desexcitação dos mesmos podem ser medidos com precisão por meio de espectroscopia gama de alta resolução.

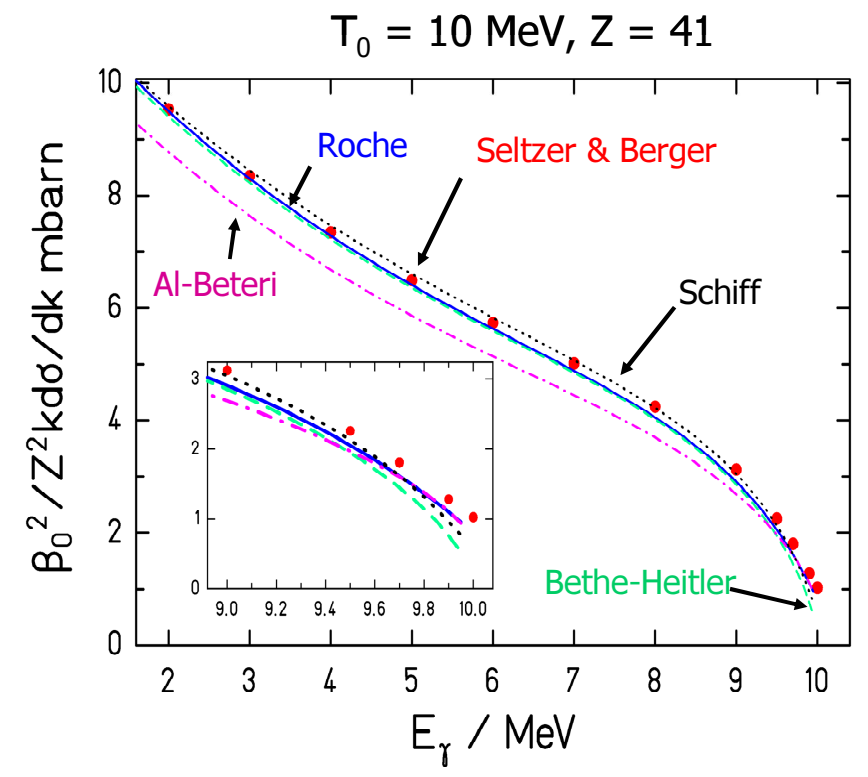

Fig. 4.27 Espectros de Bremsstrahlung, de um alvo fino, calculado por vários modelos para um radiador de $\mathrm{Nb}$ e elétrons incidentes de energia $10 \mathrm{MeV}$ [Be01].

Os aceleradores de elétrons modernos são fontes intensas de fótons. Para experimentos de NRF, onde se trabalha com $E \leq 10 \mathrm{MeV}$, são usados aceleradores de alto fator de utilização (duty cycle), de onda contínua $(C W)$, ou feixes de corrente direta $(D C)$, obtendo elevadas taxas de contagem e sem os problemas de empilhamento de pulsos característico dos feixes pulsados. Deste modo, por exemplo, o acelerador eletrostático Dynamitron de Stuttgart com $E_{\max } \leq 4,3 \mathrm{MeV}$ e $4 \mathrm{~mA}$ de corrente máxima trabalha com 400 - $450 \mu \mathrm{A}$ de $D C$ em experimentos de NRF, devido à capacidade limitada de refrigeração do radiador que produz bremsstrahlung [Be01]. Os aceleradores lineares clássicos, também alcançam correntes médias de várias centenas de microamperes, porém, devido ao baixo fator de utilização, da ordem de $10^{-3}-10^{-2}$, reduz-se drasticamente a taxa máxima de contagem por causa do empilhamento de pulsos. As taxas de contagens máximas são da ordem de um décimo da taxa de repetição destas máquinas, que está na faixa de $0,5-5 \mathrm{kHz}$. Este problema é resolvido em aceleradores de $C W$ como o acelerador linear supercondutor de Darmstadt SDALINAC [Au93]. Assim, usando aceleradores de $D C$ ou $C W$ a taxa máxima de 
contagem em experimentos de NRF está limitada apenas pela capacidade de processamento dos espectrômetros gamas, que é da ordem de $10 \mathrm{kHz}$ nos espectrômetros convencionais e até $80 \mathrm{kHz}$ usando sistemas que digitalizam os sinais dos detectores (Digital Signal Processor - DSP).

Para realizar uma comparação entre as diferentes fontes de fótons mencionadas, são definidos alguns parâmetros que caracterizam um sistema de NRF:

- Intensidade Espectral, número de fótons por intervalo de energia por unidade de tempo, expressa em unidades de $\gamma \mathrm{eV}^{-1} \mathrm{~s}^{-1}$, para energia de referência escolhida igual a $3 \mathrm{MeV}$.

- $\quad$ Monocromaticidade $\Delta E_{\gamma} / E_{\gamma}(\%)$, na mesma energia de referência.

- Grau de Polarização do feixe incidente $P_{\gamma}\left(E_{\gamma}\right)$ ou Sensibilidade de Polarização do polarímetro usado $Q\left(E_{\gamma}\right)$

- $\quad$ Sensibilidade Limite "S", que é o produto da mínima largura radiativa detectável $\left(\Gamma_{\min }\right)$ e a massa da amostra $(M), S=\Gamma_{\operatorname{mim}} \times M$. Tem unidades de $\operatorname{meV} \times \mathrm{g}$, e é o parâmetro mais crítico em experimentos de NRF.

Como pode ser observado na Tabela 4.6, até agora a melhor sensibilidade é obtida em experimentos que usam bremsstrahlung como fonte de fótons. Na faixa de $3 \mathrm{MeV}$ de energia, o limite de detecção é da ordem de $\Gamma_{o} \leq 1 \mathrm{meV}$, para medidas onde não existe interesse em determinar a paridade dos estados. Nesses casos, as massas do alvo de NRF são ao redor de 1 g, enriquecido no isótopo objeto de estudo, o que corresponde a sensibilidades da ordem de $B(E 1) \uparrow \approx 0.1 \times 10^{-2} e^{2} \mathrm{fm}^{2}$ e $B(M 1) \uparrow \approx 0.01 \mu_{N}^{2}$ para excitações dipolares elétricas e magnéticas, respectivamente. Nas medidas onde o objetivo é estudar a paridade dos estados, a sensibilidade é uma ordem de grandeza maior. No caso onde não são de interesse observáveis de polarização os tempos típicos de medidas são de 3 - 4 dias, e de 3 - 4 semanas quando se tem interesse nestas variáveis. 
Tabela 4.6 Comparação entre vários tipos de fontes de fótons: $L C P$ - Espalhamento de laser em elétrons de alta energia (Laser Compton Photon), $B S_{P o l}$ - Bremsstrahlung Polarizado, $B S_{\text {Nâo-Pol }}+C P$ Bremsstrahlung não polarizado mais polarímetro Compton, $B S_{N a ̂ o-P o l}-$ Bremsstrahlung não Polarizado.

\begin{tabular}{|c|c|c|c|c|c|c|c|}
\hline $\begin{array}{c}\text { Fonte de } \\
\text { Fótons }\end{array}$ & $\begin{array}{c}\text { Intensidade } \\
\text { Espectral } \\
\gamma \cdot \mathrm{eV}^{-1} \cdot \mathrm{seg}^{-1}\end{array}$ & $\begin{array}{c}\Delta E_{\gamma} / E_{\gamma} \\
{[\%]}\end{array}$ & $\begin{array}{c}P_{\gamma} \text { ou } \\
Q_{\gamma} \\
{[\%]}\end{array}$ & $\begin{array}{c}\text { Massa do } \\
\text { alvo } \\
{[g]}\end{array}$ & $\begin{array}{c}\Gamma_{\text {mim }} \\
{[\mathrm{meV}]}\end{array}$ & $\begin{array}{c}\text { Sens. } \\
\text { Limite } \\
{[\mathrm{meV} \cdot \mathrm{g}]}\end{array}$ & Laboratório \\
\hline$L C P$ & 0.15 & 2.7 & 100 & 70 & 500 & 35000 & Tsukuba* \\
\hline$B S_{P o l}$ & 20 & Contínuo & $10-30$ & 5 & 20 & 100 & $\begin{array}{c}\text { Giessen }- \\
\text { Gent** }\end{array}$ \\
\hline$B S_{\text {Nâo-Pol }}+C P$ & 1000 & Contínuo & $10-20$ & 5 & 10 & 50 & Stuttgart*** \\
\hline$B S_{\text {Nâo-Pol }}$ & 1000 & Contínuo & 0 & $1-2$ & $\leq 1$ & 1 & Darmstadt**** \\
\hline
\end{tabular}

* Ogaki et al., [Oh94]; ** Berg et al., [Be87]; Govaert et al., [Go94]; *** Schlit et al., 1994 [Sc94]; Pitz et al., [Pi89, Pi90]; **** Richter, [Ri90].

Embora o bremsstrahlung seja a fonte mais intensa empregada para gerar fótons, este apresenta algumas inconveniências. Aparece um incremento exponencial do background de fótons a baixas energias devido a espalhamentos não ressonantes, pelo que se reduz a probabilidade de detectar estados de energias baixas. Nos experimentos com bremsstrahlung polarizado, onde é necessário um "end point" de mais energia para alcançar uma intensidade espectral elevada, o espectro contínuo até energias maiores excita muitos estados de energias mais altas, que decaem a níveis menos energéticos, povoando estes últimos de forma mais intensa que a fotoexcitação direta, o que pode levar a determinações errôneas das seções de choque, dos spins e das paridades [Go94, $\mathrm{Ju} 95]$. 


\section{Capítulo 5}

\section{Medidas das Secções de Choque de produção de Bremsstrahlung}

\subsection{Irradiações dos Alvos e espectros}

Foram irradiados alvos de Ag e Au (Tabela 5.1) preparados no Laboratório de Alvos do Departamento de Física Nuclear do IFUSP. Os mesmos foram colocados em um suporte retangular de aço $(30 \times 10 \times 0,5 \mathrm{~mm})$ com um furo no centro de $\phi=7 \mathrm{~mm}$ onde ficava o alvo. Este suporte é mantido no centro da câmara de irradiação por uma torre de alvos, também de aço $(40 \times 25 \times 1 \mathrm{~mm})$, e pode ser removido de posição mediante uma translação vertical sem quebra de vácuo na câmara de irradiação, deixando incidir o feixe no alvo ou diretamente no Copo de Faraday. Os espectros de bremsstrahlung foram medidos com o detector de HPGe colocado a $30^{\circ}$ e $60^{\circ}$ em relação à direção do feixe de elétrons. Para $60^{\circ}$, foram irradiados três alvos de Au com o fim de estudar a influência da espessura nas medidas. A corrente do feixe foi fixada a valores que mantiveram o tempo morto do sistema de medidas menor que $10 \%$, e oscilou entre $20-$ 50 nA. Para corrigir qualquer possível variação da corrente durante as medidas, a carga total depositada no Copo de Faraday no tempo de coleção dos espectros foi dividida por um fator de correção de carga, determinado como a relação entre a carga com alvo e sem alvo no feixe de elétrons. Os valores desse fator para os respectivos alvos são apresentados na última coluna da Tabela 5.1. Dois tipos de espectros foram coletados para estudar o background: com feixe incidindo no copo de Faraday (CF) diretamente e outro situando o suporte de aço sem alvo na posição de irradiação (BG). As figuras 5.1 e 5.2 apresentam os espectros obtidos para $30^{\circ}$ e $60^{\circ}$ respectivamente. Observa-se a queda brusca nas contagem para a região de maior energia dos espectros medidos a $30^{\circ}$. Após a análise dos espectros sem alvo, percebemos que estes não podem ser considerados como espectros de "background", o que será discutido no item 5.3, porque não leva em conta fatores como o retro-espalhamento na câmara e no suporte de alvos 
dos fótons produzidos nos alvos, assim como dos fótons produzidos pela interação com a câmara dos elétrons desviados pelo alvo. Uma ampliação na região de maior energia dos espectros a $30^{\circ}$, desde 1700 ate $1950 \mathrm{keV}$, mostra a excelente definição da zona do tip, assim como a influência do espectro de background (Figuras 5.3 - 5.4).

Tabela 5.1 Espessura dos alvos irradiados e o respectivo fator de coleção de carga. A incerteza na espessura foi estimada em $4 \%$.

\begin{tabular}{|c|c|c|}
\hline Material do Alvo & Espessura $\left(\boldsymbol{\mu g} \mathbf{~ c m}^{-\mathbf{2}}\right)$ & Fator de coleção de carga \\
\hline $\mathrm{Ag}$ & 365 & $0,81 \pm 0,03$ \\
\hline $\mathrm{Au}$ & 131 & $0,98 \pm 0,02$ \\
\hline $\mathrm{Au}$ & 459 & $0,77 \pm 0,02$ \\
\hline $\mathrm{Au}$ & 609 & $0,66 \pm 0,02$ \\
\hline
\end{tabular}

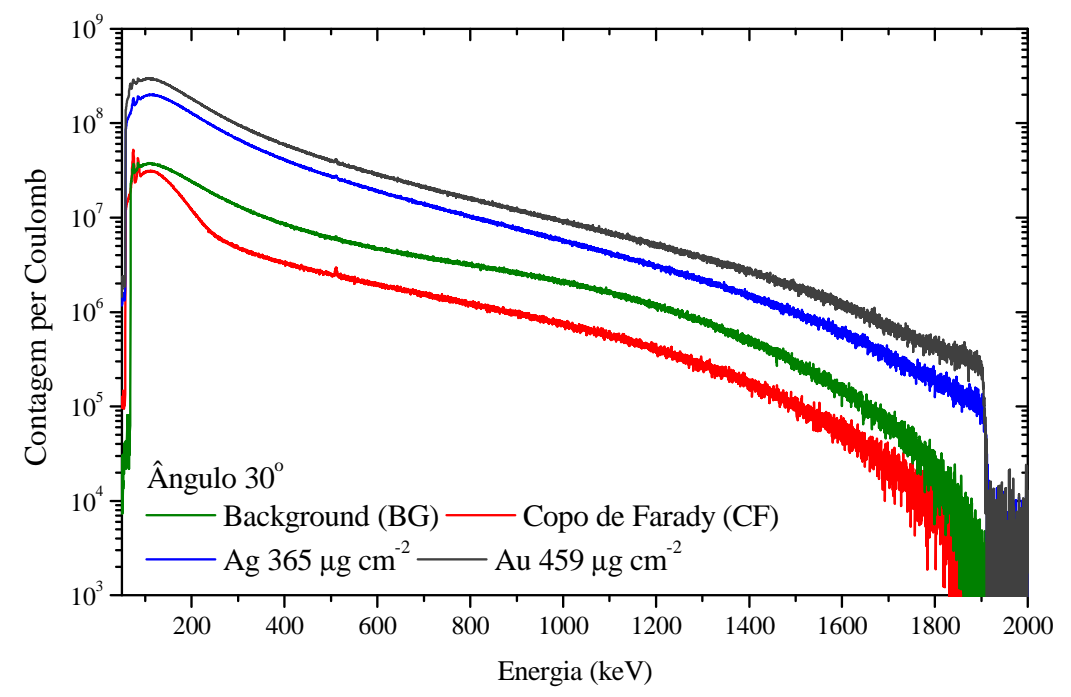

Fig. 5.1 Espectros medidos para Ag e Au, o background (BG) sem alvo e o Copo de Faraday (CF) a $30^{\circ}$.

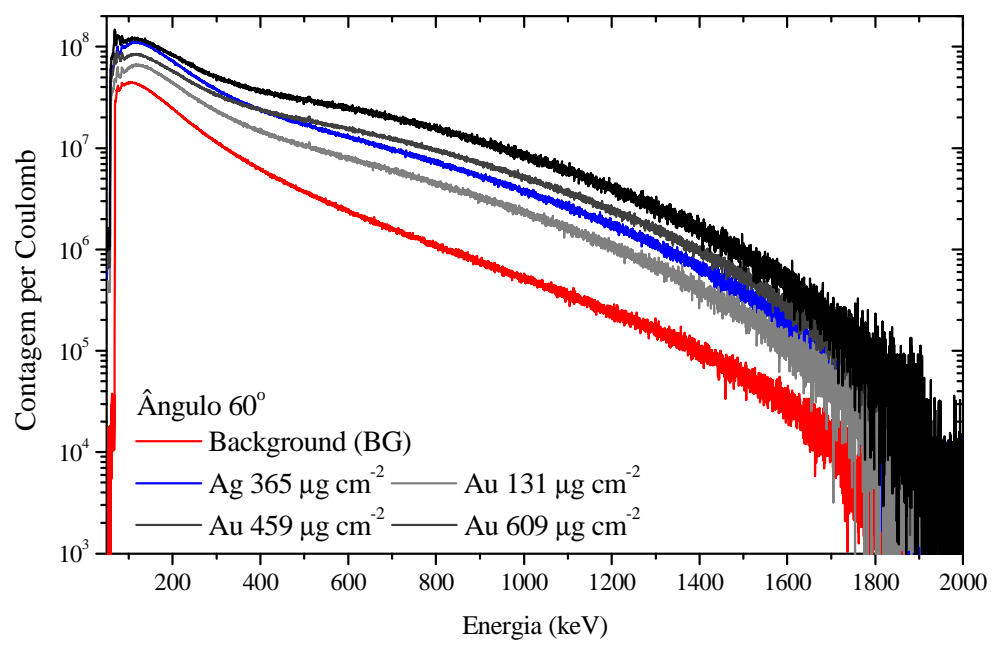

Fig. 5.2 Espectros medidos para Ag e Au, e o background (BG) sem alvo a $60^{\circ}$. 


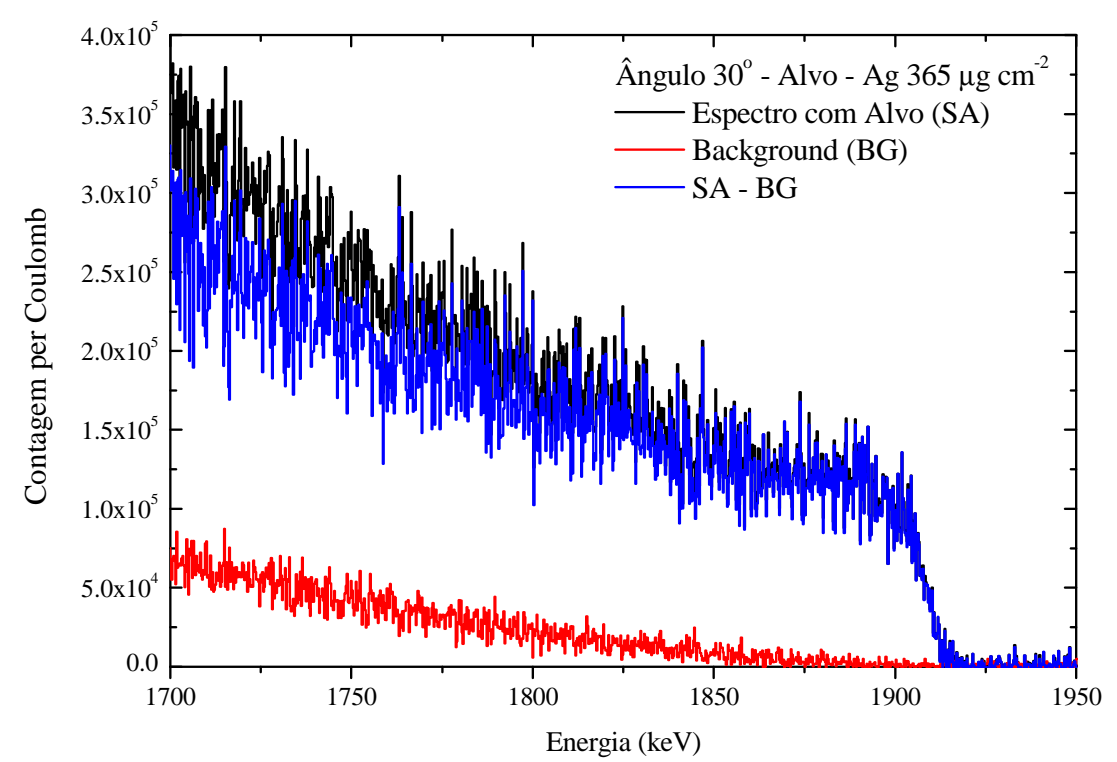

Fig. 5.3 Região de maior energia do espectro de $\mathrm{Ag}$ a $30^{\circ}$.

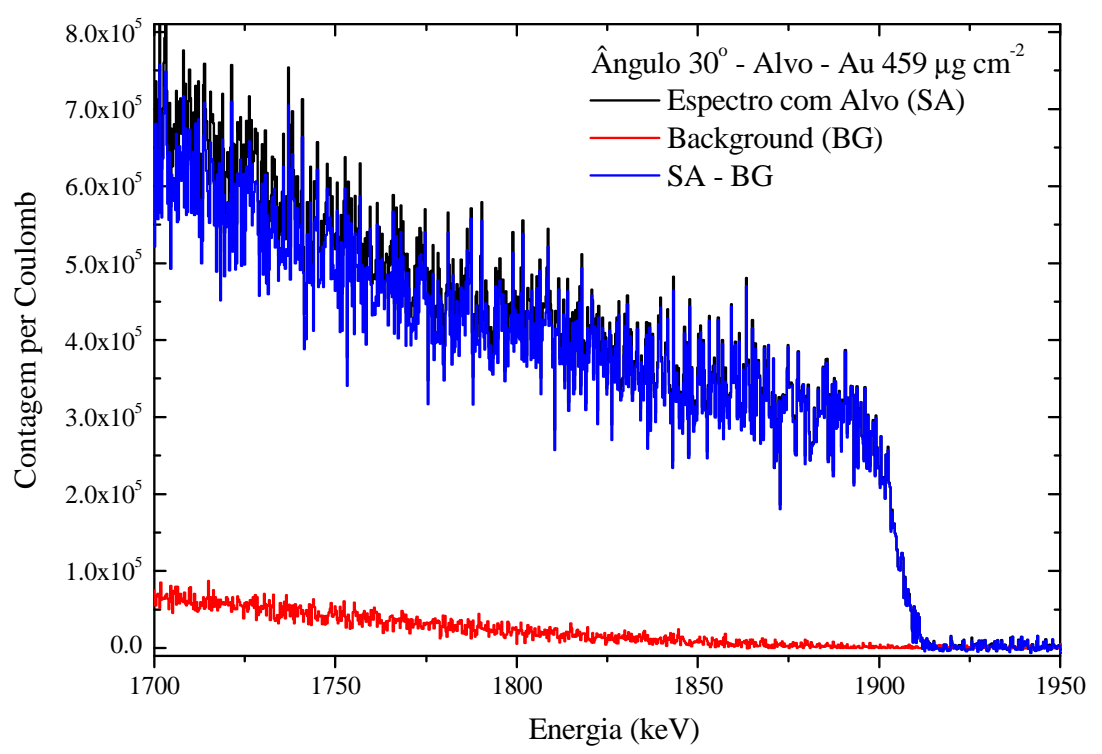

Fig. 5.4 Região de maior energia do espectro de Au a $30^{\circ}$.

\subsection{Teste do procedimento de deconvolução}

Para testar o procedimento matemático de inversão, multiplicação, e construção da matriz $\mathbb{R}$, para o qual foi desenvolvido um programa em Fortran G95 [G95], estimaram-se, com o código MCNPX, os fluxos de fótons do alvo de Ag que se propagam em direção ao detector, representados na figura 5.5 como "incidente", e, 
posteriormente, os espectros observados. Então foi realizado o procedimento de deconvolução para determinar $\mathbb{B}$. As principais diferenças entre os fluxos incidentes e os resultantes de aplicar a eq. 4.6, encontram-se na região de baixas energias. Para a geometria de $30^{\circ}$ e energias superiores a $200 \mathrm{keV}$, as discrepâncias são sempre menores que $10 \%$, e para $60^{\circ}$ esse limite é $250 \mathrm{keV}$. Existem duas razões principais que podem explicar o incremento da discrepância a energias menores: (a) a variação mais brusca de curva de eficiência, o que contradiz a suposição de parâmetros constantes nos intervalos de $50 \mathrm{keV}$, (b) as incertezas no procedimento de deconvolução vão sendo acumuladas na região de menores energias. Nos cálculos, as secções de choque serão corrigidas partindo destas diferenças.

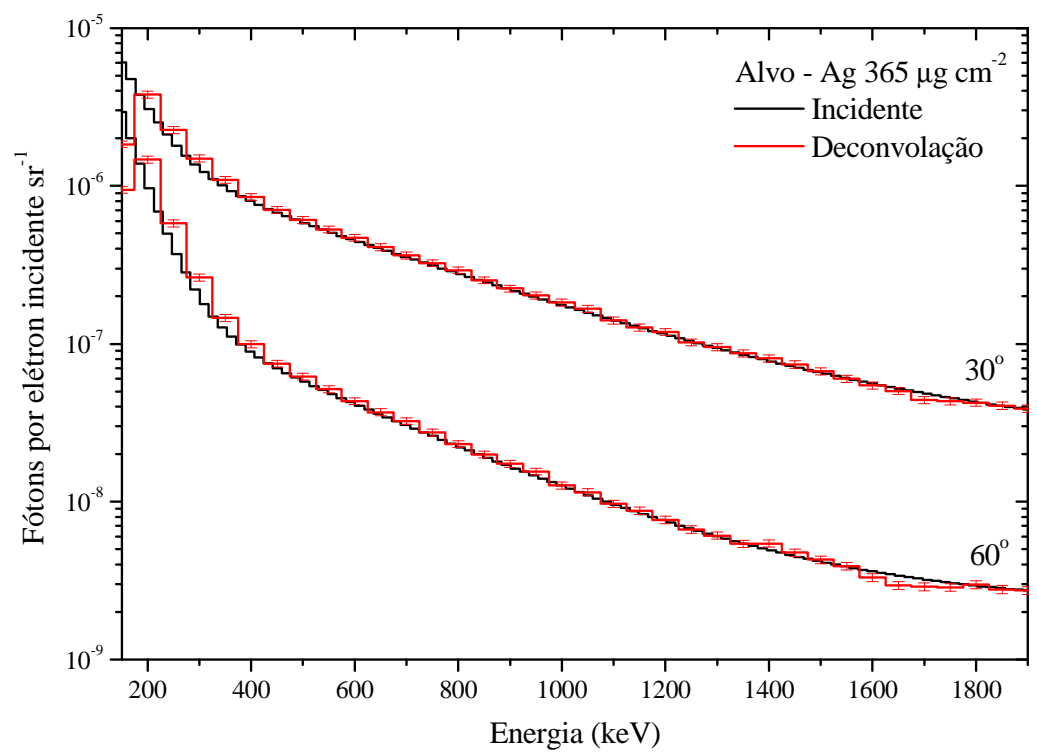

Fig. 5.5 Teste do procedimento de deconvolução. Comparação entre os fluxos de fótons incidentes e a deconvolução para o alvo de Ag, para os dois ângulos estudados.

\subsection{Secções de choque. Estimativa do background}

Os resultados obtidos para as secções de choque usando como fundo radioativo os espectros de background (BG) mostram que para $30^{\circ}$ na região do tip, figuras 5.6 e 5.7, existe uma boa concordância com os dados previstos pelos códigos MCNPX e PENELOPE. No caso de MCNPX, os pontos correspondem a simulações onde são especificados os alvos com as espessuras anteriormente descritas, com o emprego da biblioteca de elétrons el03. Para o código PENELOPE, os valores correspondem ao algoritmo de interpolação das tabelas de Seltzer e Berger [Se86]. Nos dois códigos, foi 
suposta uma energia de 1,9 MeV para os elétrons incidentes. Na realidade a energia do feixe resultou um pouco superior a $1900 \mathrm{keV}$, como evidencia a queda da curva de secção de choque. Na literatura consultada não foram encontrados resultados experimentais com a resolução energética obtida em nosso trabalho [Fa58, Fa59a, Pr60, Pr75, Ja64, St72, Da72, O178, Bo82, Fe83].

Para $60^{\circ}$ nesta mesma região do tip, figuras 5.8 e 5.9, os dados só concordam para energias maiores, onde os resultados tendem a ser menores que os previstos pelos códigos de MC. Para energias menores que $1800 \mathrm{keV}$ a influência de um "background adicional" não levado em conta pode ser a explicação da discordância encontrada, o que fica mais claro na figura 5.8 com a mudança no comportamento dos resultados experimentais dessa energia para baixo. Para energias menores que $1700 \mathrm{keV}$ a discrepância incrementa-se, o que também acontece no espectro a $30^{\circ}$. Isto motivou um estudo das causas do incremento no fundo.

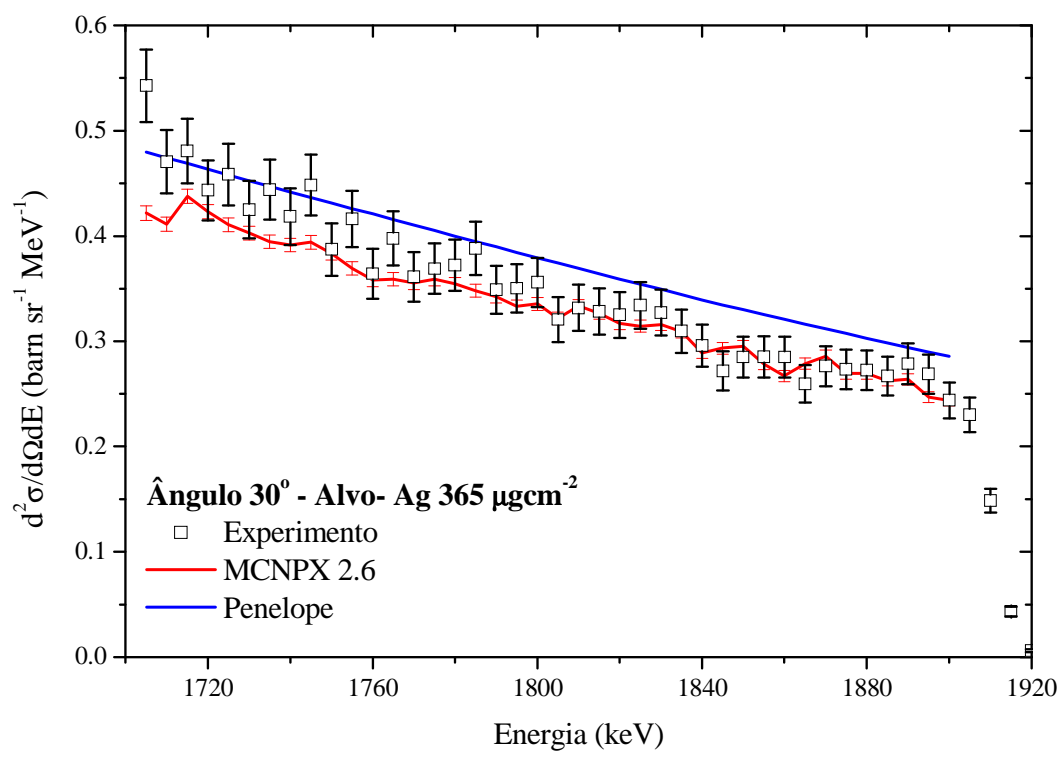

Fig. 5.6 Comparação entre o resultado experimental da secção de choque na região do tip e as previstas por MCNPX e PENELOPE para o alvo de Ag a $30^{\circ}$. Incertezas da simulação pelo MCNPX menores que $10 \%$. 


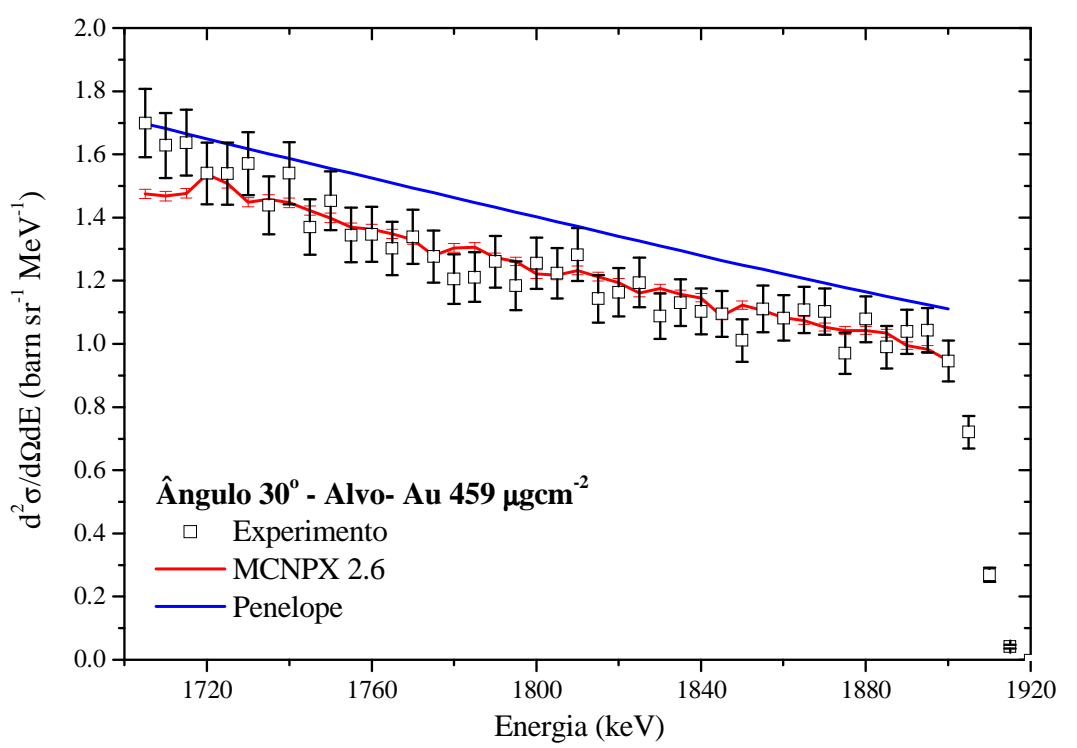

Fig. 5.7 Comparação entre o resultado experimental da secção de choque na região do tip e as previstas por MCNPX e PENELOPE para o alvo de Au a 30 . Incertezas da simulação pelo MCNPX menores que $10 \%$.

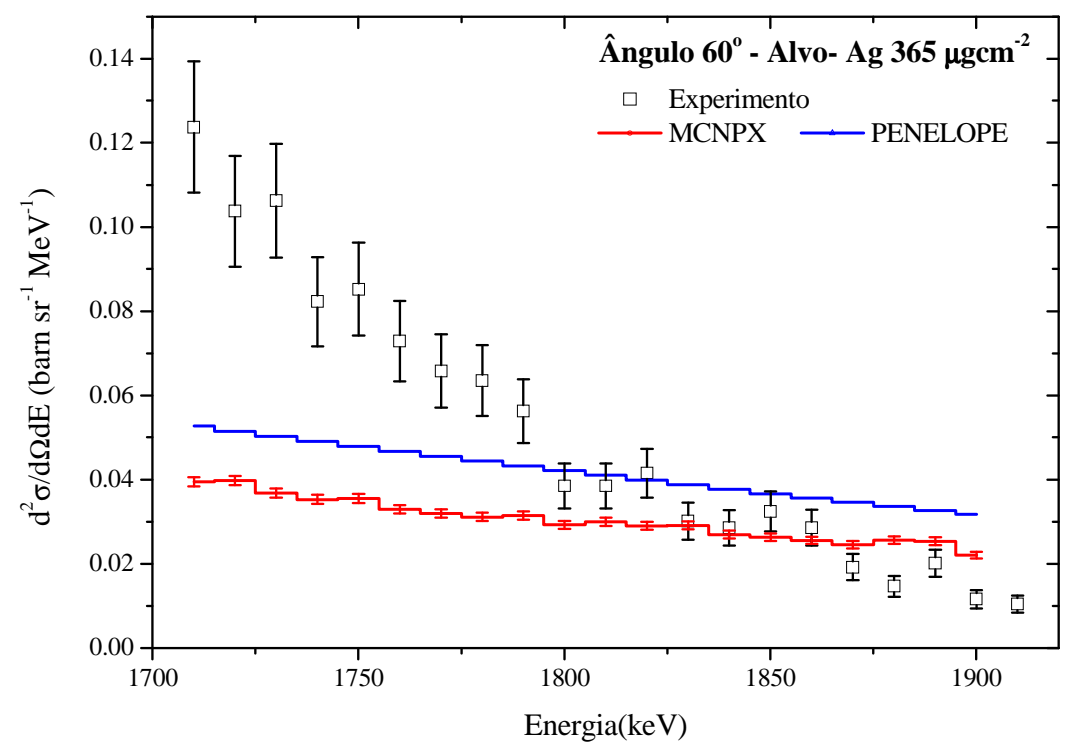

Fig. 5.8 Comparação entre o resultado experimental da secção de choque na região do tip e as previstas por MCNPX e PENELOPE para o alvo de Ag a $60^{\circ}$. Incertezas da simulação pelo MCNPX menores que $10 \%$. 


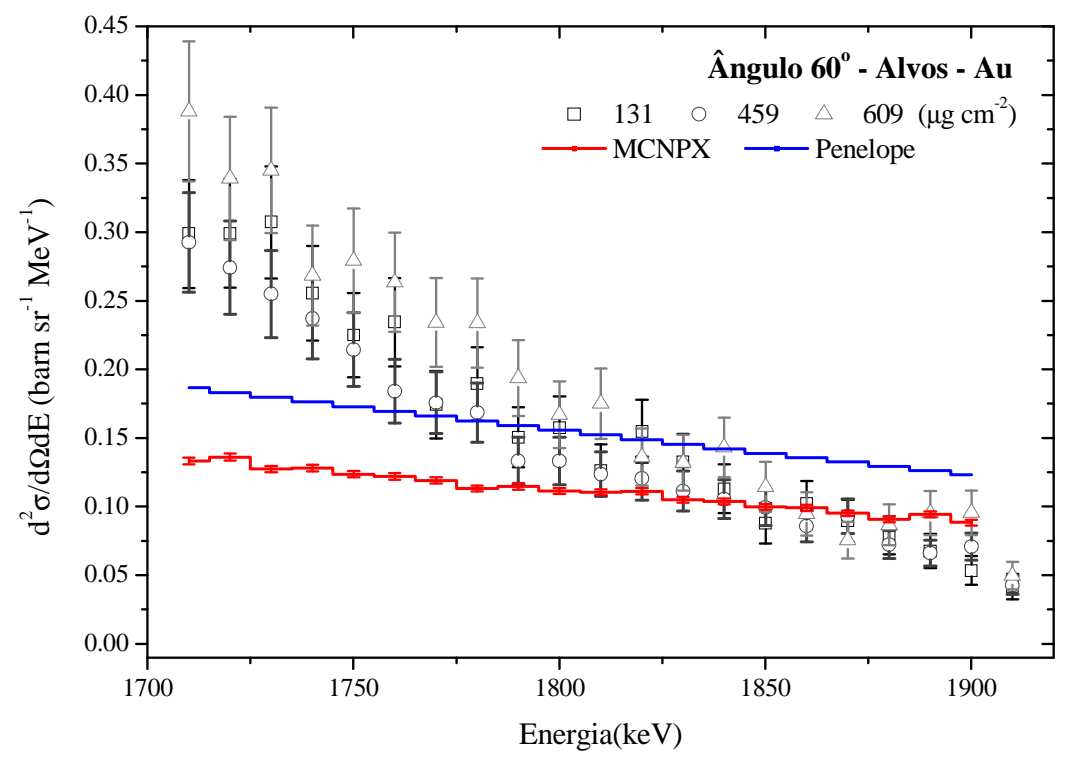

Fig. 5.9 Comparação entre o resultado experimental da secção de choque na região do tip e as previstas por MCNPX e PENELOPE para os alvos de Au a $60^{\circ}$. Incertezas da simulação pelo MCNPX menores que $10 \%$.

A primeira análise foi estimar por MCNPX a contribuição do bremsstrahlung provocado pelos elétrons que eram desviados do feixe ao interagir com o alvo, e se propagabam em direção ao detector. O resultado, exemplificado para o alvo de Ag na figura 5.10, mostrou que este aporte era bem pequeno e, portanto, não explicava o background.

Uma medida adicional foi realizada para estudar a influência dos elétrons espalhados no canal de saída do feixe de elétrons, onde fica o Copo de Faraday. O espectro de fótons, com o suporte do alvo na posição de irradiação, foi medido incidindo o feixe no Copo de Faraday para duas situações: com a geometria original de irradiação e colocando um colimador cilíndrico de grafite $(\phi=1,8 \mathrm{~cm}, \mathrm{~L}=6,0 \mathrm{~cm})$ entre o suporte do alvo e o Copo, portanto evitando o espalhamento dos elétrons no aço desse canal de saída. Foi também monitorada a corrente no suporte do alvo, eletricamente isolado. Da primeira à segunda situação a corrente no suporte diminuiu 35 $\%$, mas o número total de contagens gama por elétron incidente praticamente não teve variação, de $(3,004 \pm 0,062) \times 10^{-9}$ contagens $/ \mathrm{e}^{-}$para $(3,049 \pm 0,062) \times 10^{-9}$ contagens $/ \mathrm{e}^{-}$, indicando que a contribuição desses elétrons aos espectros não é significativa. Por outro lado, as simulações mostram uma probabilidade bem baixa de que os fótons produzidos no Copo de Faraday atravessem o furo do colimador e cheguem até o detector. Foi 
assim que surgiu a hipótese de que parte do feixe de elétrons estivesse batendo no suporte do alvo, e como sua espessura é muito maior que a dos alvos então, mesmo que essa fração de elétrons seja bem pequena, a contribuição ao bremsstrahlung medido pode ser significativa. Para determinar o valor desta fração foi estudada a variação dos espectros de $\mathrm{BG}$ a $30^{\circ}$ e $60^{\circ}$ em função da largura ou FWHM do feixe de elétrons. A figura 5.11 apresenta a média para todas as energias dos fótons, do desvio relativo entre as simulações e os resultados experimentais. Tanto para $30^{\circ}$ como para $60^{\circ}$ observa-se um mínimo em FWHM = 2,125 mm, valor que foi fixado para o FWHM do feixe, e significa que por cada $2834 \pm 282$ elétrons que batem no Copo de Faraday um deles bate no porta alvo. É importante sublinhar que, com o suporte de alvo usado, uma pequena mudança na largura do feixe pode produzir mudanças bruscas nos espectros de bremsstrahlung, pelo que é recomendado utilizar um suporte com um furo de maior diâmetro.

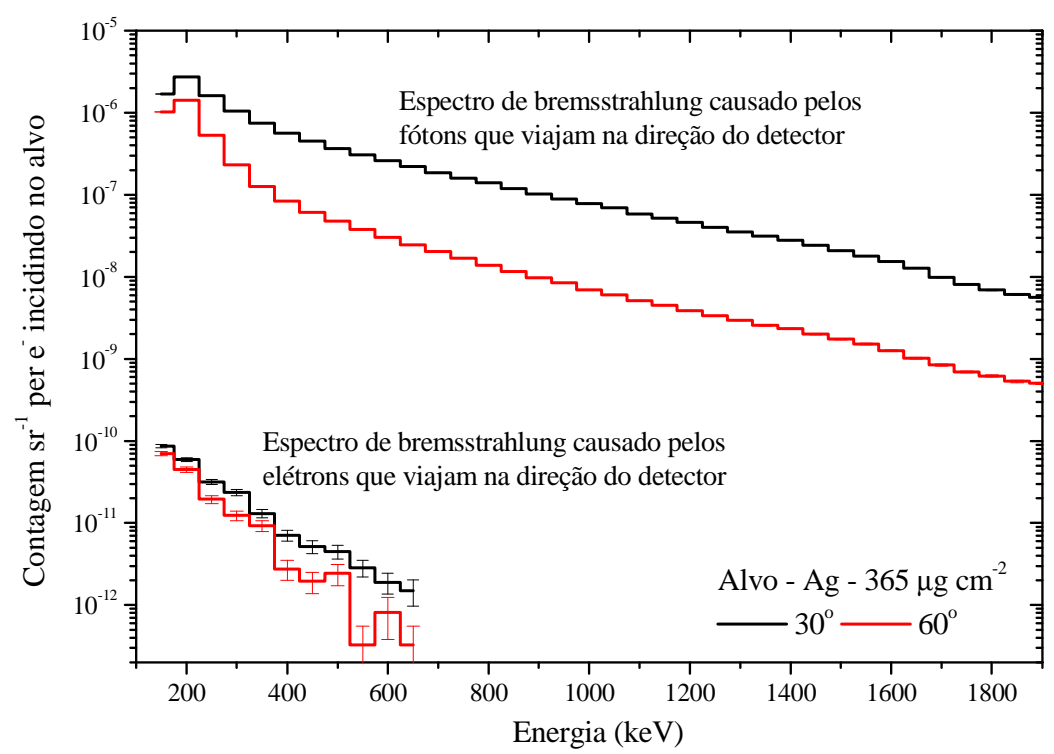

Fig. 5.10 Comparação do espectro simulado devido aos elétrons e fótons que se propagam em direção ao detector de HPGe para o alvo de Ag nos dois ângulos estudados. 


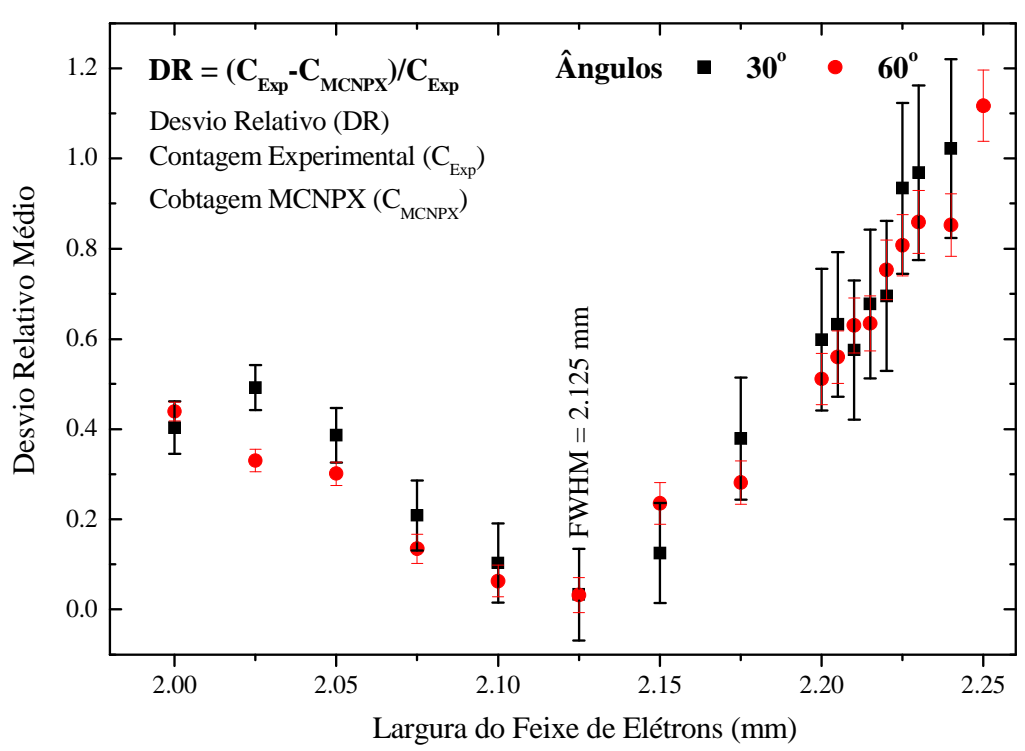

Fig. 5.11 Média do desvio relativo entre os espectros de BG obtidos mediante simulações por MC e os experimentais para $30^{\circ}$ e $60^{\circ}$.

Foi estudada também a contribuição dos fótons retro-espalhados na câmara e no porta alvo no espectro medido no detector. Para isto, foi estimado o fluxo de fótons que se propaga em direção ao detector com e sem câmara de irradiação na geometria de entrada do MCNPX, e com esses fluxos foram então determinados os espectros no detector. Como se apresenta na figura 5.12 para o alvo de $\mathrm{Au}\left(459 \mu \mathrm{g} \mathrm{cm} \mathrm{cm}^{-2}\right.$, as principais diferenças são encontradas a baixas energias, sendo estas muito mais acentuadas para o ângulo de $60^{\circ}$. Esta contribuição pode ser diminuída pelo aumento das dimensões da câmara, mas, tendo em conta o espaço disponível na sala de irradiação isso é pouco aconselhável, de modo que sugere-se incrementar o comprimento do colimador de $\mathrm{Pb}$, o que reduz o ângulo sólido $\Omega$ com que o alvo subtende o detector. Os efeitos combinados do espalhamento na câmara e dos elétrons interagindo no suporte do alvo também são mostrados na Fig. 5.12. Para $60^{\circ}$ observa-se um incremento considerável no background não só para as baixas energias, o que explica as diferenças apresentadas nas figuras 5.8 e 5.9 . 


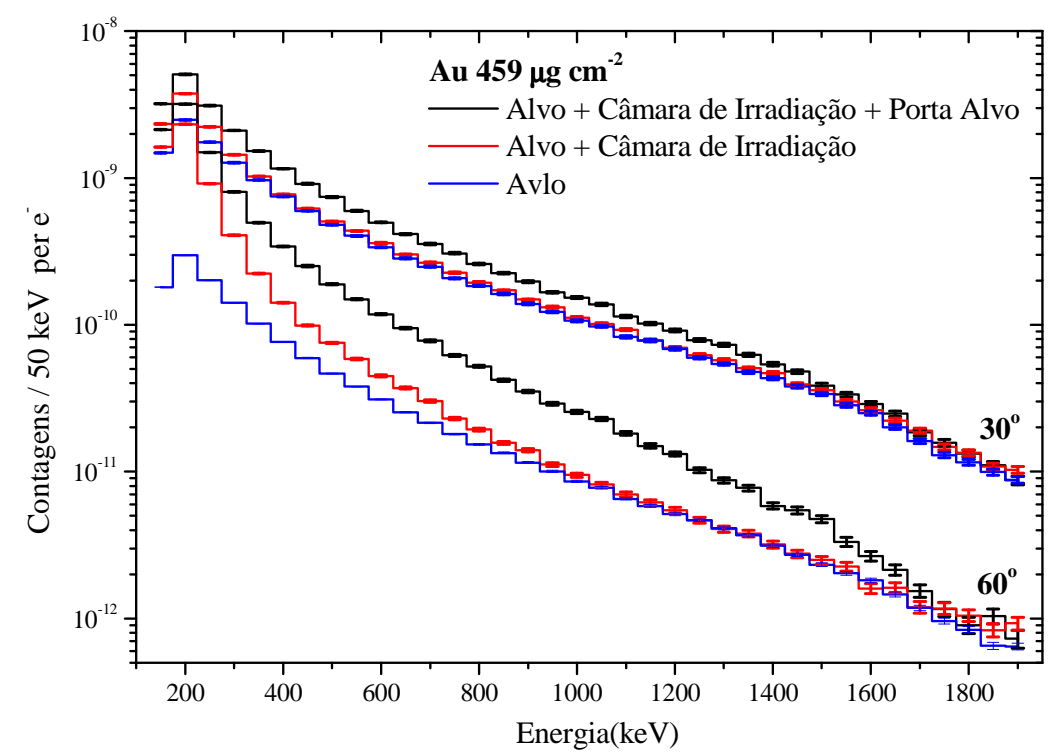

Fig. 5.12 Comparação entre os espectros estimados no detector de HPGe, especificando ou não a câmara de irradiação e o suporte do alvo na geometria de entrada do MCNPX.

Os resultados para secções de choque em todo o espectro energético são apresentados a seguir, comparando com os resultados de MCNPX e PENELOPE. Estes resultados incluem as correções de background explicadas anteriormente assim como a contribuição dos fótons que emergem da blindagem do Copo de Faraday. Para $30^{\circ}$, figuras 5.13 e 5.14, e energias superiores a $1400 \mathrm{keV}$, existe concordância entre todas as curvas, mas com a diminuição da energia os valores sem correção separam-se dos estimados pelos códigos de MC. A correção feita consegue diminuir esta diferença, mas não numa proporção que estes concordem totalmente com as simulações.

Para $60^{\circ}$, as correções realizadas não conseguem reproduzir o comportamento reportado das secções de choque como mostram as figuras 5.15 e 5.16, principalmente para os espectros dos alvos de Au mais grossos. Neste ângulo, as secções de choque são uma ordem de grandeza menor que para $30^{\circ}$, razão pela qual o background é muito mais importante. Achamos que esta diferença é devida a fótons de bremsstrahlung produzidos nos alvos e que são espalhados nos diferentes elementos do arranjo experimental, já que, com o incremento da espessura e do numero atômico do material, esta discordância é maior, ainda depois de realizadas as correções mencionadas. 


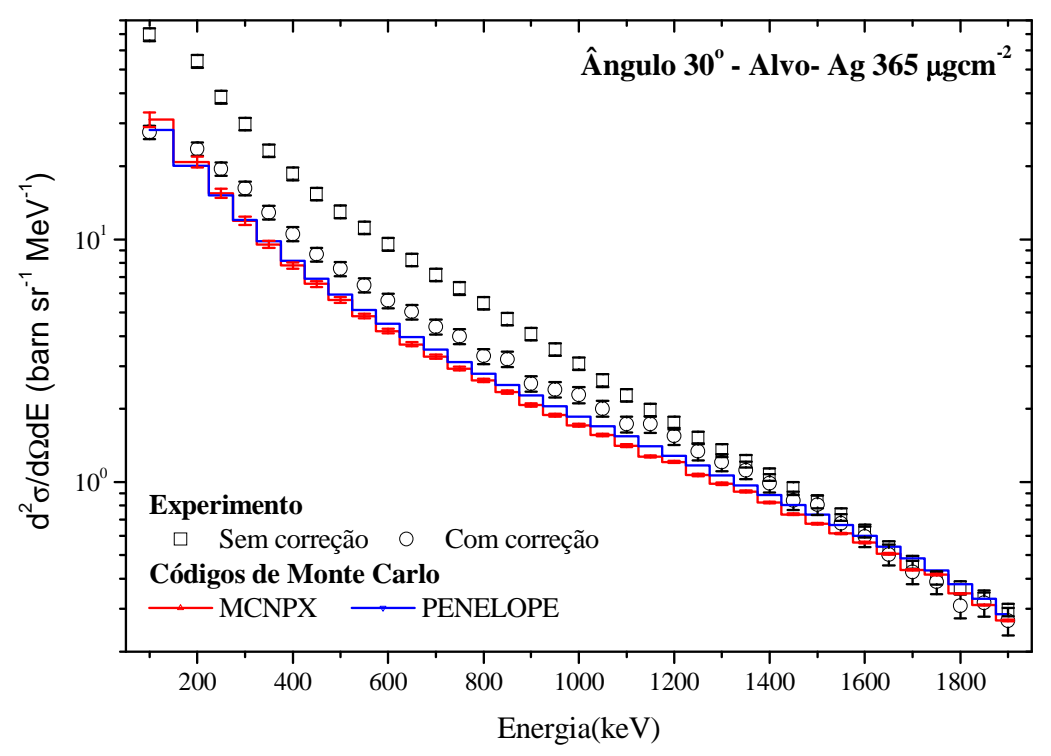

Fig. 5.13 Comparação entre o resultado experimental da secção de choque e as previsões calculadas por MCNPX e PENELOPE para o alvo de Ag a $30^{\circ}$.

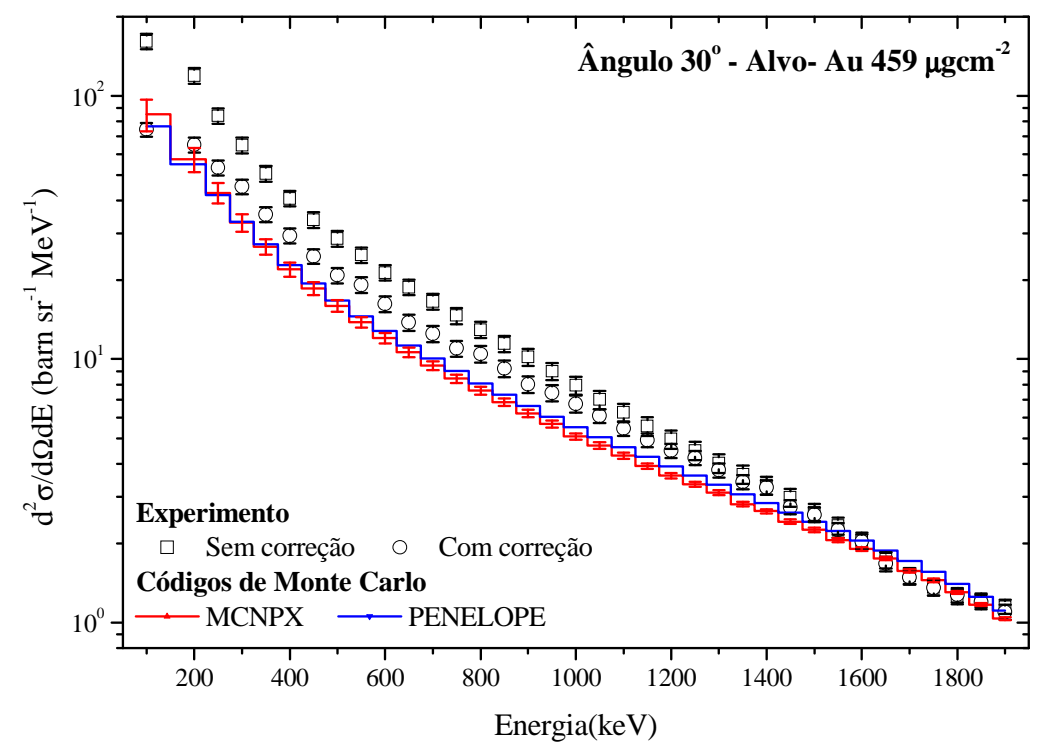

Fig. 5.14 Comparação entre o resultado experimental da secção de choque e as previsões calculadas por MCNPX e PENELOPE para o alvo de Au a $30^{\circ}$. 


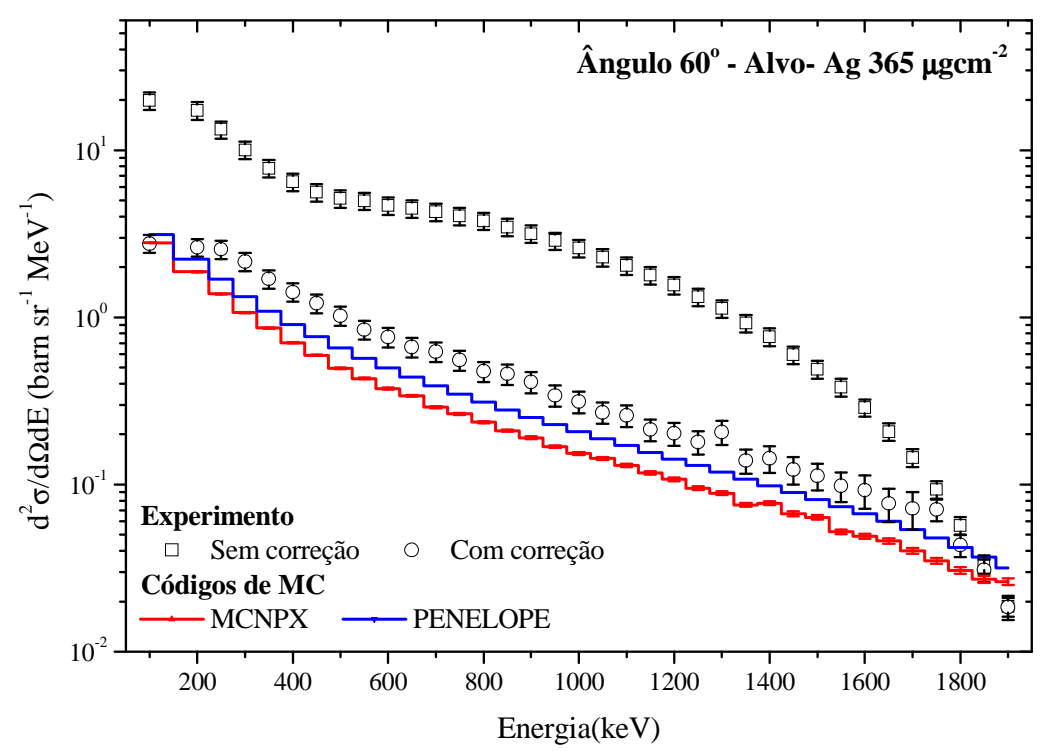

Fig. 5.15 Comparação entre o resultado experimental da secção de choque e as previsões calculadas por MCNPX e PENELOPE para o alvo de Ag a $60^{\circ}$.

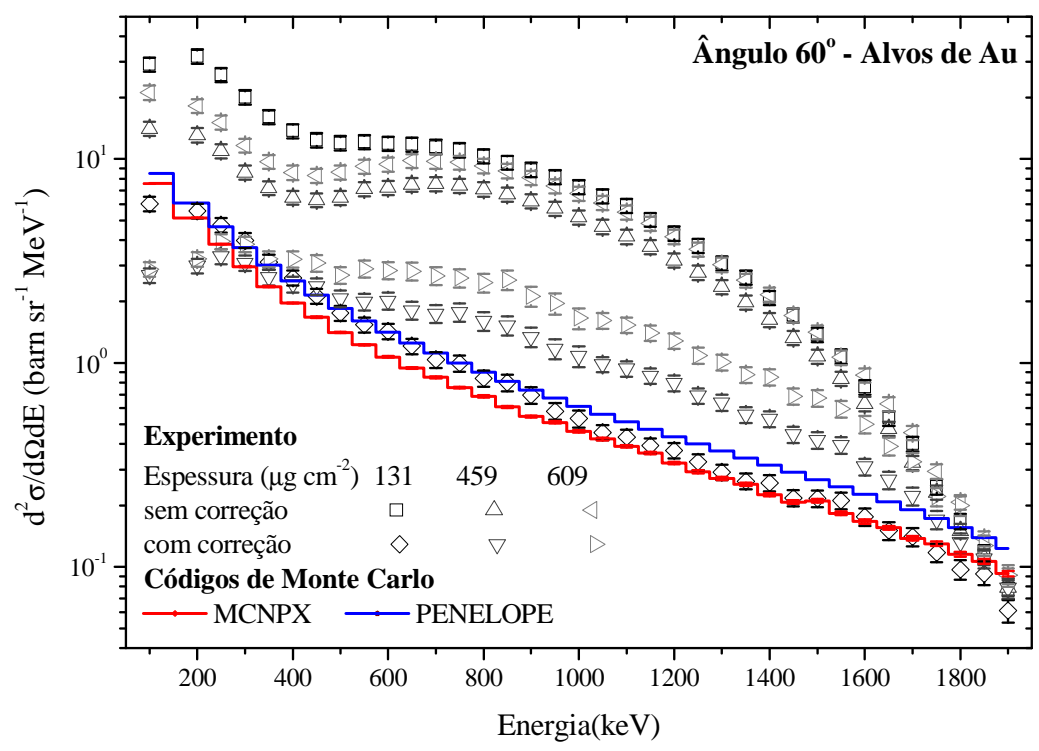

Fig. 5.16 Comparação entre o resultado experimental da secção de choque e as previsões calculadas por MCNPX e PENELOPE para os alvos de Au a $60^{\circ}$. 


\section{Capítulo 6}

\section{Arranjo para experimentos de NRF optimizado por simulação}

\subsection{Introdução}

O objetivo da simulação do sistema de medidas de NRF do LAL é encontrar a geometria, os parâmetros e os materiais ótimos para cada um dos elementos que formam o sistema. Uma vez determinadas as variantes mais adequadas, será realizada a avaliação do desempenho de todos os elementos operando em conjunto. Para fazer este estudo foi consultada uma ampla bibliografia, onde estão descritas as principais características dos sistemas de NRF mais referenciados internacionalmente [Go94, Kn96, Br01, Be01, Re97, Mo99, Sc05, Wa05]. Uma breve descrição desses sistemas está no Anexo I.

O sistema de medidas de NRF foi planejado para os elétrons incidentes de $10 \mathrm{MeV}$ de energia, típica desses estudos. Porém, foram levados em consideração diferentes detalhes para poder usar o sistema com elétrons de outras energias, uma vez que o Microtron poderá gerar elétrons com energias de 5 a $38 \mathrm{MeV}$ (Anexo IV).

Os seguintes componentes foram estudados separadamente:

(1) Fonte de fótons: Nesta primeira etapa foram simuladas diversas variantes de radiadores para produzir os fótons de bremsstrahlung. As variantes incluíram diversos materiais e espessuras. A simulação estudou a intensidade dos fótons, sua distribuição angular e a geração de nêutrons por reações $(\gamma, n)$.

(2) Colimador do feixe de fótons: Foi estudada a intensidade e a largura do feixe de fótons, na posição onde deverá ficar o alvo de NRF e foram comparadas variantes de colimadores. Estas variantes diferem em material e geometria (comprimento, diâmetros de entrada e de saída). Igualmente foi analisada a produção de nêutrons. 
(3) Blindagem dos detectores de HPGe: Para aumentar a relação pico-fundo é necessário blindar os detectores dos fótons espalhados nos diferentes elementos da sala de irradiação, portanto estudou-se o efeito do incremento da blindagem no número de fótons que chegam ao detector.

(4) Coletor do Feixe de Fótons: Da mesma maneira, com o objetivo de diminuir o background dos fótons espalhados nos elementos circundantes (paredes, suportes, equipamento auxiliar) foram simuladas variantes do coletor do feixe de fótons, buscando fazer mínima a radiação emergente deste, sem incrementar o background de nêutrons.

A última seção deste capítulo mostra uma simulação do sistema completo para ilustrar o papel combinado do colimador e do coletor em reduzir o background. A estimativa da fluência e da forma do espectro de fótons onde ficará o alvo de NRF, junto com a previsão da sensibilidade do arranjo, ficaram para o capítulo de discussão, seção 7.2.

\subsection{Fonte de fótons}

Neste estudo foi analisada a intensidade e a distribuição angular do bremsstrahlung gerado por um feixe paralelo de elétrons de energia $E_{e}$ que incide sobre um radiador. Igualmente foi estudada a energia depositada pelo feixe no radiador e a produção de fotonêutrons.

\subsubsection{Características das simulações realizadas.}

O raio do feixe de elétrons foi escolhido igual ao raio esperado para o feixe do acelerador do LAL, 0,1 cm. Vários elementos geralmente empregados como radiadores nas referências consultadas foram testados: $\mathrm{Cu}, \mathrm{W}, \mathrm{Ta}, \mathrm{Nb}$ e $\mathrm{Au}$, com espessuras de 5 até $2000 \mathrm{mg} / \mathrm{cm}^{2}$.

No Anexo II são mostradas as características principais dos materiais usados na simulação (densidade, composição isotópica, energia limiar das reações $(\gamma, n)$ e $(\gamma, p)$ ).

A intensidade de bremsstrahlung foi amostrada dentro de um cone de $5 \mathrm{mrad}$ em relação ao eixo de simetria do feixe de elétron incidentes. Foi escolhido este ângulo 
pequeno com o objetivo de analisar, principalmente, os fótons que eram emitidos na direção frontal, os quais têm maior probabilidade de alcançar o alvo de NRF. O fluxo de fótons foi dividido em dois intervalos energéticos (0 a $E_{e} / 2$ e $E_{e} / 2$ a $\left.E_{e}\right)$ [Sc05]. A distribuição angular dos fótons emitidos foi amostrada dentro de cones que variam em ângulos de abertura entre $0^{\circ}$ e $100^{\circ}$ com passo de $1^{\circ}$.

A intensidade do feixe foi obtida com o tally F1 (corrente de partículas numa superfície), e os cartões: FS (permite dividir uma célula ou uma superfície em segmentos sem necessidade de mudar a geometria do problema), FM (para expressar os resultados em fótons por $\mu \mathrm{A}$ de corrente dos elétrons incidentes), e FQ (para especificar a ordem de impressão dos resultados no arquivo de saída). O cartão BBREM, que é uma técnica de redução de variância, foi usado para gerar maior número de fótons de alta energia. Além disso, foi estimada a energia depositada no radiador utilizando o tally F6.

O número de nêutrons produzidos em função da espessura do radiador foi obtido com os tallies F2 (fluxo médio numa superfície) e F4 (fluxo médio numa célula). Adicionalmente ao cartão BBREM, foi necessário usar outras técnicas de redução de variância (WWP, WWE, WWN) devido à relativamente pequena probabilidade das reações fotonucleares em comparação com outros tipos de interação dos fótons (produção de pares, efeito Compton.). Empregando o cartão CUT foi incrementada até $5 \mathrm{MeV}$ a energia de corte para os elétrons e os fótons, abaixo da qual cessa o transporte dessas partículas. Tudo isto permitiu aumentar a estatística de nêutrons, e diminuir consideravelmente os tempos de execução dos arquivos.

Foram usadas as bibliotecas de dados $02 \mathrm{p}$ para os fótons, 03e para os elétrons, e as bibliotecas fotonucleares lanl01u, cndc01u, kaeri01u [IAEA] para estimar a produção de nêutrons. No transporte de nêutrons foi usada a biblioteca endf60 [Pe05]. A seguir são apresentados e discutidos os resultados obtidos. Vale reforçar que em todos os casos foram usados tempos de execução que garantiram incertezas relativas menores que $10 \%$. 


\subsubsection{Intensidade e distribuição angular dos Fótons de Bremsstrahlung}

As figuras 6.1 e 6.2 mostram os resultados na variação do fluxo de fótons, emitidos na direção frontal $(5 \mathrm{mrad})$, com a espessura do radiador para elétrons incidentes de energia $E_{e}=10 \mathrm{MeV}$, em dois intervalos energéticos $\left(0\right.$ a $E_{e} / 2$ e $E_{e} / 2$ a $\left.E_{e}\right)$. Como era de se esperar, os gráficos mostram um comportamento que tende à saturação com o incremento da espessura. Para espessuras maiores que a correspondente à saturação, não tem sentido incrementar o tamanho do radiador, porque quase todos os fótons adicionais são emitidos fora dos 5 mrad (Fig. 6.3 e Tabela 6.1). Em geral, a espessura de saturação em $\mathrm{mg} / \mathrm{cm}^{2}$, é praticamente a mesma para todos os materiais. Nos casos do $\mathrm{Cu}$ e $\mathrm{Nb}$, devido ao menor número atômico, é observado um menor fluxo, principalmente na faixa de maior energia do espectro $\left(E_{e} / 2<E_{\gamma}<E_{e}\right)$.

A espessura de saturação está aproximadamente entre $300-400 \mathrm{mg} / \mathrm{cm}^{2}$, similar ao reportado por Schwengner et at. [Sc05] numa simulação similar à do presente trabalho usando GEANT3 [Ag03, Al06, Vi07] em Nb e $E_{e}=12 \mathrm{MeV}$, e sugerem o uso de radiadores com menor espessura que a de saturação para que o bremsstrahlung seja produzido em só um passo de interação do elétron, e seja mais fácil estimar a forma do espectro de bremsstrahlung. O acelerador usado por Schwengner alcança uma corrente média de $1 \mathrm{~mA}$, de modo que a redução da espessura do radiador não influi drasticamente na sensibilidade do sistema. No caso de acelerador do LAL, cuja corrente máxima na saída do Microtron principal será de $50 \mu \mathrm{A}$, poderia ser recomendável escolher como espessura ótima para o radiador aquela na qual começa a saturação, porque uma espessura ainda maior implica que os elétrons emergentes do radiador fiquem mais dispersos, seu desvio da direção de incidência fique mais complexo de avaliar e a produção de nêutrons no radiador aumenta. O incremento da energia dos elétrons incidentes logicamente aumenta a espessura de saturação, como é apresentado no Anexo IV. Assim, por exemplo, para $35 \mathrm{MeV}$ de energia, o valor aproximado está entre $400-600 \mathrm{mg} / \mathrm{cm}^{2}$. 


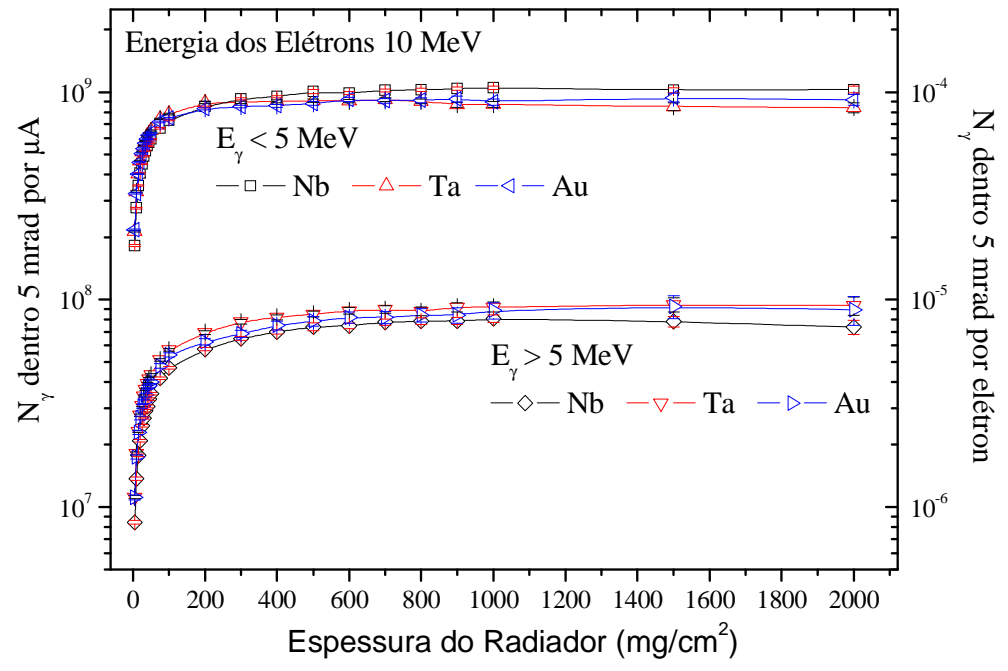

Fig. 6.1 Número de fótons por $\mu \mathrm{A}$ produzidos por elétrons de $10 \mathrm{MeV}$, dentro um ângulo de abertura de $5 \mathrm{mrad}$, em função da espessura de radiadores de $\mathrm{Nb}$, Ta e $\mathrm{Au}$.

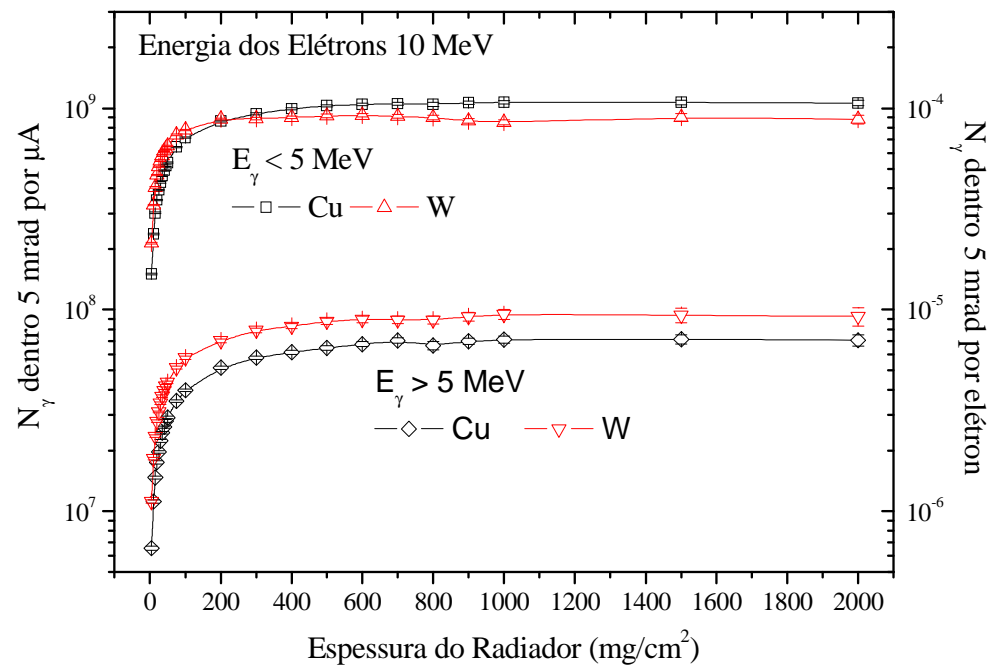

Fig. 6.2 Número de fótons por $\mu \mathrm{A}$ produzidos por elétrons de $10 \mathrm{MeV}$, dentro um ângulo de abertura de $5 \mathrm{mrad}$, em função da espessura de radiadores de $\mathrm{Cu}$ e W.

As figuras 6.3 e 6.4 mostram como varia a emissão dos fótons em função do ângulo de abertura do bremsstrahlung, para três espessuras diferentes dos radiadores. Observa-se que o número de fótons emitidos aumenta com o incremento da espessura, mas este aumento será cada vez maior na região de ângulos maiores (Tabela 6.1). Então, mesmo que o incremento da espessura conduza a um aumento da intensidade na direção frontal, a produção de fótons em outras direções é ainda maior e incrementa o 
background, de modo que escolheram-se radiadores finos para melhorar a relação sinal/ background.

Tabela 6.1. Os fluxos de fótons $\Phi\left(\gamma /\left(\mathrm{s} \mathrm{cm}^{2} \mu \mathrm{A}\right)\right)$ em três ângulos $(5,10,50 \mathrm{mrad})$ para várias espessuras dos radiadores de $\mathrm{Cu}, \mathrm{Nb}$ e Ta estão nas colunas de três à cinco, e as razões entre eles estão nas duas últimas colunas. Os resultados para Au e W são similares aos obtidos para o Ta.

\begin{tabular}{|c|c|c|c|c|c|c|}
\hline \multirow{2}{*}{$\begin{array}{l}\text { Material } \\
\text { do } \\
\text { Radiador }\end{array}$} & \multirow[b]{2}{*}{$\begin{array}{l}\text { Ângulo } \\
\text { (mrad) }\end{array}$} & \multicolumn{3}{|c|}{ Espessura $\left(\mathrm{mg} \mathrm{cm}^{-2}\right)$} & \multirow[b]{2}{*}{$\Phi_{18} / \Phi_{1.8}$} & \multirow[b]{2}{*}{$\Phi_{180} / \Phi_{1.8}$} \\
\hline & & $1.8\left(\Phi_{1.8}\right)$ & $18\left(\Phi_{18}\right)$ & $\begin{array}{c}180 \\
\left(\Phi_{180}\right)\end{array}$ & & \\
\hline \multirow{3}{*}{$\mathrm{Cu}$} & 5 & $5,00 \times 10^{12}$ & $2,71 \times 10^{13}$ & $6,44 \times 10^{13}$ & 5,42 & 12,88 \\
\hline & 10 & $4,74 \times 10^{12}$ & $2,51 \times 10^{13}$ & $6,45 \times 10^{13}$ & 5,30 & 13,63 \\
\hline & 50 & $1,07 \times 10^{12}$ & $1,06 \times 10^{13}$ & $4,51 \times 10^{13}$ & 9,86 & 41,95 \\
\hline \multirow{3}{*}{$\mathrm{Nb}$} & 5 & $6,45 \times 10^{12}$ & $3,17 \times 10^{13}$ & $7,01 \times 10^{13}$ & 4,91 & 10,86 \\
\hline & 10 & $6,32 \times 10^{12}$ & $2,93 \times 10^{13}$ & $6,48 \times 10^{13}$ & 4,64 & 10,25 \\
\hline & 50 & $1,56 \times 10^{12}$ & $1,39 \times 10^{13}$ & $4,88 \times 10^{13}$ & 8,96 & 31,37 \\
\hline \multirow{3}{*}{$\mathrm{Ta}$} & 5 & $9,41 \times 10^{12}$ & $3,46 \times 10^{13}$ & $7,21 \times 10^{13}$ & 3,67 & 7,67 \\
\hline & 10 & $8,02 \times 10^{12}$ & $3,50 \times 10^{13}$ & $6,98 \times 10^{13}$ & 4,36 & 8,70 \\
\hline & 50 & $2,14 \times 10^{12}$ & $1,76 \times 10^{13}$ & $5,20 \times 10^{13}$ & 8,20 & 24,27 \\
\hline
\end{tabular}

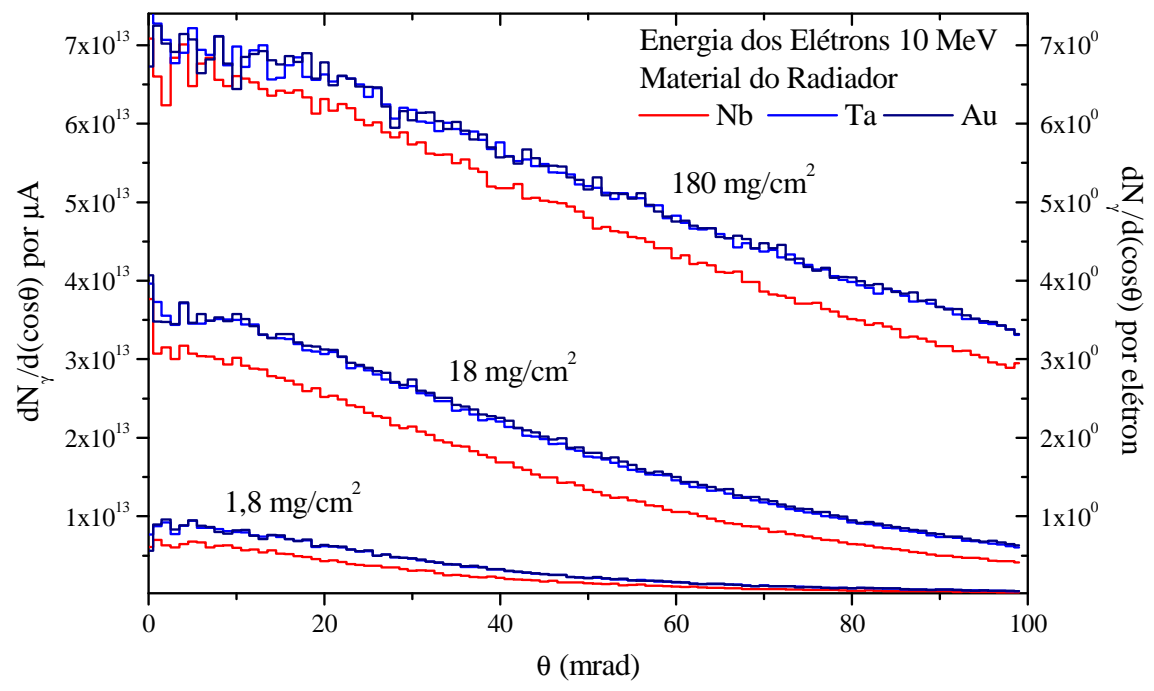

Fig. 6.3 Número de fótons emitidos em diferentes ângulos por radiadores de Ta, $\mathrm{Nb}$ e Au para três espessuras de radiador. 


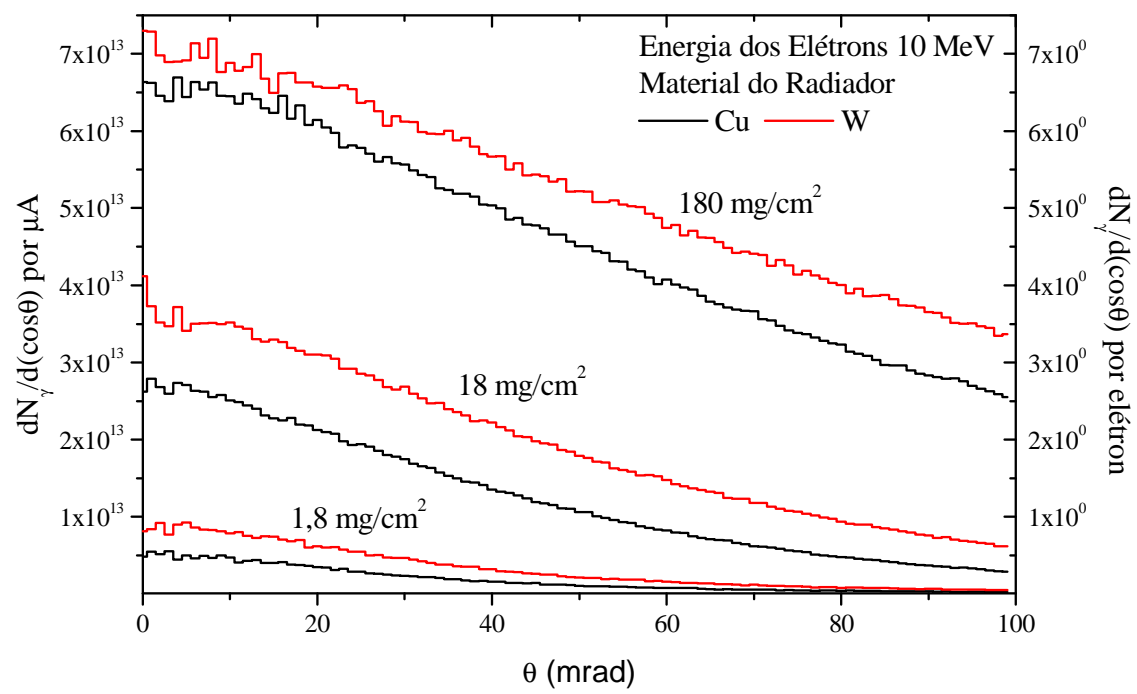

Fig. 6.4 Número de fótons emitidos em diferentes ângulos por radiadores de $\mathrm{Cu}$ e W para três espessuras de radiador.

\subsubsection{Fotonêutrons produzidos no radiador}

Um aspecto importante na escolha do radiador ótimo é a produção de nêutrons, que pode afetar o espectro gama medido nos detectores de HPGe [Mo99]. A figura 6.5 mostra o incremento do número de nêutrons produzidos nos radiadores com o aumento da espessura e do número atômico do material. Para elétrons de $10 \mathrm{MeV}$, praticamente não existe geração de nêutrons no radiador de $\mathrm{Cu}$ porque as energias limiares das reações $(\gamma, n)$ estão bem próximas da energia máxima (Anexo II). Com o incremento da energia dos elétrons (Anexo IV) a produção de nêutrons aumenta consideravelmente, em mais de uma ordem de grandeza quando a energia varia de 10 até $35 \mathrm{MeV}$. Assim, por exemplo, com $35 \mathrm{MeV}$ a produção de nêutrons nos radiadores de $\mathrm{Cu}$ e $\mathrm{Nb}$ é menor que nos radiadores de $\mathrm{Au}, \mathrm{W}$, Ta. Por isto o uso de um radiador de $\mathrm{Cu}$ ou de $\mathrm{Nb}$, mesmo que a intensidade do bremsstrahlung não seja a maior possível, é recomendável em experimentos de NRF. 


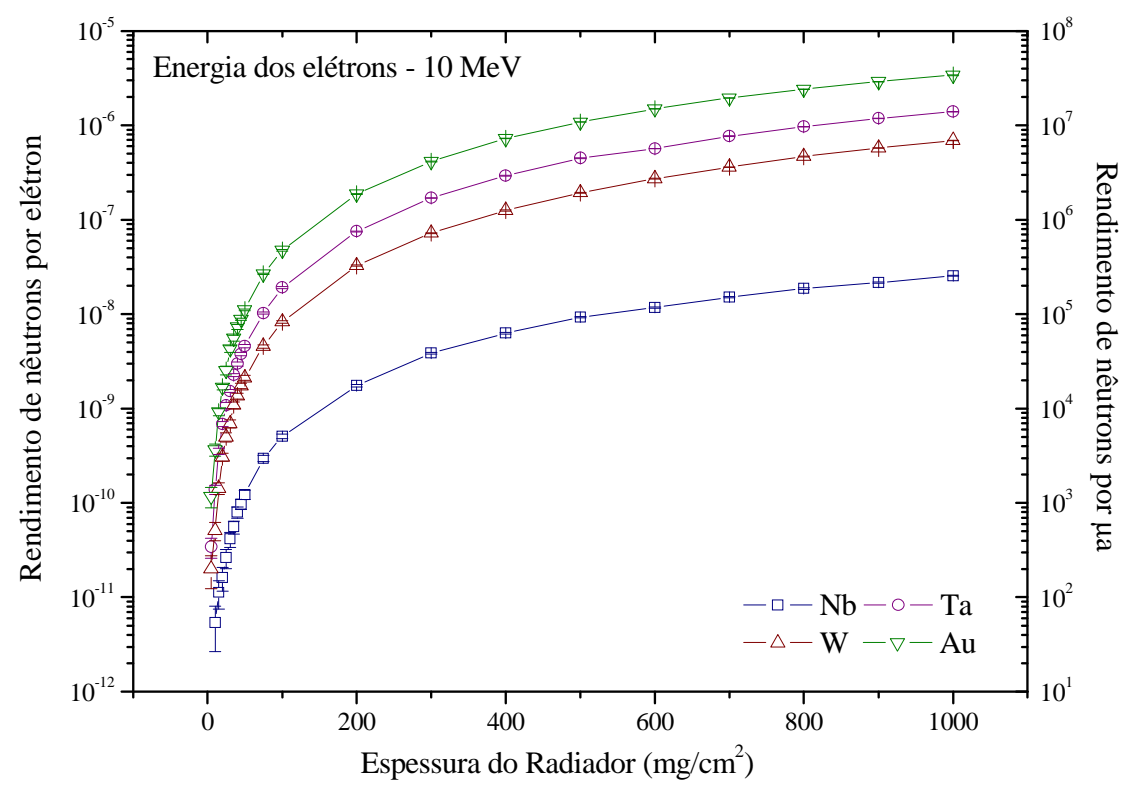

Fig. 6.5 Produção de fotonêutrons por elétrons de $10 \mathrm{MeV}$ em função da espessura dos radiadores de $\mathrm{Nb}$, $\mathrm{Ta}, \mathrm{W}$, e Au. O rendimento de nêutrons no $\mathrm{Cu}$ é insignificante para $10 \mathrm{MeV}$, (limiar da reações ${ }^{63} \mathrm{Cu}(\gamma, n)$ $\mathrm{e}^{65} \mathrm{Cu}(\gamma, \mathrm{n})$ é 9,9 e $10,8 \mathrm{MeV}$ respectivamente).

Os rendimentos de nêutrons $\left(Y_{\text {Brems }}\right)$ apresentados na figura 6.5 são menores que os calculados se são usadas diversas seções de choque reportadas na literatura [Be68, Le71]. Isto se deve ao processo de electro-desintegração que não é considerado nos algoritmos de simulação do MCNPX, e sua contribuição à produção de nêutrons é relevante principalmente em radiadores finos [Ma96]. Então o rendimento total de nêutrons $\left(Y_{\text {Total }}\right)$ é a soma do rendimento estimado pelo MCNPX e o devido à electrodesintegração $\left(Y_{e, x n}\right)$, que pode ser determinado calculando o "espectro de fótons virtuais" $\Phi_{\text {Virtual }}[\mathrm{Za98}]$ junto com a integral:

$$
Y_{(e, x n)}=\int_{0}^{E_{\text {elérov }}}\left(\sigma_{(\gamma, n)}(E)+2 \sigma_{(\gamma, 2 n)}(E)+\sigma_{(\gamma, n+p)}(E)+2 \sigma_{(\gamma, 2 n+p)}(E)\right) \Phi_{\text {Virtual }}(E) \frac{d E}{E}
$$

onde os termos $\sigma(\gamma, n), \sigma(\gamma, 2 n) \sigma(\gamma, n)$ e $\sigma(\gamma, 2 n+p)$ são as seções de choque de interação de fótons com os núcleos. Com o objetivo de testar o procedimento do cálculo do rendimento de eletro-desintegração, comparamos para o caso do ${ }^{63} \mathrm{Cu}$ e ${ }^{181} \mathrm{Ta}$ com resultados experimentais disponíveis [Sc55, Ma84, Ca88]. A figura 6.6, mostra o rendimento de nêutrons por elétron em função da energia dos elétrons onde se observa uma boa concordância entre os resultados experimentais e os calculados. 


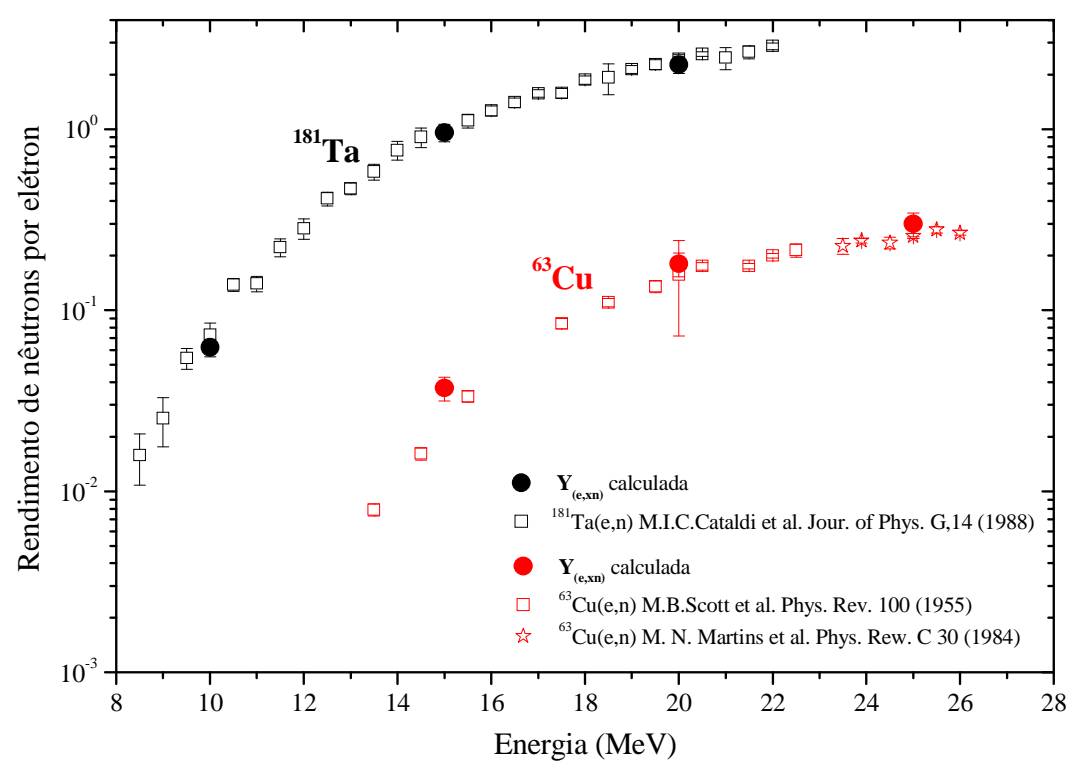

Fig. 6.6 Comparação entre os resultados do procedimento de calculo de $Y_{e, x n}$ e resultados experimentais [Sc55, Ma84, Ca88].

As figuras 6.7 e 6.8 apresentam os números de nêutrons por $\mu \mathrm{A}$ ou por elétron de $10 \mathrm{MeV}$ de energia que são produzidos em Nb, Ta, W e Au. Observa-se que a contribuição de $Y_{e, x n}$ é mais importante para radiadores finos e, por exemplo, no Ta para espessuras menores que $100 \mathrm{mg} / \mathrm{cm}^{2}$ esta contribuição é maior que o rendimento devido a reações $(\gamma, n)$ causada pelos fótons de bremsstrahlung. O número de nêutrons produzidos nos radiadores de $\mathrm{Au}$, Ta e W para $300 \mathrm{mg} / \mathrm{cm}^{2}$ (espessura de saturação nos cálculos que deram origem às Fig. 6.1 e 6.2) é da ordem de $10^{6}$ nêutrons por $\mu \mathrm{A}$ de corrente. Este valor é pequeno comparado com a intensidade total do bremsstrahlung, mas de acordo com a literatura [Mo99] contribui nos espectros de altura de pulso dos detectores.

A tabela 6.2 resume os resultados da simulação para as intensidades de fótons e nêutrons nos radiadores em duas situações: (a) com a espessura correspondente à saturação na produção de bremsstrahlung; e (b) com a espessura que produz um rendimento de nêutrons, incluindo o processo de eletro-desintegração, igual a 1/100 do caso (a). Assim, por exemplo, para um radiador de Ta de $300 \mathrm{mg} / \mathrm{cm}^{2}$ (espessura de saturação) e elétrons de $10 \mathrm{MeV}$, a produção de fótons e nêutrons é $7,8 \times 10^{7}$ fótons $/ \mu \mathrm{A}$ $\left(\mathrm{E}_{\gamma}>5 \mathrm{MeV}\right)$ e $1,5 \times 10^{6}$ nêutron $/ \mu \mathrm{A}$, respectivamente. Reduzindo a espessura para $10 \mathrm{mg} / \mathrm{cm}^{2}$, o número de nêutrons diminui aproximadamente em duas ordens de 
grandeza enquanto que a intensidade de fótons diminui por um fator de quatro. Portanto, é recomendável o emprego de radiadores com espessuras bem menores que a correspondente à saturação, e com baixo número atômico. Então o $\mathrm{Cu}$ e $\mathrm{Nb}$ constituem as melhores alternativas de materiais para um radiador de NRF.

Tabela 6.2 Intensidades de fótons e nêutrons para a espessura de saturação $300 \mathrm{mg} / \mathrm{cm}^{2}$ e para a espessura que diminui o rendimento de nêutrons num fator de 0,01. As incertezas dos valores que aparecem na tabela são menores que $10 \%$.

\begin{tabular}{|c|c|c|c|c|}
\hline \multirow{2}{*}{ Material } & \multirow{2}{*}{$\begin{array}{c}\text { Espessura } \\
\left(\mathbf{m g} / \mathrm{cm}^{2}\right)\end{array}$} & \multirow{2}{*}{$\begin{array}{c}\text { Rendimento } \\
\text { Nêutrons }\left(n \mu A^{-1}\right)\end{array}$} & \multicolumn{2}{|c|}{$\begin{array}{c}\text { Intensidade } \gamma \text { - 5mrad } \\
\left(\gamma \mu \mathrm{A}^{-1}\right)\end{array}$} \\
\hline & & & $\left(\mathbf{E}_{\gamma}<\mathrm{E}_{0} / 2\right)$ & $\left(\mathbf{E}_{\gamma}>E_{0} / 2\right)$ \\
\hline $\mathrm{Cu}$ & 300 & - & $9,4 \times 10^{8}$ & $5,8 \times 10^{7}$ \\
\hline \multirow{2}{*}{$\mathrm{Nb}$} & 300 & $5,6 \times 10^{4}$ & $9,3 \times 10^{8}$ & $6,5 \times 10^{7}$ \\
\hline & 5 & $5,4 \times 10^{2}$ & $1,8 \times 10^{8}$ & $8,4 \times 10^{6}$ \\
\hline \multirow{2}{*}{$\mathrm{Ta}$} & 300 & $1,5 \times 10^{6}$ & $8,9 \times 10^{8}$ & $7,8 \times 10^{7}$ \\
\hline & 10 & $1,5 \times 10^{4}$ & $3,3 \times 10^{8}$ & $1,8 \times 10^{7}$ \\
\hline \multirow{2}{*}{ W } & 300 & $1,0 \times 10^{6}$ & $8,9 \times 10^{8}$ & $6,8 \times 10^{7}$ \\
\hline & 10 & $1,9 \times 10^{4}$ & $3,3 \times 10^{8}$ & $1,8 \times 10^{7}$ \\
\hline \multirow{2}{*}{$\mathrm{Au}$} & 300 & $3,0 \times 10^{6}$ & $8,5 \times 10^{8}$ & $6,8 \times 10^{7}$ \\
\hline & 10 & $1,7 \times 10^{4}$ & $3,2 \times 10^{8}$ & $1,7 \times 10^{7}$ \\
\hline
\end{tabular}

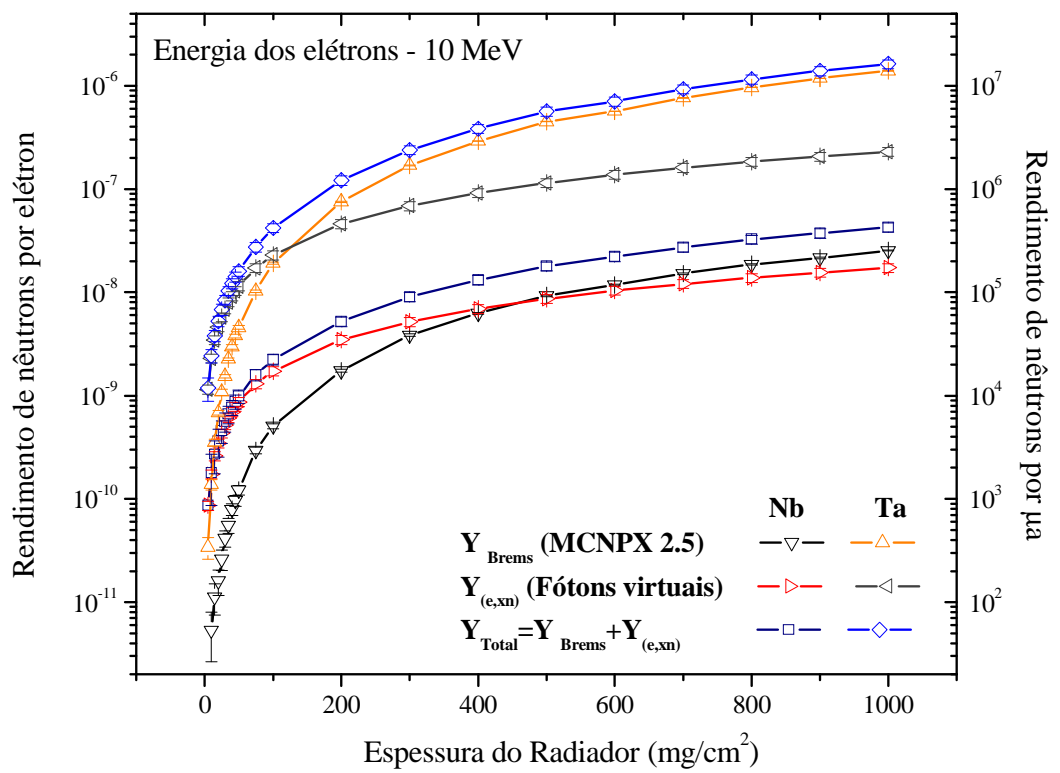

Fig. 6.7 Rendimento de nêutrons nos radiadores de $\mathrm{Nb}$ e Ta devido à eletro-desintegração $Y_{e, x n}$, ao bremsstrahlung $Y_{\text {Brems }}$, e o rendimento total $Y_{\text {Total }}$ 


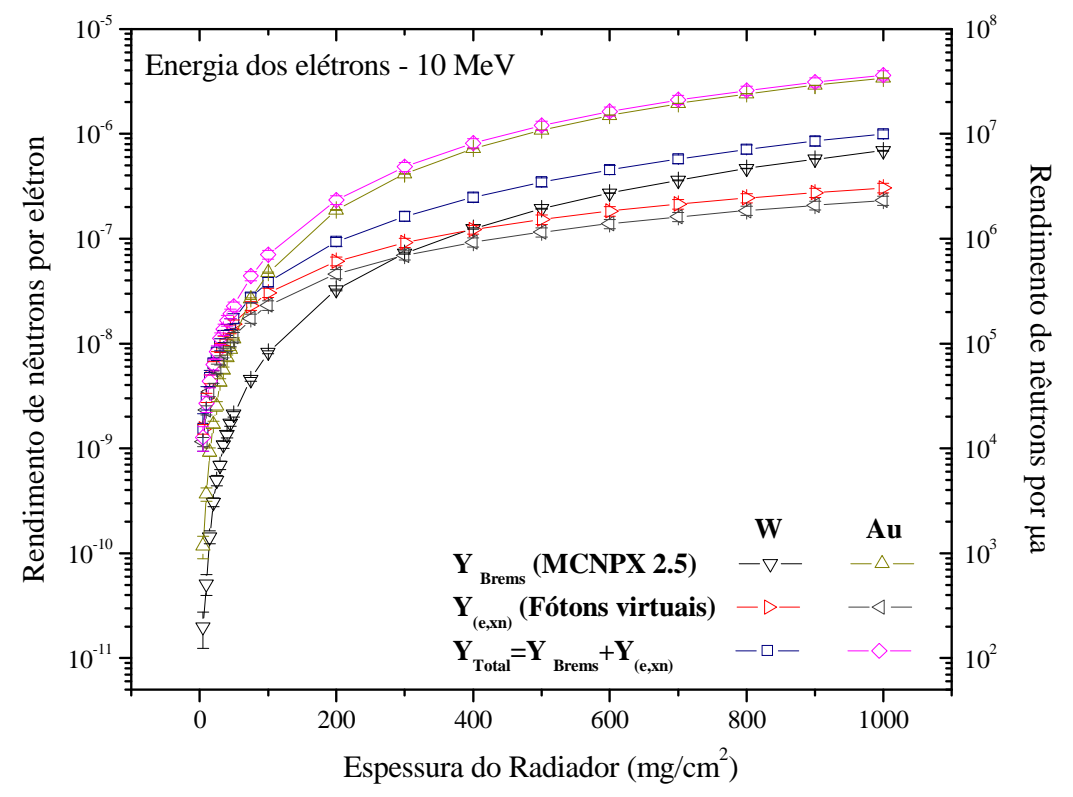

Fig. 6.8 Rendimento de nêutrons nos radiadores de $\mathrm{W}$ e Au devido à eletro- desintegração $Y_{e, x n}$, ao bremsstrahlung $Y_{\text {Brems }}$, e o rendimento total $Y_{\text {Total }}$

\subsubsection{Potência dissipada no radiador}

A figura 6.9 representa a potência dissipada no radiador pelo feixe de elétrons incidente em função da espessura. Como esperado, a potência dissipada cresce linearmente com a espessura, porque as perdas de energia para elétrons relativísticos têm um comportamento linear. Para a espessura de saturação, a potência dissipada é $18 \mathrm{~W}$ enquanto que para $10 \mathrm{mg} / \mathrm{cm}^{2}$ esse valor cai para $0,5 \mathrm{~W}$. A energia média depositada no radiador por elétrons incidente varia de $0,01 \mathrm{MeV}\left(10 \mathrm{mg} / \mathrm{cm}^{2}\right)$ a $0,36 \mathrm{MeV}\left(300 \mathrm{mg} / \mathrm{cm}^{2}\right)$. Para calcular a potência dissipada, foi multiplicada a energia depositada (obtida no MCNPX mediante o tally F6) pela corrente do feixe de elétrons. Assim, por exemplo, a energia depositada num alvo que absorva todos os elétrons incidentes de energia $E_{e}$ está dada por $P($ Watts $) \approx E_{e}(M e V) \cdot I(\mu \mathrm{A})$ sendo $I(\mu \mathrm{A})$ a corrente do feixe [Mo99]. Então outro parâmetro importante na eleição do material para o radiador é sua temperatura de fusão, que no $\mathrm{Nb}$ é $2477 \mathrm{C}^{\circ}$, duas vezes maior que à do $\mathrm{Cu}$ de $1084 \mathrm{C}^{\mathrm{o}}$, portanto o uso de um radiador de $\mathrm{Nb}$ fica sendo a melhor opção. 


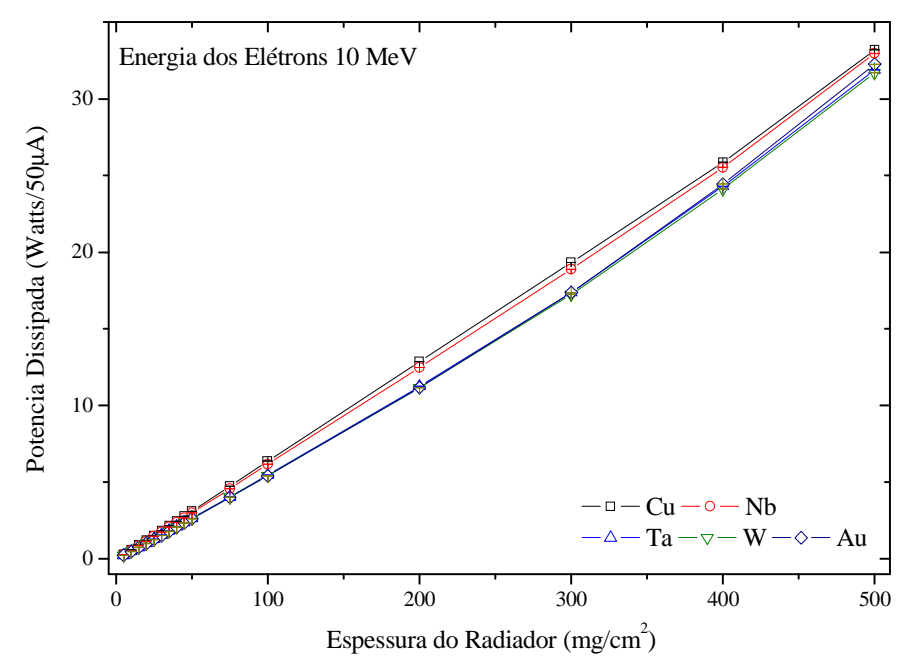

Fig. 6.9 Potência dissipada nos radiadores para $50 \mu \mathrm{A}$ (máxima corrente no acelerador do LAL).

\subsection{Colimador do Feixe de Fótons}

$\mathrm{O}$ arranjo de NRF foi desenvolvido para ser usado tanto com o tagger quanto sem ele. Assim, inicialmente, determinaram-se as características ideais - comprimento, diâmetros e material - do colimador localizado logo após o irradiador, que serviram de estimativas iniciais do colimador a ser usado na saída do feixe de fótons do tagger. Após a análise dos resultados das simulações observou-se que a localização do colimador não influenciava em suas características.

\subsubsection{Colimador junto ao radiador}

\subsubsection{Descrição do sistema e da simulação}

A figura 6.10 ilustra o arranjo experimental e define os parâmetros do colimador: comprimento e raios de entrada $\phi_{i}$ e de saída $\phi_{f}$. Na figura também se vêem as posições dos detectores virtuais para amostragem do feixe de fótons, marcados pelos tallies usados: F4 e F5.

Os parâmetros adotados nas simulações foram:

- Fonte monodirecional e monoenergética de elétrons $(10 \mathrm{MeV})$.

- Raio do feixe de elétrons $0,1 \mathrm{~cm}$. 
- Radiador de Tungstênio (W) para aumentar a proporção de fótons de maior energia.

- $\quad$ Material do Colimador: Pb.

- Diâmetro de entrada do colimador $\phi_{i}=0,8$ a 2,0 cm.

- Diâmetro de saída do colimador $\phi_{f \mathrm{n}}=0,8$ a 2,8 cm; os passos para ambos os diâmetros foi $0,4 \mathrm{~cm}$ (Fig. 6.10),

- Comprimentos do colimador de $20 \mathrm{~cm}$ até $100 \mathrm{~cm}$, em passos de variação de $10 \mathrm{~cm}$.

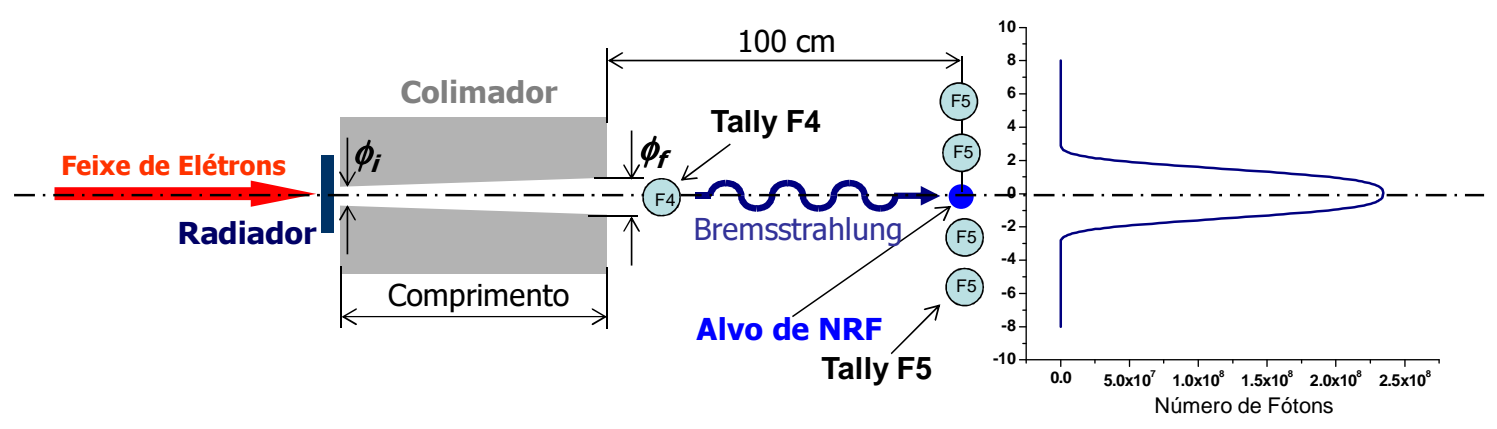

Fig. 6.10 Esquema da simulação para colimador situado imediatamente depois do radiador.

Para estimar a intensidade dos fótons foi empregado o tally F5, definindo detectores esféricos de $0,1 \mathrm{~cm}$ de raio situados $100 \mathrm{~cm}$ de após a borda do colimador (Fig. 6.10), que é uma posição típica para alvos de NRF [Kn96]. Isto permitiu estudar a largura do feixe na posição do alvo de NRF. Para diferenciar os fótons espalhados no colimador dos provenientes diretamente do radiador foi usado o cartão $\mathrm{CF}$. Este cartão estava associado ao tally F4, definido em uma celula esférica localizada à saída do colimador a $1 \mathrm{~cm}$ da borda externa, a fim de diminuir o tempo de execução do programa. O cartão BBREM foi utilizado para gerar um maior número de fótons de altas energias.

Foram empregadas as bibliotecas de dados $02 \mathrm{p}$ para os fótons, a 03e para os elétrons, e as bibliotecas fotonucleares lanl01u, cndc01u, kaeri01u [IAEA] para estimar a produção de nêutrons. No transporte de nêutrons foi usada a biblioteca endf60 [Pe05].

No total, foram analisadas mais de cem variantes de colimador diferenciadas por suas dimensões. Os resultados obtidos para algumas das variantes de colimadores são mostrados a seguir. Em todos os casos, o número de histórias garantiu que as incertezas 
relativas sejam menores que $10 \%$, nas posições mais importantes de amostragem do fluxo de fótons.

\subsubsection{Largura do feixe de Bremsstrahlung}

As figuras 6.11 e 6.12, que mostram a largura do feixe de fótons na posição do alvo de NRF para colimadores de $\mathrm{Pb}$ com diâmetro de entrada $\phi_{i}=1,2 \mathrm{~cm}$ e diâmetros de saída de $\phi_{f}=1,2$ e 1,6 cm, respectivamente. Na horizontal fica a distância ao eixo de simetria do feixe de elétrons (eixo central). No eixo vertical é indicada a intensidade relativa de fótons, ou seja, o número de fótons em cada posição com relação ao máximo que é obtido no eixo central (posição zero no eixo horizontal). O termo "largura do feixe" especifica o dobro do raio do feixe de bremsstrahlung, que é o parâmetro representado no eixo horizontal dos gráficos. Nos colimadores com furos cilíndricos da Fig. 6.11 e comprimento entre 70 e $100 \mathrm{~cm}$ são observados praticamente os mesmos comportamentos: o feixe tem uma largura entre 2 e $4 \mathrm{~cm}$. Por outro lado, para os colimadores com furos cônicos e diâmetros de entrada de $1,6 \mathrm{~cm}$, na posição do alvo o feixe só tem larguras menores que $4 \mathrm{~cm}$, para comprimentos maiores que 70 e $100 \mathrm{~cm}$, respectivamente. Analisando todas as variantes estudadas podemos escolher aquelas dimensões que permitem lograr um feixe de bremsstrahlung com um diâmetro de aproximadamante dois a quatro centímetros na posição de alvo de NRF [Go94, Mo99]. A tabela 6.3 resume os principais resultados.

Tabela 6.3 Diâmetros e comprimentos de colimadores de Pb que garantem feixes com uma largura menor que $4 \mathrm{~cm}$ na posição do alvo.

\begin{tabular}{|c|c|c|c|}
\hline $\begin{array}{c}\text { Diâmetro } \mathrm{D}_{\mathrm{c}} \text { do feixe de Fótons na } \\
\text { posição do alvo }(\mathrm{cm})\end{array}$ & $\begin{array}{c}\text { Diâmetro de entrada } \\
\text { do colimador } \phi_{i}(\mathrm{~cm})\end{array}$ & $\begin{array}{c}\text { Diâmetro de saída do } \\
\text { colimador } \phi_{f}(\mathrm{~cm})\end{array}$ & $\begin{array}{c}\text { Comprimento do } \\
\text { colimador de } \mathrm{Pb}(\mathrm{cm})\end{array}$ \\
\hline $\mathrm{D}_{\mathrm{c}}<2$ & 0,8 & 0,8 & $\geq 80$ \\
\hline \multirow{5}{*}{$2<\mathrm{D}_{\mathrm{c}}<4$} & 0,8 & 0,8 & $60-80$ \\
\cline { 2 - 4 } & 0,8 & 1,2 & $60-100$ \\
\cline { 2 - 4 } & 0,8 & 1,6 & $70-100$ \\
\cline { 2 - 4 } & 1,2 & 1,2 & $60-100$ \\
\cline { 2 - 4 } & 1,2 & 1,6 & $70-100$ \\
\cline { 2 - 4 } & 1,6 & 1,6 & $70-100$ \\
\hline
\end{tabular}




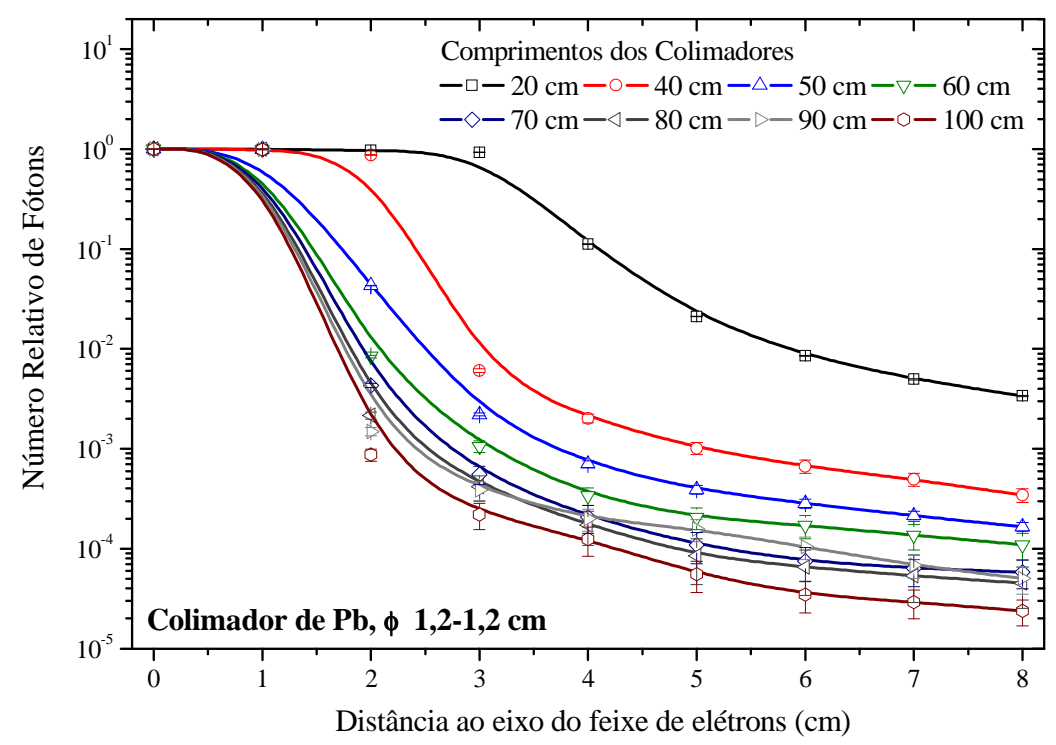

Fig. 6.11 Variação da largura do feixe de fótons para colimadores de $\mathrm{Pb}$ com $\phi_{i}=1,2 \mathrm{~cm}$ e $\phi_{f}=1,2 \mathrm{~cm}$.

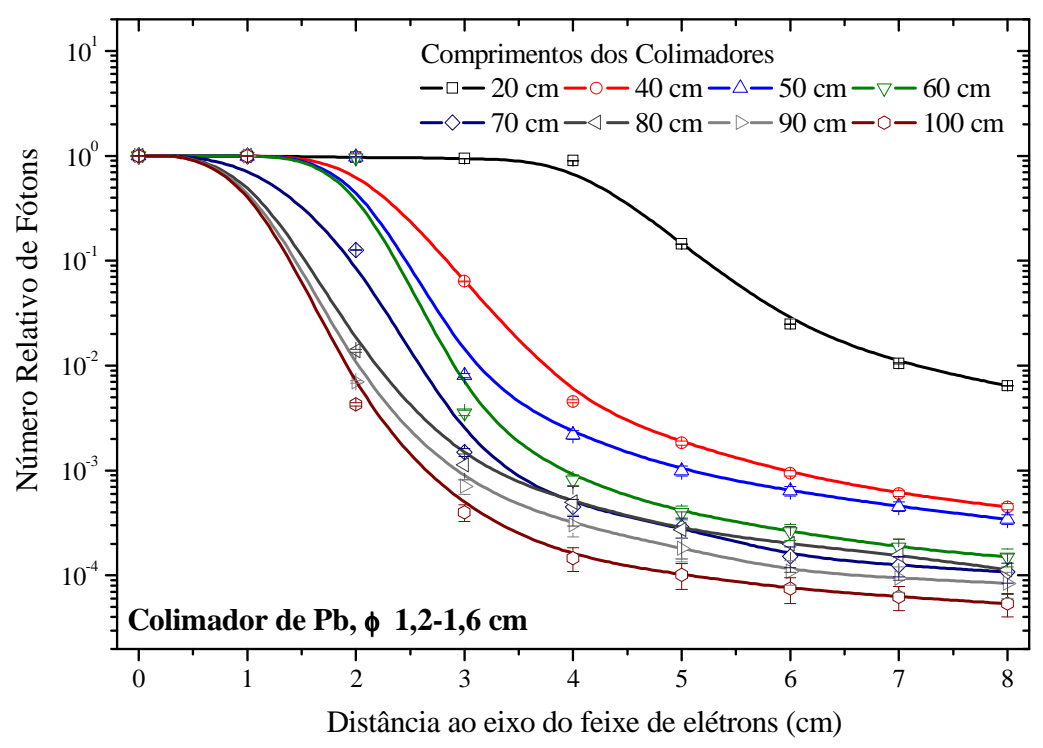

Fig. 6.12 Variação da largura do feixe de fótons para colimadores de $\mathrm{Pb} \operatorname{com} \phi_{i}=1,2 \mathrm{~cm}$ e $\phi_{f}=1,6 \mathrm{~cm}$.

\subsubsection{Espalhamento dos fótons no colimador}

Um aspecto importante no desenho de um colimador é a influência dos fótons espalhados no material do colimador no espectro de energias do feixe, na posição onde ficará o alvo objeto de estudo. No caso dos experimentos de NRF, é desejado que o espectro energético de bremsstrahlung fique o mais puro possível, sem influências 
significativas de espalhamentos em outros elementos do sistema. Isto permite estimar com maior precisão a forma do bremsstrahlung mediante cálculos teóricos, simulações por Monte Carlo e medidas experimentais parciais [Be01].

No feixe de bremsstrahlung de elétrons de alta energia, os fótons são emitidos preferencialmente na direção frontal, pelo que os efeitos dos espalhamentos no colimador serão menores que no caso de uma fonte que emite isotropicamente, ainda mais quando analisamos o feixe longe $(100 \mathrm{~cm})$ da borda de saída do colimador. Isto é observado na figura 6.13 que representa o número de fótons espalhados em relação ao número de fótons transmitidos sem interação em função da distância à borda de saída do colimador. Esta razão vai ficando cada vez menor com o aumento da distância, chegando a ser de só 1,5 \% para distâncias de $90 \mathrm{~cm}$.

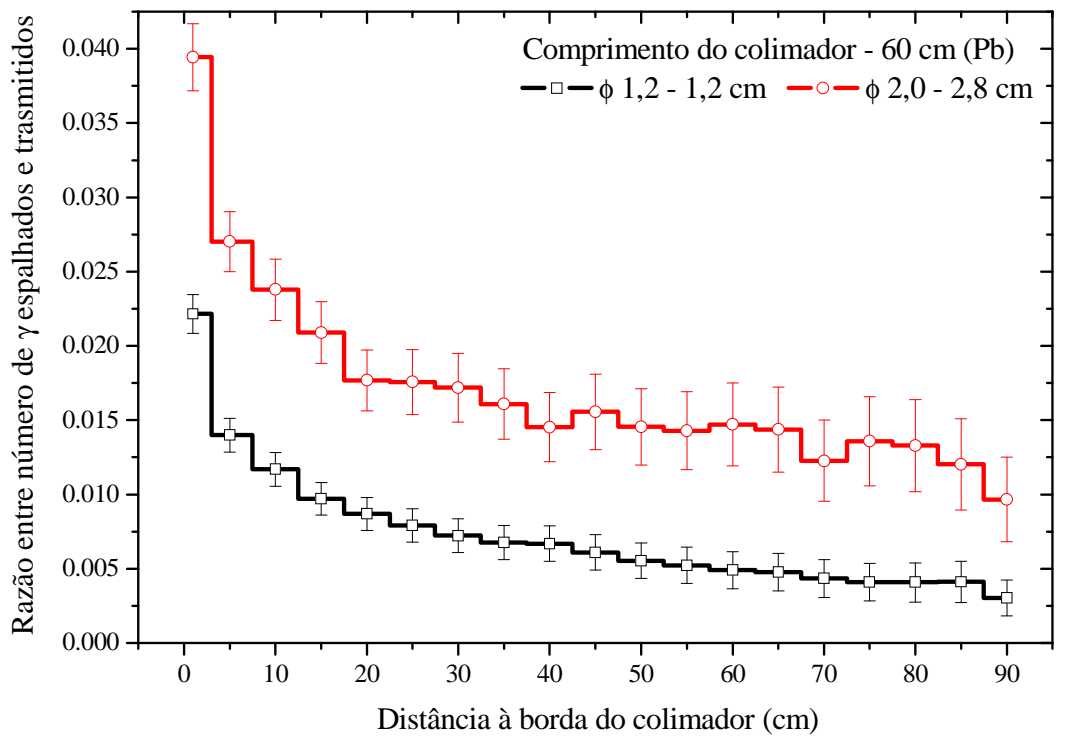

Fig. 6.13 Razão entre o número de fótons espalhados e transmitidos sem interação, na saída de colimadores de $60 \mathrm{~cm}$ de $\mathrm{Pb}$ com diâmetros de $\phi_{i}=1,2-\phi_{f}=1,2 \mathrm{~cm}$ e $\phi_{i}=2,0-\phi_{f}=2,8 \mathrm{~cm}$.

Considerando a fraca estatística de fótons espalhados no colimador a grandes distâncias do mesmo, foi decidido amostrar estes fótons na saída do colimador, e estudar a influência do comprimento e da forma (cilíndrica ou cônica) dos colimadores no número de fótons espalhados. A figura 6.14 serve de exemplo deste estudo, mostrando que a fração de fótons espalhados no colimador decresce radicalmente para comprimentos até $60 \mathrm{~cm}$, ficando praticamente constante a partir daí com valores entre 2 e $4 \%$, sem distinção clara entre as formas. Isto sugere que, deste ponto de vista, o 
emprego de um colimador cônico não fornece vantagens adicionais sobre o uso de um cilíndrico. Esta conclusão é similar à reportada por Nath et al. [Na73], quando a propósito de discrepâncias entre os dados experimentais e as previsões teóricas das seções de choque nas reações fotonucleares, estudaram os efeitos dos colimadores na distribuição espectral de bremsstrahlung com energias entre 20 e $30 \mathrm{MeV}$.

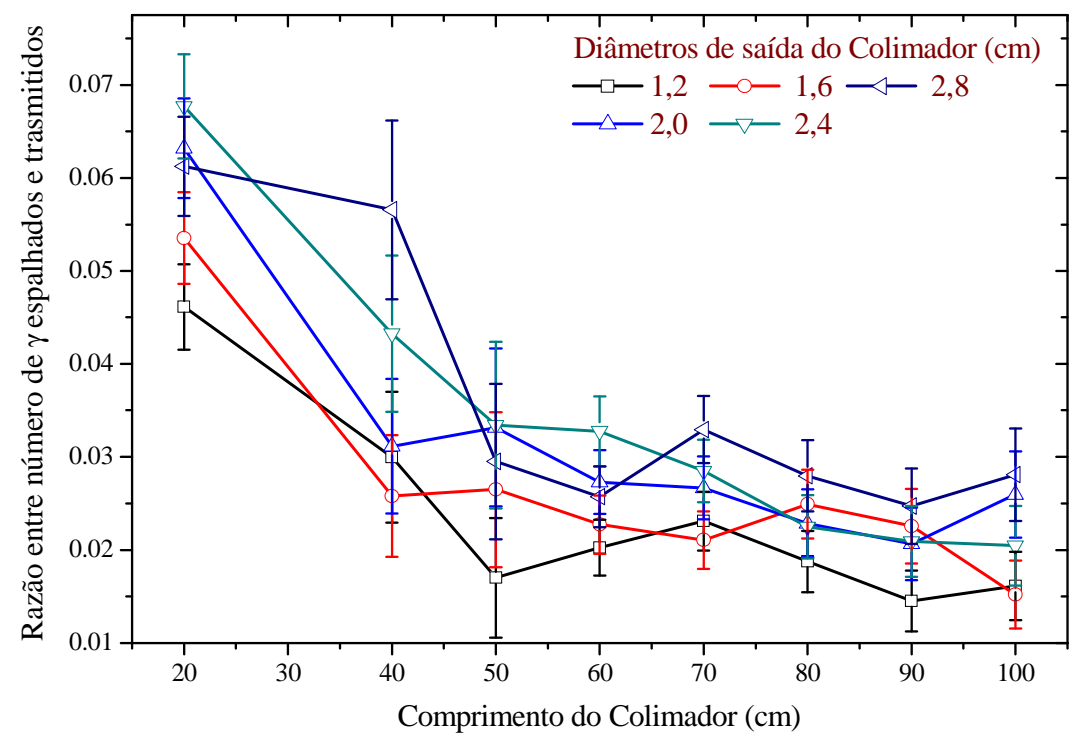

Fig. 6.14 Razão de fótons espalhados com diâmetro $\phi_{i}=1,2 \mathrm{~cm}$ em função do comprimento.

\subsubsection{Colimador depois do "Tagger".}

A figura 6.15 ilustra o arranjo experimental quando o colimador é colocado depois do tagger; fora do posicionamento do colimador, essa figura é similar à figura 6.10. Exceto por uma faixa mais restrita de dimensões do colimador: $0,8 \leq \phi_{i} \leq 1,6 \mathrm{~cm}$; $0,8 \leq \phi_{f} \leq 1,6 \mathrm{~cm} ; 60 \leq$ comprimento $\leq 100 \mathrm{~cm}$, os demais parâmetros adotados foram os mesmos apresentados na seção 6.3.1.1, mas também Cu e Ni foram testados, além do $\mathrm{Pb}$, para construir o colimador. 


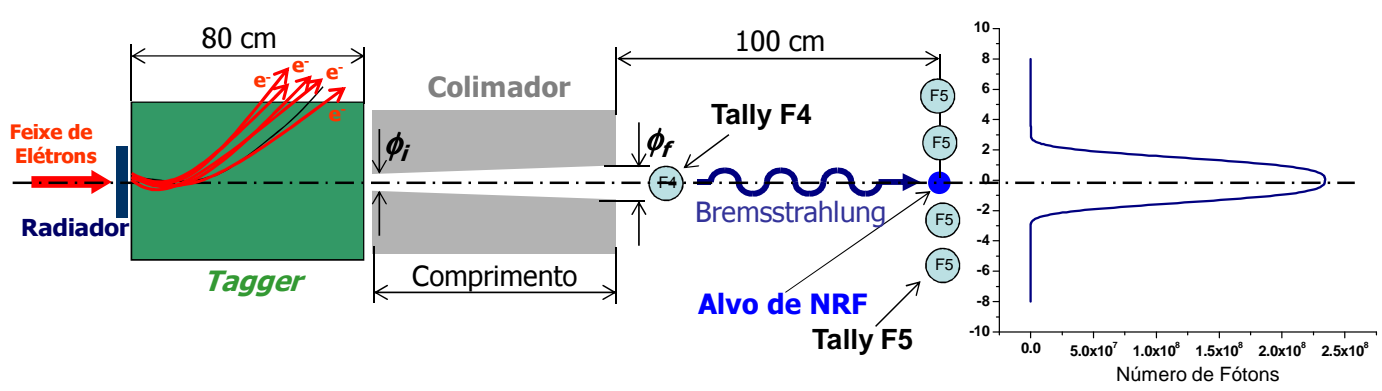

Fig. 6.15 Esquema da simulação para o colimador situado depois do tagger.

Os mesmos testes de comportamento do fluxo de fótons - largura e contaminação do feixe - foram realizados e os resultados são similares, de modo que aqui só se apresentam alguns resultados, para ilustração. As posições usadas para amostrar os fluxos também foram as mesmas da subseção anterior.

\subsubsection{Largura do feixe de Bremsstrahlung e comparação entre $\mathrm{Cu}, \mathrm{Ni}$ e $\mathrm{Pb}$.}

As figuras 6.16 a 6.18 apresentam alguns dos resultados obtidos nas simulações dos colimadores de $\mathrm{Pb}, \mathrm{Cu}$ e $\mathrm{Ni}$. Elas mostram que a largura do feixe, com um valor entre 2 e $2,5 \mathrm{~cm}$, é praticamente independente do comprimento do colimador, quando este é maior que $60 \mathrm{~cm}$. No caso do colimador cilíndrico $0,8-0,8 \mathrm{~cm}$ a largura do feixe é menor que $2 \mathrm{~cm}$. Por outro lado o comportamento do feixe de fótons com colimadores de $\mathrm{Cu}$ ou $\mathrm{Ni}$ é praticamente o mesmo que o obtido no caso do $\mathrm{Pb}$, o que pode ser melhor observado na figura 6.19 onde uma comparação entre $\mathrm{Cu}$ e $\mathrm{Pb}$ evidencia que para comprimentos de $70 \mathrm{~cm}$ ou mais o comportamento é muito similar. Devido às características semelhantes do $\mathrm{Cu}$ e do $\mathrm{Ni}$ são omitidas as comparações $\mathrm{Pb}-\mathrm{Ni}$ e $\mathrm{Cu}-\mathrm{Ni}$. Os efeitos de espalhamento nos colimadores são semelhantes aos descritos anteriormente. 


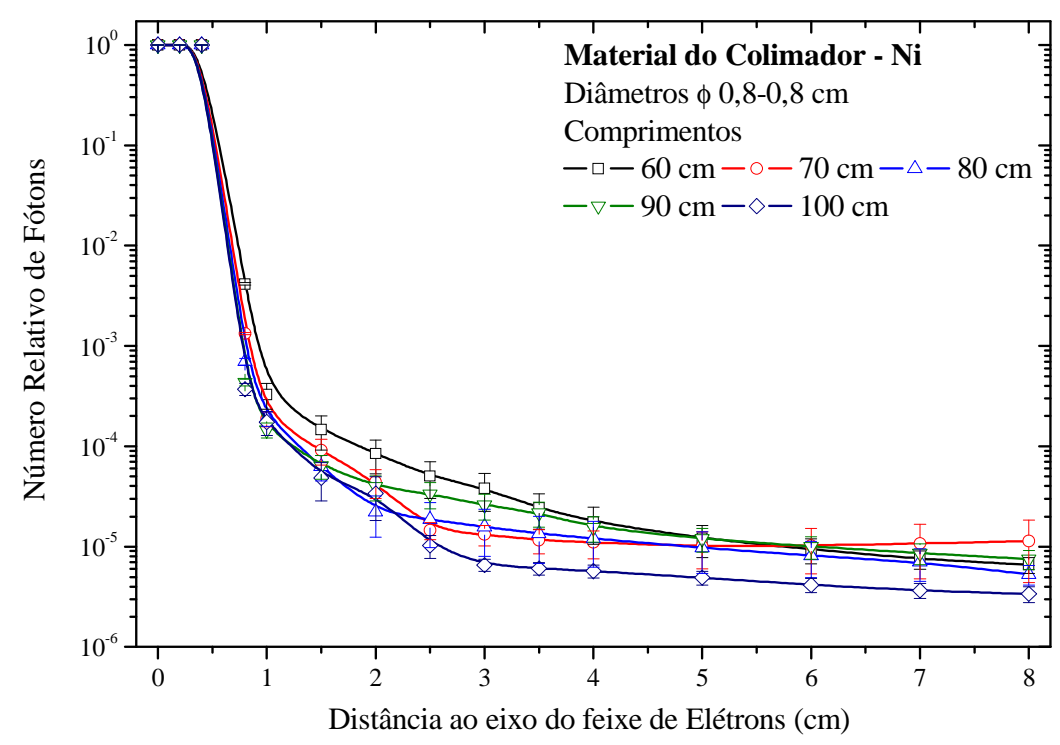

Fig. 6.16 Variação da largura do feixe de fótons para colimadores cilíndricos de Ni com comprimento entre 60 e $100 \mathrm{~cm}$ e diâmetro $\phi=0,8 \mathrm{~cm}$.

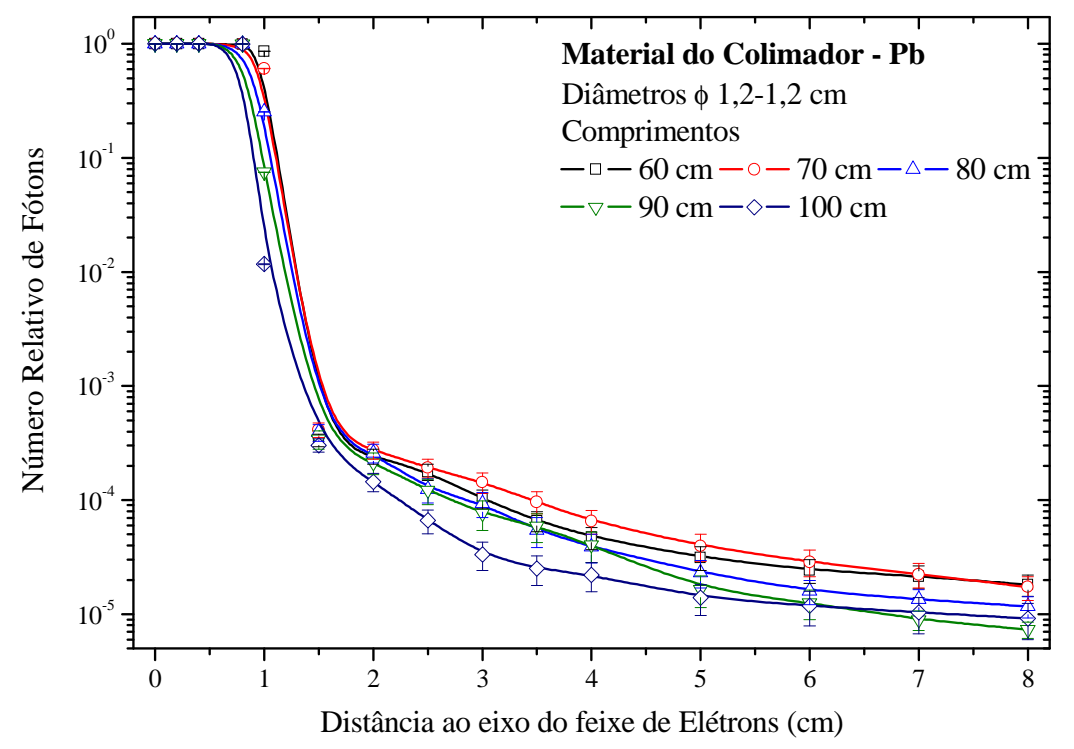

Fig. 6.17 Variação da largura do feixe de fótons para colimadores cilíndricos de $\mathrm{Pb}$ com comprimento entre 60 e $100 \mathrm{~cm}$ e diâmetro $\phi=1,2 \mathrm{~cm}$. 


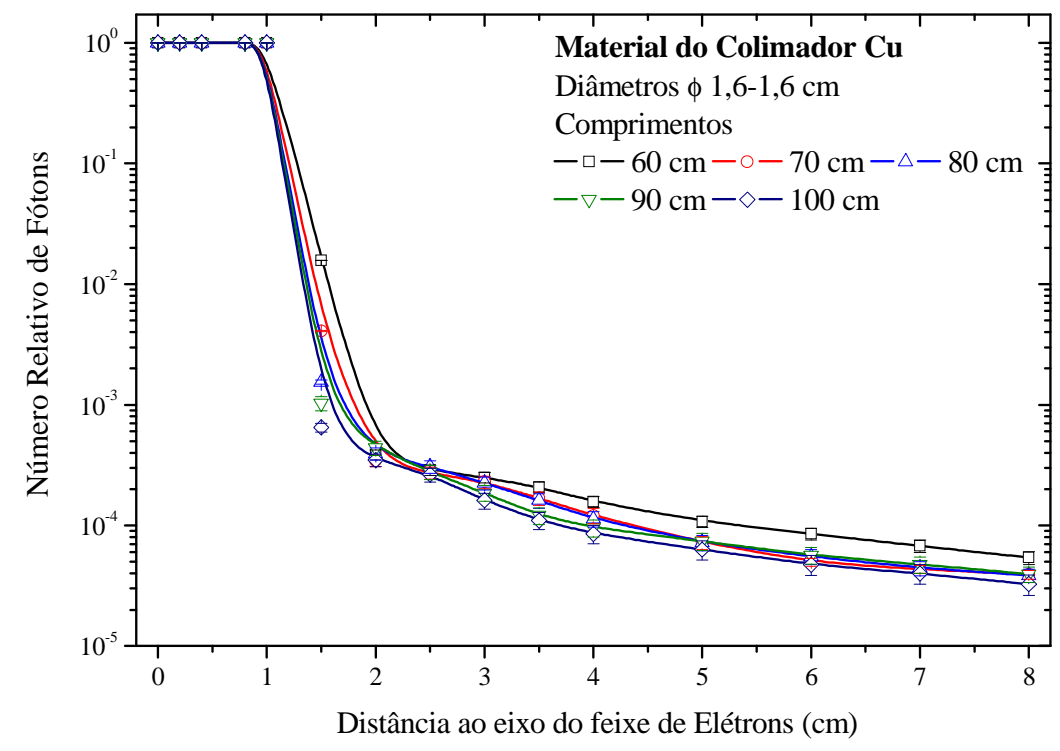

Fig. 6.18 Variação da largura do feixe de fótons para colimadores cilíndricos de $\mathrm{Cu}$ com comprimento entre 60 e $100 \mathrm{~cm}$ e diâmetro $\phi=1,6 \mathrm{~cm}$.

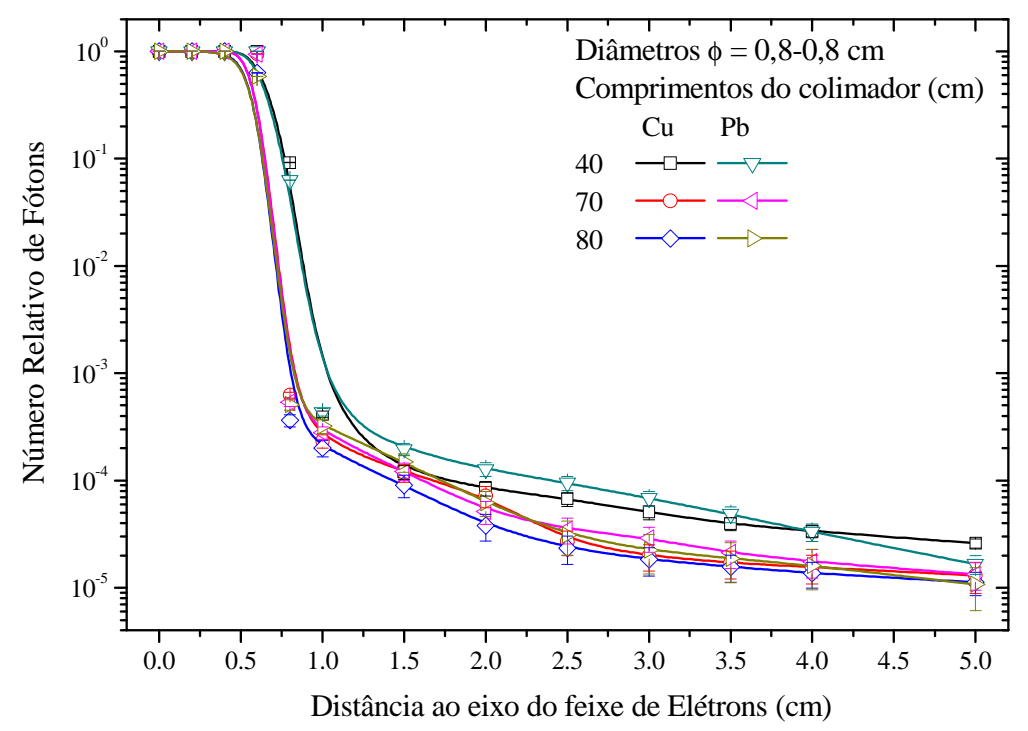

Fig. 6.19 Comparação entre colimadores de $\mathrm{Cu}$ e $\mathrm{Pb}$ com comprimentos de 40, 70 e $80 \mathrm{~cm}$.

\subsubsection{Produção de nêutrons no colimador.}

Outro detalhe importante no desenho do colimador é a produção de nêutrons devido às reações fotonucleares no mesmo. Está claro que substituindo o $\mathrm{Pb}$ por um material de maior energia limiar para as reações $(\gamma, n)$ como o $\mathrm{Cu}$ ou $\mathrm{Ni}$ diminui o fluxo de nêutrons. Porém, é interessante conhecer como a geometria do colimador influi no 
fluxo de nêutrons emergentes. Para estudar isto foi estimado o fluxo de nêutrons $100 \mathrm{~cm}$ após a borda do colimador na posição do alvo de NRF para colimadores de $\mathrm{Pb}, \mathrm{Cu}$ e $\mathrm{Ni}$ de $60 \mathrm{~cm}$ de comprimento e diferentes diâmetros de entrada e de saída. Na geração de bremsstrahlung, foi usado um radiador de $\mathrm{Nb}\left(100 \mathrm{mg} / \mathrm{cm}^{2}\right)$, minimizando a produção de nêutrons no radiador, devido a energia limiar de 8,831 MeV. Para distinguir melhor as diferenças entre os materiais do colimador, foram simuladas três energias de elétrons incidentes: 10, 15 e $20 \mathrm{MeV}$.

Na simulação por Monte Carlo, foram aplicadas várias técnicas de redução de variância, empregando os cartões WWP, WWE, WWN, além do BBREM, devido à relativamente baixa probabilidade dos processos fotonucleares com relação a outras interações dos fótons. Isto permitiu reduzir consideravelmente os tempos de execução e as incertezas estatísticas.

Nas figuras a seguir, o eixo horizontal representa o diâmetro de saída do colimador, o eixo vertical, o fluxo de nêutrons na posição do alvo, e as curvas correspondem aos três materiais estudados e diferentes diâmetros de entrada dos colimadores. A figura 6.20, correspondente a elétrons de $10 \mathrm{MeV}$, mostra o número de nêutrons no alvo em função do diâmetro de saída do colimador para os três materiais simulados $(\mathrm{Pb}, \mathrm{Ni}$ e $\mathrm{Cu}$ ). Pode-se observar um pequeno aumento, praticamente linear, do número de nêutrons emergentes com o aumento do diâmetro de saída do colimador de $\mathrm{Pb}$. Este fato sugere que a maior parte dos nêutrons são produzidos na entrada do colimador. Praticamente não são produzidos nêutrons nos colimadores de $\mathrm{Cu}$ e $\mathrm{Ni}$. O número de nêutrons estimado só com o radiador de $\mathrm{Nb}$, que chegam à posição de amostragem, è $(9,4 \pm 0,3) \times 10^{-3} \mathrm{n} / \mu \mathrm{A} \mathrm{cm} \mathrm{cm}^{2}$. 


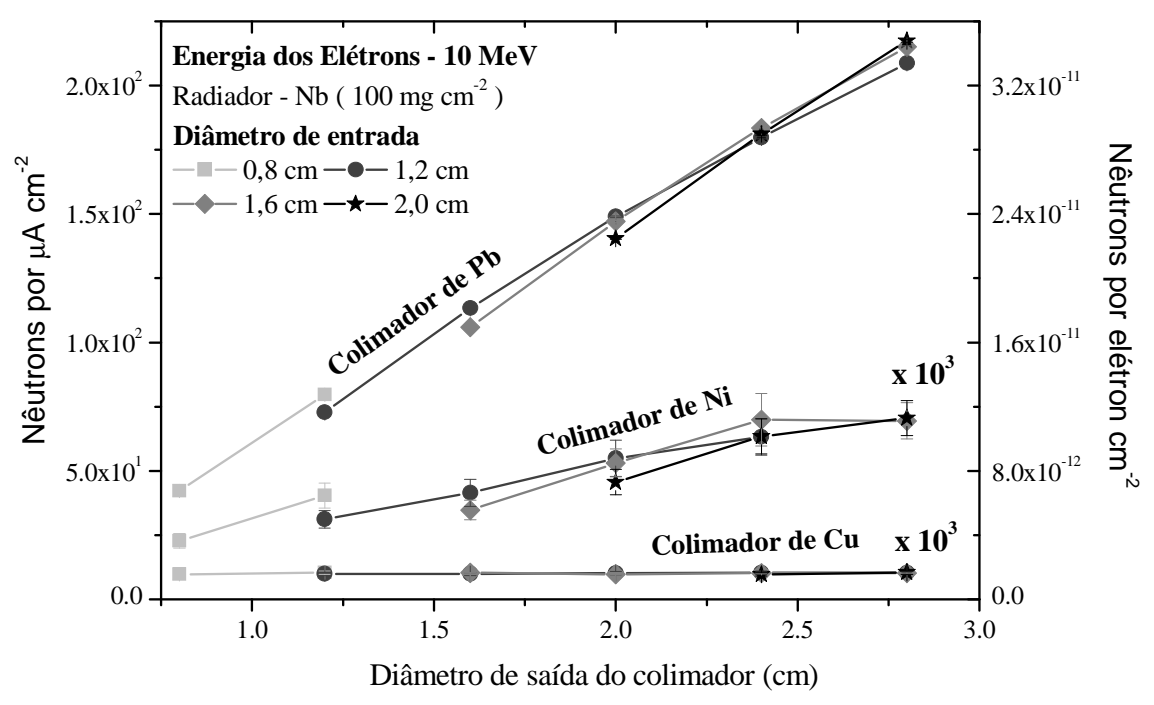

Fig. 6.20 Nêutrons na posição do alvo para colimadores de $\mathrm{Pb}, \mathrm{Cu}$ e Ni, com $60 \mathrm{~cm}$ de comprimento, e diferentes diâmetros de entrada. Energia dos elétrons incidentes $10 \mathrm{MeV}$.

Com o incremento da energia dos elétrons incidentes, aumenta consideravelmente a geração de nêutrons nos colimadores, tanto de $\mathrm{Pb}$ quanto de $\mathrm{Cu} \mathrm{e}$ Ni, (Fig. 6.21 e 6.22), mas nos colimadores de $\mathrm{Cu}$ e Ni esta é bem menor. Para $15 \mathrm{MeV}$ (Fig. 6.21) a produção de nêutrons no Ni é o dobro que no $\mathrm{Cu}$. Para $20 \mathrm{MeV}$ (Fig. 6.22) esta relação se inverte e um colimador de Ni resulta muito mais vantajoso. A energia limiar para as reações $(\gamma, n)$ no cobre natural é menor que no níquel natural (Anexo II), mas a secção de choque para ${ }^{63} \mathrm{Cu}(\gamma, n)$ é três vezes superior à do ${ }^{58} \mathrm{Ni}(\gamma, n)$ para energias maiores que $15 \mathrm{MeV}$ (Anexo III), o que explica o comportamento anterior. Desta forma um colimador de Ni com um furo cilíndrico, com possibilidades de ser empregado para maiores energias, constitui a opção mais recomendada. 


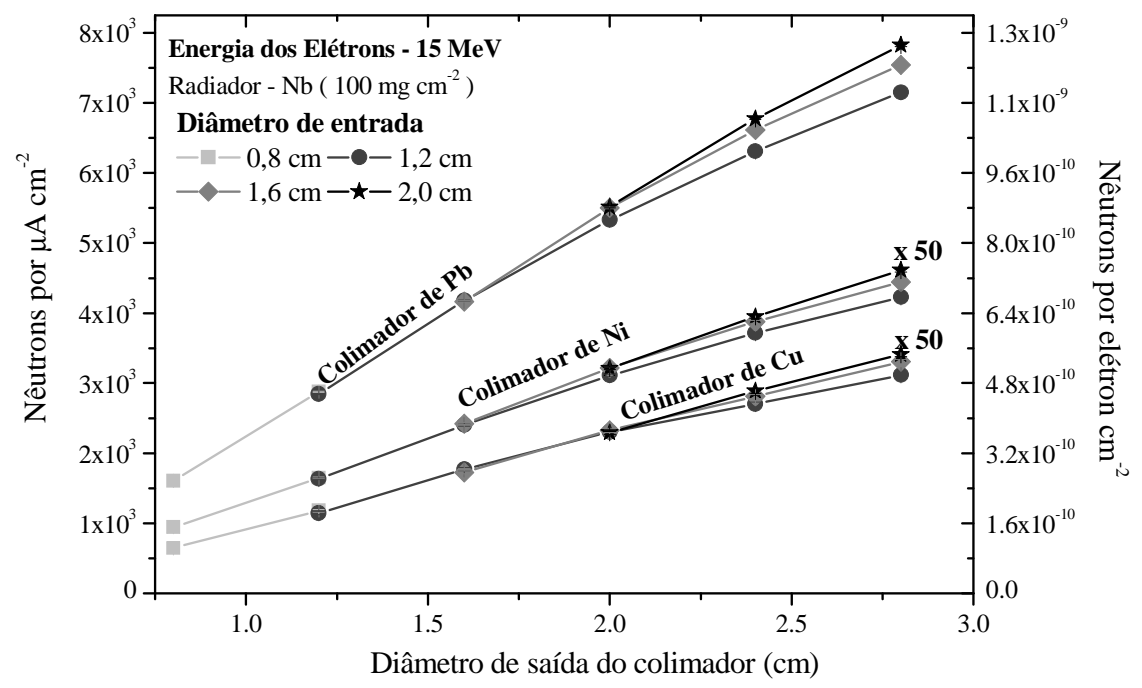

Fig. 6.21 Nêutrons na posição do alvo de NRF para colimadores de $\mathrm{Pb}, \mathrm{Cu}$ e $\mathrm{Ni}$, com $60 \mathrm{~cm}$ de comprimento, e diferentes diâmetros de entrada. Energia dos elétrons incidentes $15 \mathrm{MeV}$.

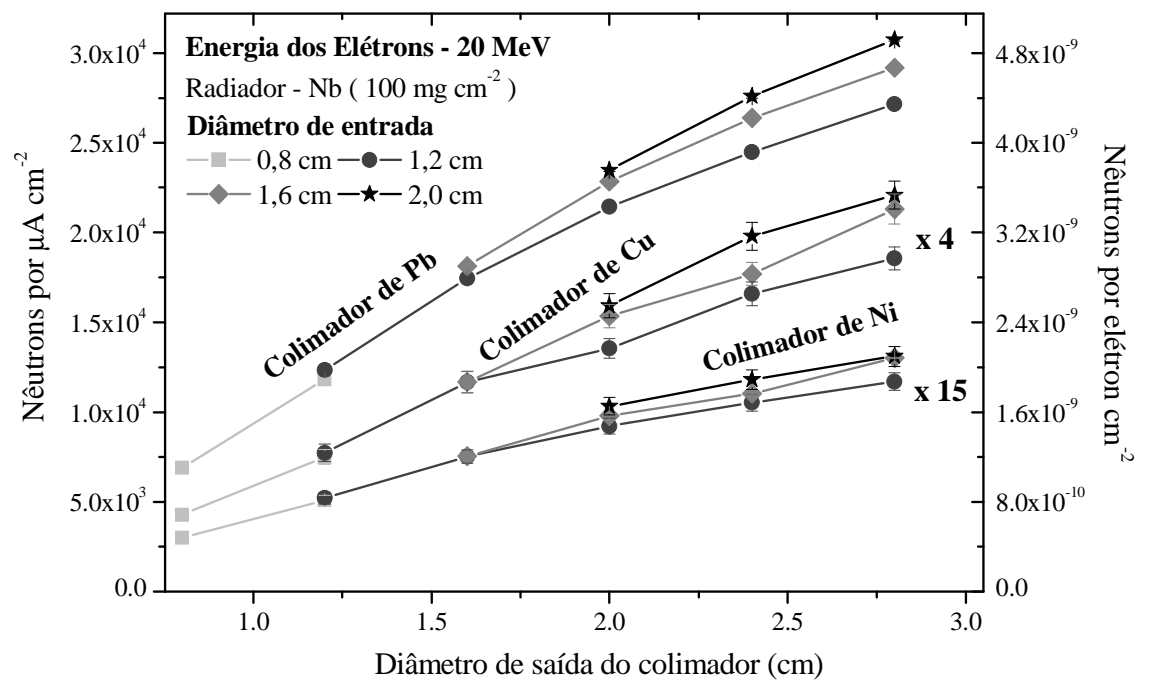

Fig. 6.22 Nêutrons na posição do alvo de NRF para colimadores de $\mathrm{Pb}, \mathrm{Cu}$ e $\mathrm{Ni}$, com $60 \mathrm{~cm}$ de comprimento, e diferentes diâmetros de entrada. Energia dos elétrons incidentes $20 \mathrm{MeV}$.

\subsubsection{Raio externo do colimador.}

O raio externo do colimador foi escolhido como a menor dimensão radial que deve ter o cilindro de $\mathrm{Ni}$ de modo que, colocando concreto tradicional [Wo82] ao redor 
do $\mathrm{Ni}$, o efeito de atenuação do feixe de fótons não experimente modificações consideráveis.

O resultado obtido, figura 6.23, apresenta o comportamento da atenuação do feixe, exatamente após a borda do colimador, em função da distância radial ao eixo do feixe de elétrons para várias situações: sem colimador, com o colimador de Ni $(100 \mathrm{~cm}$ de raio externo), ou com colimadores de $\mathrm{Ni}$ de raios 5, 10, 15, 20 e $25 \mathrm{~cm}$ rodeados de concreto. A simulação considerou um comprimento de $70 \mathrm{~cm}$ com um furo interno cilíndrico de $\phi=1,2 \mathrm{~cm}$. Observa-se que com $20 \mathrm{~cm}$ de raio externo praticamente são obtidos níveis similares de atenuação que para um raio externo de $100 \mathrm{~cm}$. Pode-se afirmar que um colimador de $\mathrm{Ni}$ de $70 \mathrm{~cm}$ de comprimento e um furo cilíndrico de $\phi=1,2 \mathrm{~cm}$, com $20 \mathrm{~cm}$ de raio externo dentro de um bloco de concreto de $200 \mathrm{~cm}$ de diâmetro, garante as exigências para um sistema de medidas de NRF.

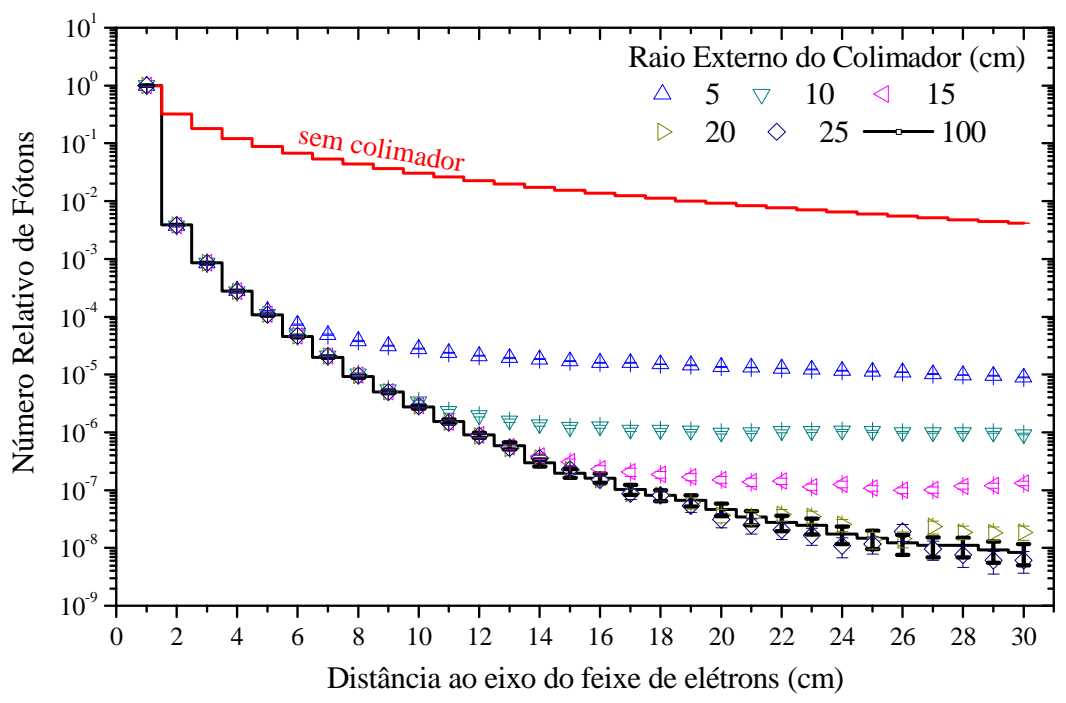

Fig. 6.23 Atenuação do feixe de fótons para diferentes raios externos do colimador de Ni rodeado de concreto.

\subsection{Blindagem dos detectores de HPGe}

Para reduzir a detecção do background produzido por espalhamento no ambiente, os detectores de fótons nos sistemas de medida de NRF devem ser blindados, o que incrementa a sensibilidade do sistema e evita o possível dano causado pelos nêutrons no cristal de HPGe. Usualmente o $\mathrm{Pb}$ é usado como blindagem para os 
detectores, colocando uma camada de $\mathrm{Cd}$ ao redor do detector para capturar os nêutrons térmicos.

Para estudar a influência da blindagem nos detectores de HPGe foi amostrado o fluxo de fótons na posição do detector empregando o tally F5. As simulações foram realizadas com e sem o alvo de NRF e diferentes espessuras de blindagem. Como alvo foi escolhido um disco de $\mathrm{Al}$ de $2 \mathrm{~g}$ e $\phi=2,0 \mathrm{~cm}$ de diâmetro. $\mathrm{O}{ }^{27} \mathrm{Al}$ é comumente empregado para realizar a calibração nos sistemas de NRF, devido a sua elevada seção de choque e ao conhecimento detalhado de todos seus estados de excitação [Kn96, Br01]. Na geometria do MCNPX foram considerados os resultados obtidos para o colimador do feixe de fótons de $\mathrm{Ni}$ com as dimensões recomendadas no item 6.3.3 e um radiador de $\mathrm{Nb}\left(5 \mathrm{mg} / \mathrm{cm}^{2}\right)$. As dimensões da sala de medida e suas paredes, e a localização relativa do sistema de NRF nesse local foram incluídos nos arquivos de entrada. Os dois detectores de HPGe, separados $20 \mathrm{~cm}$ do alvo e em ângulos de $90^{\circ} \mathrm{e}$ $127^{\circ}$ em relação ao feixe de fótons [Kn96], com seus dewars de nitrogênio também foram especificados na geometria simulada. A interação dos fótons com os núcleos que compõem o ar [Sc05], mesmo que sua contribuição fosse pequena, foi outro fator considerado. Todos estes elementos contribuem no espalhamento de fótons e o objetivo era avaliar, em uma situação o mais real possível, o efeito da blindagem no número de fótons que chegam aos detectores. O estudo foi realizado para o detector situado a $90^{\circ}$. Varias das técnicas de redução de variância mencionadas anteriormente foram aqui também utilizadas.

A figura 6.24 apresenta a fração entre o número de fótons que chegam ao detector com alvo e sem o alvo nos arquivos de entrada, em função da espessura da blindagem, para duas faixas de energias: fótons com energias menores que $2 \mathrm{MeV}$ e menores que $4 \mathrm{MeV}$. A probabilidade de que fótons com energias maiores atinjam o detector depois de eventos de espalhamento é muito pequena. A blindagem de $\mathrm{Pb}$ contribui a incrementar a fração estudada de 1 sem $\mathrm{Pb}$ até um fator 10 para $12 \mathrm{~cm}$ de espessura, observando se um comportamento que tende à saturação a partir de $10 \mathrm{~cm}$ como foi visto por Schwengner et al. [Sc05] que usam detectores blindados com $10 \mathrm{~cm}$ de $\mathrm{Pb}$. Adicionalmente, dado o espaço disponível na sala de medidas do Microtron, podem ser usados blocos de concreto para assegurar uma melhor blindagem. 


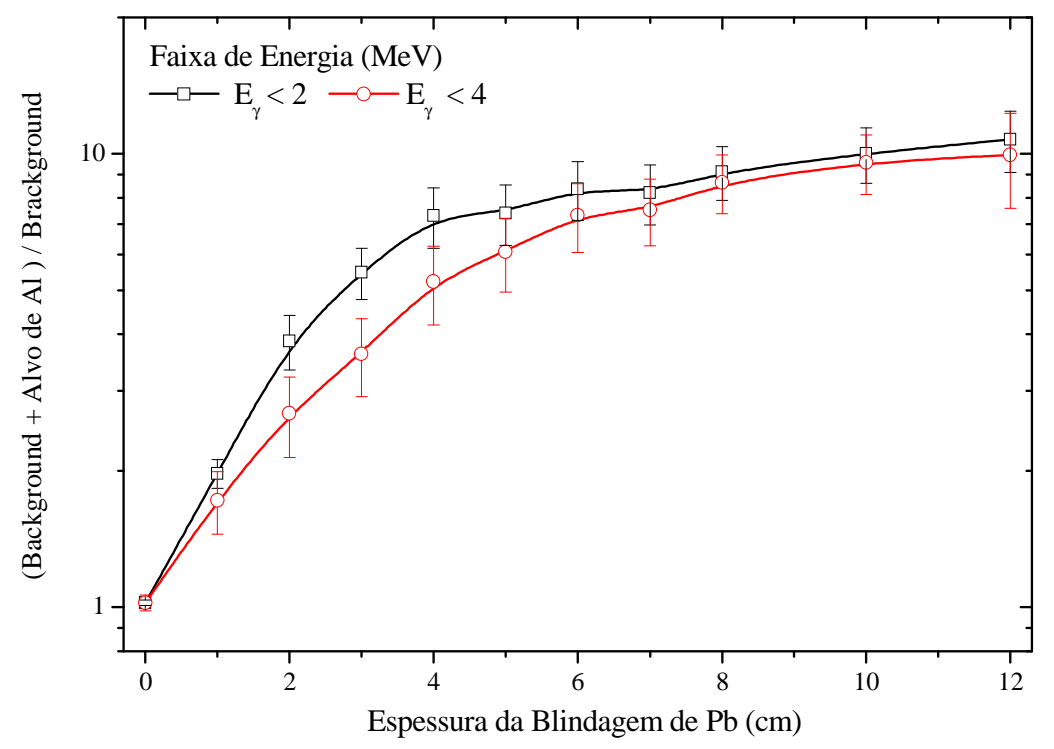

Fig. 6.24 Fração entre o número de fótons espalhados que chegam ao detector com alvo de $\mathrm{Al}$ e sem o alvo em função da espessura da blindagem de $\mathrm{Pb}$, situada ao redor do detector de HPGe localizado a $90^{\circ}$ em relação ao feixe de fótons primário.

\subsection{Coletor do Feixe de Fótons}

Nas medidas de NRF, é extremadamente importante minimizar o background. Porém, além de usar blindagens ativas (BGO) ou passivas ( $\mathrm{Pb}$ e $\mathrm{Cd}$ ) dos detectores [Ma96a], é preciso minimizar os efeitos da radiação espalhada devido à interação do feixe de fótons com as paredes da sala de medida. Para isso, são utilizados coletores do feixe de fótons (photon beam dumps), que reduzem o feixe depois que passa pelo alvo, como a figura 6.25 apresenta esquematicamente.

O coletor foi desenhado como uma combinação de materiais de baixo e elevado Z. Os primeiros são empregados para reduzir a produção de nêutrons, a produção de pares $\mathrm{e}^{-}-\mathrm{e}^{+}$e os subseqüêntes fótons de aniquilação. Em nosso trabalho, foram estudados polietileno (PE), grafite (C), e alumínio (Al) que são acessíveis, e apresentam uma baixa secção de choque para as reações $(\gamma, n)$. Por outro lado, os materiais de alto $Z$ são utilizados para blindar a radiação produzida pela interação do feixe de fótons com os materiais de baixo $Z$ [Sc05]. Níquel, cádmio e chumbo foram os materiais de maior Z incluídos nas variantes de coletores analisados. As dimensões dos diversos elementos do sistema de NRF anteriormente recomendadas foram consideradas. 


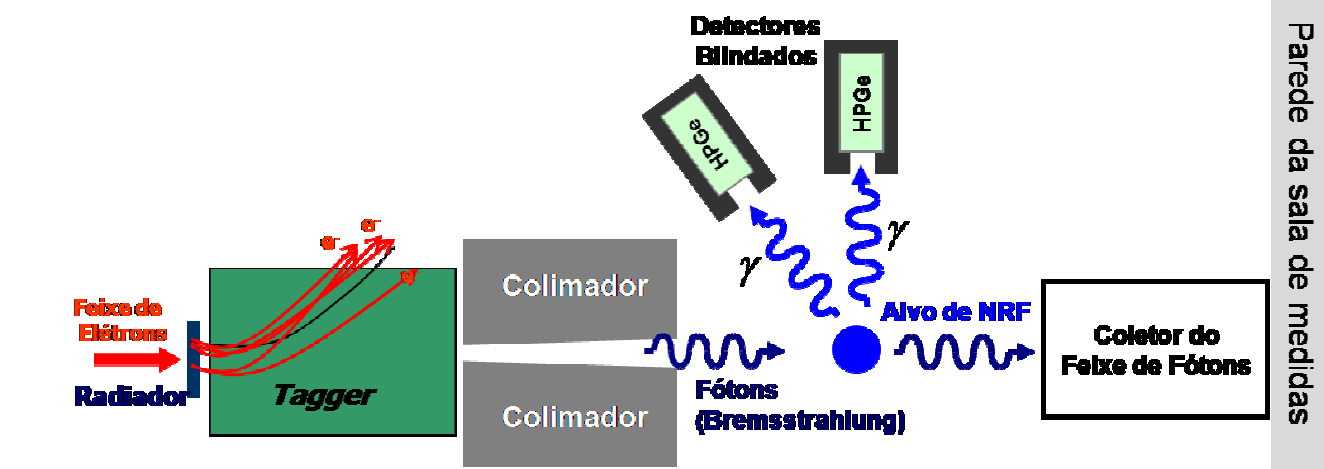

Parede da sala de medidas

Fig. 6.25 Localização relativa dos elementos do sistema de NRF.

\subsubsection{Variantes estudadas}

Estudamos em primeiro lugar o número de fótons retro-espalhados em função da espessura $D$ dos materiais de baixo $Z$, com o tally F4. Na geometria de MCNPX, foram especificados cilindros com raio muito maior que o comprimento $D$, colocados na frente de um cilindro de $\mathrm{Pb}$ de $20 \mathrm{~cm}$ de comprimento. Deste modo, o feixe de fótons incidente, o bremsstrahlung de $10 \mathrm{MeV}$ colimado, interage com o $\mathrm{Pb}$ ou com $\mathrm{PE}, \mathrm{C}$ ou Al de diferentes espessuras. A figura 6.26 apresenta a fração de fótons retro espalhados para duas faixas de energias: $\mathrm{E}_{\gamma}<1 \mathrm{MeV}$ e $1 \mathrm{MeV}<\mathrm{E}_{\gamma}<10 \mathrm{MeV}$. No primeiro intervalo, a fração de retro-espalhamento aumenta até um nível de saturação, alcançando aproximadamente os $15 \mathrm{~cm}$ de espessura, sendo 1,25 vezes menor no Al que no PE e C. Para fótons com $E_{\gamma}>1 \mathrm{MeV}$ a fração diminui com o incremento da espessura até valores praticamente constantes de $1,1 \times 10^{-6}$ para $\mathrm{PE}(\mathrm{D}=80 \mathrm{~cm}) ; 1,9 \times 10^{-6}$ para $\mathrm{C}$ $(\mathrm{D}=40 \mathrm{~cm})$ e $1,6 \times 10^{-5}$ para $\mathrm{Al}(\mathrm{D}=30 \mathrm{~cm})$ por fóton simulado. $\mathrm{O}$ que indica a vantagem do uso de $\mathrm{PE}$. $\mathrm{O}$ incremento do retro-espalhamento para $\mathrm{E}_{\gamma}<1 \mathrm{MeV}$ não constitui um problema porque estes são facilmente detidos pela blindagem dos detectores e não produzem interferências na região de interesse no NRF. 


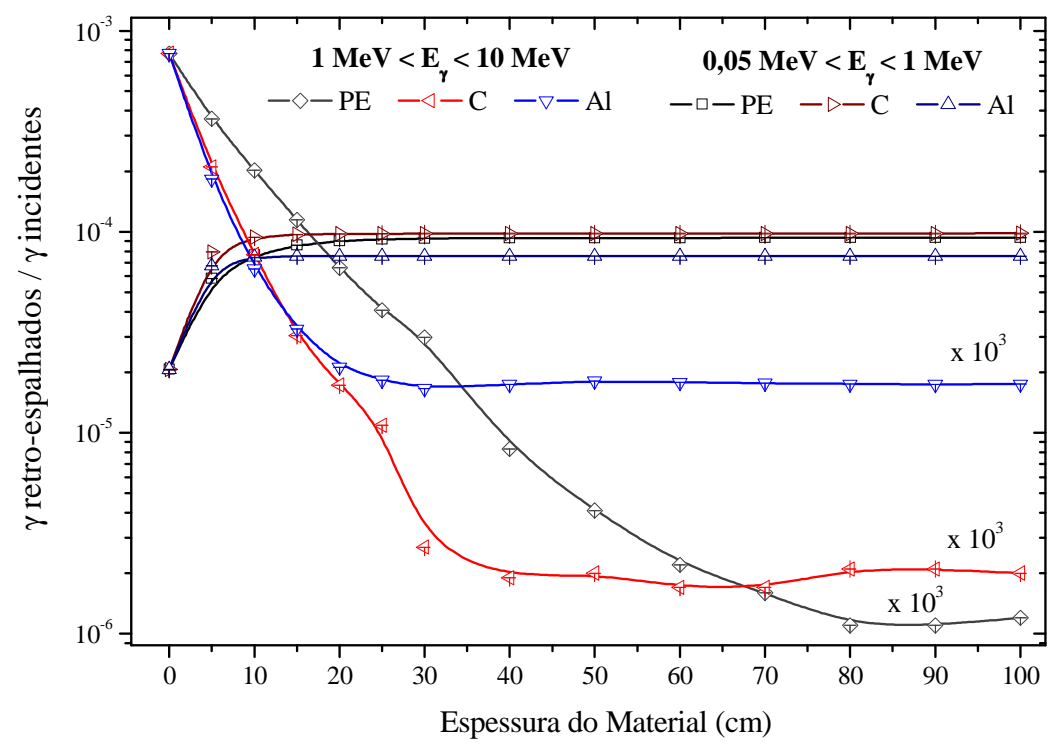

Fig. 6.26 Fração de fótons retro-espalhados em função da espessura dos materiais de baixo $Z$.

Estudamos também os fótons que escapam pela superfície lateral do cilindro de $\mathrm{PE}$, fato importante porque eles vão interagir com o material de alto $Z$ que fica ao redor desse cilindro e poderiam produzir nêutrons. Para um feixe de fótons monoenergéticos de $10 \mathrm{MeV}$, a probabilidade de que escapem fótons de $\mathrm{E}_{\gamma}>5 \mathrm{MeV}$ cai de $1,9 \times 10^{-1}$ para $10 \mathrm{~cm}$ de raio a $1,6 \times 10^{-3}$ para $30 \mathrm{~cm}$. Baseados nestes dados foram estudadas seis configurações de coletores, figura 6.27, formadas por um cilindro de PE de $80 \mathrm{~cm}$ de comprimento, outro de $\mathrm{Ni}$ de $20 \mathrm{~cm}$ para diminuir em três ordens de grandeza a probabilidade de que fótons de alta energia alcancem o $\mathrm{Pb}$ que rodeia esses cilindros. Dispositivos com duas espessuras de $\mathrm{Pb}(5$ e $10 \mathrm{~cm})$ e três raios para os cilindros de $\mathrm{PE}$ $(10,20$ e $30 \mathrm{~cm})$ foram simulados. Entradas cônicas de $\phi_{i}=5,4 \mathrm{~cm}(\mathrm{~Pb}-5 \mathrm{~cm}) \mathrm{e}$ $\phi_{i}=8,3 \mathrm{~cm}(\mathrm{~Pb}-10 \mathrm{~cm})$, correspondentes a um ângulo de abertura de $30^{\circ}$, foram especificadas na parte frontal do $\mathrm{Pb}$ para permitir a entrada do feixe de fótons. 


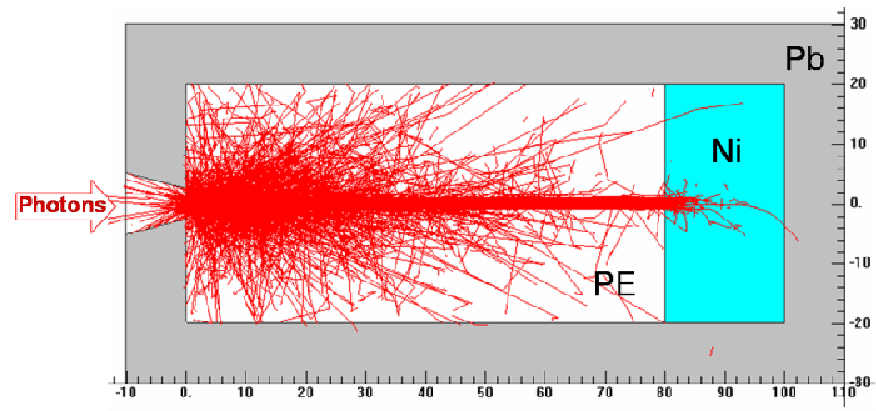

Fig. 6.27 Trajetórias de fótons com $\mathrm{E}_{\gamma}>0,05 \mathrm{MeV}$ na configuração com os cilindros de $\mathrm{PE}$ $(\mathrm{R}=20$ e $1=80 \mathrm{~cm})$, de $\mathrm{Ni}(\mathrm{R}=20$ e $1=20 \mathrm{~cm})$ e o $\mathrm{Pb}(10 \mathrm{~cm}$ de espessura $)$, para $5 \times 10^{4}$ eventos computados. Escala em centímetros.

Os resultados das simulações mostram que a maior parte dos fótons que escapa, o fazem pelo furo de entrada, $2,4 \%$ e $1,6 \%$ do feixe incidente para 5 e $10 \mathrm{~cm}$ de espessura do $\mathrm{Pb}$, respectivamente, independentemente do raio do cilindro de $\mathrm{PE}$, mas $99 \%$ desses fótons tem $\mathrm{E}_{\gamma}<0,5 \mathrm{MeV}$. O escape pela lateral depende do raio e da espessura de $\mathrm{Pb}$ sendo $2,1 \times 10^{-1} \%, 1,0 \times 10^{-1} \%$, e $4,0 \times 10^{-2} \%$ para $5 \mathrm{~cm}$ de $\mathrm{Pb}$ e $\mathrm{R}=10$, 20, $30 \mathrm{~cm}$ respectivamente. Para $10 \mathrm{~cm}$ de $\mathrm{Pb}$, esses valores são 40 vezes menor. Aproximadamente $90 \%$ dos fótons que emergem pela parede lateral tem $\mathrm{E}_{\gamma}<2 \mathrm{MeV}$.

Para reduzir o escape lateral, o cilindro de PE pode ser rodeado de $10 \mathrm{~cm}$ de $\mathrm{Al}$ (Fig. 6.28) sem aumentar a produção de nêutrons e dos fótons retro-espalhados. A outra mudança em relação à proposta da figura 6.27 foi reduzir o raio do cilindro de $\mathrm{Ni}$, a fim de reduzir a produção de nêutrons. O PE atua como termalizador, de modo que os nêutrons podem ser capturados colocando entre o $\mathrm{Pb}$ e os cilindros de $\mathrm{PE}, \mathrm{Ni}$ e $\mathrm{Al}$ uma camada de $1 \mathrm{~mm}$ de $\mathrm{Cd}$, exceto na abertura de entrada do feixe. A figura 6.28 apresenta trajetórias de fótons e nêutrons no coletor desenhado, que reduz por um fator $200 \mathrm{o}$ número de fótons espalhados com $\mathrm{E}_{\gamma}>2 \mathrm{MeV}$ e fótons incidentes de $5 \mathrm{MeV}$, e em um fator 100 para fótons incidentes de $10 \mathrm{MeV}$. Os nêutrons produzidos no PE devido à reação ${ }^{2} \mathrm{H}(\gamma, \mathrm{n})$ são termalizados e praticamente reabsorvidos dentro do mesmo PE. Para esta configuração, $10^{-14}$ nêutrons escapam do coletor por cada fóton incidente. 

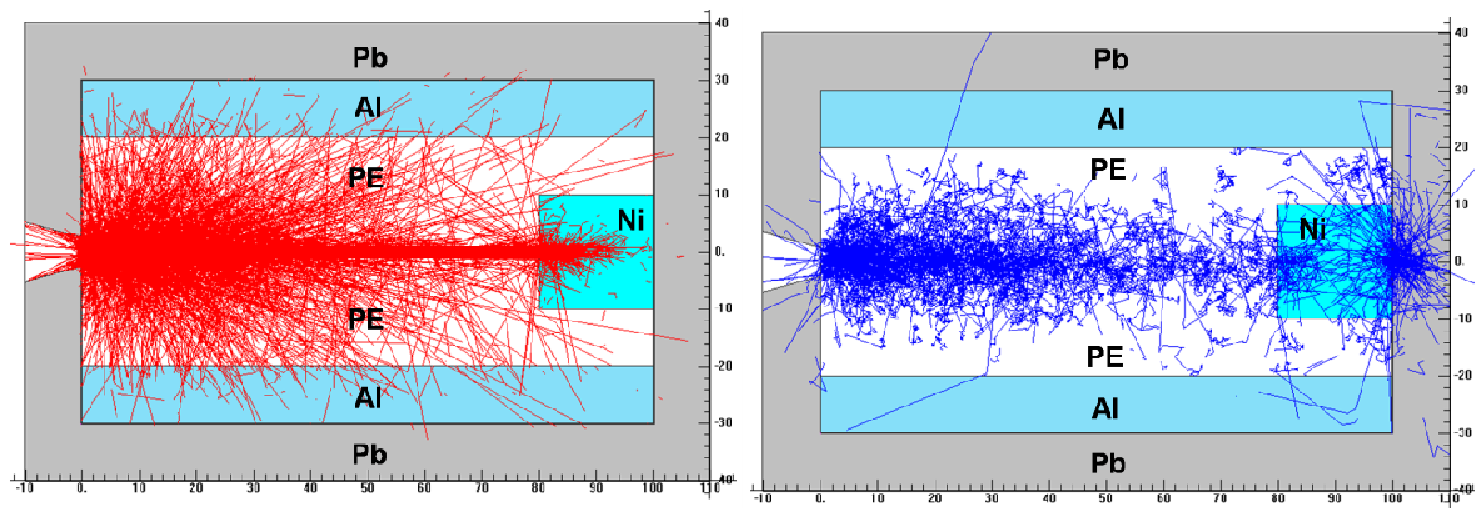

Fig. 6.28 Trajetórias de fótons com $0,05<\mathrm{E}_{\gamma}<10 \mathrm{MeV}$ (esquerda) e de nêutrons (direita) para o coletor desenhado. Para as figuras foram computados $1 \times 10^{5}$ eventos de fótons e $7 \times 10^{4}$ eventos de nêutrons.

\subsubsection{Efeito do coletor em uma simulação completa do experimento}

Para avaliar o efeito do coletor de fótons na redução do background nos espectros de NRF dos detectores de HPGe foram realizadas várias simulações, estudando a distribuição energética dos fótons retro-espalhados, a probabilidade de que eles cheguem à superfície da blindagem do detector situado a $90^{\circ}$, e finalmente a distribuição de alturas de pulso que eles provocam no cristal de HPGe. Estas simulações foram feitas para duas situações: com o feixe de fótons batendo na parede da sala de medidas, e com o feixe batendo no coletor de fótons desenhado, separado $160 \mathrm{~cm}$ da borda do colimador (Fig. 6.25). Como detector foi escolhido um cristal de HPGe de $70 \%$ de eficiência caracterizado previamente [De05], blindado por $10 \mathrm{~cm} \mathrm{de} \mathrm{Pb} \mathrm{e}$ separado $20 \mathrm{~cm}$ de um alvo de $\mathrm{Al}$ com $2 \mathrm{~g}$ e 2,0 cm de diâmetro [Kn96].

A contribuição do espalhamento inelástico no alvo foi estimada fazendo incidir o espectro de bremsstrahlung colimado no alvo e estudando a distribuição energética dos fótons que se propagam em direção ao detector. Para estimar a distribuição de alturas de pulso devido à parte elástica, foi calculada a intensidade dos principais raios gamas emitidos pelo ${ }^{27} \mathrm{Al}$ [En90] partindo da secção de choque $I_{s}$ (eq. 6.2,) com os valores de spin do estado fundamental $J_{o}$, do estado excitado, $J$, e as larguras respectivas desses níveis $\Gamma_{o}$ e $\Gamma$ empregando os valores publicados por Endt [En90].

$$
I_{S}=\frac{2 J+1}{2 J_{o}+1}\left(\frac{\pi \hbar c}{E_{\gamma}}\right)^{2} \frac{\Gamma_{o}^{2}}{\Gamma}
$$


Então o número de fótons para a energia de ressonância $E_{\gamma}$ que se propagam na direção do ângulo $\theta, I_{A l}\left(E_{\gamma}, \theta\right)$, é a multiplicação da secção de choque $I_{S}\left(E_{\gamma}\right)$, do número de fótons incidentes ou intensidade espectral no alvo $N_{\gamma}\left(E_{\gamma}\right)$, do número $N_{A l}$ de núcleos de ${ }^{27} \mathrm{Al}$, e da distribuição angular desses fótons de ressonância $W(\theta)$ [Br01]:

$$
I_{A l}\left(E_{\gamma}, \theta\right)=N_{\gamma} \cdot N_{A l} \cdot I_{S}\left(E_{\gamma}\right) \cdot W(\theta) / 4 \pi
$$

Como o ${ }^{27} \mathrm{Al}$ é um núcleo ímpar e spin 5/2 no estado fundamental, os fótons são emitidos praticamente com uma distribuição isotrópica $\left(W_{A l}(\theta) \approx 1\right)$ [Kn96, Br01]. Então, tendo a intensidade de emissão dos fótons de ressonância, foram estimados os correspondentes espectros de alturas de pulsos no cristal de HPGe. A soma de todas as contribuições elásticas e inelásticas para a duas situações comparadas é apresentada na figura 6.29. A contribuição do espalhamento inelástico ao espectro é reduzida significativamente pelo coletor, passando a ser o espalhamento inelástico no alvo a principal componente de background [Go94]. Para 1,5 $<\mathrm{E}_{\gamma}<4,5 \mathrm{MeV}$, o uso do coletor duplica a relação pico - background no caso do ${ }^{27} \mathrm{Al}$.

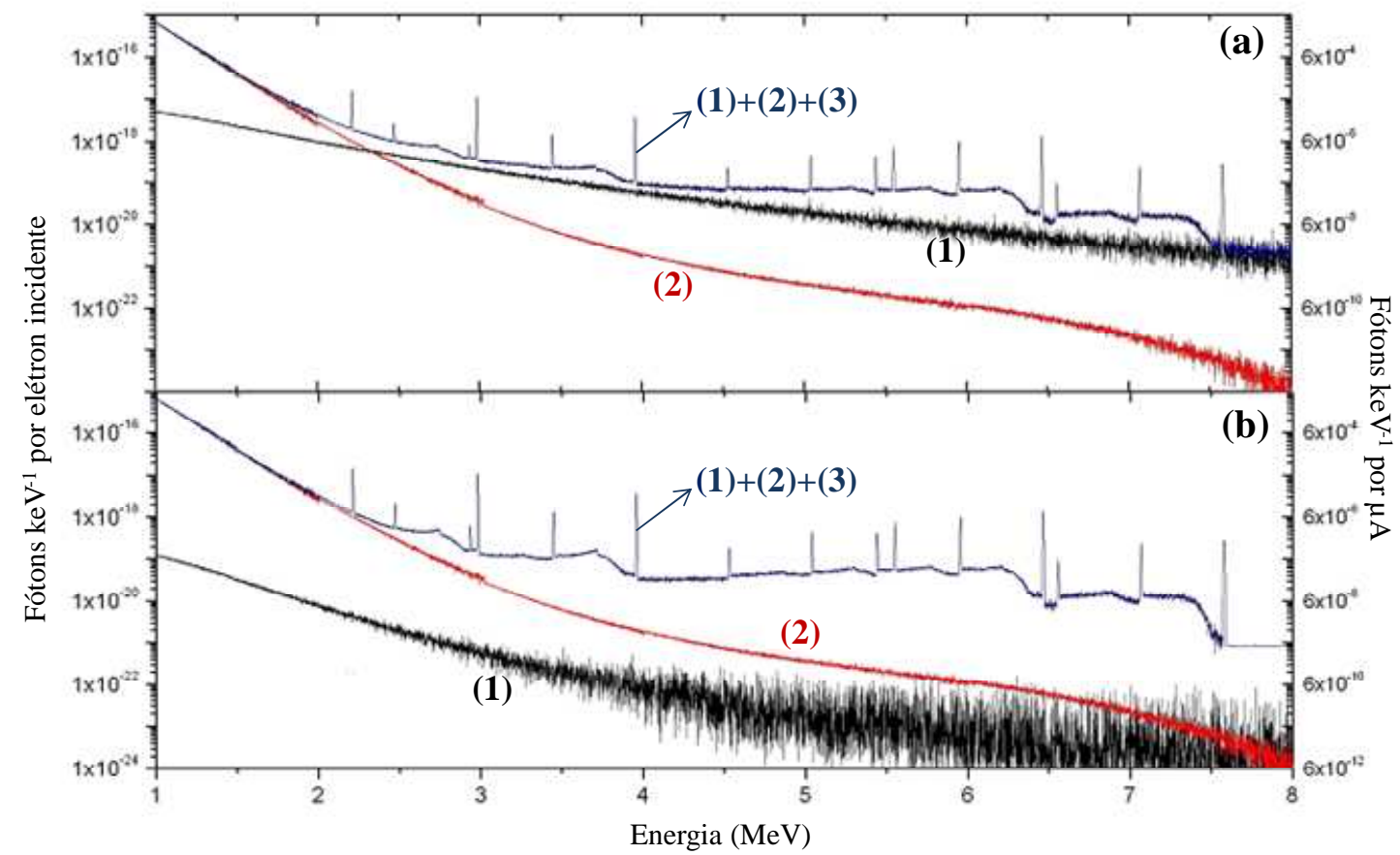

Fig. 6.29 Comparação entre os espectros gamas sem (a) ou com (b) o emprego do coletor do feixe de fótons. As legendas (1), (2), e (3) representam as contribuições de espalhamentos nas paredes, e os inelásticos e o elásticos no alvo de NRF, respectivamente. 


\subsection{Projeto Final de arranjo para o sistema de NRF}

O sistema de NRF projetado está formado por um radiador de $\mathrm{Nb}$ com uma espessura de $5 \mathrm{mg} \mathrm{cm}^{-2}$; um colimador de $\mathrm{Ni}$ com um furo cilíndrico de $\phi_{\text {Furo }}=1,2 \mathrm{~cm} \mathrm{e}$ dimensões externas de $\phi_{\text {Externo }}=40 \mathrm{~cm}$, rodeado de concreto para complementar a colimação; detectores de HPGe blindados com $10 \mathrm{~cm}$ de $\mathrm{Pb}$, comumente localizados a $90^{\circ}$ e $127^{\circ}$ em relação à direção do feixe de bremsstrahlung colimado, e separados $20 \mathrm{~cm}$ do alvo, que ficaria a $100 \mathrm{~cm}$ de distância da borda do colimador; e um coletor para o feixe de fótons que se encontraria $60 \mathrm{~cm}$ após o alvo, próximo à parede da sala de medidas. A figura 6.30 apresenta os pontos de colisão de fótons em três faixas de energias $\left(0,05<\mathrm{E}_{\gamma}<10 \mathrm{MeV}, 1<\mathrm{E}_{\gamma}<5 \mathrm{MeV}, 5<\mathrm{E}_{\gamma}<10 \mathrm{MeV}\right)$, obtidos mediante simulação por MCNPX do sistema de NRF projetado. Observa-se o efeito de colimação e a função do coletor na diminuição do background. No Capítulo 7 , correspondente à discussão dos resultados, serão expostos para o sistema projetado elementos acerca da intensidade espectral e outros parâmetros característicos de um arranjo de NRF.

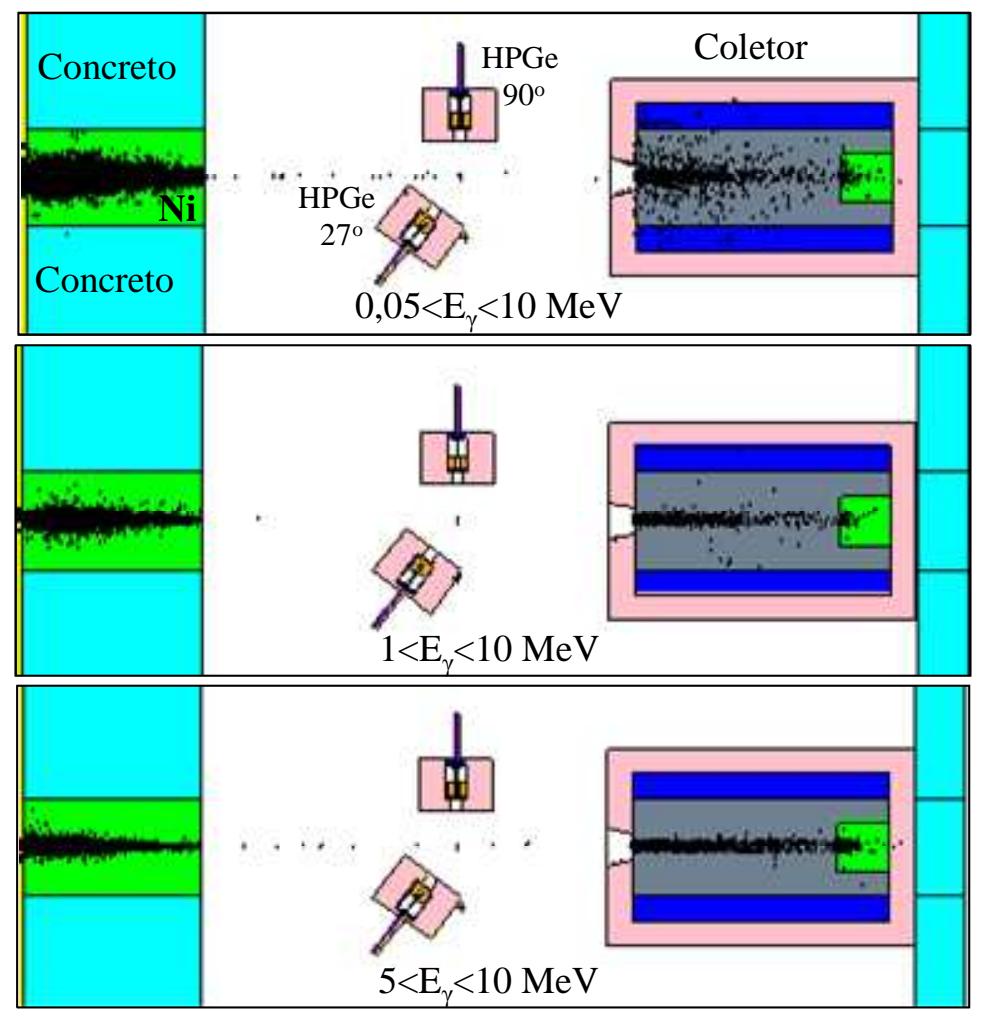

Fig. 6.30 Pontos de colisão de fótons em três faixas de energia obtidos mediante simulação por MCNPX do sistema de NRF projetado. O numero de elétrons simulados foi $10^{4}$ nas duas primeiras faixas e na última $10^{5}$. 


\section{Capítulo 7}

\section{Discussão}

\subsection{Bremsstrahlung: distribuição angular e intensidade no tip.}

Os resultados experimentais expostos no Capítulo 5, relativos à determinação das secções de choque de produção de bremsstrahlung, permitiram verificar as previsões calculadas pelo código MCNPX, amplamente empregado neste trabalho como instrumento para planejar e otimizar arranjos experimentais, assim como para determinar a função resposta do detector de HPGe. As discordâncias encontradas nas seções de choque para produção de fótons com energias menores que $1700 \mathrm{keV}$ e $1800 \mathrm{keV}$ a $30^{\circ}$ e $60^{\circ}$ em relação feixe de elétrons, respectivamente, foram igualmente explicadas nos diferentes cálculos realizados com o código MCNPX, estudando as componentes que influenciam no background.

Já na região de energia de fótons perto do tip, praticamente não há influência do background, o que permite a comparação dos resultados com cálculos teóricos e outros resultados experimentais relatados na literatura. As figuras $7.1-7.4$ apresentam nossos resultados experimentais junto com as curvas teóricas para uma energia dos elétrons de 1,84 MeV [Pr75]. Nessas figuras, as três linhas simbolizadas pelas legendas BA, EH e KS representam os resultados obtidos, respectivamente, pela fórmula de Bethe - Heitler [Be84], por cálculos analíticos de Elwert - Haug [El69] e usando o potencial relativista auto-consistente de Kohn - Sham [Ko65]. Os resultados publicados por Pratt e Tseng [Pr75] correspondem à secção de choque integrada sobre todos os ângulos. Para obter a secção de choque diferencial em ângulo sólido, a secção de choque integral foi multiplicada pela probabilidade de emissão de fótons num ângulo dado, que para 
elétrons com energias maiores que $0,5 \mathrm{MeV}$ é aproximadamente igual à distribuição clássica de emissão de um dipolo, com a correção relativística [Sa03, Ha03].

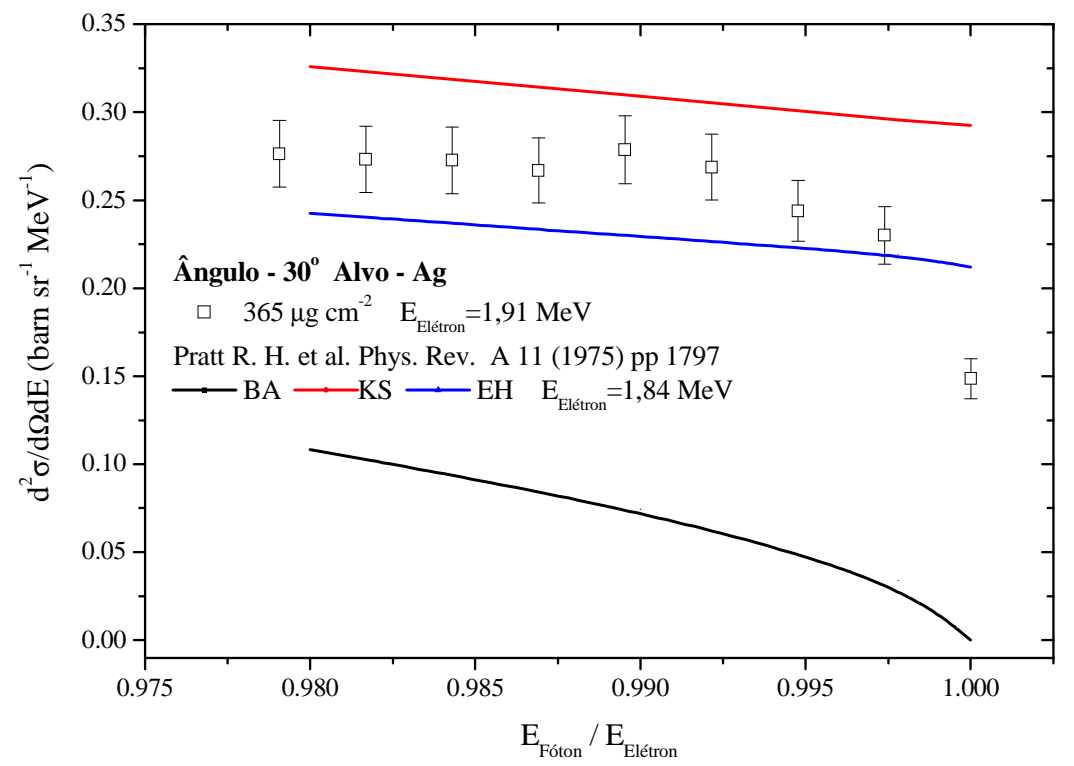

Fig. 7.1 Comparação entre o resultado experimental da secção de choque na região do tip para fótons a $30^{\circ}$ em relação ao feixe e alvo de Ag e as previsões teóricas com três aproximações diferentes [Pr75].

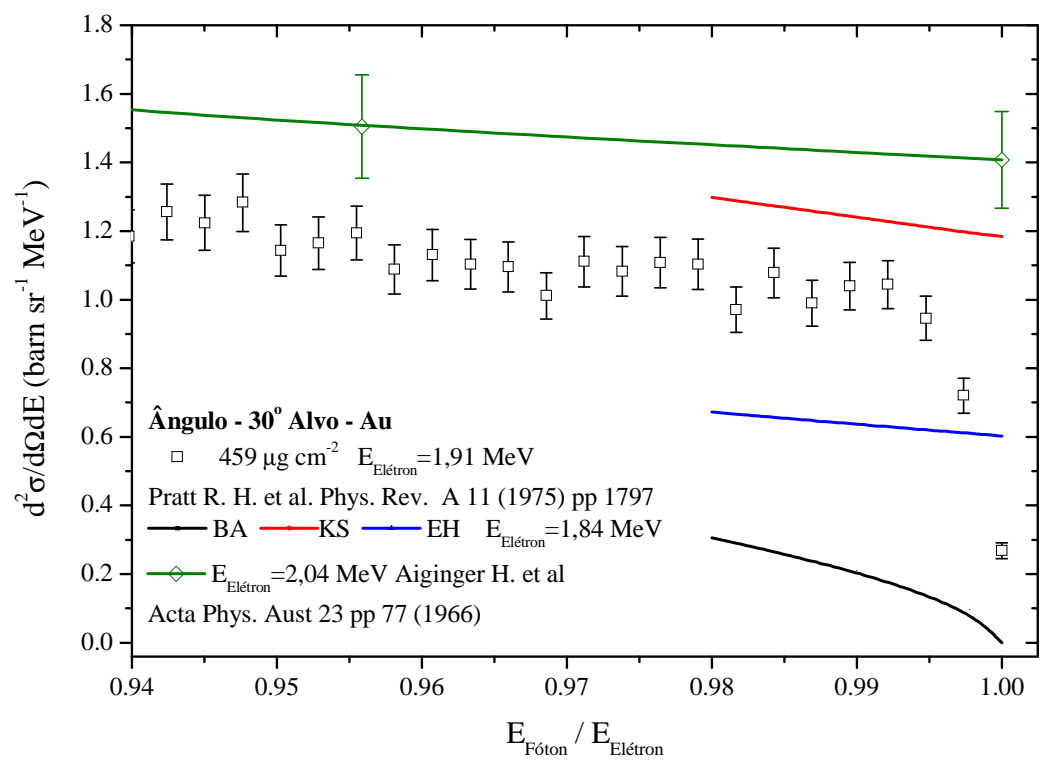

Fig. 7.2 Comparação entre o resultado experimental da secção de choque na região do tip para fótons a $30^{\circ}$ em relação ao feixe e alvo de Au e as previsões teóricas com três aproximações diferentes [Pr75] e os dados experimentais de Aiginger e Zinke [Ai66]. 


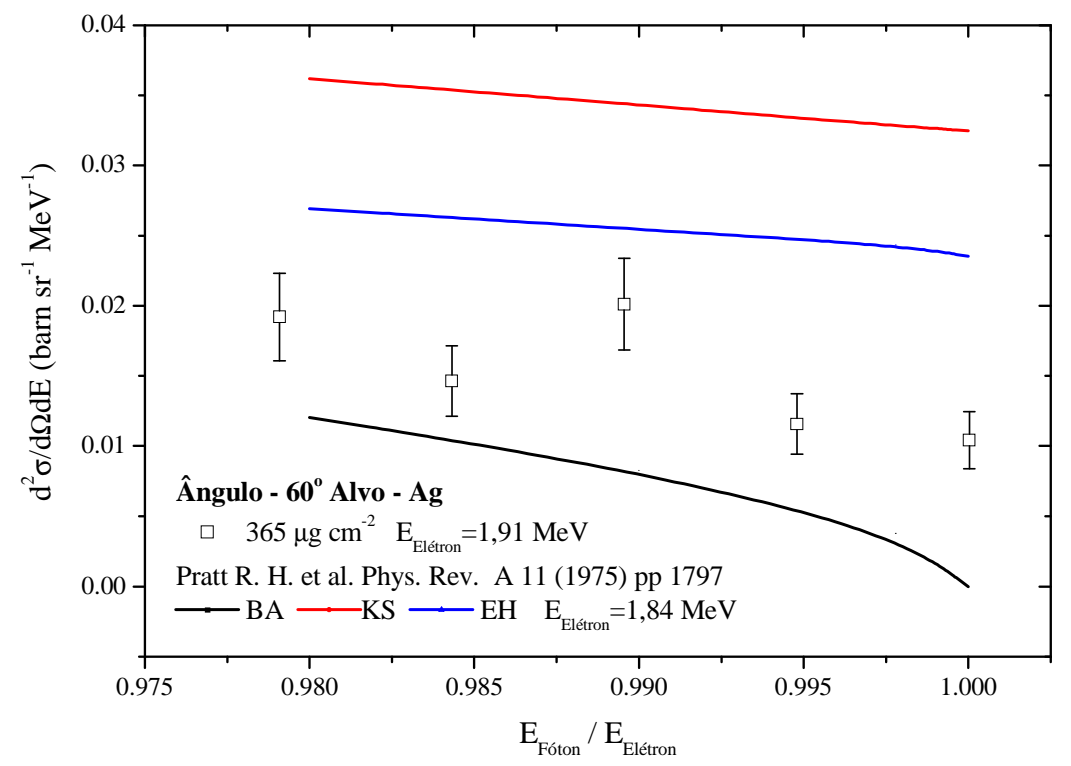

Fig. 7.3 Comparação entre o resultado experimental da secção de choque na região do tip para fótons a $60^{\circ}$ em relação ao feixe e alvo de Au e previsões teóricas com três aproximações [Pr75].

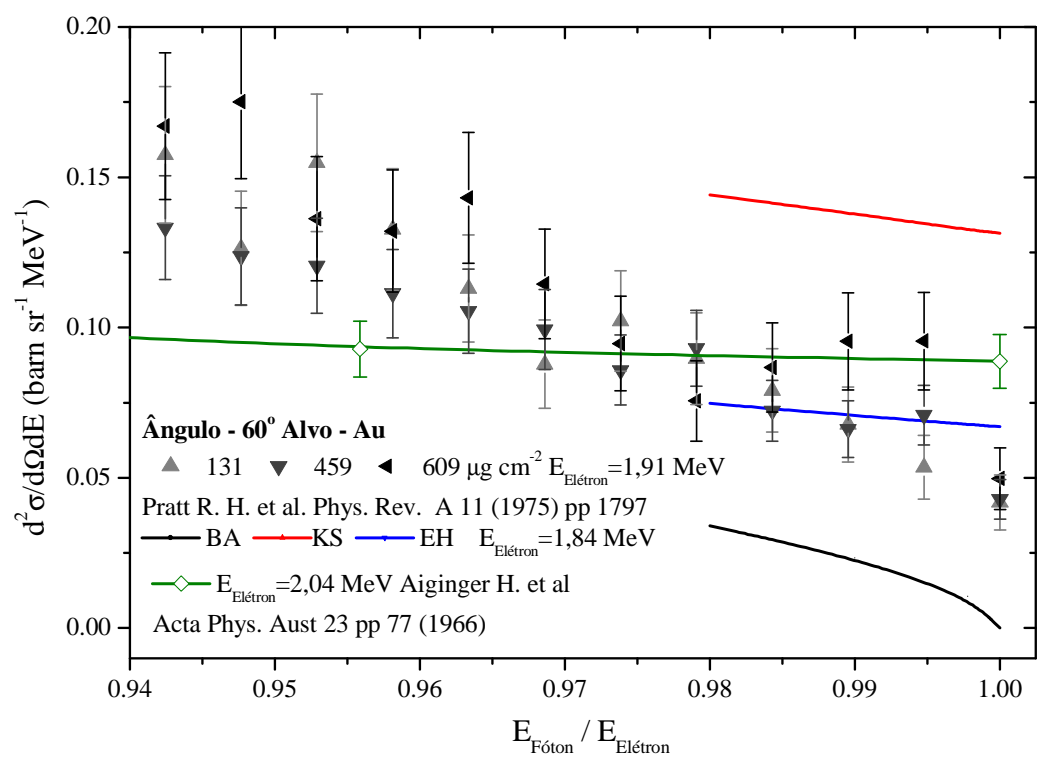

Fig. 7.4 Comparação entre o resultado experimental da secção de choque na região do tip para fótons a $60^{\circ}$ em relação ao feixe e alvo de $\mathrm{Au}$, as previsões teóricas com três aproximações [Pr75] e os dados experimentais de Aiginger e Zinke [Ai66].

Nossos dados experimentais de seção de choque de emissão de fótons a $30^{\circ} \mathrm{em}$ relação ao feixe encontram-se entre as previsões correspondentes a KS e EH, e são maiores que os resultados da BA, cuja validade na região do tip é limitada [Pr75]. Por outro lado para emissão de fótons a $60^{\circ}$ os resultados obtidos tendem a ser menores que 
as previsões teóricas $\mathrm{KS}$ e EH, em particular, no caso da $\mathrm{Ag}$ o dado experimental cai entre as linhas BA e KS, e no caso do Au, sobre a linha KS.

Nas figuras 7.2 e 7.4 também são apresentados outros dados experimentais. Comparando nossos resultados com os de Aiginger e Zinke [Ai66] para 2,04 MeV, pode se observar que eles são $15 \%$ menores para $30^{\circ}$ e tendem a coincidir para $60^{\circ}$. Por outra parte os dados de Rester e Dance [Re67], para elétrons de 1,7 MeV, são cerca de 50\% maiores que os nossos para os dois ângulos.

Os desacordos vistos nas figuras anteriores podem ser observados de outra maneira, usando a aproximação de emissão dipolar para fazer a conversão da seção de choque diferencial medida a $30^{\circ}$ e $60^{\circ}$ para seção de choque integrada em todos os ângulos. A figura 7.5 apresenta a secção de choque integrada para a energia máxima do espectro de fótons, em função do número atômico do material. Os resultados obtidos a partir das medidas a $30^{\circ}$ concordam com a curva construída pelas tabelas de Pratt e Tseng [Pr77, Pr81], mas aqueles obtidos a partir das medidas a $60^{\circ}$ ficam abaixo da curva. A figura 7.6 mostra o comportamento da secção de choque integrada em função da energia dos elétrons incidentes. Os círculos cheios em vermelho correspondem a resultados experimentais para o Au publicados por diversos autores [Re67, Mo55, Mo58, Ai66, Ai72, Re72]. Novamente, nosso resultado fica abaixo do comportamento geral para $60^{\circ}$. Assim, esse desacordo entre nosso dado a $60^{\circ}$ com a expectativa teórica pode estar indicando que a aproximação de distribuição angular dipolar não é adequada.

Estas medidas de secções de choques de produção de bremsstrahlung, que integram as primeiras experiências no novo acelerador do LAL, permitiram também ajustar e testar vários detalhes no funcionamento do acelerador tais como a estabilidade da corrente e o monitoramento da mesma, e das dimensões do feixe. Parâmetros imprescindíveis para o acoplamento e teste do booster, que fornecerá elétrons de $5 \mathrm{MeV}$ de energia e permitirá a ampliação das linhas de pesquisas, inclusive a medida da NRF, como discutido a seguir. 


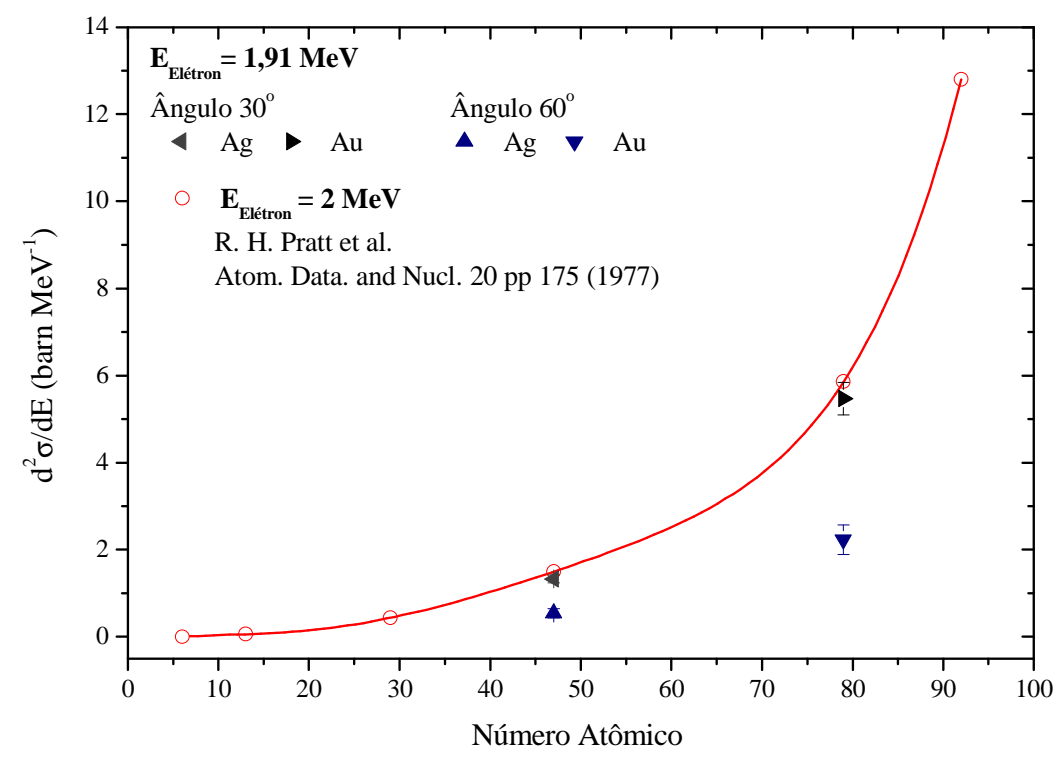

Fig. 7.5 Secção de choque para a energia máxima do espectro de fótons, integrada em todos os ângulos, em função do numero atômico do material. Comparação entre os dados obtidos a partir das medidas a $30^{\circ}$ e $60^{\circ}$ com a curva construída pelas tabelas de Pratt e Tseng [Pr77]

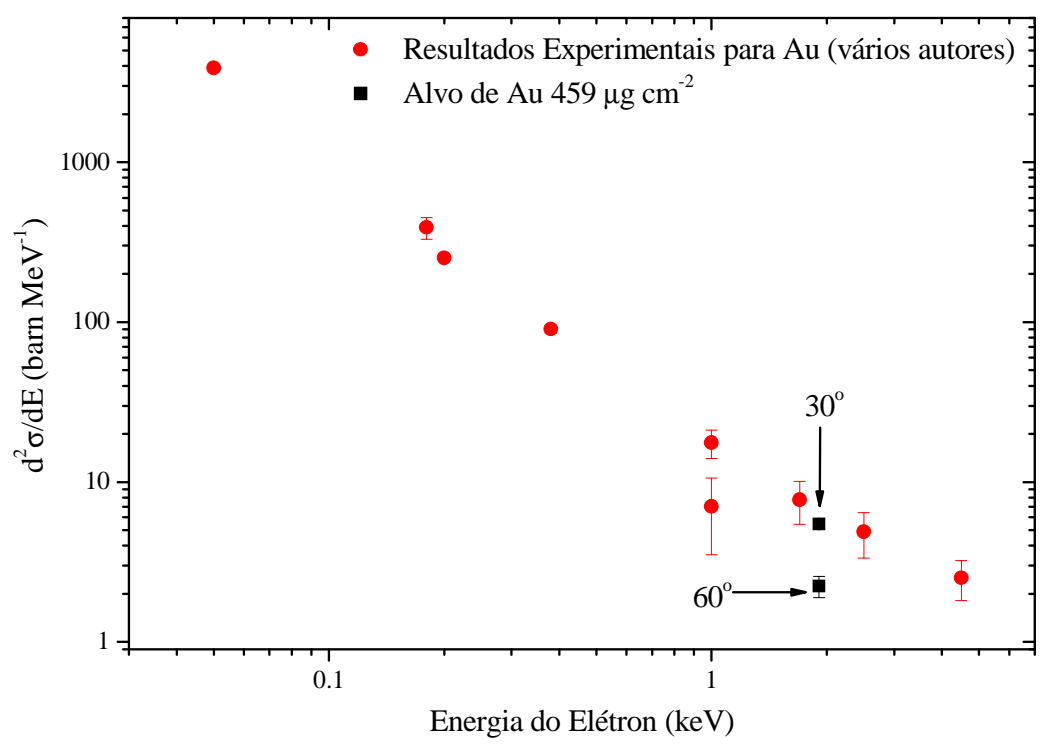

Fig. 7.6 Secção de choque para a máxima energia do espectro de fótons, integrada em todos os ângulos, em função da energia dos elétrons incidentes. Comparação entre os resultados obtidos partindo das medidas a $30^{\circ}$ e $60^{\circ}$ para o alvo de Au com aqueles obtidos por vários autores [Re67, Mo55, Mo58, Ai66, Ai72, Re72].

\subsection{Arranjo para medidas de NRF}

Uma avaliação para o sistema de NRF projetado pode ser feita estimando a intensidade espectral $N_{\gamma}$, o número de fótons emitidos por um alvo característico, e as 
intensidades dos picos de absorção total observados no detector de fótons, correspondentes às diferentes energias de espalhamento elástico nesse alvo. Novamente o isótopo de ${ }^{27} \mathrm{Al}$ foi escolhido como referência. Foi suposto um alvo com 2 g [Kn96] de massa e $2 \mathrm{~cm}$ de diâmetro. Lembrando as equações (6.2) e (6.3), as intensidades dos picos no detector $A_{A l}\left(E_{\gamma}, \theta\right)$ foram calculadas pela equação (7.1), onde $\varepsilon\left(E_{\gamma}\right)$ representa a eficiência do pico de absorção total [Br01].

$$
A_{A l}\left(E_{\gamma}, \theta\right)=N_{\gamma} \cdot \varepsilon\left(E_{\gamma}\right) \cdot N_{A l} \cdot I_{S}\left(E_{\gamma}\right) \cdot W(\theta) / 4 \pi
$$

A figura 7.6 apresenta os espectros de bremsstrahlung na posição do alvo determinados com o MCNPX e a comparação com o cálculo usando a formula de Schiff [Sc51]. As curvas preta e vermelha correspondem aos casos sem e com o tagger, respectivamente; a relação de intensidades entre elas é aproximadamente dois. Para a corrente máxima do acelerador do LAL, $50 \mu \mathrm{A}$, a intensidade espectral para fótons de $3 \mathrm{MeV}$ de energia é aproximadamente $500 \gamma /(\mathrm{s} \mathrm{eV}), 50 \%$ do relatado para outros sistemas de NRF como o S-DALINAC em Darmstadt [Kn96, Mo99]. A Tabela 7.1 resume os dados obtidos para as principais linhas de NRF do ${ }^{27} \mathrm{Al}$ [En90]. Nesses cálculos, a contribuição devida à desexcitação de estados de maior energia não foi considerada.

Para experimentos com feixes de bremsstrahlung não polarizado e $1 \mathrm{~g}$ de massa (alvo enriquecido no isótopo de interesse), os tempos de medida tradicionais são de 3 - 4 dias [Kn96], que deve corresponder a 6-8 dias de medição com nosso sistema, devido à menor intensidade espectral conseguida com nosso arranjo. Com experimentos dessa duração, para o ${ }^{27} \mathrm{Al}$ seriam obtidos $850 \pm 120$ e $62 \pm 10$ contagens nos picos de 2211 e $7578 \mathrm{keV}$, respectivamente. A alimentação dos níveis de menores energias pelos mais excitados faz com que a diferença de intensidades entre os picos de menor e os de maior energia seja, na realidade, superior à que consta na tabela.

Nestes tipos de experiências (feixe não polarizado, massa do alvo $1 \mathrm{~g}$ ) a largura de transição do estado básico ao excitado, $\Gamma_{\mathrm{o}}$, tem um limite de detecção da ordem de $\Gamma_{\mathrm{o}} \leq 1 \mathrm{meV}$ [Kn96]. Supondo $\Gamma_{\mathrm{o}}=1 \mathrm{meV}$ e usando as relações entre a probabilidade reduzida de transição $B\left(\Pi L, E_{\gamma}\right) \uparrow$ e $\Gamma_{0}$, para transições dipolares em núcleos par - par, eqs. 2.11 e 2.12, respectivamente, obtêm-se limites mínimos de deteção de $B(E 1) \uparrow \approx 0.11 \times 10^{-2} e^{2} \mathrm{fm}^{2}$ e $B(\mathrm{M} 1) \uparrow=0,01 \mu_{\mathrm{N}}{ }^{2}$ para as transições elétricas 
e magnéticas, respectivamente. A sensibilidade limite, que é a multiplicação de $\Gamma_{\mathrm{o}}$ pela massa do isótopo e se expressa em unidades de $\mathrm{meV} \times \mathrm{g}$, aumenta com o incremento da massa do isótopo, mas pode ser inviável utilizar quantidades grandes de material enriquecido nos casos de abundância isotópica extremadamente baixa.

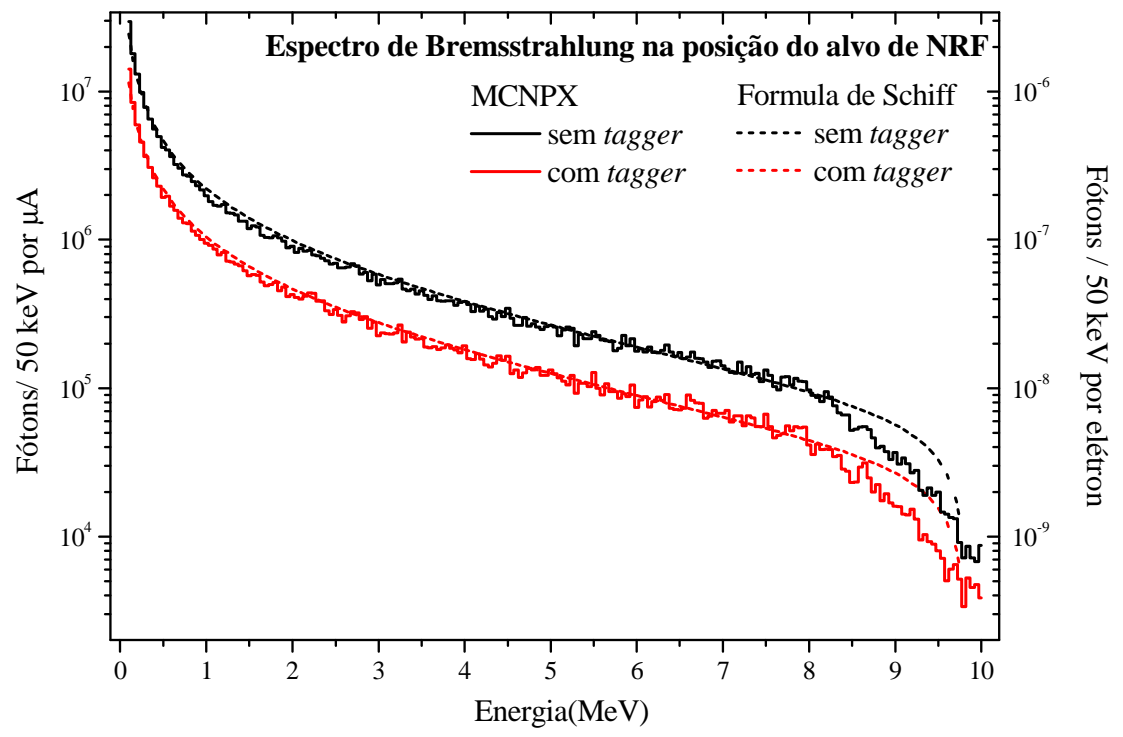

Fig. 7.6 Espectros de bremsstrahlung na posição do alvo para um radiador de $\mathrm{Nb}\left(5 \mathrm{mg} \cdot \mathrm{cm}^{-2}\right)$ estimados com o MCNPX e comparação com o calculado pela fórmula de Schiff [Sc51].

Tabela 7.1 Intensidade espectral na posição do alvo e intensidade nos fotopicos para $50 \mu \mathrm{A}$ de corrente e $2 \mathrm{~g}$ de massa do alvo de ${ }^{27} \mathrm{Al}$, no sistema de NRF sem tagger.

\begin{tabular}{ccccc}
\hline $\begin{array}{c}\text { Níveis do }{ }^{27} \mathbf{A l}[\mathbf{E n 9 0}] \\
(\mathbf{k e V})\end{array}$ & $\begin{array}{c}\mathbf{I}_{\mathbf{s}} \\
(\mathbf{e V} \text { barn })\end{array}$ & $\begin{array}{c}\text { Intensidade } \\
\mathbf{e s p e c t r a l} \\
\left(\boldsymbol{\gamma ~ s}^{-\mathbf{1}} \mathbf{e V}^{-\mathbf{1}}\right)\end{array}$ & $\begin{array}{c}\text { Fótons emitidos } \\
\text { pelo alvo de Al } \\
\left(\boldsymbol{\gamma} \mathbf{~ s}^{-\mathbf{1}}\right)\end{array}$ & $\begin{array}{c}\text { Intensidade do fotopico } \\
\text { detector de HPGe } \\
\left(\mathbf{1 0}^{-\mathbf{3}} \boldsymbol{\gamma ~}_{\mathbf{~}} \mathbf{- 1}\right)\end{array}$ \\
\hline 2211 & 18,0 & 792 & 201 & 1,4 \\
\hline 2982 & 31,6 & 496 & 222 & 1,3 \\
\hline 3957 & 21,3 & 383 & 116 & 0,5 \\
\hline 5551 & 12,2 & 211 & 36 & 0,1 \\
\hline 6463 & 38,2 & 174 & 94 & 0,3 \\
\hline 7578 & 18,3 & 102 & 26 & 0,1 \\
\hline
\end{tabular}

Nas medidas de NRF, a redução do background é um fator determinante, portanto, qualquer elemento adicional que in-situ contribua para sua diminuição deverá ser considerado, sempre com o cuidado de não interferir no fluxo de fótons que incide sobre o alvo e sem incrementar a produção de nêutrons. Atendendo ao espaço na sala de 
irradiação e à disponibilidade de blocos de concreto, recomenda-se isolar ao máximo possível as áreas de produção de bremsstrahlung e de medidas.

A estimativa da intensidade espectral do sistema permite discernir aquelas pesquisas de NRF factíveis de serem feitas no Microtron do LAL com o equipamento atualmente disponível, e ao mesmo tempo estimar os recursos para a aquisição da instrumentação nuclear complementar. 


\section{Capítulo 8}

\section{Conclusões}

As secções de choque de produção de bremsstrahlung de elétrons com 1,9 MeV, diferencial em energia e ângulo, foram medidas para Ag e Au com o feixe do injetor do Microtron, usando a câmara de irradiação localizada na linha de feixe adicionada ao projeto original do Microtron.

As medições foram realizadas com um detector de HPGe, cujas dimensões, inclusive do orifício interno e da camada morta do cristal, foram determinadas por uma combinação de medidas experimentais e simulações de Monte Carlo, com o código MCNPX. Esses parâmetros permitiram calcular por simulação a função resposta do detector, que, depois da validação experimental, foram usadas na deconvolução dos espectros de bremsstrahlung.

A análise dos resultados experimentais evidenciou discordâncias na seção de choque de bremsstrahlung para energias menores que $1800 \mathrm{keV}$ devido a diversas fontes de radiação de fundo, identificadas com a ajuda de simulações por Monte Carlo, e cuja influência poderá ser reduzida significativamente fazendo mudanças nas geometrias de irradiação e medição. Em particular, se fez evidente a necessidade de alterar a moldura do alvo, melhorar a estabilidade da corrente de feixe e, em conseqüência, a medida da corrente de elétrons.

Na região próxima ao tip do espectro de Bremsstrahlung, entre 1700 e $1910 \mathrm{keV}$, os resultados obtidos encontram-se na faixa de valores publicados na literatura, mas conseguimos determiná-lo com uma resolução de $5 \mathrm{keV}$ y $10 \mathrm{keV}$ para $30^{\circ}$ e $60^{\circ}$ respectivamente. As comparações efetuadas mostram a necessidade de seguir pesquisando este tema, especificamente com estudos experimentais em uma faixa ampla de valores de número atômico e de ângulos de emissão dos fótons. Os experimentos anteriores usaram detectores com pior resolução em energia que os de HPGe ou restringiram-se a medidas em ângulos frontais, ou, ainda, empregaram aceleradores pulsados. Assim, o uso de detectores de HPGe no Microtron, que trabalha em regime de 
onda contínua, fornecerá resultados experimentais de qualidade que poderão contribuir para desenvolver a teoria de bremsstrahlung nessa faixa de energia intermediária.

A simulação do arranjo de medidas de Fluorescência de Ressonância Nuclear, NRF, projetado para elétrons com energia de $10 \mathrm{MeV}$, permitiu estabelecer as dimensões e materiais dos diversos elementos que formam o mesmo, sob a exigência de minimizar o background devido aos fótons espalhados e aos nêutrons de reações fotonucleares. O arranjo desenhado usa materiais facilmente encontrados e não apresenta nenhuma dificuldade técnica excepcional para sua construção. Para o arranjo projetado, foram estimadas a intensidade do espectro de bremsstrahlung incidente no alvo e as taxas de contagem esperadas nos detectores de fótons com alvos comumente usados na calibração dos arranjos de NRF. Os resultados obtidos indicam a viabilidade desse tipo de experimento com o Microtron. 


\section{Anexos}

\section{Anexo I Sistemas de medidas de NRF em outros laboratórios}

\section{I.1 Arranjo no acelerador DYNAMITRON 4,3 MV em Stuttgart}

A figura AI.1 mostra o sistema instalado no acelerador eletrostático DYNAMITRON 4,3MV do Institut für Strahlenphysik da Universidade de Stuttgart, e no qual podem ser acelerados tanto elétrons $\left(I_{\max }=4 \mathrm{~mA} E_{\max }=4,1 \mathrm{MeV}\right)$ como íons positivos $\left(I_{\max }=2 \mathrm{~mA} E_{\max }=q V\right)$. Os elétrons que emergem do DYNAMITRON são conduzidos até o radiador de Au pelo interior de um tubo que se encontra em vácuo $\left(10^{-6}-10^{-7} \mathrm{mbar}\right)$, para evitar espalhamento dos elétrons nas moléculas do ar. Este radiador possui uma espessura de $4 \mathrm{~mm}$ que absorve completamente os elétrons. $\mathrm{O}$ radiador, isolado eletricamente para monitorar e integrar a corrente do feixe, é resfriado por água a alta pressão (50 bar), a qual penetra no mesmo por dez perfurações de $1 \mathrm{~mm}$ de diâmetro. O sistema de arrefecimento permite que a corrente de elétrons de 4,1 MeV alcance $250 \mu \mathrm{A}$. O fluxo típico de fótons de $3 \mathrm{MeV}$ é ao redor de $10^{6}$ fótons por $\mathrm{keV}$ por segundo. Antes de penetrar na sala experimental, onde ficam os detectores e os alvos de NRF, o espectro de bremsstrahlung é filtrado em um absorvedor de $\mathrm{Pb}$ que elimina os fótons de energia mais baixa, e também é colimado em um tubo de $\mathrm{Pb}$ de $1 \mathrm{~m}$ de comprimento e 10 mm de diâmetro [Be01, Br01].

A sala experimental está separada do local onde o bremsstrahlung é gerado por uma parede de concreto de 2 metros de espessura, que trabalha como blindagem contra o background de fótons gerados no acelerador e no sistema de transporte do feixe. $\mathrm{O}$ feixe de fótons colimado penetra em um tubo em vácuo $\left(10^{-3}-10^{-4}\right.$ bar $)$ para evitar os espalhamentos nas moléculas do ar. Dentro deste tubo ficam os alvos de NRF. Devido à alta qualidade do intenso feixe de fótons é possível operar dois arranjos de NRF, simultaneamente. 
O primeiro arranjo de detectores, correspondente na Fig. AI.1 ao alvo NRF 1, é empregado para realizar medidas de distribuição angular $\left(\gamma, \gamma^{\prime}\right)$. Este arranjo consiste em dois detectores de HPGe com eficiência relativa de $100 \%$, e resolução de 2,0 keV para a energia de $1,33 \mathrm{MeV}$ do ${ }^{60} \mathrm{Co}$, posicionados em $90^{\circ}$ e $127^{\circ}$ em relação à direção do feixe de fótons incidentes. Os tempos típicos de medição neste arranjo são de 2 dias para os núcleos par - par e 4 dias para núcleos com massa A ímpar. Estes tempos de medição relativamente baixos são devidos às altas taxas de contagem em torno $5 \mathrm{kHz}$. Tipicamente os alvos de NRF neste arranjo têm massas entre 1-2 g, enriquecida no isótopo que se deseja estudar.

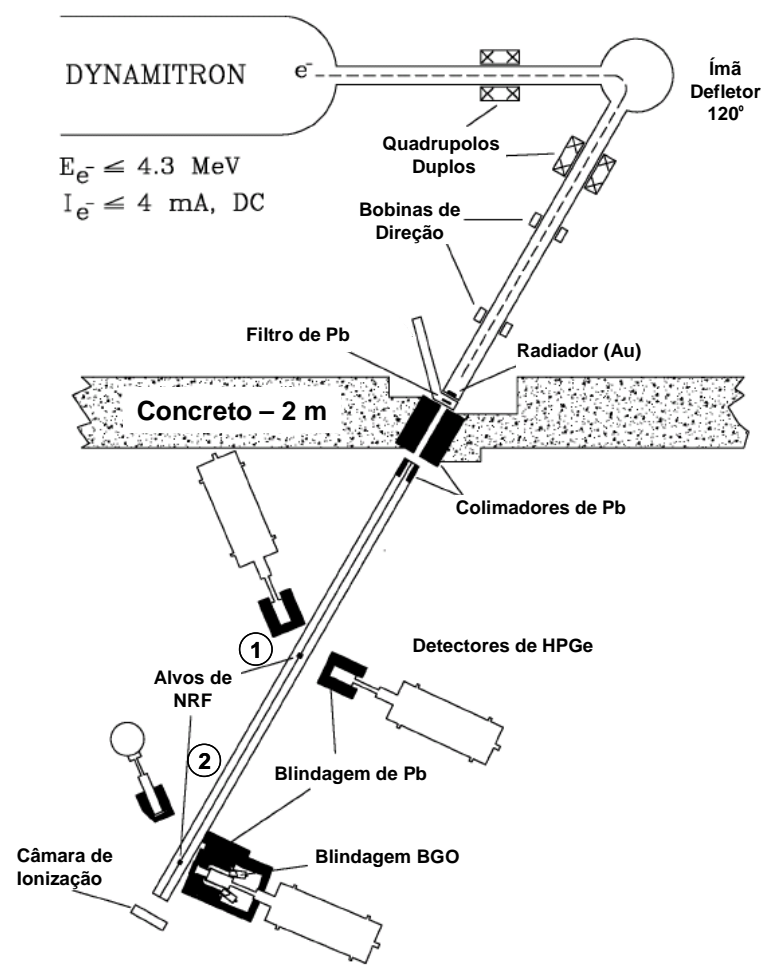

Fig. AI.1 Esquema do sistema de medidas de NRF instalado no acelerador DYNAMITRON 4,3 MV em Stuttgart [Be01, Br01]

O segundo arranjo, correspondente na Fig. AI.1 ao alvo de NRF 2, é usado para realizar medidas combinadas de correlação angular $\left(\gamma, \gamma^{\prime}\right)$ e polarização linear $\left(\gamma, \vec{\gamma}^{\prime}\right)$. Este arranjo consiste em dois polarímetros Compton localizados a $95^{\circ}$ e um detector adicional de $\mathrm{HPGe}$ situado a $127^{\circ}$. Os polarímetros de Compton são empregados para determinar a polarização linear dos fótons espalhados ressonantemente e com isto deduzir as paridades dos níveis excitados. Também, usando o sinal do "core" central 
dos polarímetros, podem-se realizar simultaneamente medições de correlação angular. Neste sistema só é possível levar a cabo medidas de núcleos par - par, porque é impossível determinar as paridades dos níveis dos núcleos de A ímpar. Os tempos típicos de medição para obter dados com bastante estatística são de 3 a 4 semanas. Normalmente, os alvos de NRF neste arranjo têm massas entre 1 e 5 g, enriquecidos no isótopo a estudar.

Na parte frontal de cada um dos detectores de Ge ou dos polarímetros Compton é colocado um filtro de $\mathrm{Pb}$, para reduzir a intensidade dos fótons de menor energia, que podem provocar pile-up no detector. A taxa de contagem nos detectores não deve ser maior que $10 \mathrm{kHz}$. Cada detector de Ge é rodeado com blindagem passiva de $\mathrm{Pb}$ e/ou ativa de BGO anti-Compton.

\section{I.1.1 Calibração do Sistema}

Para a calibração de energia dos elétrons do feixe, uma tarefa importante numa máquina eletrostática, mede-se on-line a energia máxima do bremsstrahlung por meio do espectro de fótons medidos nos detectores de Ge. Outros pontos de calibração de energia para o voltímetro da máquina são obtidos irradiando alvos com transições de energia bem conhecidas $\left({ }^{7} \mathrm{Li},{ }^{13} \mathrm{C},{ }^{19} \mathrm{~F},{ }^{27} \mathrm{Al},{ }^{63} \mathrm{Cu},{ }^{64} \mathrm{Cu}\right)$ pela técnica de energia limiar.

A medição da forma do espectro de bremsstrahlung é uma tarefa experimental muito mais complicada que a medição da energia final do espectro, em particular para baixas energias e radiadores grossos. O emprego direto de espectrômetros cintiladores ou de Ge é limitado pela necessidade de se saber a função resposta destes sistemas. Por outro lado, a aplicação da técnica de partícula associada, que usa a fotodesintegração do dêuteron (fazendo espectroscopia de prótons ou de nêutrons) consome tempo e é impraticável para baixas energias $\left(E_{\gamma}<4 \mathrm{MeV}\right)$. Igualmente o uso de espectrômetros magnéticos (espectrômetros de pares ou de Compton), que fornecem com precisão a forma do espectro de bremsstrahlung, está limitado em geometrias próximas como as dos sistemas de NRF. Um procedimento alternativo simples é combinar as medidas de fluxo obtidas a partir de isótopos com fortes excitações dipolares "low-lying" bem

estudadas $\left({ }^{7} \mathrm{Li},{ }^{13} \mathrm{C},{ }^{19} \mathrm{~F},{ }^{27} \mathrm{Al},{ }^{63} \mathrm{Cu},{ }^{64} \mathrm{Cu}\right)$, com o espectro de bremsstrahlung obtido por meio da simulação de Monte Carlo do sistema, usando algum código já conhecido (MCNPX [Pe05, Vi07], GEANT [Ag03, Al06, Vi07] ou EGS [Je99, Ne85, Vi07]. D. 
Belic et al. usaram o código GEANT Versão 3.21 para gerar o espectro de bremsstrahlung, e os isótopos de ${ }^{13} \mathrm{C}$ e ${ }^{27} \mathrm{Al}$ como estimadores experimentais da intensidade dos fótons como mostra a Fig. AI.2 [Be01].

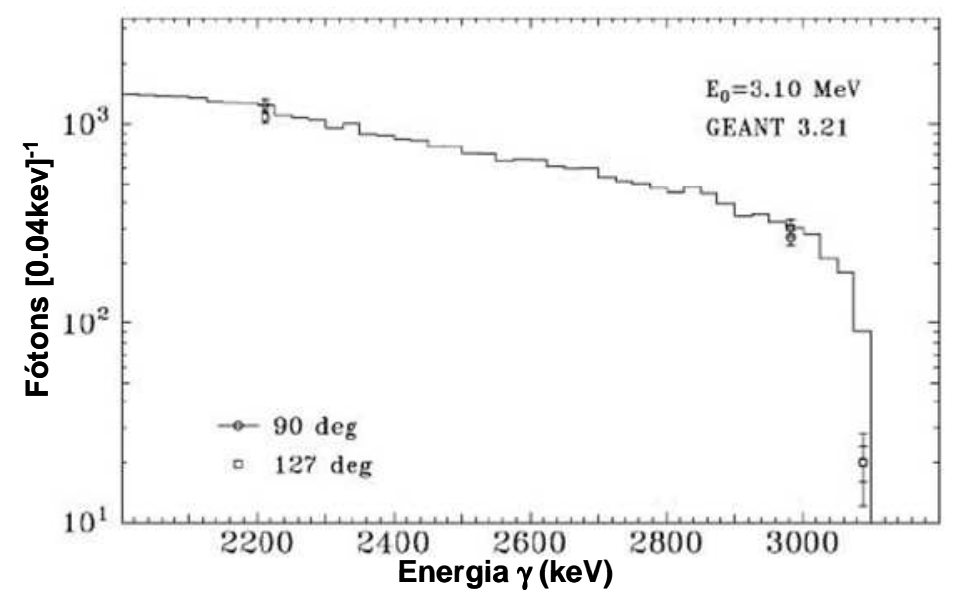

Fig. AI.2 Espectro de bremsstrahlung simulado por Belic et al. usando o código GEANT, e os dados experimentais por meio da excitação de níveis do ${ }^{13} \mathrm{C}$ e o ${ }^{27} \mathrm{Al}[\mathrm{Be} 01]$.

\section{I.2 Arranjo no acelerador S-DALINAC em Darmstadt}

Outro dos laboratórios de NRF mais reconhecidos é o instalado no Institut für Kernphysik da Universidade de Tecnologia de Darmstadt, associado ao acelerador supercondutor S-DALINAC. O arranjo de NRF usa como fonte de elétrons o injetor de $10 \mathrm{MeV}$ do acelerador supercondutor de onda contínua S-DALINAC de $130 \mathrm{MeV}$. Este injetor permite obter uma corrente de elétrons de até $60 \mu \mathrm{A}$ [Mo99]. A seguir, descrevemos tanto o arranjo construído inicialmente quanto o atual, de modo a explicar que problemas surgiram com o arranjo inicial e como foram superados.

No arranjo de NRF inicial de Darmstadt (Fig. AI.3), os elétrons, depois de passar em uma janela de $\mathrm{Al}$ de $100 \mu \mathrm{m}$, são parados em um disco rotativo de Ta de 3 mm de espessura, esfriado por um ventilador. A corrente típica de trabalho era de $30 \mu \mathrm{A}$. Os fótons incidiam num colimador cônico de $\mathrm{Pb}(\phi=1,2-2,5 \mathrm{~cm})$ de $60 \mathrm{~cm}$ de comprimento. $\mathrm{O}$ alvo de NRF com diâmetro de $2 \mathrm{~cm}$ ficava $80 \mathrm{~cm}$ após o colimador. A radiação gama era medida no arranjo de detectores CLUSTER Euroball, composto por 
sete detectores de Ge encapsulados individualmente com uma eficiência de 60\%, rodeados de blindagem ativa $\mathrm{BGO}$ de $1,5 \mathrm{~cm}$ de espessura nos lados e $5 \mathrm{~cm}$ atrás. Tudo ficava dentro de uma blindagem de $\mathrm{Pb}$. Adicionalmente era colocado um detector de $\mathrm{Ge}$ de grande volume (600\% de eficiência) a $130^{\circ}$ em relação ao feixe incidente e a $48 \mathrm{~cm}$ de distância do alvo de NRF, com o objetivo de medir os raios gamas de altas energias observados nos experimentos $\left(\gamma, \gamma^{\prime}\right)$. Entre o alvo e os detectores, na frente dos colimadores dos detectores, era situado um absorvedor de $\mathrm{Pb}$ de $15 \mathrm{~mm}$ de espessura para reduzir o fluxo de fótons de baixas energias [Re97]. A elevada eficiência de detecção, a excelente resolução energética, o uso de blindagem ativa (BGO), e um sistema de supressão de Compton permitiram incrementar consideravelmente a sensibilidade dos experimentos de NRF [Mo99].

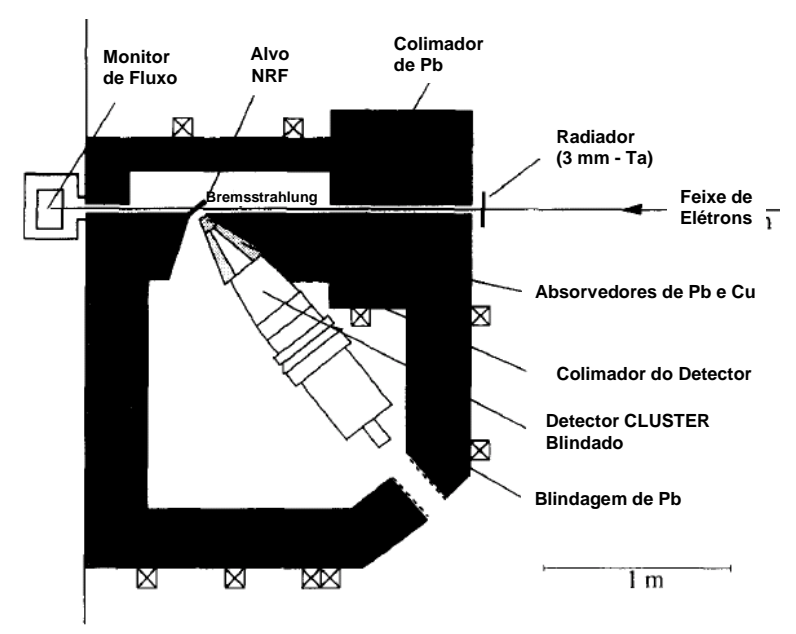

Fig. AI.3 Arranjo inicial de NRF em Darmstadt [Re97]

Com este arranjo foi possível realizar medidas sem interferência de nêutrons com elétrons incidentes de $7 \mathrm{MeV}$, mas acima dessa energia começava a produção de nêutrons no $\mathrm{Pb}$, pela reação ${ }^{207} \mathrm{~Pb}(\gamma, n)$ com energia limiar de $6,74 \mathrm{MeV}$. A Fig. AI.4 mostra os espectros gama obtidos em experimentos com um alvo de NRF que era um sanduíche de ${ }^{88} \mathrm{Sr}$ com o ${ }^{11} \mathrm{~B}$ como isótopo de calibração, para energias máximas de 6,8 e 7,2 MeV. Observe-se o incremento do background no espectro gama para a energia de 7,2 MeV assim como a presença de picos com energia maior que 7,2 $\mathrm{MeV}$ devido a reações de captura de nêutrons [Mo99]. 


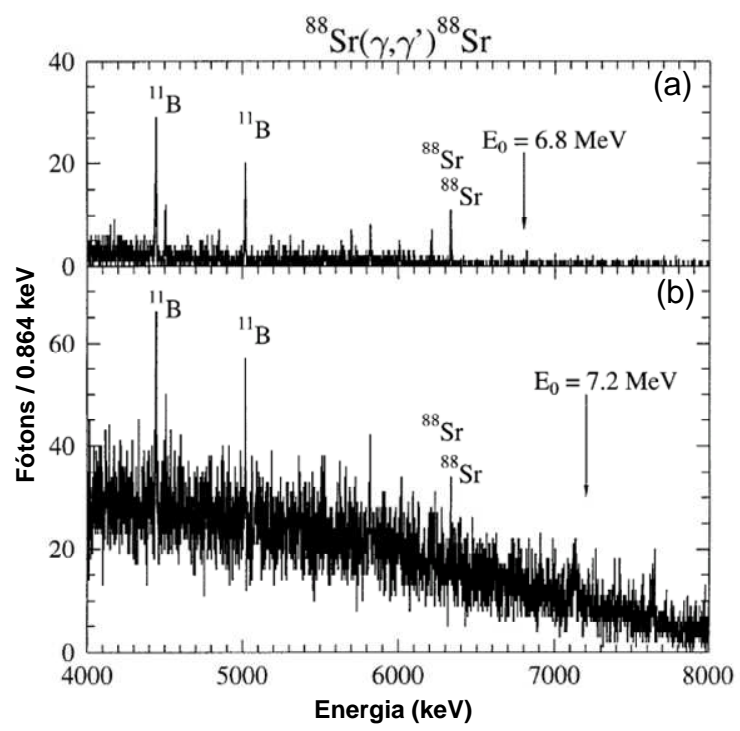

Fig. AI.4 Espectros gama da reação ${ }^{88} \operatorname{Sr}\left(\gamma, \gamma^{\prime}\right)$ realizados com energias máximas de elétrons de a) 6,8 MeV e b) 7,2 MeV. Observe o aumento do background e os picos acima de 7,2 MeV na figura b, devido aos nêutrons [Mo99].

No novo arranjo, o radiador, o alvo e os detectores estão situados em uma geometria relativamente próxima, a fim de garantir um fluxo de fótons máximo. A distância entre o radiador e o alvo é de cerca de $1,5 \mathrm{~m}$. O fluxo de fótons é monitorado por uma câmara de ionização localizada $1 \mathrm{~m}$ atrás do alvo. Os detectores de Ge ficam a $90^{\circ}$ e $127^{\circ}$ em relação ao feixe incidente, e pela razão de intensidades dos raios gamas nos mesmos é determinada a multipolaridade da transição. Estes detectores têm uma eficiência de $100 \%$. O detector situado a $90^{\circ}$ tem um cristal segmentado em quatro partes, e constitui um polarímetro Compton, que permite determinar as paridades dos estados. O outro detector, que fica a $20 \mathrm{~cm}$ de distância do alvo de NRF, está blindado com $\mathrm{Pb}$ e na parte frontal dele são colocadas lâminas finas de $\mathrm{Cu}$ e $\mathrm{Pb}$ para reduzir $\mathrm{o}$ fluxo de fótons de baixa energia. As taxa típicas de contagem nestes detectores de HPGe são de alguns milhares de eventos por segundo, para uma corrente de $5 \mu \mathrm{A}$ [Mo99].

Com o objetivo de eliminar o incremento do background gama devido às reações $(\gamma, n)$, que acontecem principalmente no colimador de $\mathrm{Pb}$, este foi substituído por outro de $\mathrm{Cu}$ com 95,5 cm de comprimento. Foi escolhido o $\mathrm{Cu}$ porque é um material estável mecânica e quimicamente, cujos isótopos $A=63$ e $A=65$ tem energias limiares 
para as reações $(\gamma, n)$ iguais a $10,9 \mathrm{MeV}$ e $9,9 \mathrm{MeV}$, respectivamente. Além disso, os isótopos produzidos nas reações ${ }^{63} \mathrm{Cu}(\gamma, p){ }^{62} \mathrm{Ni} \quad(Q=6,1 \mathrm{MeV})$ e ${ }^{65} \mathrm{Cu}(\gamma, p){ }^{64} \mathrm{Ni}$ $(Q=7,4 \mathrm{MeV})$ são estáveis, o Cobre normalmente é vendido com alta pureza, sendo relativamente barato. O novo colimador tem forma cônica $(\phi=1,2-2,0 \mathrm{~cm})$, e foi construído com blocos de $300 \times 300 \times 300 \mathrm{~mm}^{3}$ e $70 \mathrm{~kg}$ de peso. Foram colocados blocos de $\mathrm{Cu}$ adicionais de $200 \times 200 \times 100 \mathrm{~mm}^{3}$ ao redor do radiador na parte frontal do colimador. A Fig. AI.5a mostra claramente a redução de background para uma energia final de 7,7 MeV, comparada com a figura AI.4b. No espectro se distinguem facilmente as linhas do ${ }^{11} \mathrm{~B}$ e não são observados picos para energias superiores. Porém, para energias dos elétrons maiores que $8,3 \mathrm{MeV}$ apareciam novamente picos com energia maior que a final, e um incremento do background (Fig. AI.5b).

$\mathrm{O}$ aumento do background para energias maiores que $8,3 \mathrm{MeV}$ se deve as reações $(\gamma, n)$ no radiador de Ta. A reação ${ }^{181} \mathrm{Ta}(\gamma, n)^{180} \mathrm{Ta}$ tem una energia limiar de 6,6 MeV. Para eliminar este problema, o Ta foi substituído por $14 \mathrm{~mm}$ de $\mathrm{Cu}$. Devido ao menor peso atômico do $\mathrm{Cu}$, a produção de bremsstrahlung diminui, mas só num fator dois comparado com o Ta, como confirma a simulação por Monte Carlo (código GEANT) do bremsstrahlung que é mostrada na Fig. AI.6 [Mo99].

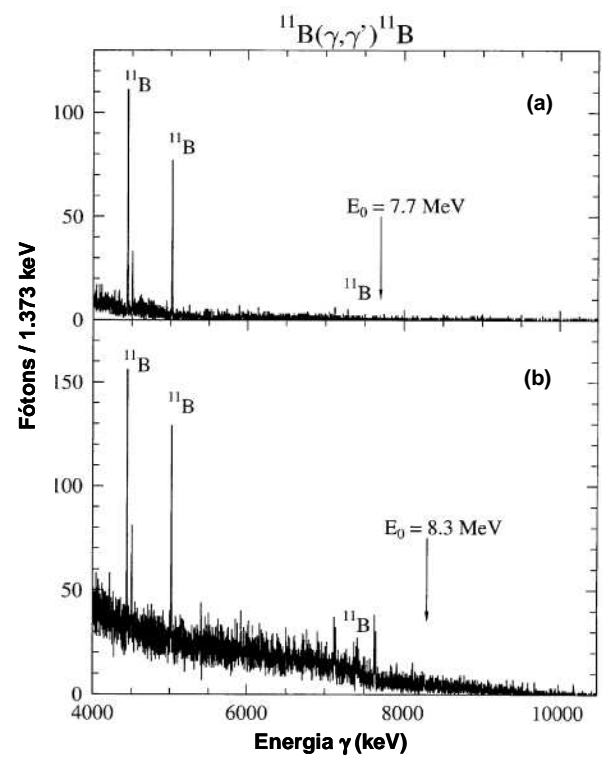

Fig. AI.5 Espectro gama na reação ${ }^{11} \mathrm{~B}\left(\gamma, \gamma^{\prime}\right)^{11} \mathrm{~B}$. (a) Redução do background com relação à Fig. AI.4. (b) Incremento do background para energias dos elétrons superiores a 8,3 MeV devido as reações $(\gamma, n)$ no radiador de Ta [Mo99]. 


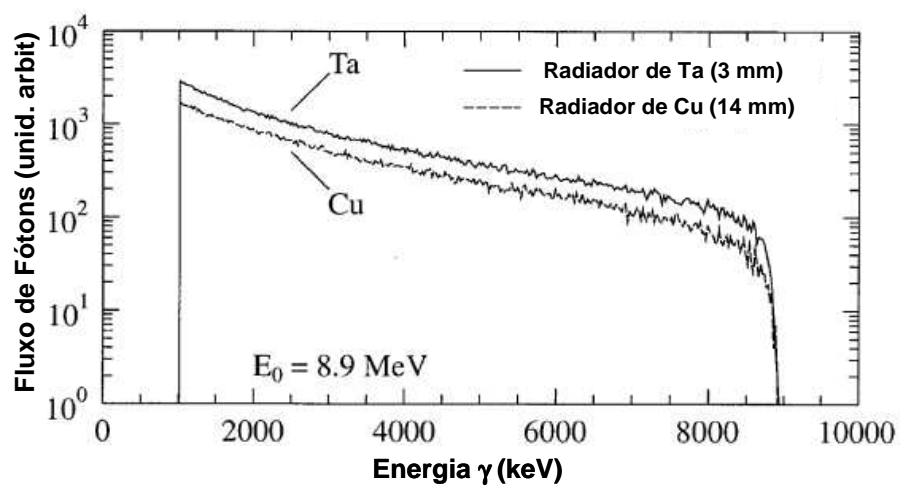

Fig. AI.6 Espectro de bremsstrahlung simulado mediante o código GEANT para elétrons de 8,9 MeV que incidem em radiadores de $\mathrm{Ta}(3 \mathrm{~mm})$ e $\mathrm{Cu}(14 \mathrm{~mm})$ [Mo99]

\section{I.3 Arranjo no acelerador linear de $15 \mathrm{MeV}$ em Gent}

Este sistema de NRF é um exemplo no qual é utilizado bremsstrahlung polarizado como feixe incidente, o que para experimentos de NRF exige um acelerador de elétrons que satisfaça os seguintes requisitos:

- $\quad$ Corrente do feixe elevada para obter as maiores taxas de contagem possíveis,

- $\quad$ Alto fator de utilização ou ao menos uma elevada frequiência de repetição para evitar empilhamento de pulsos nos espectrômetros gama,

- $\quad$ Feixe estável em energia, posição e diâmetro, e que permita a mudança do ângulo $\left(\Theta_{o} \approx m_{o} c^{2} / E_{o}\right)$ de incidência do feixe no radiador de modo reprodutível.

$\mathrm{O}$ acelerador linac de $15 \mathrm{MeV}$ da Universidade de Gent reúne estes requisitos. Ele opera com um ciclo útil de $D C$ de $2 \%$, que ainda representa uma limitação para a técnica de NRF, sendo menor que nos aceleradores de onda continua, mas é maior que os ciclos de outros linacs convencionais como o acelerador de Giessen $(0,12 \%$ e 600 Hz). Algumas das características deste acelerador aparecem na Tabela AI.1 [Go94]. 
Tabela AI.1 Características do acelerador linac de $15 \mathrm{MeV}$ da Universidade de Gent [Go94]

\begin{tabular}{|l|c|c|}
\hline & Valores Máximos & $\begin{array}{c}\text { Valores típicos usados em } \\
\text { experimentos de NRF }\end{array}$ \\
\hline Energia do Feixe & $15 \mathrm{MeV}$ & $12 \mathrm{MeV}$ \\
\hline Fator de utilização do feixe & $2 \%$ & $0,8 \%$ \\
\hline Largura do pulso & $10 \mu \mathrm{s}$ & $2 \mu \mathrm{s}$ \\
\hline Frequiência de repetição do pulso & $5000 \mathrm{~Hz}$ & $4000 \mathrm{~Hz}$ \\
\hline Corrente média do feixe & $2 \mathrm{~mA}$ & $350 \mu \mathrm{A}$ \\
\hline
\end{tabular}

A Fig. AI.7 apresenta um esquema do arranjo experimental. O feixe de elétrons é transportado desde o acelerador por um analisador magnético (M1 e M2), e posteriormente é focalizado por um dubleto de quadrupolos QD antes de incidir no radiador BT. As bobinas SC1 e SC2 (steerings) permitem variar o ângulo de incidência do feixe no radiador (lâmina de $\mathrm{Al}$ de $25 \mu \mathrm{m}$ ). O feixe de elétrons que atravessa o radiador é desviado pelo ímã defletor CM para o "electron beam dump" isolado eletricamente, que permite fazer medidas precisas da intensidade do feixe de elétrons.

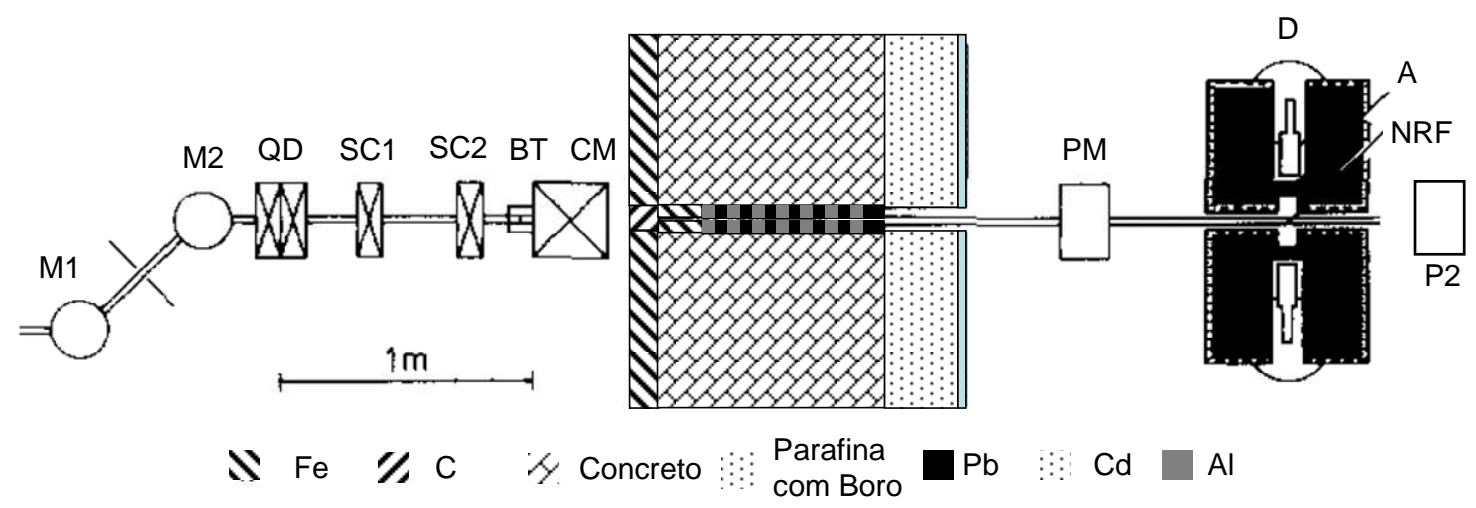

Fig. AI.7 Arranjo de NRF no linac de $15 \mathrm{MeV}$ da Universidade de Gent, onde é empregado bremsstrahlung polarizado como feixe incidente [Go94].

A área de medidas, parte direita na Fig. AI.7, está separada do local onde é produzido o bremsstrahlung e onde fica o "electron beam dump" por meio de uma parede de 1 metro de espessura de ferro, concreto, parafina, e cádmio. Esta parede tem um colimador e na entrada do mesmo é colocado um bloco de grafite de $10 \mathrm{~cm}$ de espessura para diminuir o fluxo de fótons de baixa energia. As dimensões do colimador são $95 \mathrm{~cm}$ de comprimento e $7 \mathrm{~mm}$ de diâmetro. Os primeiros $20 \mathrm{~cm}$ são de $\mathrm{Fe}$ e os últimos $15 \mathrm{~cm}$ são de $\mathrm{Pb}$. A parte intermediaria está composta por anéis intercalados de $\mathrm{Pb}$ e $\mathrm{Al}$ de $5 \mathrm{~cm}$ de espessura. O ferro é usado na entrada do colimador e na primeira camada da blindagem (Fig. AI.7) porque tem uma energia limiar para as reações $(\gamma, n)$ relativamente elevada de $11,2 \mathrm{MeV}\left({ }^{56} \mathrm{Fe}\right)$ comparada com os 7,4 Mev do ${ }^{207} \mathrm{~Pb}$. 
Depois do concreto são adicionadas camadas de parafina com boro e de cádmio para reduzir o background de nêutrons.

O feixe de bremsstrahlung colimado incide no alvo localizado $160 \mathrm{~cm}$ após o colimador, onde tem um diâmetro ao redor de $25 \mathrm{~mm}$. Este alvo está rodeado de quatro detectores de $\mathrm{Ge}$ blindados com $\mathrm{Pb}$ e $\mathrm{Cd}$ para reduzir o background gama e de raios $\mathrm{X}$. $\mathrm{Na}$ parte frontal de cada detector é colocado um colimador com ângulos de abertura entre $14^{\circ}$ e $16^{\circ}$. Na abertura são colocadas lâminas de $\mathrm{Pb}$ como filtro, cuja espessura (2 $-4 \mathrm{~cm}$ ), é escolhida de maneira que as taxas de contagem nos quatro detectores fiquem similares. A distância dos detectores ao alvo é de $20-25 \mathrm{~cm}$. A eficiência dos detectores está entre $16 \%$ e $40 \%$. Dois dos detectores estão instalados permanentemente acima e abaixo do alvo em ângulos de $90^{\circ}$ com relação ao feixe incidente. Os outros dois ficam á esquerda e á direita com ângulos de $90^{\circ}$ e $127^{\circ}$. Este arranjo permite fazer experimentos de distribuições angulares com feixes não polarizados, para determinar os spins, e experimentos com bremsstrahlung polarizado, para determinar as paridades dos estados excitados.

O monitor PM (Fig. AI.7) é usado para medir o grau de polarização do feixe incidente, usando a reação ${ }^{2} H(\gamma, p) n$ como método de análise [De85]. Depois de atravessar o alvo, o feixe incidente alcança a câmara de ionização P2, que monitora o fluxo de fótons, e finalmente o feixe é absorvido em uma parede de concreto - terra. A fim de evitar espalhamentos nas moléculas de oxigênio e nitrogênio do ar, o colimador, o monitor de polarização PM e o alvo estão no vácuo.

O sistema instalado em Gent permite fazer experimentos com alvos de massas relativamente pequenas, o que constitui uma vantagem quando a disponibilidade do isótopo enriquecido é menor que $1 \mathrm{~g}$. Para incrementar a corrente de elétrons além dos $350 \mu \mathrm{A}$, o radiador estacionário de $\mathrm{Al}$ deve ser substituído por outro rotatório para impedir seu aquecimento. Para evitar problemas de empilhamento de pulsos, as taxas de contagem nos detectores gama são limitadas a um décimo da frequiência de repetição dos pulsos. Este acelerador tem uma freqüência excepcionalmente elevada de $5000 \mathrm{~Hz}$, pelo que, com taxas de contagem de até $500 \mathrm{~Hz}$, os tempos de duração dos experimentos são entre cinco e dez vezes menores que num linac pulsado convencional. 
Este sistema é útil na determinação das paridades de estados com energias maiores que 4 ou $5 \mathrm{MeV}$. O grau de polarização do bremsstrahlung decresce com o aumento da energia do fóton e é praticamente zero perto da energia final. Deste modo, os elétrons incidentes devem ter vários $\mathrm{MeV}$ de energia além da faixa de energia que é objeto de estudo. Por exemplo, para estudar as excitações dipolares ao redor de $6 \mathrm{MeV}$ dos isótopos ${ }^{116} \mathrm{Sn}$ e ${ }^{124} \mathrm{Sn}$, Govaert et al. [Go98] usaram um feixe de elétrons de 12 $\mathrm{MeV}$. Para energias abaixo de 4 ou $5 \mathrm{MeV}$ a relação pico - background obtida não é favorável, tornando difícil a análise nessa faixa de energias [Mo96].

\section{I.4 Arranjo no acelerador ELBE em Dresden}

Um sistema de NRF foi construído recentemente no acelerador ELBE (Electron Linear accelerator of high Brilliance and low Emittance) do Forchugszentrum Rossendorf (Institut für Kern-und Hadronenphysik) em Dresden. Este acelerador combina uma energia máxima elevada com uma corrente média alta e um ciclo útil elevado, permitindo obter elétrons de até $20 \mathrm{MeV}$ com correntes médias de $1 \mathrm{~mA}$ em experimentos com reações induzidas por fótons. As freqüências básicas de repetição dos pulsos são 26 e $260 \mathrm{MHz}$. A freqüência de $26 \mathrm{MHz}$ pode ser diminuída num fator entre 2 e 256 vezes, o que permite escolher uma freqüência de operação entre $100 \mathrm{kHz}$ e $260 \mathrm{kHz}$, tornando possível a diferenciação entre os fótons emitidos por estados isômeros e os provenientes de fontes de background distantes. Adicionalmente podem ser obtidos pulsos de 0,1 - $36 \mathrm{~ms}$ de duração com períodos de repetição entre $40 \mathrm{~ms}$ e $1 \mathrm{~s}$ [Sc05, Wa05]. O sistema de NRF do ELBE, figura AI.8, foi planejado com especial cuidado para minimizar a produção de nêutrons e os espalhamentos dos fótons nos materiais circundantes. 


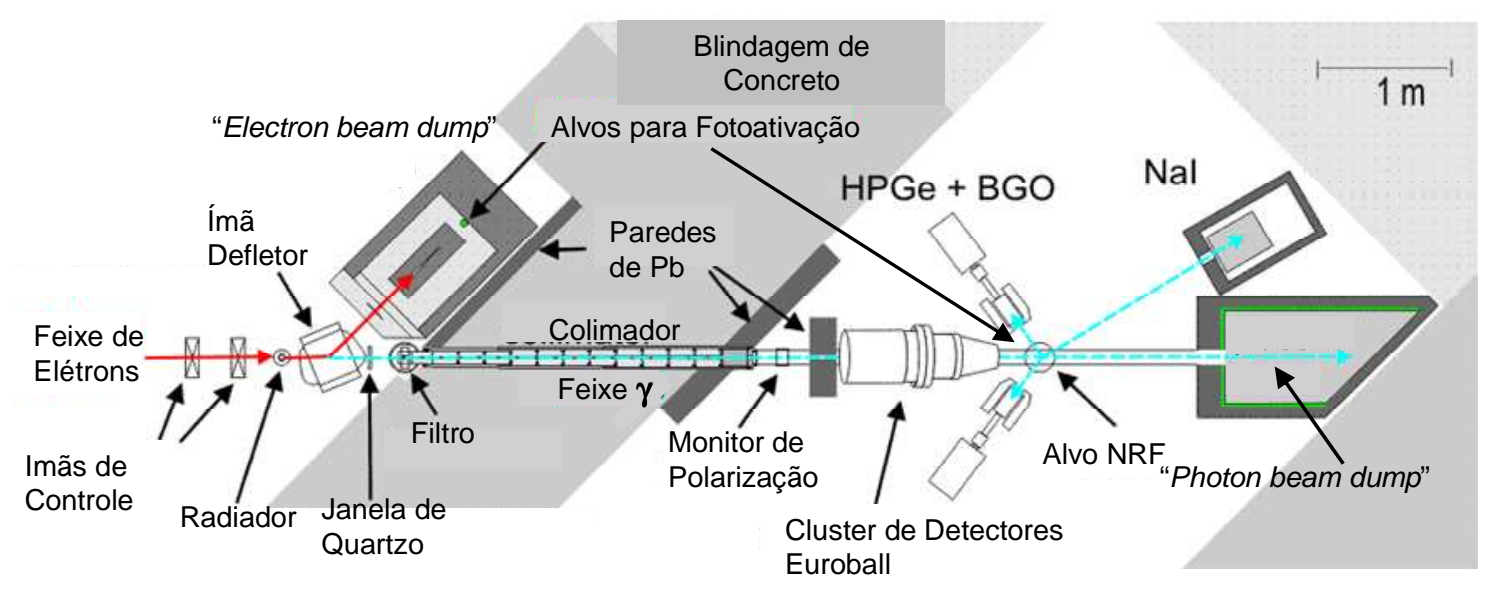

Fig. AI.8 Esquema do sistema de medidas de NRF do acelerador ELBE [Wa05]

\section{I.4.1 Radiador}

O feixe de elétrons que incide no radiador é controlado por dois "ímãs de controle" que mudam o ângulo de incidência com objetivo de produzir bremsstrahlung polarizado. A espessura e o material do radiador foram escolhidos de maneira que a produção de bremsstrahlung fosse máxima na direção frontal. O Nióbio foi escolhido como material para o radiador devido a sua elevada temperatura de fusão $\left(2460{ }^{\circ} \mathrm{C}\right.$ ) e seu peso atômico intermediário. A temperatura local num radiador de $3,5 \mathrm{mg} / \mathrm{cm}^{2}$ de $\mathrm{Nb}$ alcança os $1200{ }^{\circ} \mathrm{C}$ para uma corrente média de $600 \mu \mathrm{A}$ e $12 \mathrm{MeV}$ de energia dos elétrons. Para achar a espessura ótima foi realizada uma simulação por Monte Carlo empregando o código GEANT3, chegando à conclusão que não é necessário usar um radiador muito grosso para produzir mais fótons de bremsstrahlung porque, com o incremento da espessura do radiador, mais fóton são gerados, mas uma parte crescente deles é emitida em ângulos maiores que a abertura do colimador. Desta maneira, dependendo da energia do experimento é escolhido um dos seis radiadores de $\mathrm{Nb}$ de 16 mm de diâmetro e espessuras de 1,$7 ; 2,6 ; 3,4 ; 4,3 ; 6,0$ e $10,6 \mathrm{mg} / \mathrm{cm}^{2}$, montados sobre uma barra de $\mathrm{Cu}$ resfriada por água. O radiador de menor espessura é o mais apropriado para as energias menores. Os elétrons que atravessam o radiador são desviados com um ímã defletor para o "electron beam dump", que tem a dupla função de deter os elétrons, minimizando a emissão de fótons para outras áreas da sala de experimentos, e monitorar a corrente do feixe. 


\section{I.4.2 Colimador}

Para "cortar" o feixe com um diâmetro definido, o colimador foi posicionado 1 $\mathrm{m}$ depois do radiador. $\mathrm{O}$ colimador tem um comprimento de $2600 \mathrm{~mm}$, com diâmetros de entrada e saída de 5 e $24 \mathrm{~mm}$, respectivamente. Foi fabricado de alumínio de alta pureza, o qual tem um limiar de emissão de nêutrons de $13,1 \mathrm{MeV}$, e é composto por três cilindros com buracos cônicos. O último dos cilindros foi construído de metal pesado com $95 \%$ de tungstênio para aumentar a atenuação do feixe. A simulação com GEANT3 mostrou que, de cada $10^{8}$ fótons que atravessam o colimador, só 10 elétrons secundários alcançam o alvo. O colimador foi fixado dentro de uma parede de concreto pesado (50\% de $\mathrm{Fe}_{2} \mathrm{O}_{3}$ ) de 1,60 m, que separa a sala do acelerador dela experimental. A câmara de vácuo á entrada do colimador contem três cilindros movíveis, dois de 10 $\mathrm{cm}$ de diâmetro e $10 \mathrm{~cm}$ de comprimento fabricados de metal pesado e alumínio, e outro de $\mathrm{Al}$ com 0,9 $\mathrm{cm}$ de diâmetro por $10 \mathrm{~cm}$ de comprimento rodeado de metal pesado. Estes cilindros agem como filtros, assim o primeiro (só de metal pesado) fecha o feixe, o segundo (de Al) absorve principalmente os fótons de menor energia (Fig. AI.8), e o terceiro de $\mathrm{Al}$ e metal pesado trabalha como colimador adicional.

\section{I.4.3 Sistema de detectores e sua blindagem}

Os fótons espalhados no alvo de NRF são medidos em detectores de HPGe. O sistema está composto por quatro detectores de HPGe com eficiência de $100 \%$ e um cluster Euroball (Fig. AI.8). Dois dos detectores ficam acima e abaixo do alvo, enquanto os outros dois são situados horizontalmente e podem mudar sua posição entre $90^{\circ}$ e $127^{\circ}$ em relação ao feixe incidente. O cluster Euroball fica acima da linha do feixe a $145^{\circ}$. Os detectores estão rodeados de blindagem ativa de BGO com $3 \mathrm{~cm}$ de espessura. Usando esta blindagem, a relação pico de absorção total - pico de escape simples para 5 $\mathrm{MeV}$ é de 15, cinco vezes maior que sem o uso do BGO.

Para evitar que fótons provenientes de outros materiais, além do alvo de NRF, cheguem diretamente aos detectores, várias providências foram tomadas:

- A área experimental está separada da área onde se produz o
bremsstrahlung por uma parede de $1,60 \mathrm{~cm}$ construída com concreto pesado. 
Adicionalmente foram colocadas paredes de $\mathrm{Pb}$ com $10 \mathrm{~cm}$ de espessura entre $\mathrm{o}$ "electron beam dump" e a parede de concreto, e de $20 \mathrm{~cm}$ entre a parede de concreto e a área experimental (Fig. AI.8).

- $\quad$ O feixe de bremsstrahlung desde o radiador até o "photon beam dump" se propaga pelo interior de um tubo que está em vácuo. O tubo é fabricado de polietileno, cujo baixo valor de $\mathrm{Z}$ diminui o background nos detectores, devido a produção de pares e os espalhamentos Compton, assim como à produção de nêutrons. $\mathrm{O}$ feixe de elétrons, depois de passar o radiador $\left(10^{-10} \mathrm{mbar}\right)$, é separado do feixe de fótons $\left(10^{-6} \mathrm{mbar}\right)$ por uma janela de quartzo de $3 \mathrm{~mm}$ de espessura (Fig. AI.8).

- Uma parede de $\mathrm{Pb}$ de $20 \mathrm{~cm}$ de espessura e dimensões $60 \mathrm{~cm} \times 60 \mathrm{~cm}$ com um orifício interior de $40 \mathrm{~mm}$ de diâmetro foi colocada detrás do Monitor de Polarização para evitar que os fótons espalhados no monitor chegassem aos detectores de HPGe. Com este arranjo, o background nos detectores diminui em um fator de 10 a 30 na faixa de energias de $1-2,6 \mathrm{MeV}$. Para energias maiores, a redução foi maior.

- Todos os componentes do arranjo de NRF foram fabricados de Al para reduzir a produção de nêutrons devida os espalhamentos de fótons de altas energias.

- $\quad$ Os detectores de HPGe e BGO foram blindados com blocos de Pb de 10 cm de espessura e dimensões de $25 \times 36 \mathrm{~cm}^{2}$ Este blocos têm um orifício de forma cônica que atua como colimador.

- $\quad \mathrm{O}$ coletor do feixe de fótons (photon beam dump) foi desenhado de maneira a reduzir drasticamente o número de fótons espalhados para os detectores. Ele está composto por um bloco de Polietileno $(\mathrm{PE})$ de $60 \times 60 \times 100 \mathrm{~cm}^{3}$ rodeado de 0,5 $\mathrm{mm}$ de $\mathrm{Cd}$ e $10 \mathrm{~cm}$ de $\mathrm{Pb}$ aos lados, e $20 \mathrm{~cm}$ na parte frontal (Fig. AI.9). Uma simulação com GEANT3 mostrou que os fótons que incidem no interior do "photon beam dump" são espalhados dentro do polietileno e capturados pelo $\mathrm{Pb}$. Só ao redor de $0,3 \%$ dos fótons que penetram são espalhados para os detectores. 


$$
E_{\gamma}=12 \mathrm{MeV}
$$

Photon-beam dump

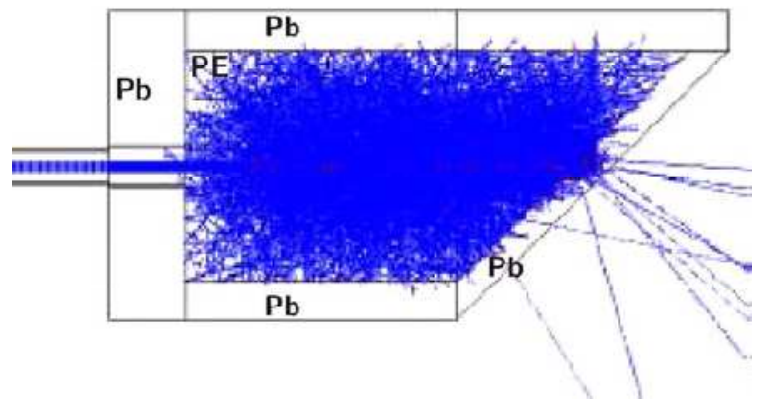

Fig. AI.9 Simulação com GEANT3 das trajetórias dos fótons no interior do "photon beam dump", para fótons incidentes de $12 \mathrm{MeV}$ [Wa05]. 
Anexo II Características gerais dos principais elementos utilizados nas simulações.

\begin{tabular}{|c|c|c|c|c|c|c|c|c|}
\hline \multirow[b]{2}{*}{ Elemento } & \multirow[b]{2}{*}{ Dens. $\left(\mathrm{g} \mathrm{cm}^{-3}\right)$} & \multirow{2}{*}{$\begin{array}{l}\text { Temp. deFusão } \\
\left(\mathrm{C}^{\mathrm{o}}\right)\end{array}$} & \multirow[b]{2}{*}{$\begin{array}{l}\text { Isótopos } \\
\text { Estáveis }\end{array}$} & \multirow[b]{2}{*}{$\begin{array}{l}\text { Abund. } \\
\text { Isotica }(\%)\end{array}$} & \multicolumn{2}{|c|}{ Reação $(\gamma, n)$} & \multicolumn{2}{|c|}{ Reação $(\gamma, p)$} \\
\hline & & & & & $\begin{array}{l}\text { Energ. Limiar } \\
\quad(\mathrm{MeV})\end{array}$ & $\begin{array}{c}\text { Isótopo } \\
\text { Produto }\left(T_{1 / 2}\right)\end{array}$ & $\begin{array}{l}\text { Energ. Limiar } \\
(\mathrm{MeV})\end{array}$ & $\begin{array}{c}\text { Isótopo } \\
\text { Produto }\left(T_{1 / 2}\right)\end{array}$ \\
\hline \multirow{2}{*}{$\mathrm{H}$} & \multirow{2}{*}{ - } & \multirow{2}{*}{$-259,14$} & ${ }^{1} H$ & 99,985 & - & - & - & - \\
\hline & & & ${ }^{2} H$ & 0,015 & 2,225 & ${ }^{1} H(\infty)$ & - & - \\
\hline \multirow{2}{*}{$\mathrm{C}$} & \multirow{2}{*}{2,267} & \multirow{2}{*}{3500,00} & ${ }^{12} \mathrm{C}$ & 98,92 & 18,73 & ${ }^{11} C(20.334 \mathrm{~m})$ & 15,968 & ${ }^{11} B(\infty)$ \\
\hline & & & ${ }^{13} \mathrm{C}$ & 1,07 & 4,95 & ${ }^{12} C(\infty)$ & 17,545 & ${ }^{12} B\left(20,2 \times 10^{-3} \mathrm{~s}\right)$ \\
\hline $\mathrm{Al}$ & 2,700 & 660,32 & ${ }^{27} \mathrm{Al}$ & 100,00 & 13,057 & $\begin{array}{c}{ }^{26} \mathrm{Al} \\
\left(1,17 \times 10^{5}-6,34 \mathrm{~s}\right)^{*}\end{array}$ & 8,271 & ${ }^{26} M g(\infty)$ \\
\hline \multirow{5}{*}{$\mathrm{Ni}$} & \multirow{5}{*}{8,908} & \multirow{5}{*}{1455,00} & ${ }^{58} \mathrm{Ni}$ & 68,07 & 12,217 & ${ }^{57} \mathrm{Ni}(35,6 \mathrm{~h})$ & 8,172 & ${ }^{57} \mathrm{Co}(271,74 \mathrm{~d})$ \\
\hline & & & ${ }^{60} \mathrm{Ni}$ & 26,22 & 11,387 & ${ }^{59} \mathrm{Ni}\left(7,6 \times 10^{4} \mathrm{a}\right)$ & 9,532 & ${ }^{59} \mathrm{Co}(\infty)$ \\
\hline & & & ${ }^{61} \mathrm{Ni}$ & 1,13 & 7,820 & ${ }^{60} \mathrm{Ni}(\infty)$ & 9,860 & $\begin{array}{c}{ }^{60} \mathrm{Co} \\
(1925,2 \mathrm{~d}-10,4 \mathrm{~m})^{*}\end{array}$ \\
\hline & & & ${ }^{62} \mathrm{Ni}$ & 3,63 & 10,596 & ${ }^{61} \mathrm{Ni}(\infty)$ & 11,136 & ${ }^{61} \mathrm{Co}(1,65 \mathrm{~h})$ \\
\hline & & & ${ }^{64} \mathrm{Ni}$ & 0,92 & 9,658 & ${ }^{63} \mathrm{Ni}(100,1 \mathrm{a})$ & 12,547 & ${ }^{63} \mathrm{Co}(27,4 \mathrm{~s})$ \\
\hline \multirow{2}{*}{$\mathrm{Cu}$} & \multirow{2}{*}{8,920} & \multirow{2}{*}{1084,62} & ${ }^{63} \mathrm{Cu}$ & 69,17 & 10,853 & ${ }^{62} \mathrm{Cu}(9,67 \mathrm{~m})$ & 6,122 & ${ }^{62} \mathrm{Ni}(\infty)$ \\
\hline & & & ${ }^{65} \mathrm{Cu}$ & 30,83 & 9,910 & ${ }^{64} \mathrm{Cu}(12,7 \mathrm{~h})$ & 7,453 & ${ }^{64} \mathrm{Ni}(\infty)$ \\
\hline $\mathrm{Nb}$ & 8,570 & 2477,00 & ${ }^{93} \mathrm{Nb}$ & 100,00 & 8,831 & $\begin{array}{c}{ }^{92} N b \\
\left(3,47 \times 10^{7} \mathrm{a}-10,15 \mathrm{~d}\right)^{*}\end{array}$ & 6,043 & ${ }^{92} \mathrm{Zr}(\infty)$ \\
\hline \multirow{2}{*}{$\mathrm{Ag}$} & \multirow{2}{*}{10,490} & \multirow{2}{*}{961,78} & ${ }^{107} \mathrm{Ag}$ & 51,839 & 9,536 & $\begin{array}{c}{ }^{106} \mathrm{Ag} \\
(23,96 \mathrm{~m}-8,98 \mathrm{~d})^{*}\end{array}$ & 5,788 & ${ }^{106} P d(\infty)$ \\
\hline & & & ${ }^{109} \mathrm{Ag}$ & 48,161 & 9,192 & $\begin{array}{c}{ }^{108} A g \\
(2,37 \mathrm{~m}-418 \mathrm{a})^{*}\end{array}$ & 6,487 & ${ }^{108} P d(\infty)$ \\
\hline
\end{tabular}




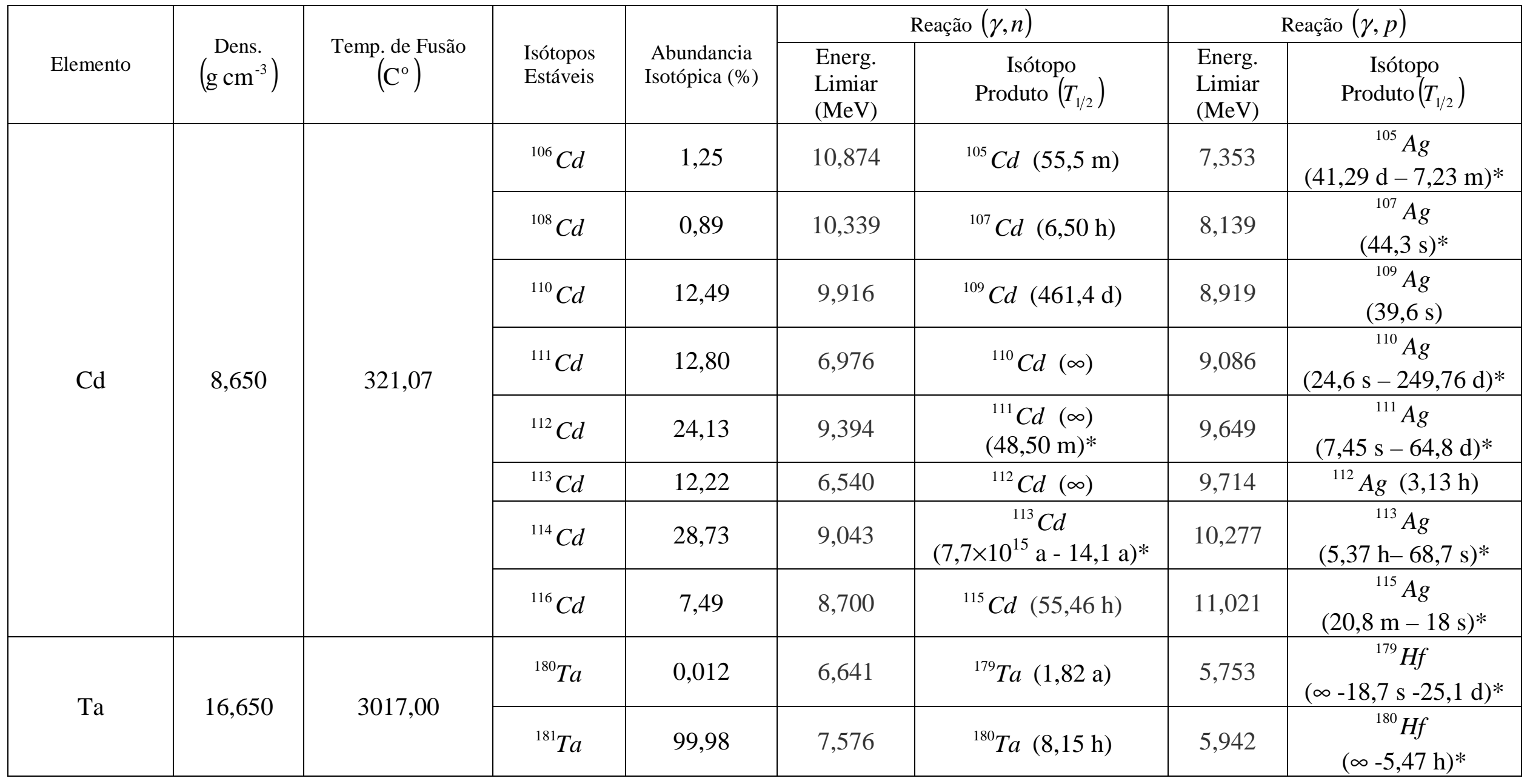




\begin{tabular}{|c|c|c|c|c|c|c|c|c|}
\hline \multirow[b]{2}{*}{ Elemento } & \multirow[b]{2}{*}{$\begin{array}{c}\text { Dens. } \\
\left(\mathrm{g} \mathrm{cm}^{-3}\right)\end{array}$} & \multirow[b]{2}{*}{$\begin{array}{l}\text { Temp. de Fusão } \\
\left(\mathrm{C}^{\mathrm{o}}\right)\end{array}$} & \multirow[b]{2}{*}{$\begin{array}{l}\text { Isótopos } \\
\text { Estáveis }\end{array}$} & \multirow[b]{2}{*}{$\begin{array}{l}\text { Abundancia } \\
\text { Isotópica (\%) }\end{array}$} & \multicolumn{2}{|c|}{ Reação $(\gamma, n)$} & \multicolumn{2}{|c|}{ Reação $(\gamma, p)$} \\
\hline & & & & & $\begin{array}{l}\text { Energ. } \\
\text { Limiar } \\
(\mathrm{MeV})\end{array}$ & $\begin{array}{c}\text { Isótopo } \\
\text { Produto }\left(T_{1 / 2}\right)\end{array}$ & $\begin{array}{l}\text { Energ. } \\
\text { Limiar } \\
(\mathrm{MeV})\end{array}$ & $\begin{array}{c}\text { Isótopo } \\
\text { Produto }\left(T_{1 / 2}\right)\end{array}$ \\
\hline \multirow{5}{*}{$\mathrm{W}$} & \multirow{5}{*}{19,250} & \multirow{5}{*}{3422,00} & ${ }^{180} W$ & 0,12 & 8,412 & $\begin{array}{c}{ }^{179} W \\
(37,05 \mathrm{~m}-6,4 \mathrm{~m})^{*}\end{array}$ & 6,567 & ${ }^{179} \mathrm{Ta}(1,82 \mathrm{a})$ \\
\hline & & & ${ }^{182} W$ & 26,50 & 8,064 & ${ }^{181} W(121,2 \mathrm{~d})$ & 7,094 & ${ }^{181} \mathrm{Ta}(\infty)$ \\
\hline & & & ${ }^{183} W$ & 14,31 & 6,190 & ${ }^{182} W\left(8,3 \times 10^{18} a\right)$ & 7,222 & $\begin{array}{c}{ }^{182} \mathrm{Ta} \\
(114,4 \mathrm{~d}-15,8 \mathrm{~m})^{*}\end{array}$ \\
\hline & & & ${ }^{184} W$ & 30,64 & 7,411 & $\begin{array}{c}{ }^{183} W \\
\left(1,3 \times 10^{19} a-5,2 s\right)^{*}\end{array}$ & 7,700 & ${ }^{183} T a(5,1 \mathrm{~d})$ \\
\hline & & & ${ }^{186} W$ & 28,43 & 7,191 & $\begin{array}{c}{ }^{185} W \\
(75,1 \mathrm{~d}-1,67 \mathrm{~m})^{*}\end{array}$ & 8,402 & ${ }^{185} \mathrm{Ta}(49,4 \mathrm{~m})$ \\
\hline $\mathrm{Au}$ & 19,300 & 1064,18 & ${ }^{197} A u$ & 100,00 & 8,072 & $\begin{array}{c}{ }^{196} A u \\
(6,2 \mathrm{~d}-9,6 \mathrm{~h})^{*}\end{array}$ & 5,782 & ${ }^{196} P t(\infty)$ \\
\hline \multirow{4}{*}{$\mathrm{Pb}$} & \multirow{4}{*}{11,340} & \multirow{4}{*}{327,46} & ${ }^{204} \mathrm{~Pb}$ & 1,4 & 8,394 & ${ }^{203} \mathrm{~Pb}(51,9 \mathrm{~h})$ & 6,637 & ${ }^{203} \mathrm{Tl}(\infty)$ \\
\hline & & & ${ }^{206} \mathrm{~Pb}$ & 24,1 & 8,086 & ${ }^{205} \mathrm{~Pb}\left(1,73 \times 10^{7} \mathrm{a}\right)$ & 7,253 & ${ }^{205} \mathrm{Tl}(\infty)$ \\
\hline & & & ${ }^{207} \mathrm{~Pb}$ & 22,1 & 6,737 & ${ }^{206} \mathrm{~Pb}(\infty)$ & 7,487 & $\begin{array}{c}{ }^{206} \mathrm{Tl} \\
(4,2 \mathrm{~m}-3,74 \mathrm{~m})^{*}\end{array}$ \\
\hline & & & ${ }^{208} \mathrm{~Pb}$ & 52,4 & 7,367 & ${ }^{207} \mathrm{~Pb}(\infty)$ & 8,003 & ${ }^{207} \mathrm{Tl}(4,77 \mathrm{~m})$ \\
\hline
\end{tabular}

*Meia-vida do isótopo e estados metaestáveis

\section{Referências}

http://www, webelements,com/ (último acesso 13/05/2011).

http://www,nndc,bnl,gov/chart/chartNuc,jsp (último acesso 13/05/2011).

http://www,nndc,bnl,gov/qcalc/ (último acesso 13/05/2011). 


\section{Anexo III. Seções de choque $(\gamma, n)$ dos isótopos empregados na simulação.}

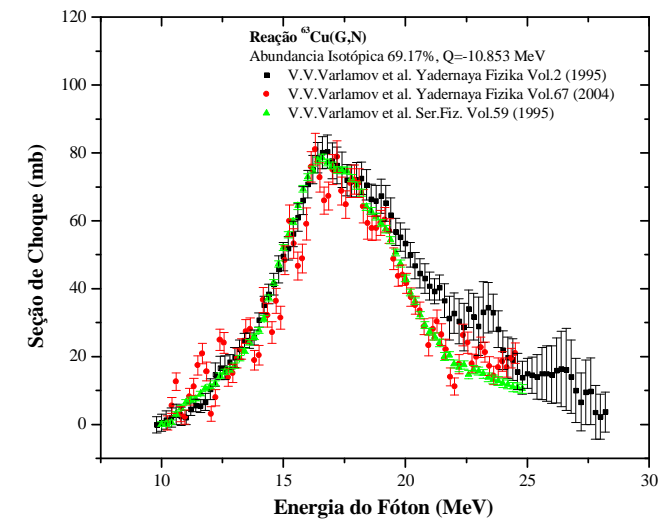

Fig. AIII.1 Seção de choque da reação ${ }^{63} \mathrm{Cu}(\gamma, \mathrm{n})$.

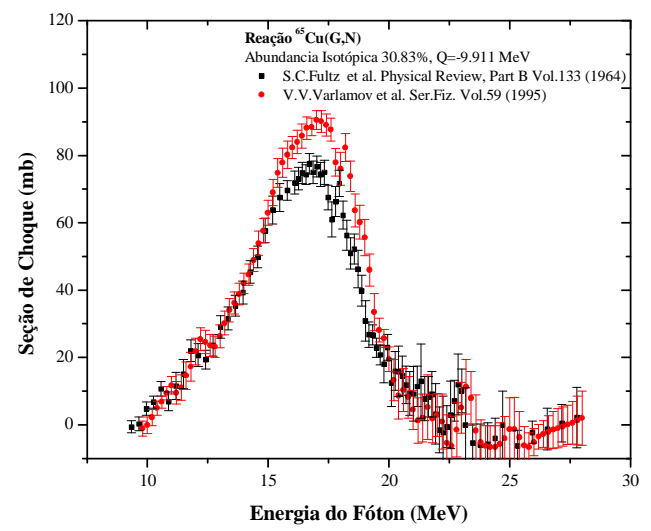

Fig. AIII.2 Seção de choque da reação ${ }^{65} \mathrm{Cu}(\gamma, \mathrm{n})$.

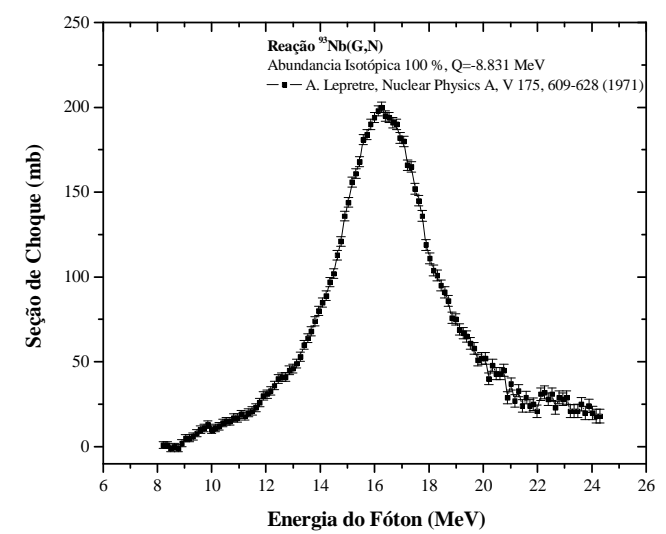

Fig. AIII.3 Seção de choque da reação ${ }^{93} \mathrm{Nb}(\gamma, \mathrm{n})$.

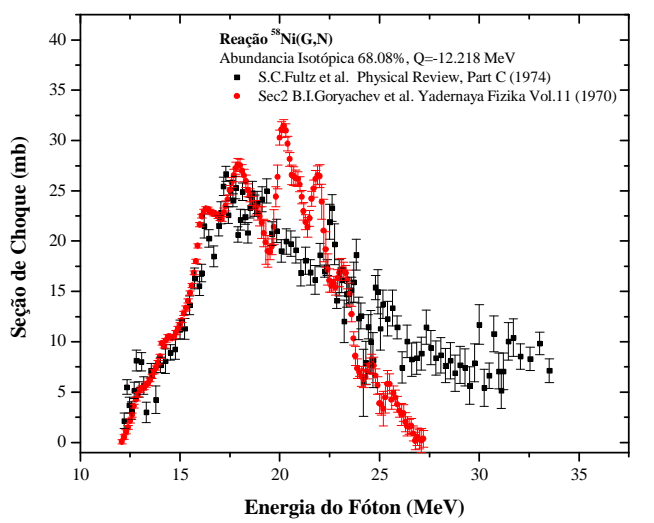

Fig. AIII.4 Seção de choque da reação ${ }^{58} \mathrm{Ni}(\gamma, \mathrm{n})$.

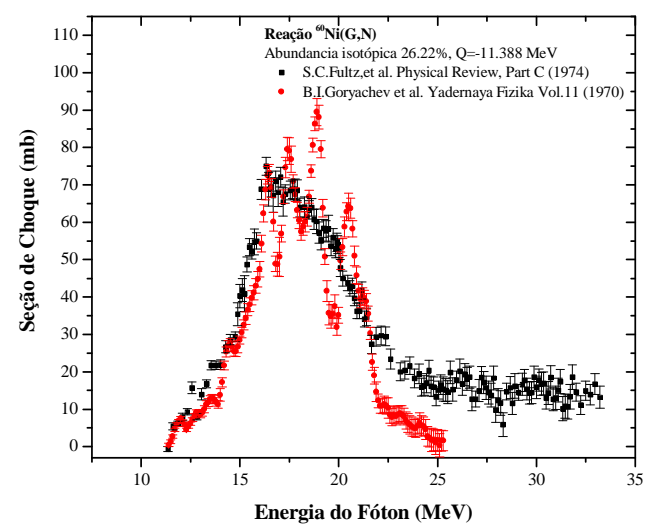

Fig. AIII.5 Seção de choque da reação ${ }^{60} \mathrm{Ni}(\gamma, \mathrm{n})$.

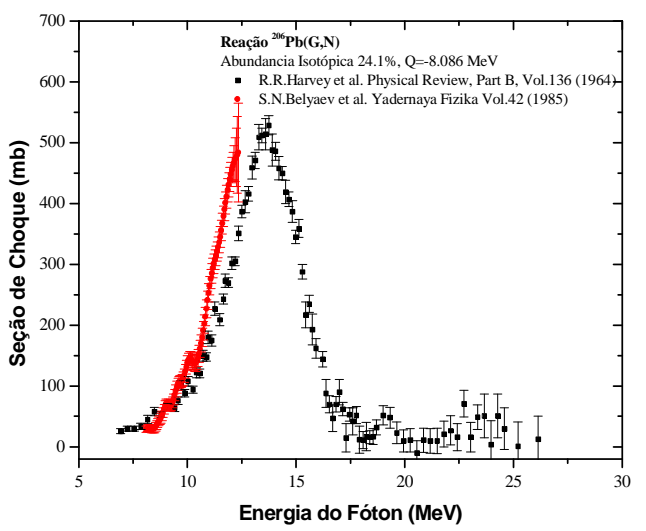

Fig. AIII. 6 Seção de choque da reação ${ }^{206} \mathrm{~Pb}(\gamma, \mathrm{n})$. 


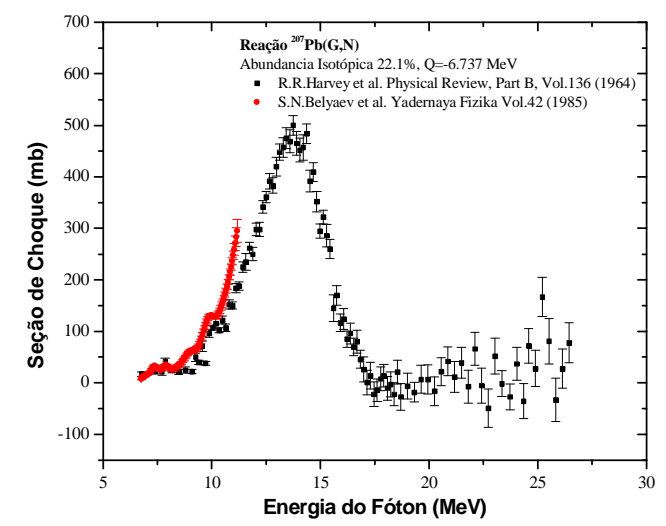

Fig. AIII. 7 Seção de choque da reação ${ }^{207} \mathrm{~Pb}(\gamma, \mathrm{n})$.

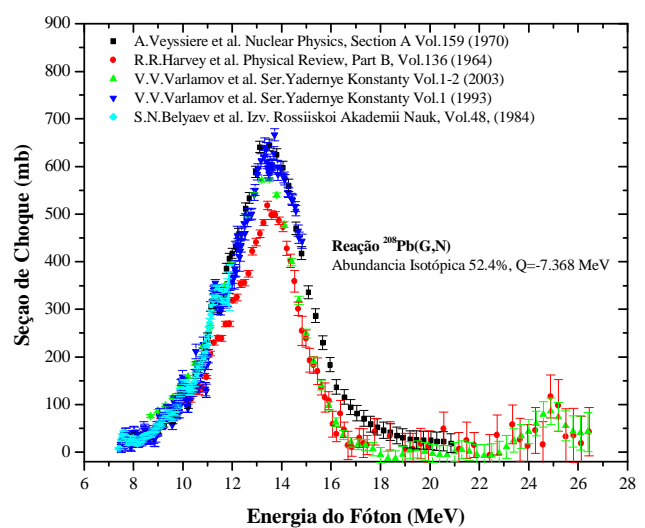

Fig. AIII. 8 Seção de choque da reação ${ }^{208} \mathrm{~Pb}(\gamma, \mathrm{n})$.

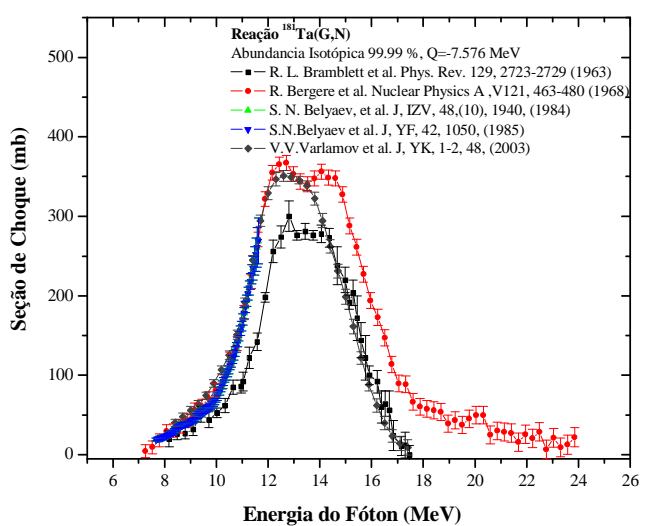

Fig. AIII. 9 Seção de choque da reação ${ }^{181} \mathrm{Ta}(\gamma, \mathrm{n})$.

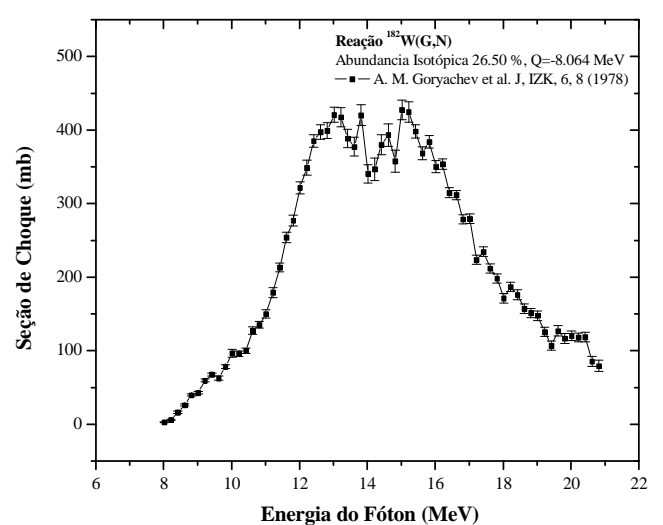

Fig. AIII. 10 Seção de choque da reação ${ }^{182} \mathrm{~W}(\gamma, \mathrm{n})$.

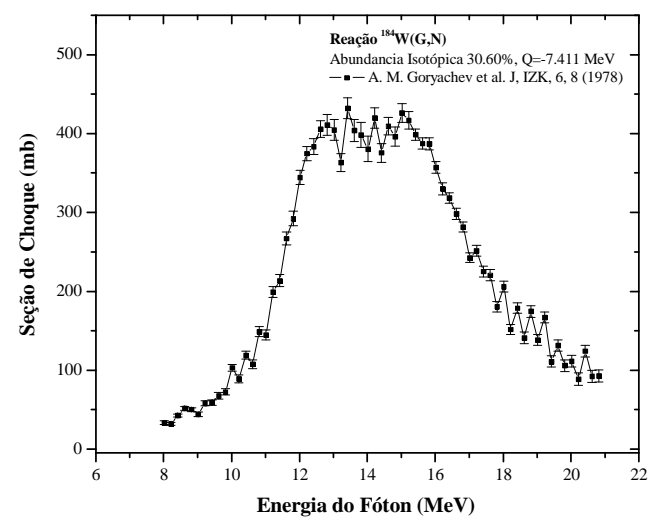

Fig. AIII. 11 Seção de choque da reação ${ }^{184} \mathrm{~W}(\gamma, \mathrm{n})$.

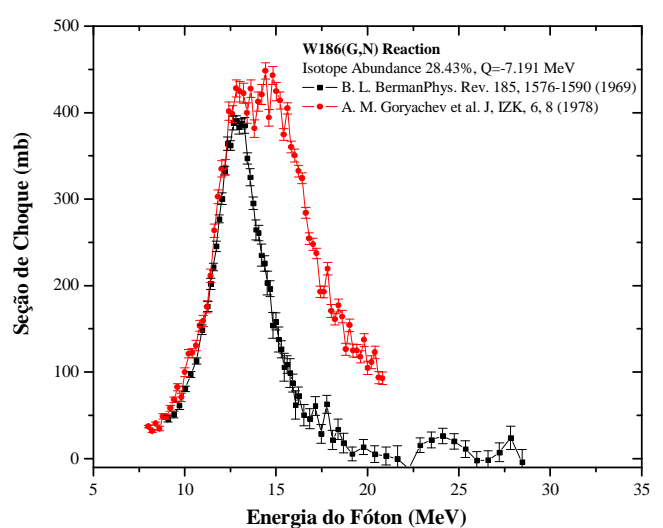

Fig. AIII. 12 Seção de choque da reação ${ }^{186} \mathrm{~W}(\gamma, \mathrm{n})$. 


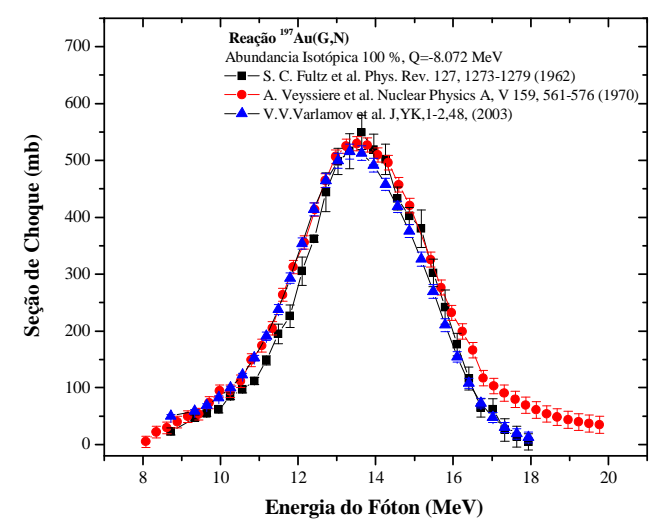

Fig. AIII. 13 Seção de choque da reação ${ }^{187} W(\gamma, n)$.

\section{Referência}

Experimental Nuclear Reaction Data (EXFOR / CSISRS)

http://www.nndc.bnl.gov/exfor7/exfor00.htm

(último acesso 14/05/2011) 


\section{Anexo IV Produção de fótons e nêutrons pelos radiadores para outras energias do feixe de elétrons incidente.}
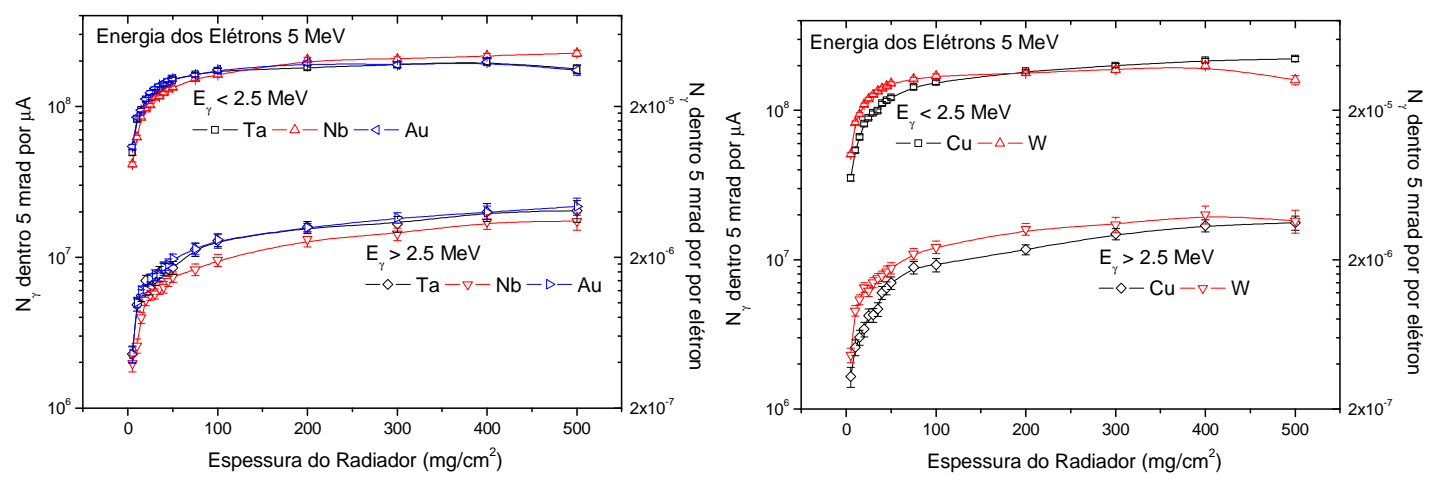

Fig. AIV.1 Número de fótons emitidos por radiadores de Ta, Nb e Au (esquerda) e Cu e W (direita). Energia dos elétrons $5 \mathrm{MeV}$.
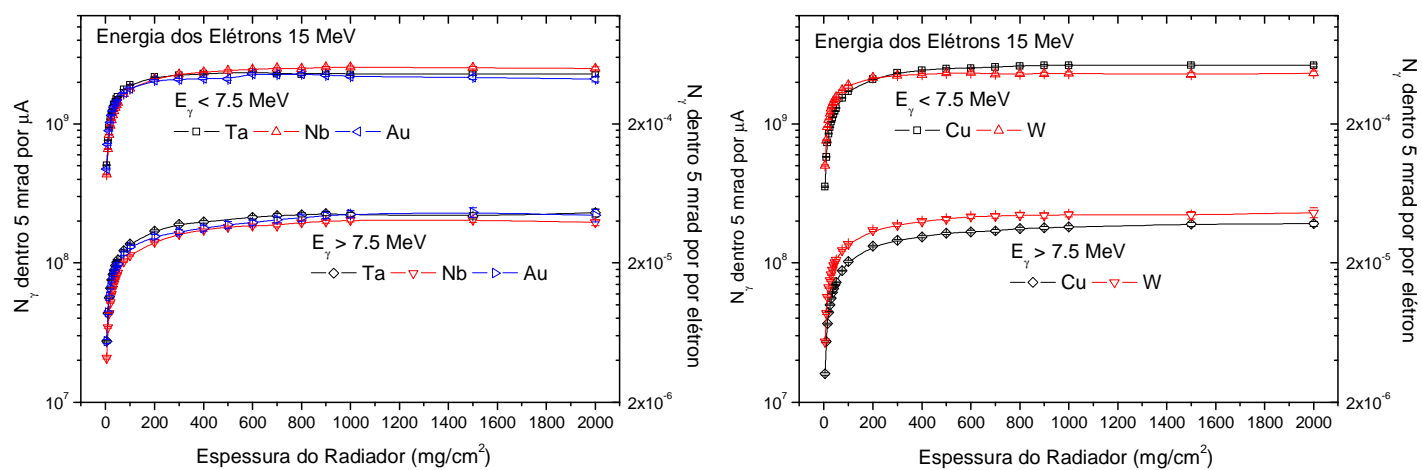

Fig. AIV.2 Número de fótons emitidos por radiadores de Ta, Nb e Au (esquerda) e Cu e W (direita). Energia dos elétrons $15 \mathrm{MeV}$.
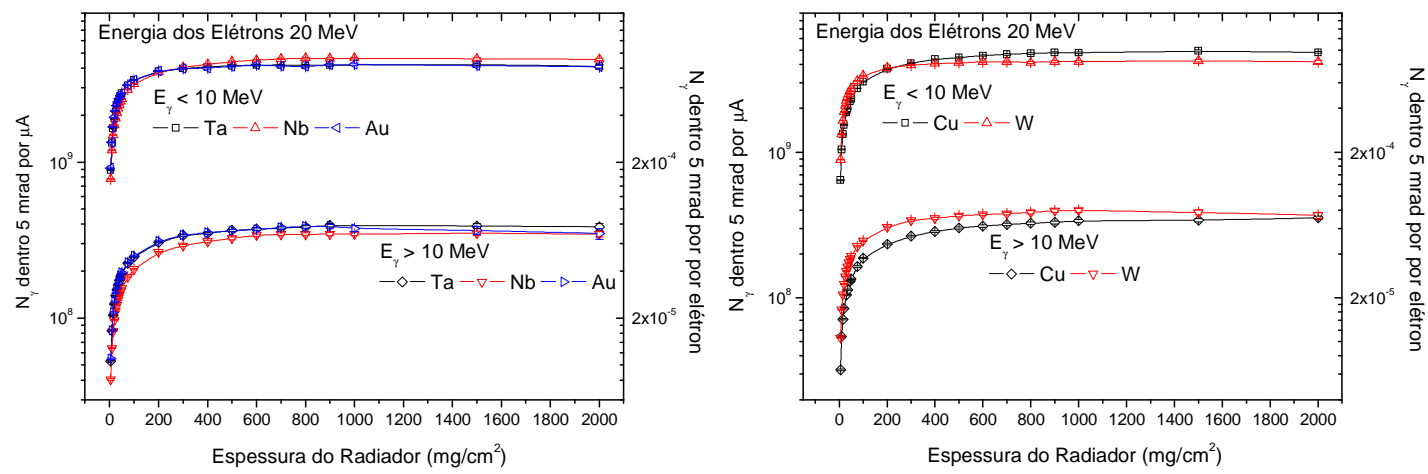

Fig. AIV.3 Número de fótons emitidos por radiadores de Ta, Nb e Au (esquerda) e Cu e W (direita). Energia dos elétrons $20 \mathrm{MeV}$. 

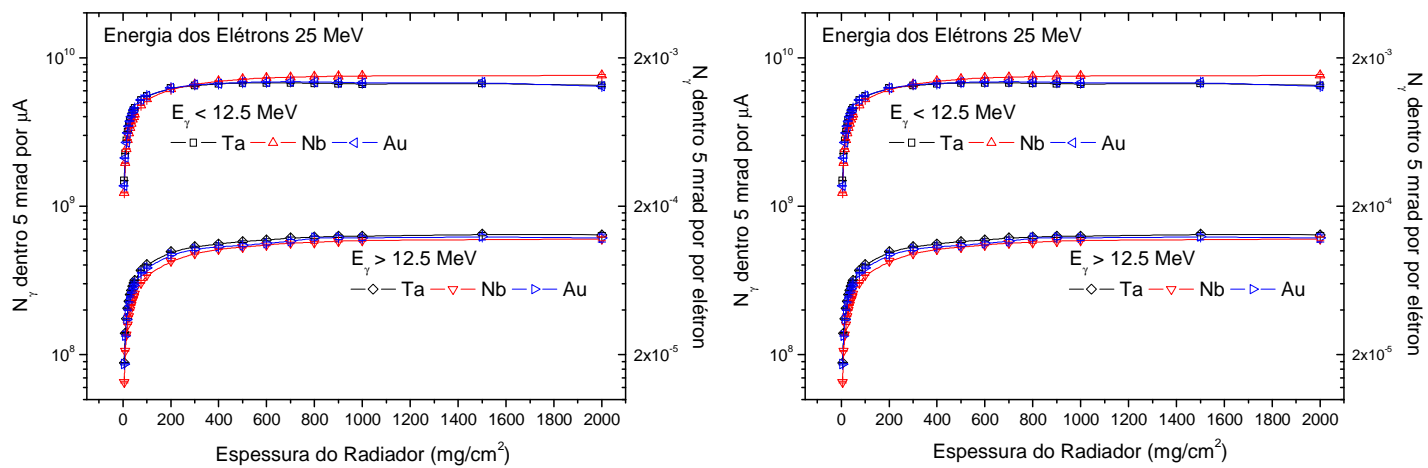

Fig. AIV.4 Número de fótons emitidos por radiadores de Ta, $\mathrm{Nb}$ e $\mathrm{Au}$ (esquerda) e $\mathrm{Cu}$ e W (direita). Energia dos elétrons $25 \mathrm{MeV}$.
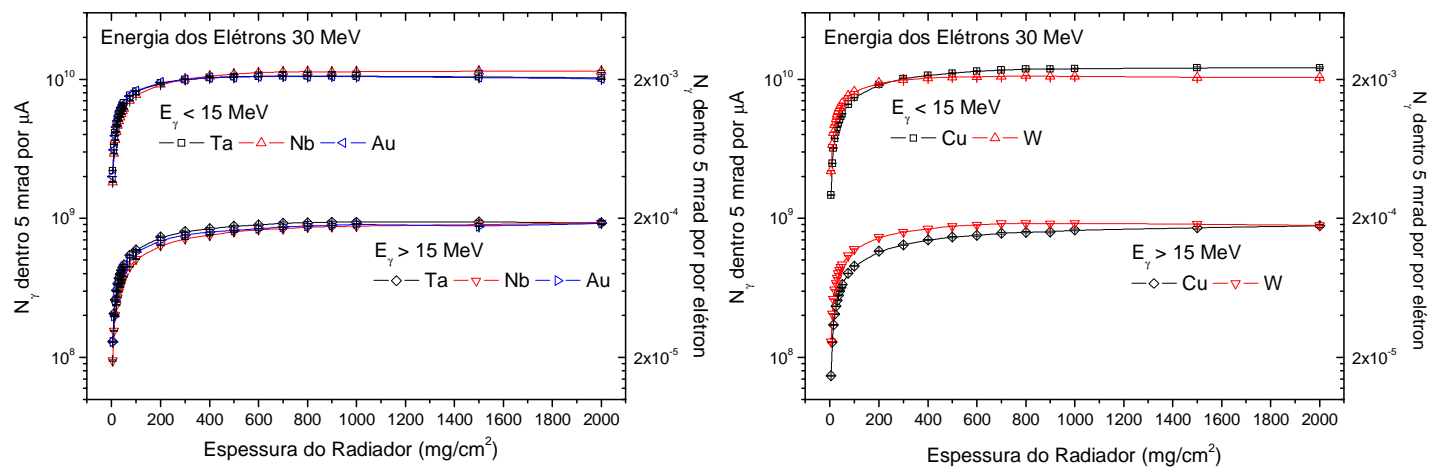

Fig. AIV.5 Número de fótons emitidos por radiadores de $\mathrm{Ta}, \mathrm{Nb}$ e $\mathrm{Au}$ (esquerda) e $\mathrm{Cu}$ e W (direita). Energia dos elétrons $30 \mathrm{MeV}$.
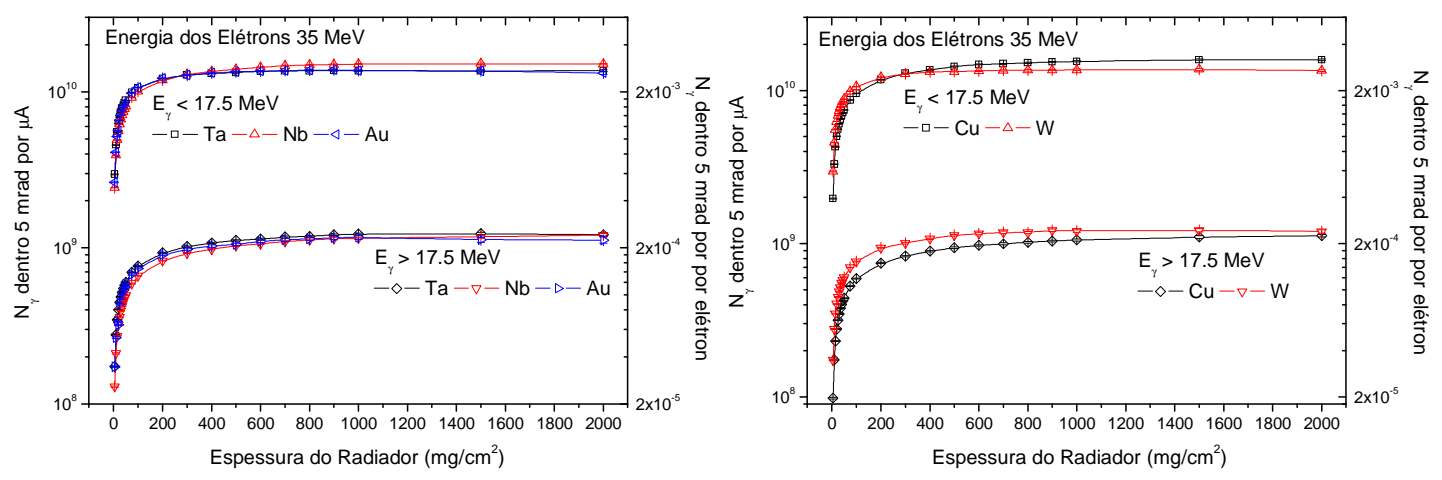

Fig. AIV.6 Número de fótons emitidos por radiadores de Ta, $\mathrm{Nb}$ e $\mathrm{Au}$ (esquerda) e $\mathrm{Cu}$ e W (direita). Energia dos elétrons $35 \mathrm{MeV}$. 


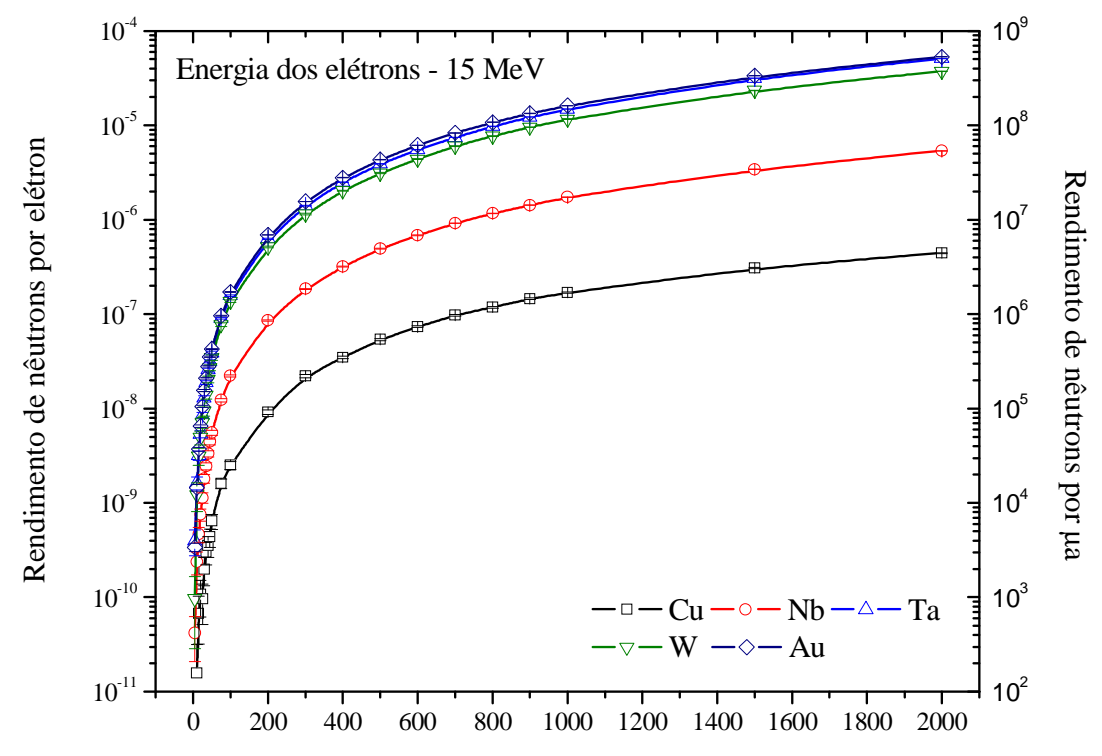

Espessura do Radiador (mg/cm²)

Fig. AIV.7 Produção de fotonêutrons por elétrons de $15 \mathrm{MeV}$ em função da espessura dos radiadores de $\mathrm{Cu}, \mathrm{Nb}, \mathrm{Ta}, \mathrm{W}$, e $\mathrm{Au}$.

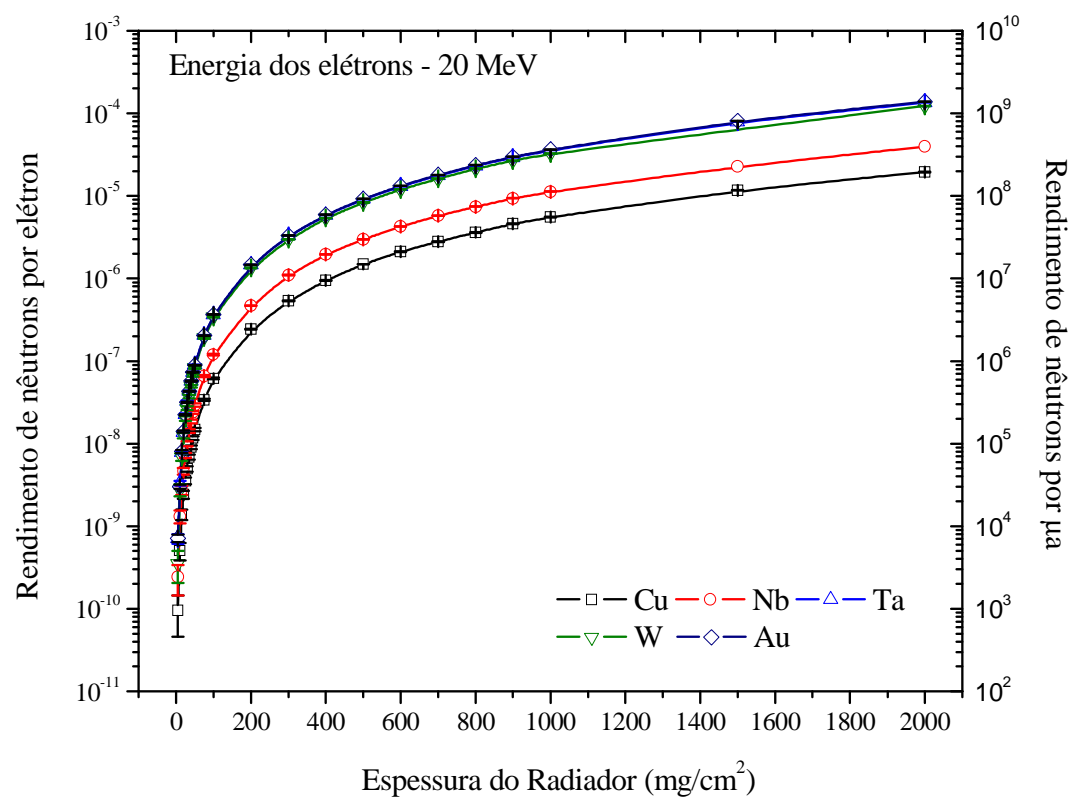

Fig. AIV.8 Produção de fotonêutrons por elétrons de $20 \mathrm{MeV}$ em função da espessura dos radiadores de $\mathrm{Cu}, \mathrm{Nb}, \mathrm{Ta}, \mathrm{W}, \mathrm{e} \mathrm{Au}$. 


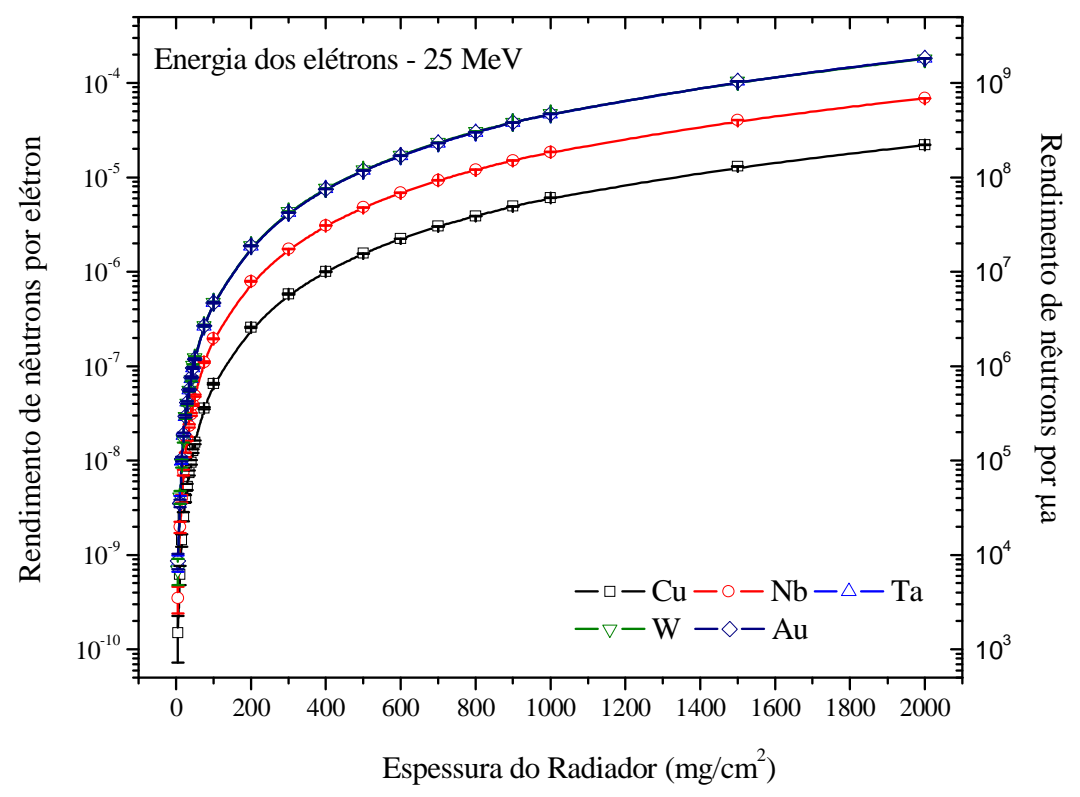

Fig. AIV.9 Produção de fotonêutrons por elétrons de $25 \mathrm{MeV}$ em função da espessura dos radiadores de $\mathrm{Cu}, \mathrm{Nb}, \mathrm{Ta}, \mathrm{W}, \mathrm{e} \mathrm{Au}$.

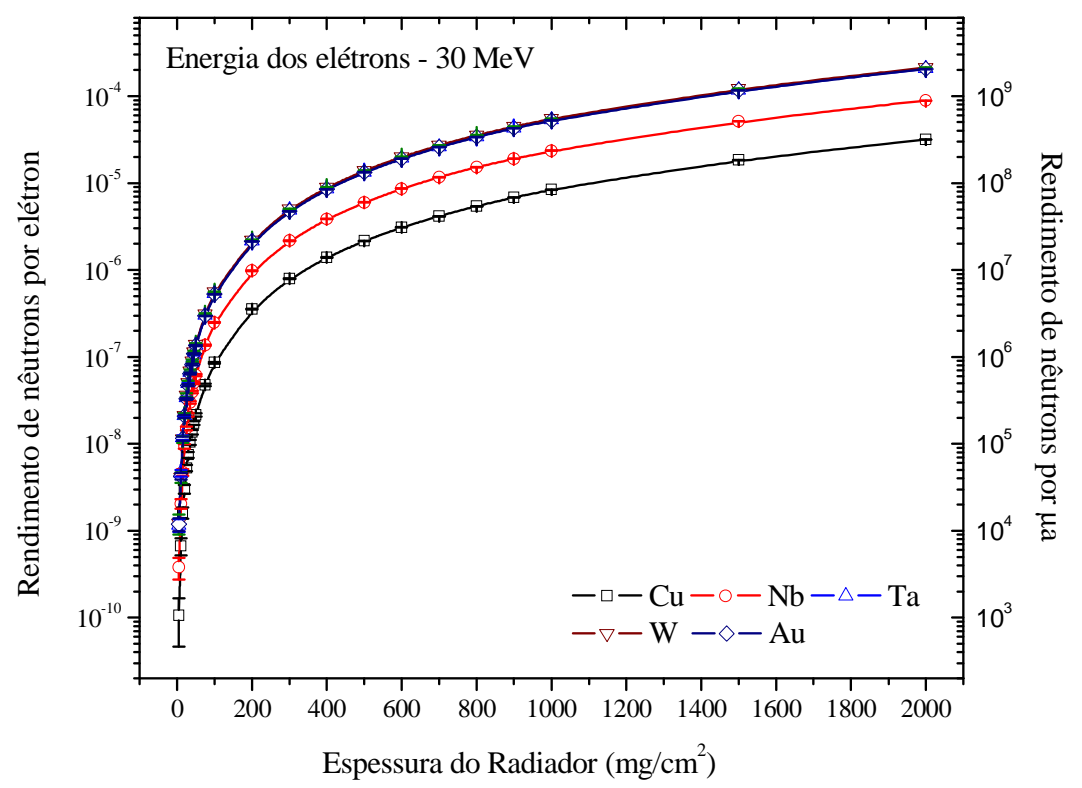

Fig. AIV.10 Produção de fotonêutrons por elétrons de $30 \mathrm{MeV}$ em função da espessura dos radiadores de $\mathrm{Cu}, \mathrm{Nb}, \mathrm{Ta}, \mathrm{W}, \mathrm{e} \mathrm{Au}$. 


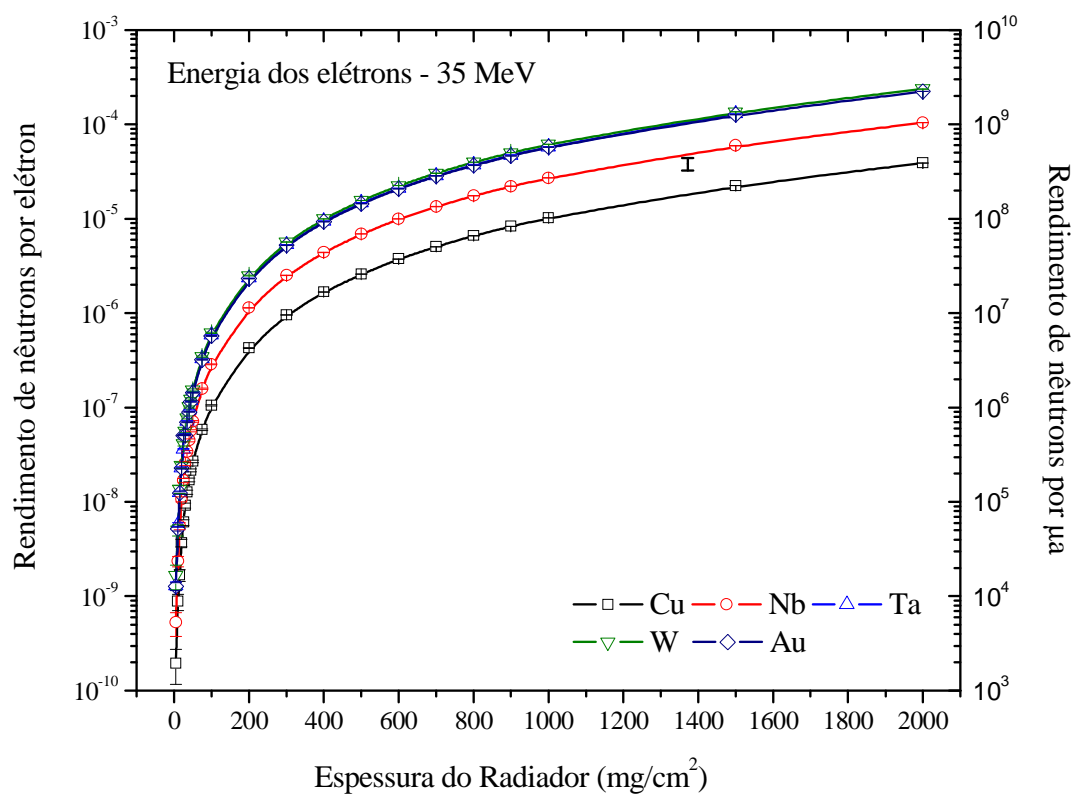

Fig. AIV.11 Produção de fotonêutrons por elétrons de $35 \mathrm{MeV}$ em função da espessura dos radiadores de $\mathrm{Cu}, \mathrm{Nb}, \mathrm{Ta}, \mathrm{W}$, e $\mathrm{Au}$. 


\section{Anexo V Medidas de Observáveis de Polarização}

\section{V.1 Feixes de Fótons Polarizados usando Bremsstrahlung}

Como foi mencionado previamente, existem duas formas de fazer medidas da polarização e assim realizar a determinação das paridades dos estados em estudo. A primeira via se consegue mediante experimentos $(\vec{\gamma}, \gamma)$ onde o alvo de NRF é bombardeado com um feixe de fótons polarizados. Em seguida descreveremos como é possível obter bremsstrahlung linearmente polarizado.

Os fótons que são emitidos fora do eixo de simetria do bremsstrahlung se encontram parcialmente polarizados. O vetor campo elétrico $\vec{E}$ é orientado preferencialmente na direção perpendicular ao plano de emissão do fóton e alinhado tangencialmente a um círculo ao redor do feixe incidente, como apresenta a Fig. AV.1. O ângulo ótimo de polarização é da ordem de $\Theta \approx m_{o} c^{2} / E_{o}$ sendo $\mathrm{m}_{\mathrm{o}} \mathrm{c}^{2}=511 \mathrm{keV}$ a energia de repouso do elétron, e $E_{o}$ a energia dos elétrons incidentes. Diferentes direções de polarização podem ser selecionadas mudando o ângulo de incidência do feixe [Be87, Go94]. Este método é usado para fótons de energias $E>5 \mathrm{MeV}$ devido ao baixo grau de polarização linear $(10-30 \%)$ obtido, como mostra a Fig. AV.2.

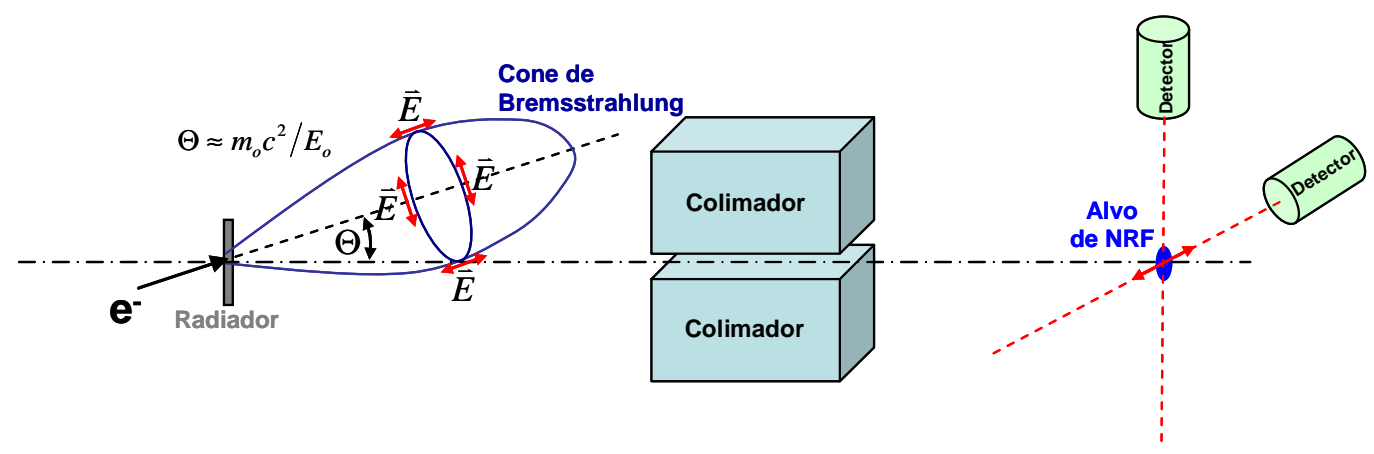

Fig. AV.1 Representação da obtenção de fótons linearmente polarizados usando bremsstrahlung. 


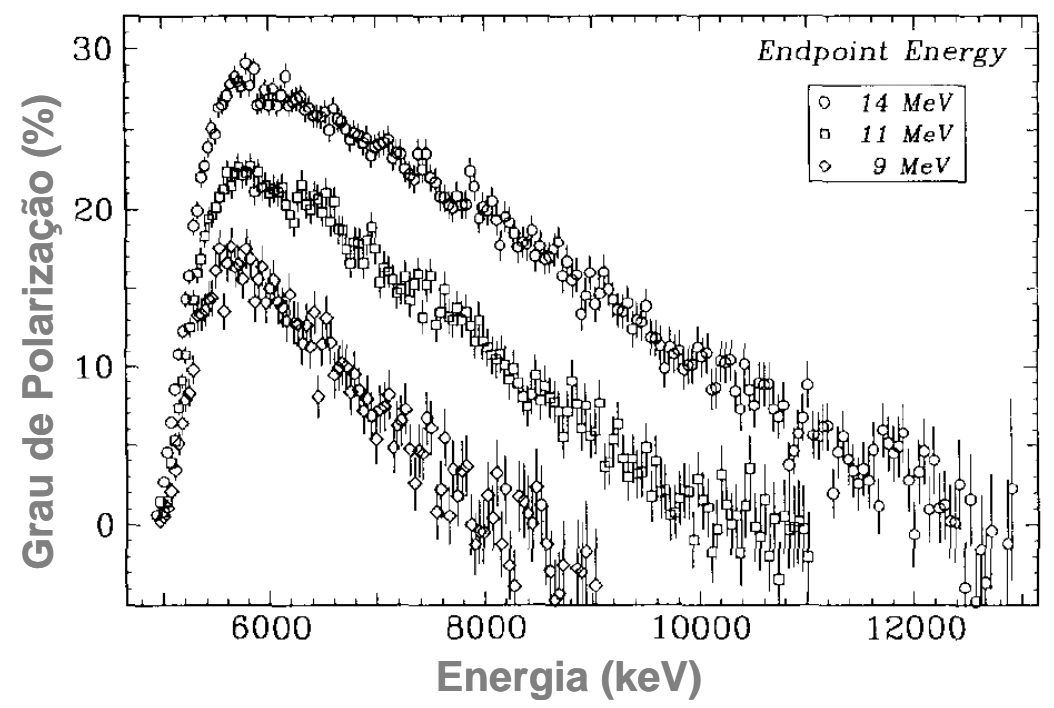

Fig. AV.2 Grau de polarização $P_{\gamma}$ em função da energia do espectro de bremsstrahlung para várias energias dos elétrons incidentes ("end point energy" na legenda do gráfico) [Ju95].

Em experimentos com "fótons marcados" (tagged photons) (Fig. AV.3) é possível aumentar a polarização com uma colimação adequada dos fótons e dos elétrons pós-bremsstrahlung. A figura AV.3 mostra o esboço de um "tagger" (tagging spectrometer), e a distribuição dos fótons polarizados na posição dos alvos descrita por Laszewski et al. [La85]. Observa-se como o grau de polarização aumenta até chegar a 50\% (Fig. AV.4). O “Tagging spectrometer" (Fig. AV.3) consiste em um espectrômetro magnético que desvia os elétrons selecionados para um sistema que determina a energia $E_{2}$ dos mesmos depois de gerar um fóton de energia $E_{\gamma}=E_{1}-E_{2}$ no radiador, sendo $E_{1}$ a energia dos elétrons incidentes. Deste jeito, mediante um esquema de coincidências retardadas é possível associar um fóton ao elétron que gerou. Por esta razão estes fótons são chamados em inglês de "tagged photon", fótons marcados. 


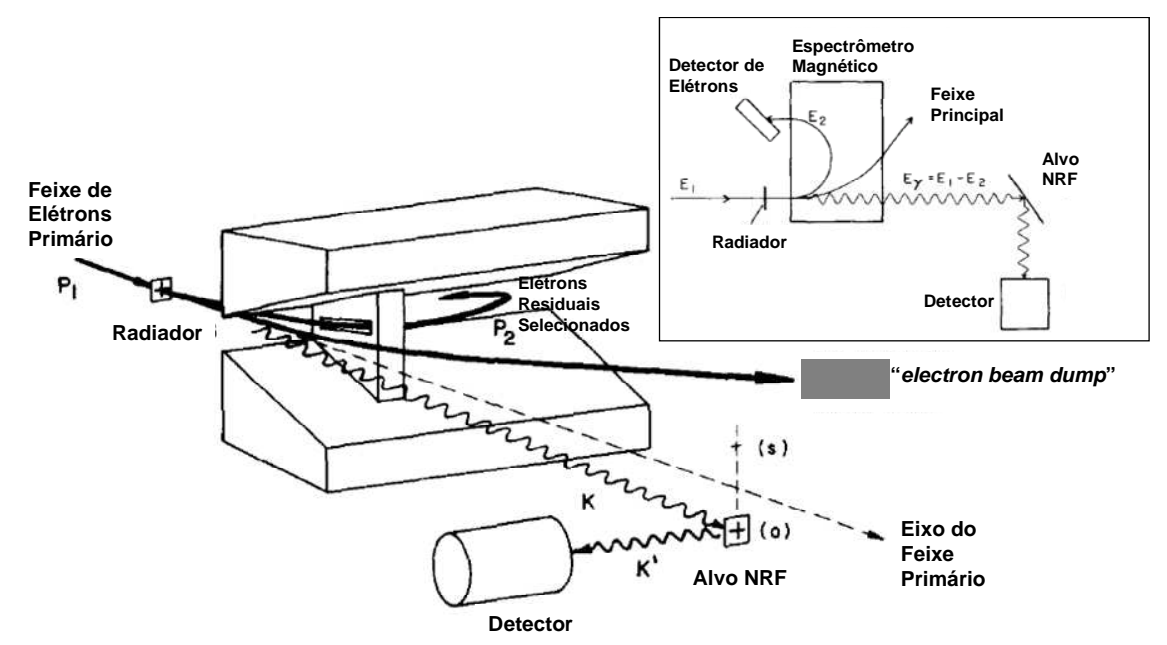

Fig. AV.3 Vista em perspectiva e superior de um "tagging spectrometer" [La85].

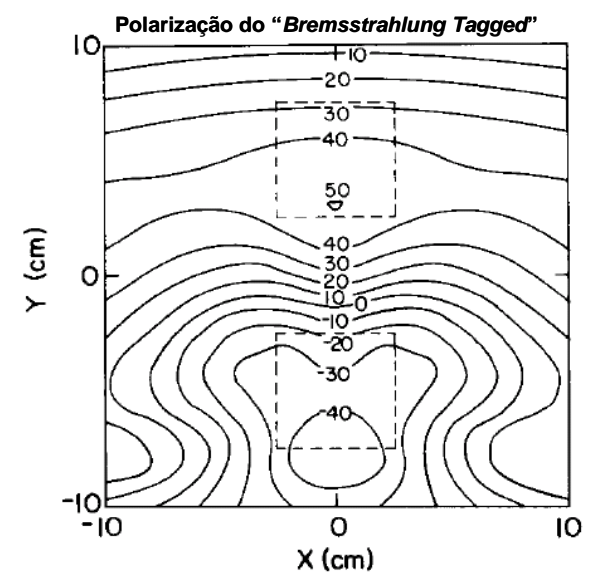

Fig. AV.4 Distribuição dos fótons polarizados na posição do alvo para energia dos elétrons incidentes de $\mathrm{E}_{1}=18,4 \mathrm{MeV}$ e dos fótons de $\mathrm{E}_{1}=11,4 \mathrm{MeV}$, reportado por Laszewski et al [La85]. As linhas descontínuas marcam as posições dos alvos.

O grau de polarização do feixe de fótons incidentes no alvo pode ser medido por meio da fotodesintegração do dêuteron ${ }^{2} H(\gamma, p) n$, cujo poder de análise $\Sigma(\Theta)$ é muito bem conhecido, sendo praticamente igual à unidade para $\Theta=90^{\circ}$ e energias não muito elevadas dos fótons incidentes. Os gráficos da Fig. AV.5 mostram $\Sigma$ em função do ângulo $\vartheta$ de emissão do nêutron no sistema de centro de massa $(\vartheta=\pi-\Theta)$, para energias diferentes dos fótons incidentes [De85]. Na Fig. AV.6 são apresentados os resultados das medidas do grau de polarização em função da energia dos fótons, realizado por Schwenger et al. usando a fotodesintegração do dêuteron [Sc05]. 

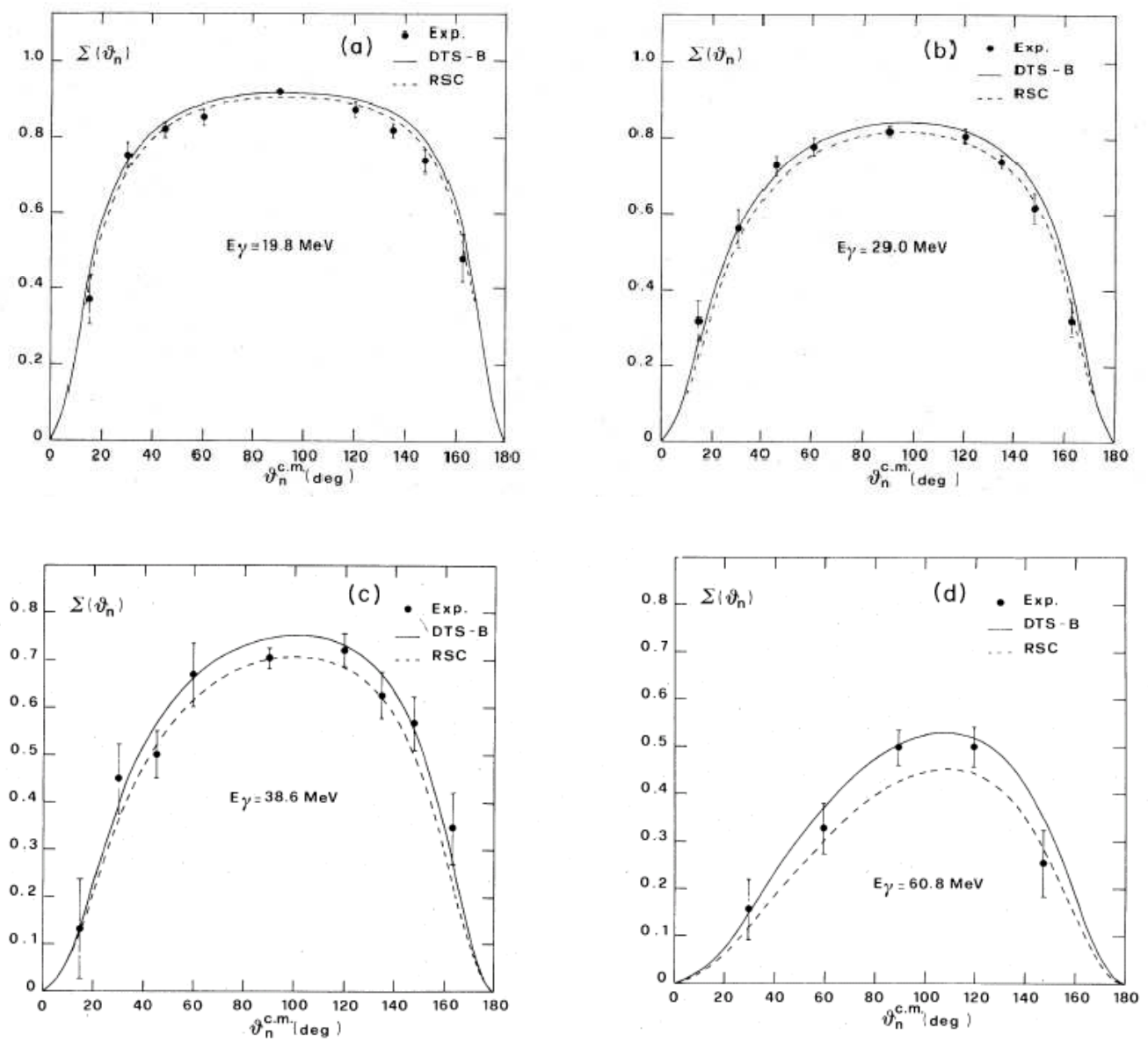

Fig. AV.5 Poder de análise $\Sigma(\vartheta)$ da fotodesintegração do dêuteron ${ }^{2} H(\gamma, p) n$ em função do ângulo $\vartheta$ de saída do nêutron no sistema de centro de massas $(\Theta=\pi-\vartheta)$, para varias energias dos raios gamas [De85].

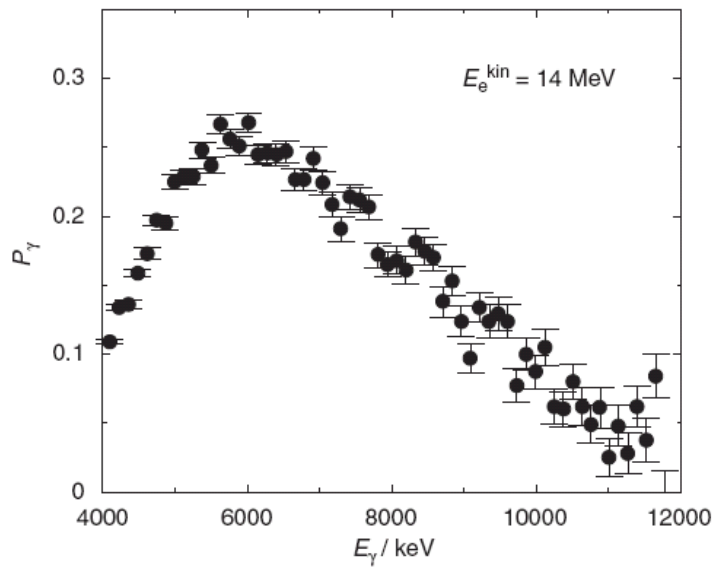

Fig. AV.6 Grau de polarização em função da energia dos fótons obtida a partir do espectro de prótons emitidos na fotodesintegração do dêuteron [Sc05]. 


\section{V.2 Medidas da Polarização dos Fótons Espalhados}

Como tínhamos mencionado previamente, uma alternativa viável ao emprego de um feixe incidente polarizado é usar detectores sensíveis à polarização realizando um experimento $(\gamma, \vec{\gamma})$.

Os polarímetros Compton com detectores semicondutores são umas das variantes mais empregadas para medir a polarização dos fótons espalhados devido à sua excelente resolução em energia. Diferentes tipos de polarímetros aparecem descritos na literatura, por exemplo, um arranjo de três detectores (um espalhador e dois que absorvem a radiação espalhada), ou um sistema de cinco detectores (um deles espalhador) [Sc94].

Atualmente, com a obtenção de cristais de germânio de grande volume são usados polarímetros que consistem num cristal de HPGe tipo p, dividido eletricamente em quatro partes, separadas por superfícies não condutoras (Fig. AV.7). A parte externa de cada um destes quatro segmentos permite a conexão com os pré-amplificadores correspondentes. A leitura do "core" central (cilindro de $9 \mathrm{~mm}$ de diâmetro na Fig. AV.7) permite determinar a energia total do fóton incidente e os sinais que emergem dos setores permitem definir os planos de espelhamento, pela escolha das coincidências apropriadas entre estes setores: plano Horizontal H com o esquema de coincidências $12 \overline{3} \overline{4}+\overline{1} \overline{2} 34$, e plano Vertical V com o esquema $1 \overline{2} \overline{3} 4+\overline{1} 23 \overline{4}$. Como o polarímetro fica normalmente em uma posição horizontal relativa ao plano da reação no alvo de $\mathrm{NRF}$, então $\mathrm{V}$ e H serão sinônimos de $N_{\perp}$ e $N_{\|}$respectivamente.
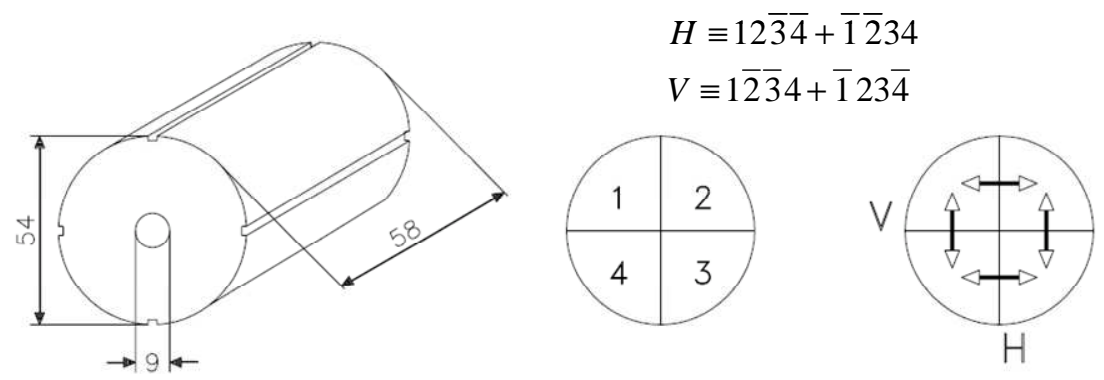

Fig. AV.7 Esboço de um polarímetro Compton com quatro setores, e esquema de coincidências para definir os eventos Compton "Horizontais" e "Verticais." As dimensões estão em milímetros [Sc94, Br01]. 
O emprego deste tipo de polarímetro em experimentos de NRF tem várias vantagens. Por exemplo, a energia total se obtém diretamente a partir do sinal no "core" central, evitando deste modo a soma de sinais como em um arranjo de detectores, o que garante uma resolução excelente e uma estabilidade durante um tempo prolongado, que é crucial em experimentos de NRF. A eficiência de coincidência $\varepsilon_{\text {coin }}$ (Fig. AV.8a) entre os quatro setores é $\varepsilon_{\text {coinc }}=(V+H) / N_{\text {simples }}$. Esta tem um valor elevado devido à geometria de feixe estreito, e ao grande ângulo sólido com que o detector subtende o alvo de NRF. A assimetria do polarímetro, definida como a razão $a$ entre as taxas de

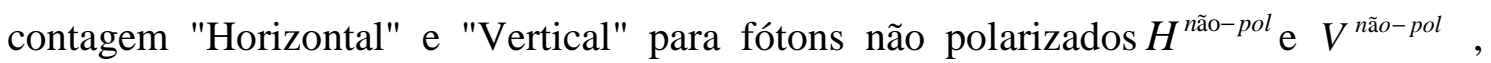
respectivamente, $\left(a=H^{n a ̃ o-p o l} / V^{n a ̃ o-p o l}\right)$, é praticamente igual a unidade (Fig. AV.8b), o que evita correções adicionais. O polarímetro também possui um tamanho bastante compacto, fácil de blindar, usando blindagem passiva, como $\mathrm{Pb}$, ou blindagem ativa como anti-Compton BGO [Ma96a].

(b)

(a)
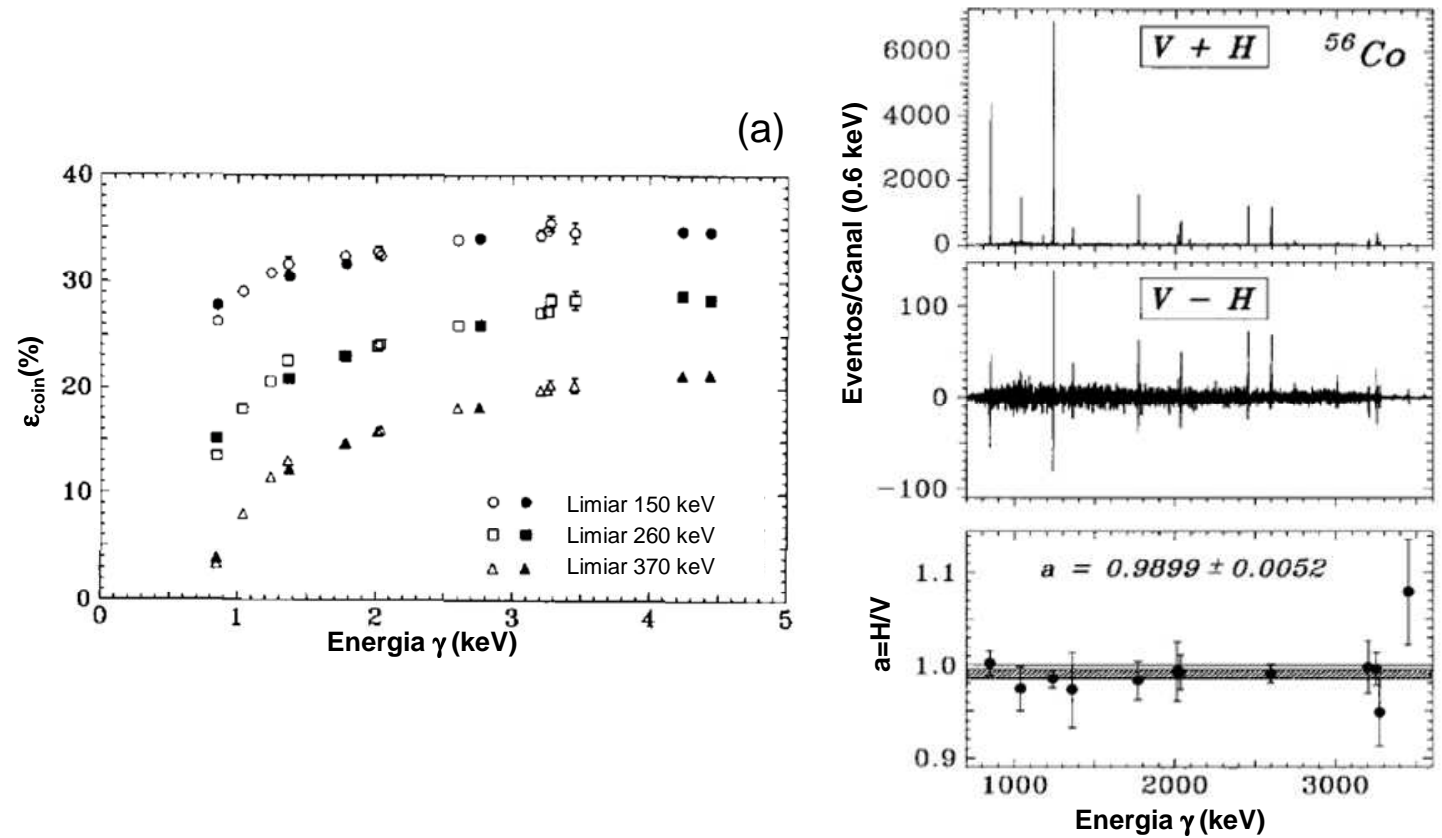

Fig. AV.8 (a) à direita o gráfico da eficiência de coincidência $\varepsilon_{\text {coin }}$ de um polarímetro Compton de quatro segmentos, (b) à esquerda medidas do grau de assimetria do mesmo polarímetro [Sc94].

Sabendo a sensibilidade de polarização $Q\left(E_{\gamma}\right)$ do polarímetro Compton em função da energia dos fótons, e registrando o número de eventos $\mathrm{V}$ e $\mathrm{H}\left(N_{\perp}\right.$ e $\left.N_{\|}\right)$, é 
determinado o grau de polarização dos fótons espalhados ressonantemente a partir da equação 2.20. Para determinar experimentalmente $Q\left(E_{\gamma}\right)$ na região de interesse da NRF são usadas reações $\left(p, p^{\prime} \gamma\right)$ em núcleos leves, que liberam fótons com um alto grau de polarização já conhecido. Para valores de menor energia $\left(E_{\gamma} \leq 1 \mathrm{MeV}\right)$ é possível fazer esta calibração a partir de cascatas intranucleares. A Fig. AV.9 mostra a calibração de um polarímetro Compton realizada por Schlitt et al. [Sc94] usando a cascata intranuclear do ${ }^{106} \mathrm{Pd}$ e reações de espalhamento inelástico de prótons em núcleos de ${ }^{12} \mathrm{C},{ }^{24} \mathrm{Mg}$ e ${ }^{28} \mathrm{Si}$. Observa-se que a sensibilidade de polarização, $Q$, cai de $20 \%$ para $0,5 \mathrm{MeV}$ de energia á $10 \%$ para $4 \mathrm{MeV}$.

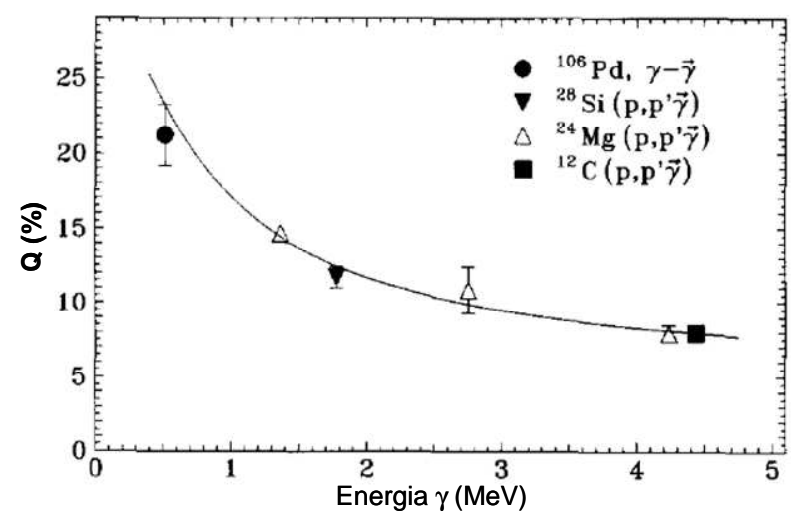

Fig. AV.9 Sensibilidade de Polarização, $Q(\%)$, de um polarímetro Compton de quatro segmentos em função da energia dos fótons [Sc94].

A função resposta de um polarímetro pode melhorar consideravelmente com o uso de uma blindagem ativa. Por exemplo, em 1996 Maser et al. usaram uma blindagem anti-Compton para fazer medidas de polarização na reação ${ }^{167} \operatorname{Er}(\gamma, \vec{\gamma})$ com oito cristais BGO em forma de trapezóide (Fig. AV.10a) [Ma96a]. Estes cristais foram separados opticamente entre si, com fotomultiplicadoras próprias, e todo o dispositivo pôde ser empregado como blindagem anti-Compton ou como espectrômetro de pares de acordo com modo de operação (coincidências ou anticoincidências). Maser et al. conseguiram reduzir o contínuo do espectro em um fator de 2 a 3 , mantendo constante a altura dos picos. Para energias maiores que o "end point" de 4,1 MeV, este fator foi de 15, o que permite determinar on-line a energia máxima do bremsstrahlung (Fig. AV.10b) com precisão de $30 \mathrm{keV}$. 
(a)

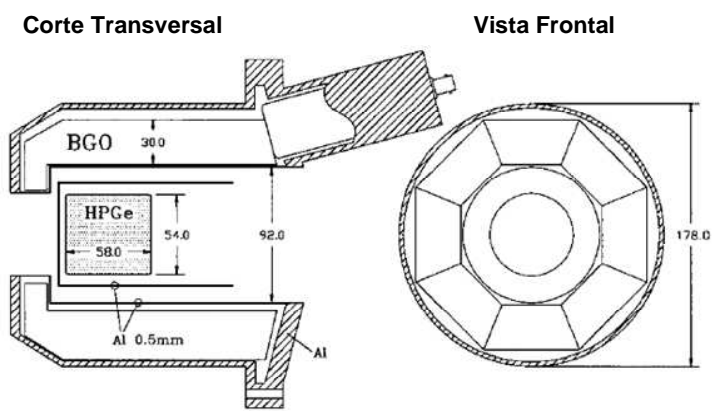

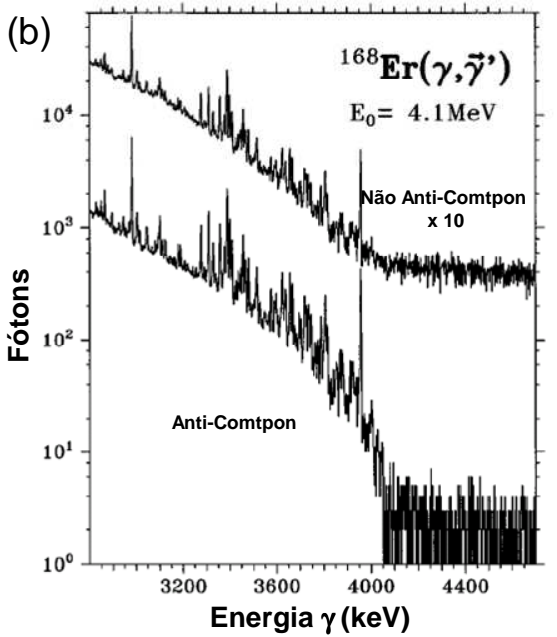

Fig. AV.10 (a) Sistema anti-Compton para um detector de HPGe constituído por oito cristais de BGO com forma trapezóidal. (b) Efeito na redução do fundo devido ao sistema anti-Compton [Ma96a]. 


\section{Anexo VI Glossário de termos relativos a cartões do código MCNPX}

\section{Cartões de saídas ou tallies}

F1: Corrente total de partículas em uma superfície (unidade $\rightarrow$ partículas)

*F1: Corrente total de partículas em uma superfície (unidade $\rightarrow \mathrm{MeV}$ )

F2: Fluxo médio de partículas em uma superfície (unidade $\rightarrow$ partículas $\mathrm{cm}^{-2}$ )

*F2: Fluxo médio de partículas em uma superfície (unidade $\rightarrow \mathrm{MeV} \mathrm{cm}^{-2}$ )

F4: Fluxo médio de partículas em uma célula (unidade $\rightarrow$ partículas $\mathrm{cm}^{-2}$ )

*F4: Fluxo médio de partículas em uma célula (unidade $\rightarrow \mathrm{MeV} \mathrm{cm}^{-2}$ )

F5: Fluxo em um detector pontual (unidade $\rightarrow$ partículas $\mathrm{cm}^{-2}$ )

*F5: Fluxo em um detector pontual (unidade $\rightarrow \mathrm{MeV} \mathrm{cm}^{-2}$ )

F6: Energia média depositada em uma célula (unidade $\rightarrow \mathrm{MeV} \mathrm{g}^{-1}$ )

*F6: Energia média depositada em uma célula (unidade $\rightarrow$ jerks $\mathrm{g}^{-1}$ )

F8: Distribuição em energias de pulsos criados em um detector por pulsos de radiação (unidade $\rightarrow$ pulsos)

*F8: Distribuição em energias de pulsos criados em um detector por pulsos de radiação (unidade $\rightarrow \mathrm{MeV}$ )

+F8: carga elétrica depositada em uma célula (unidade $\rightarrow$ carga do elétron)

\section{Cartões associados a Técnicas de Redução de Variância ou VTR}

IMP: Define em uma célula a importância de cada tipo de partícula transportada. É empregada para terminar a historia da partícula (IMP $=0$ ), ou para incrementar o número de partículas a transportar numa determinada região da geometria 3D definida no arquivo de entrada do MCNPX (IMP $\geq 1$ ).

WWG, WWGE, WWP, WWN, WWE: São conhecidos em inglês como WeightWindow Cards. Estes cartões são usados para incrementar o número de partículas geradas e transportadas em determinadas regiões da geometria 3D e permitem especificar limites energéticos e temporais para as partículas às quais serão aplicadas estas técnicas de redução de variância (VTR).

BBREM: Cartão usado para gerar maior número de fótons de freamento na região de maior energia do espectro de bremsstrahlung. 


\section{Referências Bibliográficas}

[Ad11] ADEKOLA, A.S.; ANGELL; C.T.; HAMMOND; S.L.; HILL; A.; HOWELL; C.R.; KARWOWSKI; H.J.; KELLEY; J.H.; KWAN; E. Discovery of low-lying E1 and M1 strengths in ${ }^{232}$ Th. Phys. Rev. C, V. 83, 034615, 2011.

[Ad90] ADLER, J-O.; ANDERSSON, B-E.; BLOMQVIST; K.I.; FORKMAN, B.; HANSEN, K.; ISAKSSON, L.; LINDGREN, K.; NILSSON, D.; SANDELL, A.; SCHRÖDER, B.; ZIAKAS, K. The photon tagging facility at the max accelerator system in Lund. Nucl. Inst. and Meth. in Phys. Res., v. 294, p. 15-25, 1990. Section A.

[Ae75] AEHLIG, A.; SCHEER, M; ZILKER; F. Energy dependency of the bremsstrahlung cross section at the short wavelength limit. Phys. Lett., v. 51A, p. 221- 222, 1972.

[Ag03] AGOSTINELli, S.; ALliSON, J.; AMAKO, K. et al. GEANT4-a simulation toolkit.. Nucl. Inst. and Meth. in Phys. Res., v. 506, p. 250-303, 2003, Section A.

[Ai66] AIGINGER, H.; ZINKE, H.; Messung der Elektro-Bremsstrahlungs-Wirkungsquerschnitte von 2,04-MeV- Elektronen. Acta Physica Austrica, v. 23, p. 77-87, 1966.

[Ai72] AIGINGER, H.; UNFRIED, E.; Elektron-Bremsstrahlungswechselwirkung. Acta Physica Austrica, v. 35 p. $331-348,1972$.

[Ak03] AKKURT, I.; ADLER, J.-O.; ANNAND, J.R.M.; FASOLO, F.; HANSEN, K.; ISAKSSON, L.; KARLSSON, M.; LILJA, P.; LUNDIN, M.; NILSSON, B.; ONGARO, C.; REITER, A.; ROSNER, G.; SANDELL, A.; SCHRÖDER , B.; ZANINI, A. Photoneutron yields from tungsten in the energy range of the giant dipole resonance. Phys. Med. Biol., v. 48, p. 33453352, 2003.

[A106] ALLISON, J.; AMAKO, K.; APOSTOLAKIS, J.; et al. GEANT4 Developments and Applications. IEEE transactions on nuclear science, v. 53, n. 1, p. 270-278, 2006.

[A155] ALAGA, G.; ALDER, K.; BOHR, A.; MOTTELSON, B.R.; DAN, K.; SELESK, V. Intensity rules for beta and gamma transitions to nuclear rotational states. Mat. Fys. Medd., v. 29, p. 1, 1955.

[Am89] AMUSIA, M.Y.; KOROL, A.V. Electron bremsstrahlung spectrum in the tip region. J. Phys. B: At. Mol. Opt. Phys., v. 22, p. L571-L573, 1989.

[An07] ANDONIAN, G.; FRIGOLA, P. Low Energy Faraday Cup. Radiabeam Technologies, LLC. Technical Note: FARC-02-300, 2007.

[An91] ANTHONY, I; KELLIE, JD; HALL, SJ, I.; et al. Design of a tagged photon spectrometer for use with the Mainz $840 \mathrm{MeV}$ microtron. Nucl. Inst. and Meth. in Phys. Res,. v. 301, p. 230240, 1991. Section A.

[Ar63] ARUTYUNIAN, F.R.; TUMANIAN, V.A. The Compton effect on relativistic electrons and the possibility of obtaining high energy beams. Phys. Lett., v. 4, p. 176-178, 1963.

[Au05] AUDITORE, L.; BARNÀ, R.C.; DE PASQUALE, D.; ITALIANO, A.; TRIFIRÒ, A.; TRIMARCHI, M. Study of a $5 \mathrm{MeV}$ electron linac based neutron source. Nucl. Inst. and Meth. in Phys. Res,. v. 229, p. 137-143, 2005. Section B

[Au93] AUERHAMMERA, J.; GENZA, H.; GRÄFA, H.-D.; HAHNA, R.; HOFFMANNSTASCHECKA, P.; LÜTTGEA C.; NETHINGA U., RÜHLA, K., RICHTERA, A.; 
RIETDORFA, T.; SCHARDTA, P.; SPAMERA, E.; THOMASA, F.; TITZEA, O.; TÖPPERA, J.; WEISEA H. The S-DALINAC facility - Operational experience from the accelerator and the experimental installations. Nuclear Physics A, v. 553, p.841-844, 1993.

[Av09] AVDEENKOV A.V.; KAMERDZHIEV S. P. Pygmy Dipole Resonance in Nuclei. Physics of Atomic Nuclei, v. 72, p. 1332-1339, 2009.

[Ba93] BAUSKE, I.; ARIAS, J.M.; BRENTANO, P. VON; FRANK, A.; FRIEDRICHS, H.; HEIL, R.D.; HERZBERG, R.-D.; HOYLER, F.; VAN ISACKER, P.; KNEISSL, U.; MARGRAF, J.; PITZ, H.H.; WESSELBORG, C.; ZILGES, A. First observation of scissors mode states in an odd-mass nucleus. Phys. Rev. Let,. v. 71, 000975, 1993.

[Be01] BELIC, D.; BESSERER, J.; ARLANDINI, C.; DE BOER, J.; CARROLL, J. J.; ENDERS, J.; HARTMANN, T.; KÄP.ELER, F.; KAISER, H.; KNEISSL, U. et al.. The new photoactivation facility at the 4.3 MV Stuttgart DYNAMITRON: setup, performance, and first applications. Nucl. Inst. and Meth. in Phys. Res. v. 463 p. 26-41, 2001. Section A.

[Be02] BEDOGNI, R.; GUALDRINI, G.; MONTEVENTI, F. Field parameters and dosimetric characteristics of a fast neutron calibration facility: experimental and Monte Carlo evaluations. Nucl. Inst. and Meth. in Phys. Res,. v. 476, p. 381-385, 2002 Section A.

[Be68] BERGÈRE, R.; BEIL, H.; VEYSSIÈRE A. Photoneutron cross sections of La, Tb, Ho and Ta.. Nucl. Phys. A, v. 121 p. 463-480, 1968.

[Be75] BERMAN, B.L. Atlas of Photoneutron Cross Sections Obtained with Monoenergetic Photons. Atomic Data and Nuclear Data Tables, v. 15, p.319, 1975.

[Be84] BETHE, H.A.; HEITLER, On the Stopping of Fast Particles and on the Creation of Positive Electrons. W. Proc. R. Soc. Lond. A, v. 146, p.83-112, 1984.

[Be87] BERG, U. E. P.; KNEISSL, U. Recent progress on nuclear magnetic dipole excitations. Ann. Rev. Nucl. Part. Sci. v. 37, p. 33-69, 1987.

[Be93] BELGYA, T.; SECKEL, D.; JOHNSON, E.L.; BAUM, E.M.; WANG, D.; DIPRETE, D.P.; YATES, S.W. Level lifetimes in $\mathrm{N}=82$ isotones from Doppler-Shift Attenuation Methods mixed-target measurements. Phys. Rev C,. v. 47, p. 392-394,1993.

[Bo08] BOSONA, J.; ÅGRENA, G.; JOHANSSON, L. A detailed investigation of HPGe detector response for improved Monte Carlo efficiency calculations. Nucl. Inst. and Meth. in Phys. Res,. v. 587 p. 304-314, 2008, Section A.

[Bo82] BOTTO, D.J.; GRAVILA, M. Radiative correction to atomic photoeffect and tip bremsstrahlung III. Phys. Rev A. v. 26 p. 237-249, 1982.

[Bo86] BOHLE, D.; RITCHER, A.; BERG, U.E.P.; DREXLER, J.; HEIL, R. D.; KNEISSL, U.; METZGER, H.; STOCK, R.; FISCHER, B.; HOLLICK, H.; KOLLOWE, D. Distribution of orbital magnetic dipole strength in ${ }^{156}$ Gd. Nucl. Phys. A, v. 458, p. 205-216, 1986.

[Br00] BRIESMEISTER, J.F. (Ed.) MCNP-A General Monte Carlo N-Particle Transport Code Version 4C (Los Alamos National Laboratory Report, LA-13709-M, 2000).

[BrO0a] BRYSSINCK, J.; GOVOR, L.; PONOMAREV V.YU.; BAUWENS, F.; BECK, O.; BELIC, D.; BRENTANO, P. VON; DE FRENNE, D.; ECKERT, T.; FRANSEN, C.; GOVAERT, K.; HERZBERG, R.-D.; JACOBS, E.; KNEISSL, U.; MASER, H.; NORD, A.; PIETRALLA, N.; PITZ, H.H.; WERNER, V. Systematic study of electric quadrupole excitations in stable even mass Sn nuclei. Phys. Rev C,. v. 61, 024309, 2000. 
[Br01] BRYSSINK, J. Search for two-phonon states in nuclei in tin region using the photon scattering technique. 2001. Tese (Doutorado) - Universidade de Gent, Belgica.

[Br97] BRIESMEISTER, J.F. (Ed.) MCNP-A General Monte Carlo N-Particle Transport Code, Version 4B (Los Alamos National Laboratory, Report LA-126 25 -M, 1997).

[Ca04] CASANOVA, A.O.; LÓPEZ, N.; GELEN, A.; MANSO GUEVARA, M.V.; DÍAZ, O.; CIMINO, L.; D'ALESSANDRO, K.; MELO, J.C. Shielding analysis of the Microtron MT-25 bunker using the MCNP-4C code and NCRP Report 51. A. O. Casanova, N. López, A. Gelen, M. V. Manso Guevara, O. Díaz, L. Cimino, K. D'Alessandro, and J. C. Melo. Radiat Prot Dosimetry, v. 109 p. 189 - 195, 2004.

[Ca88] CATALDI, M.I.C.; WOLYNEC, E.; MARTINS, M.N.; GOUFFON, P.; MIYAO, Y. Electrodisintegration of ${ }^{208} \mathrm{~Pb},{ }^{209} \mathrm{Bi}$ and ${ }^{181}$ Ta. J. Phys. G: Nucl. Phys. v. 14, p. 779-786, 1988.

[Ch76] CHECHIN, V.A.; ERMILOVA, V.C. The ionization-loss distribution at very small absorber thickness. Nucl. Instr. and Meth., v. 136, p. 551-558, 1976.

[Da54] DAVIES, H.; BETHE, H.A.; MAXIMON, L.C. Theory of Bremsstrahlung and Pair Production. II. Integral Cross Section for Pair Production. Phys. Rev. v. 93, p. 788-795, 1954.

[Da68] DAVIES, K.E.; HAMILTON, W.D. Gamma-gamma linear polarization measurements. Nucl. Inst. and Meth,. v. 59, p. 1-21, 1968.

[Da72] DAUTREY, H.; DUGNE J. J.; PRORIOL, The short wavelenght limit and theoretical results. J. Phys. Lett. A, v. 47, p. 101-108, 1972.

[De05] DE OLIVEIRA G. C. Eficiência de Detectores HPGe para fótons de 4 a 10 MeV. 2005. Tese (Mestrado) - Inst. de Física da Universidade de São Paulo, São Paulo.

[De10] DEBOER, R.J.; WIESCHER, M.; GÖRRES J.; LONGLAND, R.; ILIADIS, C.; RUSEV, G.; TONCHEV A.P. Photoexcitation of astrophysically important states in ${ }^{26} \mathrm{Mg}$. II. Ground-statetransition partial widths. Phys. Rev. C, v. 82, 025802, 2010.

[De85] DE PASCALE, M.P.; GIORDANO, G.; MATONE, G.; et al. Polarization asymmetry in the photodisintegration of the dêuteron. Phys. Rev. C, v. 32, p. $1830-1841,1985$.

[De95] DEMARCO, J.J.; SOLBERG, T.D.; WALLACE, R.E.; SMATHERS, J.B. A verification of the Monte Carlo code MCNP for thick target bremsstrahlung calculations. Med. Phys., v. 22, p. 11$15,1995$.

[Di88] DIETRICH, S.S.; BERMAN, B.L. Atlas of photoneutron cross sections obtained with monoenergetic photons. Atomic Data and Nuclear Data Tables, v. 38, p.199, 1988.

[Dr06] DROSTE, CH.; CZAJKOWSKA. B.; MARCINKOWSKA, Z.; LIEDER, R.M.; MOREK, T.; RZA, T.; CA-URBAN; GAST, W. Polarisation sensitivity of the CLUSTER detector used in EUROBALL array. Nucl. Inst. and Meth. in Phys. Res., v.556, p. 182-186, 2006. Section A.

[Eb03] EBERHARD, H.; WERNER, N. The elementary Process of Bremsstrahlung. World Scientific Note in Physics. v.73., 2003.

[El69] ELWER,T G.; HAUG, E. Calculation of Bremsstrahlung Cross Sections with SommerfeldMaue Eigenfunctions. Phys. Rev., v. 183, p. 90-105, 1969.

[En90] ENDT, P.M. Energy levels of A = 21-44 nuclei (VII). Nucl. Phys. A, v. 521, p. 1-830, 1990. 
[Er06] ERHARD, M.; JUNGHANS, A.R.; BEYER, R.; GROSSE, E.; KLUG, J.; KOSEV, K.; NAIR, C.; NANKOV, N.; RUSEV, G.; SCHILLING, K.D.; SCHWENGNER, R.; WAGNER, A. Photodissociation of p-process nuclei studied by bremsstrahlung induced activation.. Eur. Phys. J. A, v.27, p. 135-140, 2006.

[Er09] ERTUGRAL, F.; GULIYEV, E.; KULIEV, A.; YILDIRIM, Z. Fine structure of the dipole excitations of the even-even ${ }^{160} \mathrm{Gd}$ nucleus in the spectroscopic region. Cent. Eur. J. Phys. v. 7, p.731-737, 2009.

[Er10] ERHARD, M.; JUNGHANS, A. R.; NAIR, C.; SCHWENGNER, R.; BEYER, R.; KLUG, J.; KOSEV, K.; WAGNER, A. Experimental study of the electric dipole strength in the even Mo nuclei and its deformation dependence. Phys. Rev. C, v.81, 034319, 2010.

[Es05] ESHWARAPPA, K.M.; GANESH; SIDDAPPA, K.; KASHYAP, Y.; SINHA, A.; SARKAR, PS., GODWAL, BK. Estimation of photoneutron yield from beryllium target irradiated by variable energy microtron-based bremsstrahlung radiation. Nucl. Inst. and Meth. in Phys. Res., v. 540, p. 412-418, 2005. Section A

[Fa08] FADDEGON, B. A.; ASAI, M.; PERL, J.; ROSS, C.; SEMPAU, J.; TINSLAY, J.; SALVAT, F. Benchmarking of Monte Carlo simulation of bremsstrahlung from thick targets at radiotherapy energies. Med. Phys., v. 35 p. 4308-4317, 2008.

[Fa58] FANO, U.H.; KOCH, H.W.; MOTZ, J.W. Evaluation of bremsstrahlung cross section at the High-Frequency Limit. Phys. Rev., v. 102 p. 1679-1683, 1958.

[Fa59] FAGG, L.W.; HANNA, S.S. Polarization Measurement on nuclear gamma rays. Rev. Mod. Phys., v. 31, p. 711-758, 1959.

[Fa59a] Fano, U.H. High Frequency Limit of bremsstrahlung in the Sauter approximation. Phys. Rev., v. 116, p. 1156-1158, 1959.

[Fe80] FEDERICI, L.; GIORDANO, G.; MATONE, G.; PASQUARIELLO, G.; PICOZZA, P. G.; CALOI, R.; CASANO,L.; DE PASCALE, M.P.; MATTIOLI, M.; POLDI, E. Backward Compton scattering of laser light against high-energy electrons - The LADON photon beam at Frascati. Nuovo Cimento B, s 11, v. 59, p. 247-257, 1980.

[Fe83] FENG, I.J.; GOLDBERG, I.B.; KIM, YOUNG SOON; PRATT, R.H. Connection between the bremsstrahlung tip and direct recombination: Angular distributions and polarization correlations. Phys. Rev A., v. 28 p. 609-614, 1983.

[Fi80] FINDLAY, D.J.S.; DUSAUTOY, A.R. Improvements to the Blunck-Leisegang energy loss straggling distribution. Nucl. Inst. and Meth., v. 174, p. 531-533, 1980.

[F104] FLASKA, M.; BORELLA, A.; LATHOUWERS, D.; MIHAILESCU, L.C.; MONDELAERS, W.; PLOMPEN, A.J.M.; DAM, H. VAN; HAGEN; T.H.J.J. VAN DER. Modeling of the GELINA neutron target using coupled electron-photon-neutron transport with the MCNP4C3 code. Nucl. Inst. and Meth. in Phys. Res., v. 531, p. 392-406, 2004. Section A.

[Fo04] FORSTER, A.R.; COX, L.J.; BARRETT, R.F.; BOOTH, T.E.; BRIESMEISTER, J.F.; BROWN, F.B.; BULL, J.S.; GEISLER, G.C.; GOORLEY, J.T.; MOSTELLER, R.D.; et al. MCNP ${ }^{T M}$ Version 5. Nucl. Inst. and Meth. in Phys., Res., v. 213, p. 82-86, 2004. Section B.

[G95] http://www.g95.org/. (último acesso 13/05/2011).

[Ga00] GABRIEL, F.; GIPNER, P.; GROSSE, E.; JANSSEN, D.; MICHEL, P.; PRADE, H.; SCHAMLOTT, A.; SEIDEL, W.; WOLF, A. WÜNSCH, R. The Rossendorf radiation source 
ELBE and its FEL projects. Nucl. Inst. and Meth. in Phys. Res. v. 161-163 p. 1143-1147, 2000. Section B

[Ge94] GEIGER, N.; BAUSKE, ZS.I.; BRENTANO, P. VON; HEIL, R.D.; HERZBERG, R.-D; KNEISSL, U.; MARGRAF, J.; MASER, H.; PIETRALLA, N.; PITZ, H.H.; WESSELBORG, C.; ZILGES, A. Low-lying Dipole Excitations in the Isotopes ${ }^{113,114}$ Cd. W. Nucl. Phys. A, v. 580, p. 263-276, 1994.

[Gi05] GIRARD, S.M. (Ed). MCNP - A General Monte Carlo N-Particle Transport Code, Version 5. Volume I: Overview and Theory. X-5 Monte Carlo Team (Los Alamos National Laboratory Report, LA-UR-03-1987, 2005.

[Go40] GOUDSMIT, S.; SAUNDERSON, J. L. Multiple Scattering of Electrons. Phys. Rev. v. 57, p. $24-29,1940$.

[Go94] GOVAERT, K.; MONDELAERS, W.; JACOBS, E.; DE FRENNE, D.; PERSYN, K.; POMMÉ, S.; YONEAMA, M. L.; LINDENSTRUTH, S.; HUBER, K.; JUNG, A.; et al Polarized bremsstrahlung nuclear resonance fluorescence set-up at the $15 \mathrm{MeV}$ linac in Gent. Nucl. Inst. and Meth. in Phys. Res., v. 337 p. 265-273, 1994. Section A.

[Go94a] GOVAERT, K.; GOVOR, L.; JACOBS, E.; DE FRENNE, D.; MONDERLAERS, W.; PERSYN, K.; YONEAMA, M.L.; KNEISSL, U.; MARGRAF, J.; PITZ, H.H.; HUBER, K.; LINDENSTRUTH, S.; STOCK, R.; HEYDE, K.; VDOVIN, A.; YU, V. Observation of a $1^{-}$ two phonon $2^{+} \otimes 3^{-}$excitation in ${ }^{116} \mathrm{Sn}$ and ${ }^{124} \mathrm{Sn}$. Ponomarev. Phys. Lett. B, v. 335, p. 113-118, 1994.

[Go98] GOVAERT, K.; BAUWENS, F.; BRYSSINCK, J.; et al. Dipole excitations to bound states in ${ }^{116}$ Sn and ${ }^{124}$ Sn. Phys. Rev. C, v.57, p. 2229-2249, 1998.

[Ha03] HAUG, E.; NAKEL, W. The elementary Process of Bremsstrahlung. 1ed. Singapore,: World Scientific Note in Physics. Vol 73. 2003.

[Ha92] HALBLEIB, J.A.; KENSEK, R.P.; VALDEZ, G.D.; SELTZER, S.M.; BERGER, M. J. ITS: The Integrated TIGER Series of Electron/Photon Transport Codes - Version 3.0. IEEE Transactions on Nuclear Science, v. 9, No. 4, p. 1992-1025, 1992.

[He00] HENDRICKS, J.S.; ADAMS, K.J.; BOOTH, T.E.; BRIESMEISTER, J.F.; CARTER, L.L.; COX, L.J.; FAVORITE, J.A.; FORSTER, R.A.; MCKINNEY, G.W.; PRAEL, R.E. Present and future capabilities of MCNP. App. Rad.. and Isot., v. 53, p. 857-861, 2000.

[He10] HEYDE, K.; NEUMANN-COSEL, P.; RICHTER, A. Magnetic dipole excitations in nuclei: Elementary modes of nucleonic motion. Rev. Mod. Phys., v. 82, p. 2365-2419, 2010.

[Hu02] HUTTER C.; BABILON M.; BAYER W.; GALAVIZ D.; HARTMANN T.; MOHR P.; MÜLLER S.; ROCHOW W.; SAVRAN D.; SONNABEND K.; VOGT K.; VOLZ S.; ZILGES A. Polarization sensitivity of a segmented HPGe detector up to $10 \mathrm{MeV}$. Nucl. Inst. and Meth. in Phys. Res,. v. 489, Issues 1-3, p. 247-256, 2002. Section A.

[Hu06] HUANG, W.L.; LI, Q.F.; LIN, Y.Z.; SU, Q.; LUO, Y.S. Measurements of photoneutrons produced by a $15 \mathrm{MeV}$ electron linac for radiography applications. Nucl. Inst. and Meth. in Phys. Res., v. 251, p. 361-366, 2006. Section B.

[Hu07] HUY, N.Q.; BINH, D.Q.; NA, V.X. Study on the increase of inactive germanium layer in a high-purity germanium detector after a long time operation ap.lying MCNP code. Nucl. Instrum. and Methods., v. 573 p. 384-388, 2007. Section A.

[IAEA] IAEA Photonuclear Data, http://t2.lanl.gov/data/photonuclear.html (último acesso 13/05/2011). 
[Ja04] JANG, S.Y.; KIM, C.H.; REECE, W.D.; BRABY, L.A. Filtered fast neutron irradiation system using Texas A\&M University Nuclear Science Center Reactor. Nucl. Inst. and Meth. in Phys. Res., v.530, p. 493-504, 2004. Section A.

[Ja64] JABBUR, R.J.; PRATT, R.H. High-Frequency Region of the Spectrum of Electron and Positron Bremsstrahlung. II. Phys. Rev. B, v. 133, p. 1090-1091, 1964.

[Je99] JERAJ, R.; KEALL, P.J.; OSTWALD. P.M. Comparisons between MCNP, EGS4 and experiment for clinical electron beams. Phys. Med. Biol. v. 44, p. 705-717, 1999.

[Ji86] JIN, Y.; GARDNER, R.P.; VERGHESE, K.. A semi-empirical model for the gamma-ray response function of germanium detectors based on fundamental interaction mechanisms. Nucl. Inst. and Meth. in Phys. Res., v.242, p. 416-426, 1986. Section A.

[Jo95] JOLIE, J.; BERTSCHY, M. A tunable monochromatic gamma-ray source Part 1. Concept of the source. Nucl. Inst. and Meth. in Phys. Res., v. 95, p. 431-436, 1995. Section A.

[Ju95] JUNG, A.; LINDENSTRUTH, S.; SCHACHT, H.; et al. Electric and magnetic dipole excitations to bound states in ${ }^{70,72,74,76}$ Ge. Nucl. Phys. A, v. 584, p. 103-132, 1995.

[Ka03] KARAMANIS, D. Efficiency simulation of HPGe and $\mathrm{Si}(\mathrm{Li})$ detectors in $\gamma$ - and X-ray spectroscopy. Nucl. Inst. and Meth. in Phys. Res., v. 505, p. 282-285, 2003. Section A.

[Ka50] KAHN, H. Modifications of the Monte Carlo Method. In: SEMINAR ON SCIENTIFIC COMPUTATION, Nov. 1949, Proceeding, IBM, New York, p. 20-27, 1950.

[Ka98] KASSAB, L.R.P.; TAKAHASHI, J.; MARTINS, M.N.; GOUFFON, P. The design of the IFUSP main racetrack microtron accelerator end magnets. In: 1998 EUROPEAN PARTICLE ACCELERATOR CONFERENCE, Proceedings, 1998.

[Kn82] KNOWLES, J.W.; MILLS, W.F.; KING, R.N.; et al.. A high resolution bremsstrahlung monochromator for photo-nuclear experiments. Nucl. Inst. and Meth. in Phys. Res., v. 193 p. 463-483, 1982.

[Kn92] KNEISSL U. Parity assignments in Photon scattering Using Compton Polarimeters. Prog. Part. Nucl. Phys., v. 28, p. 331-340, 1992.

[Kn95] KNEISSL, U.; MALGRAF, J.; PITZ, H.H.; BRETANO, P.VON, HERZBERG, R.-D.; ZILGES, A. Photoexcitation of Magnetic and Electric Dipole transitions in Heavy Nuclei. Prog. Part. Nucl. Phys., v. 34, p. 285-294, 1995.

[Kn96] KNEISSL U.; PITZ H. H.; ZILGES A. Investigation of Nuclear Structures by Resonance Fluorescence Scattering. Prog. Part. Nucl. Phys., v. 9, p. 349-433, 1996.

[Ko05] KOHSTALL, C.; BELIC, D.; BRENTANO, P.VON, FRANSENL C.; GADEL A.; HERZBERGL R.-D.; JOLIEL J.; KNEISSLL U.; LINNEMANNL A.; NORDL A.; PIETRALLAL N.; PITZL H.H.; SCHECKL M.; STEDILEL F.; WERNERL V.; YATES, S.W. Low-lying dipole excitations in vibrational nuclei: The $\mathrm{Cd}$ isotopic chain studied in photon scattering experiments. Phys. Rev C., v. 72, 034302, 2005.

[Ko59] KOCH, H.W.; MOTZ, J.W. Bremsstrahlung Cross Section Formulas And Related Data. Rev. Mod. Phys. v. 31, p. 920-955, 1959.

[Ko65] KOHN W. SHAM L. S. Self-Consistent Equations Including Exchange and Correlation Effects. Phys. Rev., v.140, p. A1133-A1138, 1965. 
[Ku10] KULIEV A.A.; GULIYEV E.; ERTUGRAL F.; OZKAN S. The low-energy dipole structure of ${ }^{232}$ Th, ${ }^{236} \mathrm{U}$ and ${ }^{238} \mathrm{U}$ actinide nuclei. Eur. Phys. J. A, v. 43, p. 313-321, 2010.

[La44] LANDAU, L. On the Energy Loss of Fast Particles by Ionization. J. Phys. USSR v.8 p. 201, 1944.

[La85] LASZEWSKI, R.M.; RULLHUSEN, P.; HOBLIT, S.D.; LEBRUN, S.F. Enhanced lineal polarization for tagged photon beams. Nucl. Inst. and Meth. in Phys. Res.. v. 228, p. 334-342, 1985. Section A.

[Le06] LEMRANI, R.; ROBINSON, M.; KUDRYAVTSEV, V.A.; DE JESUS, M.; GERBIER, G.; SPOONER, N.J.C. Low-energy neutron propagation in MCNPX and GEANT4. Nucl. Inst. and Meth. in Phys. Res., v. 560, p. 454-459, 2006. Section A.

[Le71] LEPRETRE, A.; BEIL, H.; BERGERE, R.; CARLOS P.; VEYSSIERE, A.; SUGAWARA, M. The giant dipole states in the A = 90 mass region. Nucl. Phys. A, v. 175, p. 609-628, 1971.

[Le87] LEE, M.C.; VERGHESE, K.; GARDNER, R.P. Extension of the semiempirical germanium detector response function to low energy gamma rays. Nucl. Inst. and Meth. in Phys. Res., v. 262 p. 430-438, 1987. Section A.

[Le94] LEO, W.R. Techniques for nuclear and particle physics experiments: Techniques for nuclear and particle physics experiments: a how-to approach. 2d., New York, N. Y.: Springer Verlag, 1994.

[Ma00] MARTINS, M.N.; MALAFRONTE, A.A.; TAKAHASHI, J.; PASCHOLATI, P.R.. Resonance Frequency Stabilization of a Side-Coupled Accelerating Structure. In: 7TH EUROPEAN PARTICLE ACCELERATOR CONFERENCE, Vienna, 2000. Proceedings of the EPAC, 2000.

[Ma00a] MARTINS, M.N.; MALAFRONTE, A.A.; TAKAHASHI,J. The Control System for the IFUSP Microtron. In: 7TH EUROPEAN PARTICLE ACCELERATOR CONFERENCE, Vienna, 2000. Proceedings of the EPAC, 2000.

[Ma04] MARTINS M. N.; TABAKAHASHI J.; MALAFRONTE A. A.; RIOS P. B.; LOPES M. L.; BONINI A. L.; LIMA R. R. The IFUSP Microtron - Status and Perspectives. Braz. Jour. of Phys. v. 34, N. 3, p. 951-953, 2004.

[Ma06] MASUR, V.M.; MEL'NIKOVA, L.M. Giant Dipole Resonance in Absorption and Emission of $\gamma$ Rays by Medium and Heavy Nuclei. Phys. of Part. And Nucl. v. 37, N. 6, p. 923-940, 2006.

[Ma07] MAIDANA, N.L.; TRIDAPALLI, D.B.; RIZZUTTO, M.A.; PASCHOLATI, P.R.; MARTINS, M.N.; VANIN, V.R.. Search for the triple-escape peak in HPGe detectors. Nucl. Inst. and Meth. in Phys. Res., v. 588 p. 106-109, 2007. Section A.

[Ma10] MAIDANA, N.L.; BRUALLA, L.; VANIN, V.R.; OLIVEIRA, J.R.B.; RIZZUTTO, M.A.; NASCIMENTO, E. DO, FERNANDEZ-VAREA, J.M.. Triple- and quadruple-escape peaks in HPGe detectors: Experimental observation and Monte Carlo simulation. Nucl. Inst. and Meth. in Phys. Res., v. 615 p. 285-294, 2010. Section A.

[Ma67] MAXON, S.M.; CORMAN, E.G. Electron-Electron Bremsstrahlung from a Quantum Plasma (Z=1) Phys. Rev., v.163, p. 156-162, 1967.

[Ma84] MARTINS, M.N.; HAYWARD, E.; LAMAZE, G.; MARUYAMA, X.K.; SCHIMA, F.J.; WOLYNEC, E. Experimental test of the bremsstrahlung cross section. Phy. Rew. $\boldsymbol{C}$ v.30, p. 1855-1860, 1984. 
[Ma95] MARGRAF, J.; ECKERT, T.; RITTNER, M.; BAUSKE, I.; BECK, O.; KNEISSL, U.; MASER, H.; PITZ, H.H.; SCHILLER, A.; BRENTANO, P. VON, FISCHER, R.; HERZBERG, R.-D.; PIETRALLA, N.; ZILGES, A.; FRIEDRICHS, H. Systematics of lowlying dipole strengths in odd and even Dy and Gd isotopes. Phys. Rev. C, v. 52, 002429, 1995.

[Ma96] MAO, K.; KASE, R.; NELSON, W. Giant Dipole Resonance Neutron Yields Released by Electrons as Functions of the Material and Thickness of the Targets. Xiaotian Stanford Linear Accelerator Center, SLAC-PUB-6628, 1996.

[Ma96a] MASER, H.; LINDENSTRUTH, S.; BAUSKE, I.; et al. Systematics of low-lying dipole excitations in the deformed even-even nuclei ${ }^{164,166,168,170}$ Er. Phys. Rev. C, v. 53, p. $2749,1996$.

[Mc05] MCKINNEY, G.W.; DURKEE, J.W.; HENDRICKS, J.S.; JAMES, M.R.; PELOWITZ, D.B.; WATERS, L.S. MCNPX 2.5.0 - New Features Demonstrated. Los Alamos National Laboratory Report, LA-UR-04-8695, 2005.

[Me49] METROPOLIS, N.; ULAM, S. The Monte Carlo Method. Journal of the American Statistical Association. v. 44, N. 247, p. 335-341, 1949.

[Me53] METROPOLIS, N.; ROSENBLUTH, A.W.; ROSENBLUTH. M.N.; TELLER, A.H. Equation of State Calculations by Fast Computing Machines. The Journal of Chemical Physics, v. 21 N. 6, p. 1087-1092, 1953.

[Me59] METZGER, F.R. Resonance Fluorescence in Nuclei. Progr .in Nucl. Phys. v. 7, p. 54-88, 1959.

[Me87] METROPOLIS, N. The Beginning of the Monte Carlo Methods. Los Alamos Science Special Issue, p. 125- 130, 1987. http://library.lanl.gov/cgi-bin/getfile?00326866.pdf (último acesso 13/05/2011).

[Mi00] MILLION B.; BRACCO A.; CAMERA F.; BRAMBILLA S.; GADEA A.; GIUGNI D.; HERSKIND B.; KMIECIK M.; ISOCRATE R.; LEONI S.; MAJ A.; PRELZ F.; WIELAND O. Measurement of $15 \mathrm{MeV} \gamma$-rays with the Ge cluster detectors of EUROBALL. Nucl. Inst. and Meth. in Phys. Res., v. 452, p. 422-430, 2000. Section A.

[Mi63] MILBURN, R.H. Electron Scattering by an Intense Polarized Photon Field. Phys. Rev. Lett., v. 10, p. $75-77,1963$.

[Mo55] MOTZ J. W. Bremsstrahlung Differential Cross-Section Measurements for 0.5- and 1.0-MeV Electrons. Phys. Rev., v. 100, p. 1560-1571, 1955.

[Mo58] MOTZ J.W.; PLACIOUS R.C. Bremsstrahlung Cross-Section Measurements for 50-keV Electrons. Phys. Rev., v. 109, p. 235-242, 1958.

[Mo72] MOREH, R.; RAJEWSKI, J. Polarization measurements of resonantly scattered capture gamma rays. Nucl. Inst. and Meth., v. 98, p. 13-20, 1972.

[Mo79] MOREH, R. Review of intense gamma sources using neutron capture. Nucl. Inst. and Meth., v. 166 p. 29-38, 1979.

[Mo96] MONDELAERS, W.; VAN LAERE, K.; GOEDEFROOT ,A.; VAN DEN BOSSCHE, K.. The Gent University $15 \mathrm{MeV}$ high-current lineal electron accelerator. Nucl. Inst. and Meth. in Phys. Res,. v. 368 p. 278-282, 1996. Section A.

[Mo99] MOHR, P.; ENDERS, J.; HARTMANN, T.; KAISER, H.; SCHIESSER, D.; SCHMITT, S.; VOLZ, S.; WISSEL, F. AND ZILGES, A. Real photon scattering up to $10 \mathrm{MeV}$ : the improved 
facility at the Darmstadt electron accelerator S-DALINAC. Nucl. Inst. and Meth. in Phys. Res., v. 423 p. $480-488,1999$. Section A.

[Na03] NAQVI, A.A. A Monte Carlo comparison of PGNAA system performance using ${ }^{252} \mathrm{Cf}$ neutrons, 2.8-MeV neutrons and $14-\mathrm{MeV}$ nêutrons. Nucl. Inst. and Meth. in Phys. Res., v. 511, p. 400-407, 2003. Section A

[Na73] NATH, R.; FIRK, F.W.K. AND SCHULTZ H.L. Effects of photon collimators on the spectral distribution of bremsstrahlung radiation between 20 and $35 \mathrm{MeV}$. Nucl. Inst. and Meth., v. 108, p. 199-200, 1973.

[Ne85] NELSON, W. R.; HIRAYAMA, H.; ROGERS, D.W.O. The EGS4 Code System. Stanford Linear Accelerator Center, SLAC-265, 1985.

[No03] NORD, A.; ENDERS, J.; ALMEIDA PINTO, A.E. DE, BELIC, D.; BRENTANO, P. VON, FRANSEN, C.; KNEISSL, U.; KOHSTALL, C.; LINNEMANN, A.; NEUMANN-COSEL, P. VON, PIETRALLA, N.; PITZ, H.H.; RICHTER, A.; STEDILE, F.; WERNER, V. Low-energy photon scattering experiments of ${ }^{151,153} \mathrm{Eu},{ }^{163} \mathrm{Dy}$, and ${ }^{165} \mathrm{Ho}$ and the systematics of the M1 scissors mode in odd-mass rare-earth nuclei. Phys. Rev. C, v. 67, 034307, 2003.

[No79] NOLAN, J.P.; SHARPEY-SCHAEFER, J.F. The measurement of lifetimes of excited nuclear states. Rep. Prog. Phys., v. 42, p. 1-86, 1979.

[Oh94] OHGAKI H.; NOGUCHI T.; SUGIYAMA S.; YAMAZAKI T.; MIKADO T.; CHIWAKI M.; YAMADA K.; SUSUKI R.; SEI N. Linearly polarized photons from Compton backscattering of laser light for nuclear resonance fluorescence experiments. Nucl. Inst. and Meth. in Phys. Res., v. 353 p. 384-388, 1994. Section A.

[O155] OLSEN, H. Outgoing and Ingoing Waves in Final States and Bremsstrahlung. Phys. Rev., v. 99, p. 1335 - 1336, 1955.

[O178] OLSEN, H.A.; MARXIMON, L.C. High Frequency Limit of Bremsstrahlung. Phys. Rev. A. v. 18, p. 2517-2522, 1978.

[On00] ONGARO,C.; ZANIN, A.; NASTASI,U.; RODENAS, J.; OTTAVIANO, G.; MANFREDOTTI, C. Analysis of photoneutron spectra produced in medical accelerators. Phys. Med. Biol. v. 45 p. L55-L61, 2000.

[Ow90] OWENS, R.O. Statistical treatment of tagged photon experiments. Nucl. Inst. and Meth. in Phys. Res., v. 288 p. 574-584, 1990. Section A.

[Pa10] PADILLA CABAL, F.; LOPEZ-PINO, N.; BERNAL-CASTILLO, J.L.; MARTINEZPALENZUELA, Y.; AGUILAR-MENA, J.; D'ALESSANDRO, K.; ARBELO, Y.; CORRALES, Y.; DIAZ, O. Monte Carlo based geometrical model for efficiency calculation of an n-type HPGe detector. App. Rad. and Isot., v. 68 p. 2403-2408, 2010.

[Pe05] PELOWITZ D.D. (Ed.). MCNPX ${ }^{T M}$ User's manual. Version 2.5.0 (Los Alamos National Laboratory Report, LA-CP-05-0369, 2005).

[Pi89] PITZ, H.H.; BERG, U.E.P.; HEIL R.D.; et al. Systematic study of low-lying dipole excitations in ${ }^{156,158,160}$ Gd by photon scattering. Nucl. Phys. A, v. 492, p. 411-425, 1989.

[Pi90] PITZ, H.H.; HEIL, R.D.; KNEISSL, U.; et al. Low-energy photon scattering off ${ }^{142,146,148,150} \mathrm{Nd}$ : An investigation in the mass region of a nuclear shape transition. Nucl. Phys. A, v. 509, p. 587604, 1990. 
[Pr60] PRATT R.H. High Frequency Region of the Bremsstrahlung Spectrum. Phys. Rev. v.120, p. 1717-1722, 1960.

[Pr75] PRATT, R.H, TSENG, H K. Tip region of the bremsstrahlung spectrum for incident electron of kinetic energy $50 \mathrm{keV}-1.84 \mathrm{MeV}$. Phys. Rev. A v. 11 p. 1797-1803, 1975.

[Pr77] PRATT, R. H.; LEE, H. K.; TSENG, C. M.; KISSELL, L.; MACCALLUM, C.; RILEY, M. Bremsstrahlung energy spectra from electrons of kinetic energy $1 \mathrm{keV}<\mathrm{E}<2000 \mathrm{keV}$ incident on neutral atoms $2<$ Z<92. Atom. Data and Nuc. Data Tables, v. 20, p. 175-209, 1977.

[Pr81] PRATT, R.H.; TSENG, H.K.; LEE, C.M.; KISSEL, L.; MACCALLUM, C.; RILEY, M. Bremsstrahlung Energy Spectra from Electrons of Kinetic Energy $1 \mathrm{keV}<\mathrm{T}<2000 \mathrm{keV}$ Incident on Neutral Atoms $2<\mathrm{Z}<92$. Atom. Data and Nuc. Data Tables, V. 20, p. 175-209, 1977, errata in v. 26, p. 477, 1981.

[Pr85] PRATT, R.H.; FENG, I.J. Electron-Atom Bremsstrahlung. Book Review: Atomic inner-shell Physics. Plenum, New York, p. 533, 1985.

[Pr95] PRAEL, R.E.; MADLAND, D.G. LAHET Code System Modifications for LAHET 2.8 (Los Alamos National Laboratory Report, LA-UR-95-3605, 1995.

[Ra05] RADON, T; GUTERMUTH, F; FEHRENBACHER, G Monte Carlo simulations for the shielding of the future high-intensity accelerator facility fair at GSI. Radiat Prot Dosimetry, v. 115 , p. $212-215,2005$.

[Ra97] RANFT, J. 33 years of high energy radiation Monte Carlo calculations in Europe as seen from CERN. J. Ranft. In: $2^{\text {nd }}$ WORKSHOP ON SIMULATING ACCELERATOR RADIATION ENVIRONMENTS (SARE2), CERN, Geneva, 9-11 October 1995. Proceedings. CERN/TISRP/97-05, p. 1, 1997.

[Re67] RESTER D.H.; DANCE W.E. Bremsstrahlung Cross-Section Measurements at Incident Electron Energies of 1.0, 1.7, and 2.5 MeV. Phys. Rev., v. 161, p. 85-93, 1967.

[Re72] RESTER D.H.; EDMONSON N. Bremsstrahlung Cross-Section Measurements at an Incident Electron Energy of 0.2 MeV on Al, Cu, and Au. Phys. Rev. A, v.6, p. 1405-1409, 1972.

[Re97] REIF, J.; BRENTANO, P. VON, EBERTH, J.; ENDERS, J.; HERZBERG, R.-D.; HUXEL, N.; KÄUBLER, L.; NEUMANN-COSEL, P. VON, NICOLAY, N.; PIETRALLA,N.; et al. Resonant photon scattering on the semi-magic nucleus ${ }^{89} \mathrm{Y}$ up to $7 \mathrm{MeV}$. Nucl. Phys. A, v. 620, p. 1- 15, 1997.

[Ri75] RILEY, M.E.; MACCALLUM, C.J.; BIGGS, F. Theoretical Electron-Atom Elastic Scattering Cross Sections. Selected Elements, $1 \mathrm{keV}$ to $256 \mathrm{keV}$. Atom. Data and Nucl. Data Tables. v. 15 p. $443-476,1975$.

[Ri84] RIES, H.; KNEISSL, U.; MANK, G.; et al. Absolute photofission cross sections of ${ }^{235,238} \mathrm{U}$ measured with tagged photons between 40 and 105 MeV. Phys. Lett. B, v. 139,p. 254-258, 1984.

[Ri90] RICHTER, A. Shell model and magnetic dipole modes in deformed nuclei. Nucl. Phys. A, v. 507, p. 99c-128c, 1990.

[Ri95] RITCHER, A. Probing the Nuclear Magnetic Dipole Response with electrons, photons, and hadrons. Prog. Part. Nucl. Phys. v. 34, p. 261-284, 1995. 
[Ro00] RÓDENAS, J.; MARTINAVARRO, A.; RIUS, V. Validation of the MCNP code for the simulation of Ge-detector calibration. Nucl. Inst. and Meth. in Phys. Res.,. 450, p. 88-97, 2000. Section A.

[Ro05] RODRIGUES, T.E. O modelo de cascata intranuclear MCMC e aplicações para o mecanismo do quase-dêuteron e a fotoprodução de pions em energias intermediárias e altas. 2005. Tese (Doutorado) - Instituto de Fisica da Universidade de São Paulo.

[Ro07] RÓDENAS, J.; GAllaRdO, S.; BALleSTER, S.; PRIMAUlT, V.; ORTIZ, J. Nucl. Ap.lication of the Monte Carlo method to the analysis of measurement geometries for the calibration of a HP Ge detector in an environmental radioactivity laboratory. Inst. and Meth. in Phys. Res,. v. 263, p. 144 - 148, 2007. Section B.

[Ro72] ROCHE, G.; DUCOS, C.; PRORIOL, J. Bremsstrahlung Cross-Section Formula Including a High-Order Coulomb Correction. Phys. Rev. V. A 5, p. 2403 - 2408, 1972.

[Ru09] RUSEV G.; TONCHEV A. SCHWENGNER P.; SUN R.; TORNOW C.; W.; WU Y. K. Multipole mixing ratios of transitions in ${ }^{11}$ B. Phys. Rev. C, v.79, 047601, 2009.

[Sa03] SALVAT F.; FERNANDEZ-VAREA, J.M.; SEMPAU J. PENELOPE - A Code System for Monte Carlo Simulation of Electron and Photon Transport. Workshop Proceedings. Issy-lesMoulineaux, ISBN 92-64-02145-0, France, 2003.

[Sa05] SAVRAN, D.; MÜlleR, S.; ZILGES, A.; BABILON, M.; AHMED, M.W.; KELLEY, J.H.; TONCHEV, A.; TORNOW, W.; WELLER, H.R.; PIETRALLA, N.; LI, J.; PINAYEV, I.V.; WU, Y.K. Parity assignments in ${ }^{172,174} \mathrm{Yb}$ using polarized photons and the $K$ quantum number in rare earth nuclei. Phys. Rev. C. v. 71, 034034, 2005.

[Sa08] SAVRAN D.; FRITZSCHE M.; HASPER J.; LINDENBERG K.; MÜLLER S.; V. PONOMAREV YU.; SONNABEND K.; ZILGES A. Fine Structure of the Pygmy Dipole Resonance in 136Xe. Phys. Rev. Lett. v. 100, 232501, 2008.

[Sc02] SCHAART. D.R.; JANSEN, J.TH.M.; ZOETELIEF, J.; LEEG, P.F.A.DE. A comparison of MCNP4C electron transport with ITS 3.0 and experiment at incident energies between $100 \mathrm{keV}$ and $20 \mathrm{MeV}$ : influence of voxel size, substeps and energy indexing algorithm. Phys. Med. Biol., v. 47, N 9, p. 1459-1484, 2002.

[Sc05] SCHWENGNER, R.; BEYER, R.; DÖNAU, F.; GROSSE, E.; HARTMANN, A.; JUNGHANS, A.R.; MALLION, S.; RUSEV, G.; SCHILLING, W.; SCHULZE, K.D. et al. The photon-scattering facility at the superconducting electron accelerator ELBE. Nucl. Inst. and Meth. in Phys. Res., v. 555, p. 211-219, 2005. Section A.

[Sc06] SCATES, W.; HARTWELL, J.K.; ARYAEINEJAD, R.; MCILWAIN, M.E. Optimization studies of a Compton sup.ression spectrometer using experimentally validated Monte Carlo simulations. Nucl. Inst. and Meth. in Phys. Res., v. 556, p. 498-504, 2006. Section A.

[Sc08] SCHWENGNER R.; RUSEV G.; TSONEVA N.; BENOUARET N.; BEYER, R. ERHARD M.; GROSSE E.; JUNGHANS A. R.; KLUG, KOSEV J. K.; LENSK H.; NAIR C.; SCHILLING K. D.; WAGNER A. Pygmy dipole strength in ${ }^{90}$ Zr. Phys. Rev. C, v. 78, 064314, 2008.

[Sc51] SCHIFF, L. I. Energy-Angle Distribution of Thin Target Bremsstrahlung. Phys. Rev. v. 83 p. 252-253, 1951.

[Sc55] SCOTT, M. B.; HANSON, A. O.; KERST D. W. Electro- and Photodisintegration Cross Sections of $\mathrm{Cu}^{63}$. Phys. Rev. v. 100, p. 209-214, 1955. 
[Sc94] SCHLITT B.; MAIER U.; FRIEDRICHS H.; ALBERS S.; BAUSKE I.; BRENTANO P.; HEIL R. D.; HERZBERG R. D.; KNEISSL U.; MARGRAF J.; PITZ H. H.; WESSELBORG C.; ZILGES A. A sectored Ge-Compton polarimeter for parity assignments in photon scattering experiments. Nucl. Inst. and Meth. in Phys. Res. v. 337, Issues 2-3, p. 416-426, 1994. Section A.

[Se85] SELTZER, S.M.; BERGER, M.J. Bremsstrahlung Spectra from Electron Interactions with Screened atomic Nuclei and Orbital Electrons. Nucl. Inst. and Meth. in Phys. Res., v. 12, p. 95-134, 1985. Section B.

[Se86] SELTZER S. M.; BERGER M.J. Bremsstrahlung Energy Spectra from Electrons with Kinetic Energy $1 \mathrm{keV}-10 \mathrm{GeV}$ Incident on Screened Nuclei and Orbital Electrons of Neutral Atoms with $Z=1$ to 100. Atom. Data and Nuc. Data Tables, v. 35, p. 345, 1986.

[Se91] SELTZER, S.M. Electron-Photon Monte Carlo Calculations: The ETRAN Code. App. Radiat. Isot., v. 42, No. 10, p. 917-941, 1991.

[Si65] SIEGBAHN, K. $\boldsymbol{\alpha}, \boldsymbol{\beta}$, $\boldsymbol{\gamma}$-Spectroscopy. 1ed. Amsterdam, North Holland, 1965.

[So04] SOOD, A.; FORSTER, R. A.; ADAMS, B.J.; WHITE, M.C. Verification of the pulse height tally in MCNP 5. Nucl. Inst. and Meth. in Phys. Res., v. 213, p. 167-171, 2004. Section B.

[St71] STERNHEIMER, R.M.; PEIERLS, R.F. General Expression for the Density Effect for the Ionization Loss of Charged Particles. Phys. Rev. B, v. 3, p. 3681 - 3692, 1971.

[St72] STAREK B; AIGINGER H. UNFRIED E. Bremsstrahlung cross-section measurements at the short-wavelength limit. Phys. Lett. A, v. 39, p. 151-152, 1972.

[St82] STERNHEIMER, R.M.; SELTZER, S.M.; BERGER, M.J. Density effect for the ionization loss of charged particles in various substances. R. M. Sternheimer, Phys. Rev. B, v. 26, p. 6067 - 6076, 1982.

[St96] STRITT, N.; JOLIE, J.; MASER, H.; PITZ, H.H. A MeV tunable gamma-ray source by Compton scattering. Nucl. Inst. and Meth. in Phys. Res., v. 381, p. 443-452, 1996. Section A.

[Ta92] TAKAHASHI, J.; MIYAO, Y.; MARTINS, M.N.; et al. The IFUSP racetrack Microtron. In: THIRD EUROPEAN PARTICLE ACCELERATOR CONFERENCE, France, Proceedings. V. 1, p. 429 a 431, 1992.

[Ta99] TAKAHASHI, J.; MARTINS, M.N.; PORTANTE, L.; et al..Vacuum system for the accelerating structure of the IFUSP Microtron. In: 1999 PARTICLE ACCELERATOR CONFERENCE, New York City March 29th - April 2nd, Proceedings, 1999.

[Th89] THORN, C.E.; GIORDANO, G.; KISTNER, O.C.; MATONE, G.; SANDORFI, A.M.; SCHAERF, C.; WHISNANT, C.S. The legs electron spectrometer for tagging backscattered photons. Nucl. Inst. and Meth. in Phys. Res., v. 285, p. 447-458, 1989. Section A.

[Ti05] TITT, U.; NEWHAUSER, W.D. Neutron shielding calculations in a proton therapy facility based on Monte Carlo simulations and analytical models: criterion for selecting the method of choice. Radiat. Prot Dosimetry, v. 115, p. 144 - 148, 2005.

[Ts71] TSENG, H.K.; PRATT, R.H. Exact Screened Calculations of Atomic-Field Pair Production and Low-Energy Screening. Phys. Rev. A, v. 4, p. 1835 - 1843, 1971.

[Ts74] TSENG, H.K.; PRATT, R.H. Electron Bremsstrahlung from Neutral Atoms. Phys. Rev. Lett., v. 33, p. 516 - 518, 1974. 
[Tu75] TURNER, J.N.; HAUSNER JR, G.G.; PARSONS, D.F. An optimized Faraday cage design for electron beam current measurements. Journal of Physics E: Scientific Instruments, v. 8 p. 954-957, 1975.

[Ut05] UTSUNOMIYA, H.; AKIMUNE H.; OSAKA, K.; KAIHORI, T.; FURUTAKA, K.; HARADA, H. Surface channel effect on.; $\gamma$-ray response functions of coaxial germanium detectors. Nucl. Inst. and Meth. in Phys. Res., v. 548 p. 455 - 463, 2005. Section A.

[Va11] VANIN, V.R.; MAIDANA, N.L.; LÓPEZ-PINO, N.; et al. First Experiments with the IFUSP Microtron Injector. In: XXXIII BRAZILIAN WORKSHOP ON NUCLEAR PHYSICS. Vito R. Vanin (editor). AIP Conference Proceedings 1351.Campos Do Jordão, SP, Brazil, 7-10 September 2010. 2011. In press.

[Va92] VAN HOOREBEKE, L.; RYCKBOSCH, D.; VAN DEN ABEELE, et al. Determination of the random particle energy spectrum in tagged photon experiments. Nucl. Inst. and Meth. in Phys. Res., v. 321, p. 230-237, 1992. Section A.

[Vi07] VILCHES, M.; GARCÍA-PAREJA, S.; GUERRERO, R.; ANGUIANO, M.; LALLENA, A.M. Monte Carlo simulation of the electron transport through thin slabs: A comparative study of PENELOPE, GEANT3, GEANT4, EGSnrc and MCNPX. Nucl. Inst. and Meth. in Phys. Res., v. 254, p. 219-230, 2007. Section B.

[Vo01] VOGNAR, M.; ŠIMÁNĚ, Č.; CHVÁTIL, D. Faraday Cup for Electron Flux Measurements on the Microtron MT 25. Acta Polytechnica, v. 41 N.1, p. 11-13, 2001.

[Vo06] VOLZ, S.; TSONEVA, N.; BABILON, M.; ELVERS, M.; HASPER, J.; HERZBERG, R.-D.; LENSKE, H.; LINDENBERG, K.; SAVRAN, D.; ZILGES, A. The photoresponse of stable $\mathrm{N}=82$ nuclei below $10 \mathrm{MeV}$. Nucl. Phys. A, v. 779, p. 1-20, 2006.

[Wa02] WATERS L.S. (Ed.) MCNPX User's Manual Version 2.4.0 (Los Alamos National Laboratory Report, LA-CP-02-408, 2002).

[Wa05] WAGNER A, BEYER R, ERHARD M.; DÖNAU F.; GROSSE E.; HARTMANN. A, JUNGHANS. A R, KÄUBLER. L, KOSEV. K, MALLION. S, NAIR C.; NANKOV N.; RUSEV. G, SCHILLING K. D.; SCHULZE. W, R SCHWENGNER. The new bremsstrahlung facility at the superconducting electron accelerator ELBE. J. Phys. G: Nucl. Part. Phys. v. 31, p. S1969-S1972, 2005.

[Wa99] WATERS L.S. (Ed.) MCNPX User's Manual Version 2.1.5 (Los Alamos National Laboratory Report, LA-UR-99-1995, 1999).

[We67] WEIGT, P.; HÜBEL, H.; GÖTTEL, P.; HERZOG, P.; BODENSTEDT, E. A multidetector aparatus for linear polarisation correlation measurements. Nucl. Inst. and Meth., v. 57, p. 295$312,1967$.

[Wi96] WILHELM M.; EBERTH J.; PASCOVICI G.; RADERMACHE E.; THOMAS H. G.; BRENTANO P.; PRADE H.; LIEDER R. M.. The response of the Euroball Cluster detector to $\gamma$-radiation up to $10 \mathrm{MeV}$. Nucl. Inst. and Meth. in Phys. Res., v. 381, p. 462-465, 1996. Section A.

[Wo82] WOOD, J. Computational Methods in Reactor Shielding. 1d. Oxford. Pergamon Press, 1982.

[Wr62] WRIGHT. K.A.; TRUMP, J.G. Back-Scattering of Megavolt Electrons from Thick Targets. Appl. Phys., v. 33, p. 687-691, 1962. 
[Ya04] YACOUT, A.M.; DUNN W.L. EGS OvrEzy, the object-oriented visual user interface for the EGS particle transport code. Nucl. Inst. and Meth. in Phys. Res., v. 213, p. 149-154, 2004. Section B.

[Ye10] YEVETSKA O.; ENDERS J.; FRITZSCHE M.; NEUMANN-COSEL P.; OBERSTEDT S.; RICHTER A.; ROMIG C.; SAVRAN D.; SONNABEND K. Dipole strength in the ${ }^{235} \mathrm{U}\left(\gamma, \gamma^{\prime}\right)$ reaction up to $2.8 \mathrm{MeV}$. Phys. Rev. C, v. 81, 044309, 2010.

[Za04] ZANINI, A.; DURISI, E.; FASOLO, F.; ONGARO, C.; VISCA, L.; NASTASI, U.; BURN, K.W.; SCIELZO, G.; ADLER, J.O.; ANNAND, J.R.M.; ROSNER, G. Monte Carlo simulation of the photoneutron field in linac radiotherapy treatments with different collimation systems. Phys. Med. Biol., v. 49, p. 571-582, 2004.

[Za98] ZAMANI-NOOR, F.; ONLEY, D. S. Calculation of the virtual photon spectrum for a finite nucleus in distorted wave methods. Comput. Phys. Commun., v. 48 p. 241-253, 1998.

[Ze01] ZEVALlOS-CHÁVEZ, J.Y.; DA CRUZ, M.T.F.; MARTINS, M.N.; LIKHACHEV, V.P.; ZAMBONI, C.B.; CAMARGO, S.P.; GENEZINI, F.A.; MEDEIROS, J.A.G.; HINDI, M.M. Response function of a germanium detector to photon energies between 6 and $120 \mathrm{keV} \mathrm{Nucl}$. Inst. and Meth. in Phys. Res., v. 457 p. 212-219, 2001. Section A. 
